\begin{tabular}{|c|c|c|c|c|c|c|c|c|}
\hline \multicolumn{3}{|c|}{$\begin{array}{l}\text { 2. To: (Receiving Organization) } \\
\text { Distribution }\end{array}$} & \multicolumn{2}{|c|}{$\begin{array}{l}\text { 3. From: (Originating Organization) } \\
\text { Nuclear Safety }\end{array}$} & \multicolumn{4}{|c|}{$\begin{array}{l}\text { 4. Related EDT No.: } \\
\qquad 624293,624294\end{array}$} \\
\hline \multicolumn{3}{|c|}{$\begin{array}{l}\text { 5. Proj./Prog/Dept./Div.: } \\
\text { Spent Nuclear Fuel }\end{array}$} & \multicolumn{2}{|c|}{$\begin{array}{l}\text { 6. Design Authority/ Design Agent/Cog. Engr.: } \\
\text { D. E. Krahn }\end{array}$} & \multicolumn{4}{|c|}{$\begin{array}{r}\text { 7. Purchase Order No.: } \\
\text { N/A }\end{array}$} \\
\hline \multicolumn{5}{|c|}{ 8. Originator Remarks: } & \multicolumn{4}{|c|}{$\begin{array}{r}\text { 9. Equip./Component No.: } \\
\text { N/A }\end{array}$} \\
\hline \multicolumn{5}{|c|}{ For approval and release. } & \multicolumn{4}{|c|}{$\begin{array}{r}\text { 10. System/Bddg.Facility: } \\
\text { W-44I }\end{array}$} \\
\hline \multirow{3}{*}{\multicolumn{3}{|c|}{ 11. Receiver Remarks: }} & \multirow{3}{*}{\multicolumn{2}{|c|}{ Document? [] Yes $[x]$ No }} & \multicolumn{4}{|c|}{$\begin{array}{l}\text { 12. Major Assm. Dwg. No.: } \\
\text { N/A }\end{array}$} \\
\hline & & & & & \multicolumn{3}{|c|}{ 13. Permit/Permit Application No.: } & $N / A$ \\
\hline & & & & & \multicolumn{4}{|c|}{$\begin{array}{l}\text { 14. Required Response Date: } \\
\text { N/A }\end{array}$} \\
\hline 15. & \multicolumn{4}{|c|}{ DATA TRANSMITTED } & (F) & (G) & (H) & (l) \\
\hline $\begin{array}{l}\text { (A) } \\
\text { litem } \\
\text { No. }\end{array}$ & (B) Documen/Drawing No. & $\begin{array}{l}\text { (C) } \\
\text { Sheet } \\
\text { No. }\end{array}$ & $\begin{array}{l}\text { (D) } \\
\text { Rev. } \\
\text { No. }\end{array}$ & (E) Title or Description of Data Transminted & $\begin{array}{l}\text { Approval } \\
\text { Designator }\end{array}$ & $\begin{array}{c}\text { Reason } \\
\text { for Trans. } \\
\text { mitral }\end{array}$ & 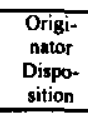 & $\begin{array}{c}\text { Receiver } \\
\text { Disposition }\end{array}$ \\
\hline 1 & HNF-3673 & $\mathrm{N} / \mathrm{A}$ & 0 & $\begin{array}{l}\text { Cold Vacuum Drying Facility } \\
\text { Technical Safety Requirements }\end{array}$ & $\overline{\text { ESQD }}$ & 1,2 & 1 & 1 \\
\hline & & & & & & & & \\
\hline & & & & & & & & \\
\hline & & & & & & & & \\
\hline & & & & & & & & \\
\hline & & & & & & & & \\
\hline
\end{tabular}

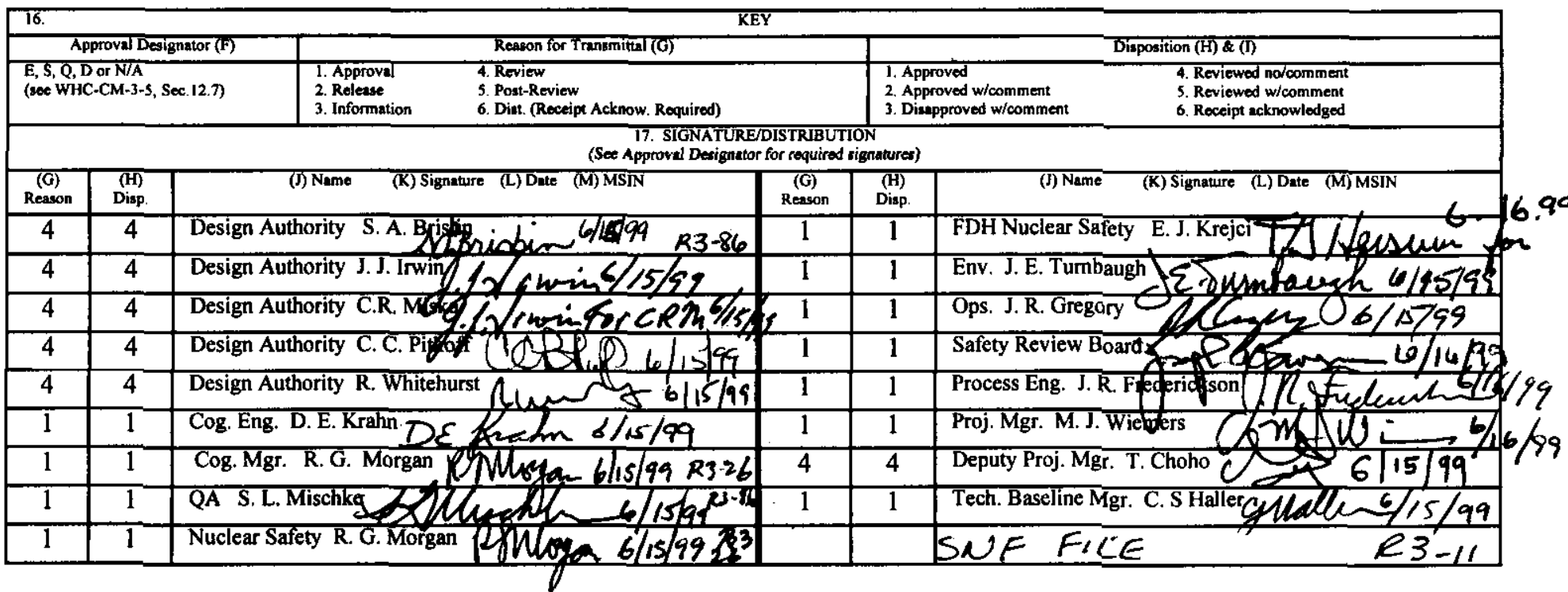

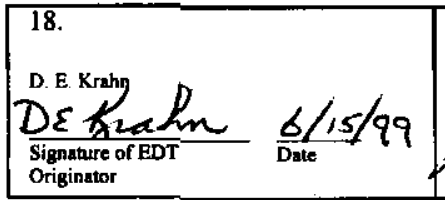

19.

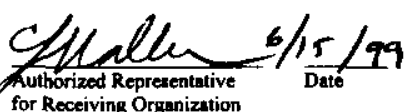
for Receiving Organization

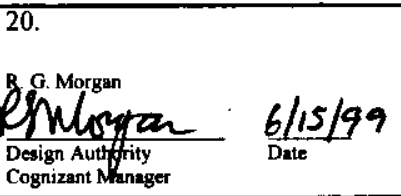

21. DOE APPROVAL (if required) Ctrl. No. 9959002

(X) Approved

[1] Approved w/comments

[] Disapproved w/comments 


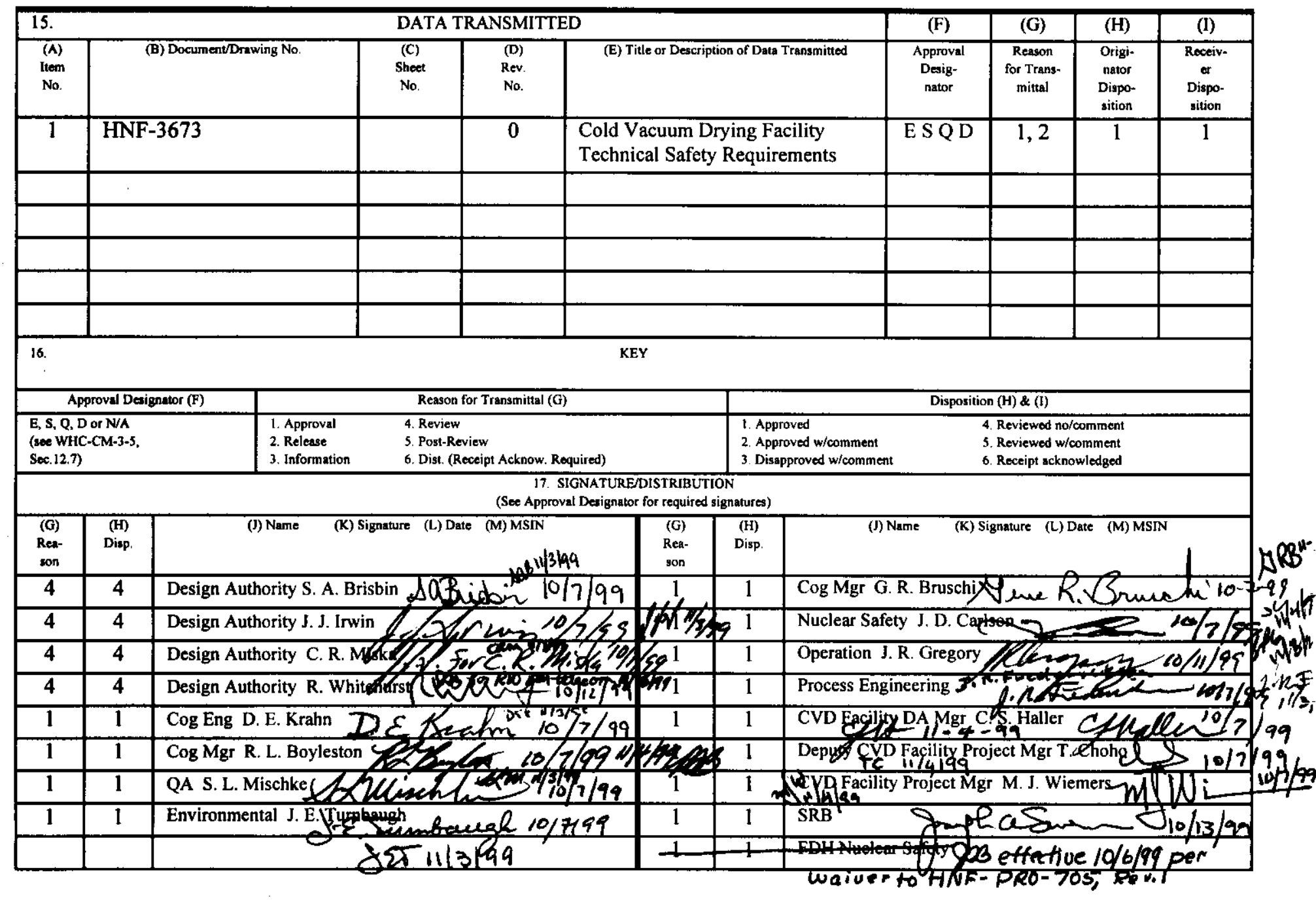

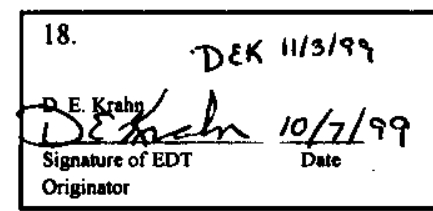

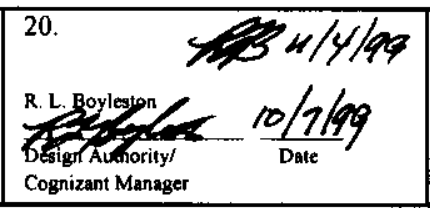

21. DOE APPROVAL (if required) Ctrl. No.

[] Approved

[] Approved w/comments

[] Disapproved w/comments 
HNF-3673, Rev. 0

\section{Cold Vacuum Drying Facility Technical Safety Requirements}

\section{E. Krahn}

Fluor Daniel Northwest, Inc., Richland, WA 99352

U.S. Department of Energy Contract DE-AC06-96RL13200

EDT: 626884

Org Code: 2 F200

B\&R Code: 39EW40400
UC: 620

Charge Code: $105350 / \mathrm{CB} 80$

Total Pages: 292

Key Words: Technical Safety Requirements, Cold Vacuum Drying Facility

Abstract: The Technical Safety Requirements (TSRs) for the Cold Vacuum Drying Facility define acceptable conditions, safe boundaries, bases thereof, and management or administrative controls required to ensure safe operation. Controls required for public safety, significant defense-indepth, significant worker safety, and for maintaining radiological and toxicological consequences below risk evaluation guidelines are included.

The format and content for the Cold Vacuum Drying Facility TSRs are based on DOE 5480.22, Technical Safety Requirements; contractor policy; NUREG 1431, Standard Technical Specifications, Westinghouse Plants, and HNF-SD-MP-TSR-001, TSR Writer's Guide.

TRADEMARK DISCLAIMER. Reference herein to any specific commercial product, process, or service by trade name, trademark, manufacturer, or otherwise, does not necessarily constitute or imply its endorsement, recommendation, or favoring by the United States Government or any agency thereof or its contractors or subcontractors.

Printed in the United States of America. To obtain copies of this document, contact: Document Control Services, P.0. Box 950, Mailstop H6-08, Richland WA 99352, Phone (509) 372-2420; Fax (509) 376-4989.
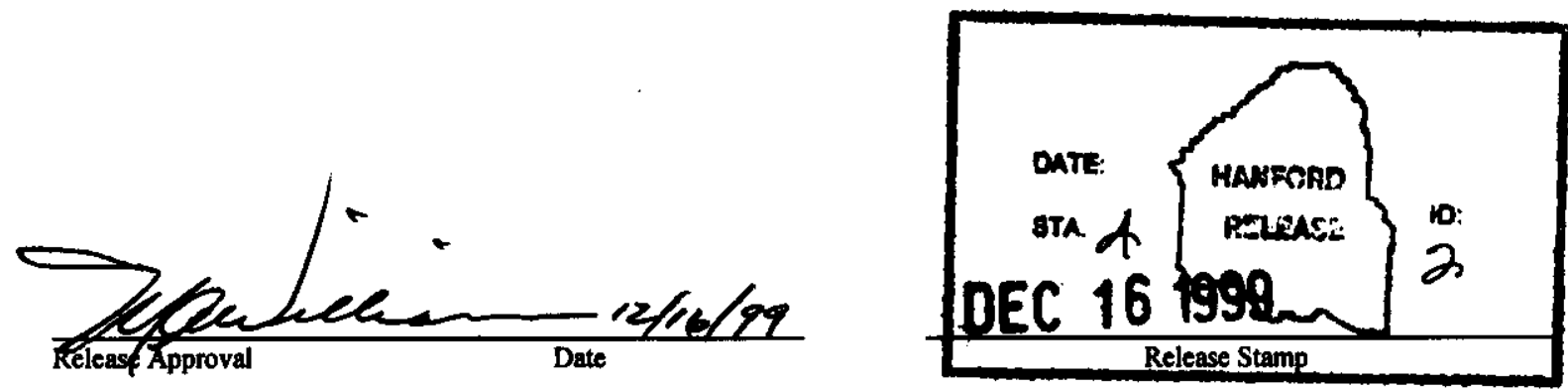

\section{Approved for Public Release}

A-6400-073 (01/97) GEF321 
HNF-3673 REV 0

COLD VACUUM DRYING FACILITY

TECHNICAL SAFETY REQUIREMENTS 


\section{PREFACE}

The Technical Safety Requirements (TSRs) for the Cold Vacuum Drying Facility define acceptable conditions, safe boundaries, bases thereof, and management or administrative controls required to ensure safe operation during receipt of multi-canister overpacks (MCOs) containing spent nuclear fuel, removal of free water from the MCOs using the cold vacuum drying process, and inerting and testing of the MCOs before transport to the Canister Storage Building. Controls required for public safety, significant defense in depth, significant worker safety, and for maintaining radiological and toxicological consequences below risk evaluation guidelines are included.

The TSRs are based on the preventive and mitigative features determined to be essential in HNF-3553, Spent Nuclear Fuel Project Final Safety Analysis Report, Annex B, "Cold Vacuum Drying Facility Final Safety Analysis Report," which is based on DOE 5480.23, Nuclear Safety Analysis Reports. The Cold Vacuum Drying Facility TSRs constitute an agreement or contract between the U.S. Department of Energy and Fluor Daniel Hanford, Incorporated regarding the safe operation of the Cold Vacuum Drying Facility. As such, once approved, the TSRs cannot be changed without the approval of the Cognizant Secretarial Officer, or designee, and Fluor Daniel Hanford, Incorporated.

The format and content of the Cold Vacuum Drying Facility TSRs are based on DOE 5480.22, Technical Safety Requirements; the Project Hanford Management System; NUREG 1431, Standard Technical Specifications, Westinghouse Plants; and HNF-SD-MP-TSR-001, TSR Writers' Guide. The TSRs are maintained as a separate, controlled document (HNF-3673, Cold Vacuum Drying facility Technical Safety Requirements).

The TSRs apply to the Cold Vacuum Drying Facility process bay area (four active process bays and a fifth, unequipped bay); the process support area (transfer corridor, process bay support rooms, mechanical equipment room); the process water tank room; and the administrative building. The N Reactor fuel specifically addressed by HNF-3553 and the TSRs includes Mark IA, Mark IB, Mark IC, Mark IV, or Mark IVB fuel. Cold vacuum drying of the single-pass reactor fuel in the $100 \mathrm{~K}$ Reactor spent nuclear fuel storage basins is currently not addressed by HNF-3553 or the TSRs. An addendum to HNF-3553 will be prepared to address processing of this type of fuel before it is loaded into an MCO, processed at the Cold Vacuum Drying Facility, and stored in the Canister Storage Building. The TSRs will be revised, as necessary, based on the revisions to HNF-3553.

The Cold Vacuum Drying Facility TSRs do not specifically address environmental regulatory requirements, that is, those contained in Title 40 of the Code of Federal Regulations, "Protection of Environment." Instead, environmental protection is assured as part of the Cold Vacuum Drying Facility environmental permitting and effluent emission monitoring program, which is more completely discussed in Spent Nuclear Fuel Project administrative procedures and applicable environmental process standards. The TSRs also do not specifically apply to the engineered and administrative features identified as "important to safety" to meet equivalent U.S. Nuclear Regulatory Commission requirements, except where the features were also selected to prevent or mitigate identified hazards and design basis accidents. 


\section{PREFACE (continued)}

Protection of occupational workers from radiological and toxicological hazards is achieved by hardware systems and integrated safety management programs that provide operational control and discipline for preventing accidents. These programs are prescribed in Spent Nuclear Fuel Project regulatory and contractual systems (e.g., CFRS, DOE Orders, SRIDs) that implement the applicable requirements. The safety management programs applicable to the Cold Vacuum Drying Facility are discussed in the programmatic chapters of HNF-3553, and therefore, are not included in the TSRs. 
PREFACE ........................... . . .

TABLE OF CONTENTS . . . . . . . . . . . . . . . . . . . . . . . . iv

LIST OF TERMS . . . . . . . . . . . . . . . . . . . . . viii

LIST OF TABLES . . . . . . . . . . . . . . . . . . . . . . xi

Section 1 USE AND APPLICATION . . . . . . . . . . . . . . . . . . 1-1

1.1 Definitions .................... 1.1-1

1.2 Logical Connectors .................. . . 1.2-1

1.3 Completion Times .................. . . 1.3-1

1.4 Frequency ..................... . 1.4-1

1.5 Notes........................ 1.5-1

1.6 MODES . . . . . . . . . . . . . . . . . 1.6-1

1.7 Safety Limits (SLs) . . . . . . . . . . . . . . . 1.7-1

1.8 Limiting Control Settings (LCSs) . . . . . . . . . . 1.8-1

1.9 Limiting Conditions for Operation (LCOS) . . . . . . . 1.9-1

1.10 Surveillance Requirements (SRs) . . . . . . . . . . . 1.10-1

1.11 Administrative Controls (ACS) . . . . . . . . . . . . 1.11-1

1.12 Cross References .................... . . . . . . . . 12

Section 2 SAFETY LIMITS . . . . . . . . . . . . . . . . . . 2-1

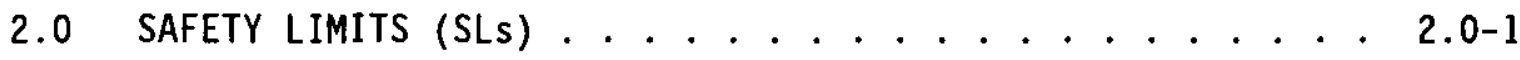

2.1.1 Multi-Canister Overpack Maximum Pressure . . 2.0-1

Section 3 OPERATING LIMITS AND SURVEILLANCE REQUIREMENTS . . . . . . . 3-1

3.0 LIMITING CONDITIONS FOR OPERATION (LCOS) APPLICABILITY • . 3.0-1

3.0 SURVEILLANCE REQUIREMENTS (SRS) APPLICABILITY . . . . . . . 3.0-3

3.1 INSTRUMENTATION . . . . . . . . . . . . . . . 3.1-1

3.1.1 Safety-Class Instrumentation and Control System 3.1-1

3.1.2 Vacuum Purge System Pressure Instrumentation . 3.1-7

3.1.3 General-Service Helium System Flow

3.1.4 Tempered Water (Annuius) System Temperature

Instrumentation ............. . 3.1-12

3.1.5 Tempered Water (Annulus) System Level Detector 3.1-14

3.1.6 Process Bay Temperature Instrumentation . . . 3.1-16

3.1.7 Seismic Trip Instrumentation . . . . . . . 3.1-18

3.1.8 Isolation Valve Interlocks . . . . . . . 3.1-20 
Table of Contents (continued)

3.2 HELIUM SYSTEMS .................... 3.2-1

3.2.1 Safety-Class Helium System ...... 3.2-1

3.3 MULTI-CANISTER OVERPACK PRESSURE PROTECTION . . . . . 3.3-1

3.3.1 Multi-Canister Overpack Vacuum Purge System

3.3.2 Connections . Pressure . . . . 3.3-1

3.3.2 Pressure Safety Relief Valves ...... 3.3-3

3.4 HEATING, VENTILATION, AND AIR CONDITIONING SYSTEMS . . . 3.4-1

3.4.1 Process General Supply/Exhaust Heating,

3.4.2 Pentilation, and Air Conditioning System 2 Process Bay Local Exhaust Heating, Ventilation,

3.4.3 $\quad$ and Air Conditioning and Process Vent System $3.4-2$

3.4.4 High-Efficiency Particulate Air Filter Loading 3.4-11

3.5 STANDBY POWER ................. . . . . . . . .

3.5.1 Diesel Generator .......... 3.5-1

3.6 TRANSPORTATION-RELATED ACTIVITIES . . . . . . . 3.6-1

3.6.1 Receipt Transportation Window...... 3.6-1

Section 4 SURVEILLANCE REQUIREMENTS . . . . . . . . . . . 4-1

Section 5 ADMINISTRATIVE CONTROLS ............. 5-1

5.0 ADMINISTRATIVE CONTROLS (ACs) ............... . . .

5.1 Purpose . . . . . . . . . . . . . . 5.1-1

5.2 Contractor Responsibility . . . . . . 5.2-1

5.3 Compliance . . . . . . . . . . . . . . 5.3-1

5.4 Technical Safety Requirement VIOLATIONS . . . . . 5.4-1

5.5 0ccurrence Reporting ............ 5.5-1

5.6 Organization ............... . . . . . .

5.7 Nuclear Criticality Safety . . . . . . . . . 5.7-1

5.8 Measurement and Test Equipment . . . . . . . . 5.8-1

5.9 Configuration Management . . . . . . . 5.9-1

5.10 Transporter Placement . . . . . . . . . 5.10-1

5.11 Helium Cyl inder Receipt Acceptance . . . . . . . . . 5.11-1

5.12 Process Bay Telescoping Door ........ . 5.12-1 
Table of Contents (continued)

5.13 Combustible Loading Limits . . . . . . . . . . . 5.13-1

5.14 Bridge Crane Movement Restrictions . . . . . . . 5.14-1

5.15 Multi-Canister Overpack Process Port Valve Isolation 5.15-1

5.16 Preparation of Multi-Canister Overpack for Shipment . 5.16-1

5.17 Dryness Testing ................ 5.17-1

5.18 Safety Programs . . . . . . . . . . . . 5.18-1

Section 6 REFERENCES .................. 6-1

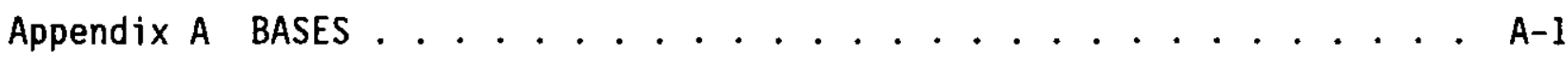

B 2.0 SAFETY LIMITS $(S L S) \ldots \ldots$. . . . . . . . . . . . . . . .

B 2.1.1 Multi-Canister Overpack Maximum Pressure . A 2.0-1

B 3.0 LIMITING CONDITIONS FOR OPERATION (LCOS) AND SURVEILLANCE

REQUIREMENTS (SRS) ............... A 3.0-1

B 3.1 INSTRUMENTATION . . . . . . . . . . . . . . . A 3.1-1

B 3.1.1 Safety-Class Instrumentation and Control

B 3.1.2 Vacuum Purge system Pressure Instrumentation A $3.1-18$

B 3.1.3 General-Service Helium System Flow

B 3.1 .4 Tempered Water (Annuius) System Temperature

B 3.1.5 Tempered Water (Annuius) System Levei

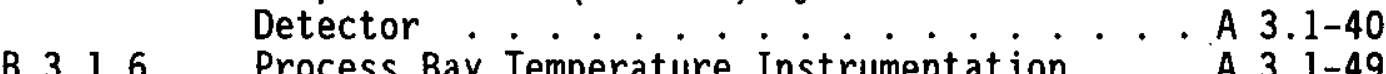

B 3.1.7 Seismic Trip Instrumentation ....... . A 3.1-60

B 3.1.8 Isolation Valve Interlocks . . . . . . . A 3.1-67

B 3.2 HELIUM SYSTEMS . . . . . . . . . . . . A 3.2-1

B 3.2.1 Safety-Class Helium System ....... . A 3.2-1

B 3.3 MULTI-CANISTER OVERPACK PRESSURE PROTECTION . . . . . A 3.3-1

B 3.3.1 Multi-Canister Overpack Vacuum Purge System

Connections . . . A 3.3-1

B 3.3.2 Pressure Safety Relief Valves....... A 3.3-8

B 3.4 HEATING, VENTILATION, AND AIR CONDITIONING SYSTEMS . . A 3.4-1

B 3.4.1 Process General Supply/Exhaust Heating,

Ventilation, and Air Conditioning System . A 3.4-1 
Table of Contents (continued)

B 3.4.2 Process Bay Local Exhaust Heating, Ventilation, and Air Conditioning and

B 3.4.3 Reference Air System . * . . . . . A 3.4-8

B 3.4.4 High-Efficiency Particulate Air Filter Loading . . . . . . . . A 3.4-33

B 3.5 STANDBY POWER ................... . . . 3.5-1

B 3.5.1 Diesel Generator ........... A 3.5-1

B 3.6 TRANSPORTATION-RELATED ACTIVITIES . . . . . . . . . A 3.6-1

B 3.6.1 Receipt Transportation Window ....... A 3.6-1

Appendix B DESIGN FEATURES . . . . . . . . . . . . . . . . . . . . . B-l 
List of Terms

AC

${ }^{\circ} \mathrm{C}$

CFR

$\mathrm{cm}$

$\mathrm{cm}^{3}$

CPS

CSB

CSER

CSO

CTC

CVDF

DBA

DBE

DOE

FSAR

ft

$f t^{3}$

h

HEPA

HVAC

in.

$i^{2}$

$1 \mathrm{~b} / \mathrm{in}^{2}$ gauge

LCO

LCS
Administrative Control

degrees Celsius

Code of Federal Regulations

centimeter

cubic centimeter

criticality prevention specification

Canister Storage Building

criticality safety evaluation report

Cognizant Secretarial officer

Calibration and Test Computer

Cold Vacuum Drying Facility

design basis accident

design basis earthquake

U.S. Department of Energy

final safety analysis report

foot

cubic feet

hour

high-efficiency particulate air (filter)

heating, ventilation, and air conditioning

inch

square inch

pounds per square inch gauge

Limiting Condition for Operation

Limiting Control Setting 
List of Terms (continued)

\begin{tabular}{|c|c|}
\hline LFL & lower flammability limit \\
\hline MCS & monitoring and control system \\
\hline $\mathrm{MCO}$ & multi-canister overpack \\
\hline $\min$ & minute \\
\hline mm & millimeter \\
\hline $\mathrm{mR}$ & mi11iroentgen \\
\hline NUREG & $\begin{array}{l}\text { U.S. Nuclear Regulatory Commission-produced reference } \\
\text { document }\end{array}$ \\
\hline PHMC & Project Hanford Management Contractor \\
\hline PLC & programmable logic controller \\
\hline PM & Program Manager \\
\hline PWC & process water conditioning \\
\hline s & second \\
\hline SCHe & safety-class helium \\
\hline SCIC & safety-class instrumentation and control \\
\hline SL & Safety Limit \\
\hline SNF & spent nuclear fuel \\
\hline SR & Surveillance Requirement \\
\hline SRV & safety relief valve \\
\hline SSCs & structures, systems, and components \\
\hline standard $\mathrm{ft}^{3} / \mathrm{min}$ & $\begin{array}{l}\text { standard cubic feet per minute (at standard conditions } \\
\text { of one atmosphere pressure, at } 0^{\circ} \mathrm{C} \text { ) }\end{array}$ \\
\hline TSR & Technical Safety Requirement \\
\hline TW & tempered water \\
\hline USQ & unreviewed safety question \\
\hline VPS & vacuum purge system \\
\hline
\end{tabular}




\begin{tabular}{ll}
\hline$\geq \quad$ & greater than \\
& greater than or equal to \\
& less than \\
\hline & less than or equal to \\
$*$ & percent \\
& $\begin{array}{l}\text { asterisk; used in piping (1 ine), equipment, } \\
\text { instrument, and valve tag numbers; takes the place of } \\
\text { the process bay number of the Cold Vacuum Drying } \\
\text { Facility in which the equipment is installed; footnote } \\
\text { reference }\end{array}$ \\
\hline \hline
\end{tabular}




\section{List of Tables}

Table

1.4-1 Frequencies and Allowable Extensions ........ 1.4-2

3.1.1-1 Safety-Class Instrumentation and Control System Trip, Interlock, and $\mathrm{Al}$ arm Functions............. . . 3.1-4

3.1.1-2 Safety-Class Instrumentation and Control System FUNCTIONAL TEST Requirements ............. 3.1-6

5.6-1 Cold Vacuum Drying Facility Minimum Operations Shift Complement ............. 5.6-2 


\section{SECTION 1}

USE AND APPLICATION 
Section 1 USE AND APPLICATION

1.1 Definitions

NOTE-

The defined terms of this section are unique definitions. They appear in CAPITALIZED type and are applicable throughout these Technical Safety Requirements (TSRS) and BASES. Some terms in this section refer the user to another section for the definition. This approach will prevent a shortened definition from being supplied and used out of context. Source documents from which the definitions are taken are referenced at the end of each definition. Definitions that have been annotated technically are noted as such.

Term

ACTIONS

AND

BASES

CALIBRATION

\section{Definition}

ACTIONS shall be that part of a Limiting Condition for Operation (LCO) that prescribes Required Actions to be taken under designated Conditions within specified Completion Times.

(NUREG 1431)

See Section 1.2, "Logical Connectors."

(NUREG 1431)

BASES shall provide statements of the reasons for the Safety Limits, Operating Limits, and associated Surveillance Requirements. The BASES shall show how the numeric values, the Conditions, the ACTIONS statements, and the Surveillances fulfill the purpose derived from the safety basis documentation (see Appendix A "BASES").

(DOE 5480.22) - annotated.

A CALIBRATION shall be the adjustment, as necessary, of the device, channel, or instrument loop so that it responds within the required range and accuracy to known input. The CALIBRATION shall include the FUNCTIONAL TEST.

(NUREG 1431) - annotated. 


\subsection{Definitions (continued)}

CHANNEL CHECK

DESIGN FEATURES

FUNCTIONAL TEST

MODE / SUBMODE

OPERABLE/OPERABILITY
A CHANNEL CHECK shall be the qualitative assessment of channel behavior during operation. The assessment is by observation and where possible, by comparison of the channel indication and status to other independent channels measuring the same parameter.

(NUREG 1431) - annotated.

DESIGN FEATURES are those design characteristics, primarily passive in nature, that are of a special importance to maintaining adequate control, shielding, or containment of radiological or toxicological material and for which indiscriminate changes are to be prevented. See Appendix B, "DESIGN FEATURES," for DESIGN FEATURES criteria.

A FUNCTIONAL TEST shall be the injection of a simulated or actual signal into the device, system, or channel as close to the sensor as practicable to VERIFY OPERABILITY of the system or channel including interlocks and setpoints.

MODES/SUBMODES are used (1) to determine SL, LCS, LCO, and $A C$ program applicabilities; (2) to distinguish facility operational conditions; (3) to determine minimum staffing requirements; and (4) to provide an instant facility status report. See also Section 1.6, "MODES."

(DOE 5480.22) - annotated.

A system, subsystem, train, component, or device shall be OPERABLE or have OPERABILITY when it is capable of performing its specified safety function(s) and (a) setpoints are within limits; (b) operating parameters necessary for OPERABILITY are within limits; and (c) when all necessary attendant instrumentation, controls, electrical power, cooling or seal water, lubrication, or other auxiliary equipment that are required for the system, subsystem, train, component, or device to perform its safety function(s) are also capable of performing their related safety support function(s).

(DOE 5480.22) - annotated. 
1.1 Definitions (continued)

$\underline{\mathrm{OR}}$

See Section 1.2, "Logical Connectors."

(NUREG 1431)

VERIFY/VERIFICATION A qualitative assessment to confirm or substantiate that specific plant conditions exist. This may include collecting sample data or quantitative data; taking instrument readings; recording data and information on logs, data sheets, or electronic media; and evaluating data and information according to procedures.

VIOLATION

See Section 5.4, "Technical Safety Requirement VIOLATIONS."

(DOE 5480.22) - annotated. 
Section 1 USE AND APPLICATION

\subsection{Logical Connectors}

PURPOSE

The purpose of this section is to explain the meaning of logical connectors with specific examples.

Logical connectors are used in Technical Safety

Requirements (TSRs) to discriminate between, and yet connect, discrete Conditions, Required Actions, Completion Times, Surveillances, and Frequencies. The only logical connectors that appear in TSRs are AND and OR. The physical arrangement of these connectors constitutes logical conventions with specific meanings.

Several levels of logic may be used to state Required Actions. These levels are identified by the placement (or nesting) of the logical connectors and by the number assigned to each Required Action. The first level of logic is identified by the first digit of the number assigned to a Required Action and the placement of the logical connector in the first level of nesting (i.e., left-justified with the number of the Required Action). The successive levels of logic are identified by additional digits of the Required Action number and by successive indentations of the logical connectors.

When logical connectors are used to state a Condition, usually only the first level of logic is used, and the logical connector is left-justified with the Condition statement. In a few cases, successive levels of logic are used. This is identified solely by indenting the logical connector, because subparts of a Condition statement are not numbered separately.

When logical connectors are used to state a Completion Time, Surveillance, or Frequency, only the first level of logic is used, and the logical connector is left-justified with the statement of the Completion Time, Surveillance, or Frequency. 
EXAMPLES The following examples illustrate the use of logical connectors.

\section{Example 1.2-1}

ACTIONS

\begin{tabular}{|c|c|c|}
\hline CONDITION & REQUIRED ACTION & COMPLETION TIME \\
\hline $\begin{array}{l}\text { A. System } \\
\text { inoperable. }\end{array}$ & $\begin{array}{l}\text { A.1 Restore } \\
\text { AND } \\
\text { A.2 Be in }\end{array}$ & $\begin{array}{l}x \text { hours } \\
y \text { hours }\end{array}$ \\
\hline
\end{tabular}

In hypothetical Example 1.2-1 the logical connector AND is used to demonstrate that when in Condition $A$, both Required Actions A.1 and A.2 must be completed. 


\subsection{Logical Connectors (continued)}

EXAMPLES (continued)
Example 1.2-2

ACTIONS

\begin{tabular}{|c|c|c|}
\hline CONDITION & REQUIRED ACTION & COMPLETION TIME \\
\hline $\begin{array}{l}\text { System } \\
\text { inoperable. }\end{array}$ & $\begin{array}{l}\text { A.1 Restore } \\
\underline{O R} \\
\text { A.2 Align } \\
\underline{\text { OR }} \\
\text { A.3.1 VERIFY } \\
\text { A.3.2.1 Reduce } \\
\text { A.3.2.2 Perform }\end{array}$ & $\begin{array}{l}s \text { hours } \\
t \text { hours } \\
\text { u hours } \\
v \text { hours } \\
\text { w hours }\end{array}$ \\
\hline
\end{tabular}

Hypothetical Example 1.2-2 represents a more complicated use of logical connectors. Required Actions A.1, A.2, and A.3 are alternative choices, only one of which must be performed as indicated by the use of the logical connector $Q R$ and the left-justified placement. Any one of these three Required Actions may be chosen. If A.3.1 is chosen, an additional requirement, indicated by the indented logical connector AND, is imposed. This additional requirement is met by choosing A.3.2.1 or A.3.2.2. The indented position of the logical connector $\underline{O R}$ indicates that A.3.2.1 and A.3.2.2 are alternate and equal choices, only one of which must be performed. 
Section 1 USE AND APPLICATION

1.3 Completion Times

PURPOSE

The purpose of this section is to establish the Completion Time convention and to provide guidance for its use.

BACKGROUND Limiting Conditions for Operation (LCOS) specify minimum requirements for ensuring safe operation of the facility. The ACTIONS associated with an LCO state Conditions that typically describe the ways in which the requirements of the LCO can fail to be met. Specified with each stated Condition are Required Action(s) and Completion Time(s).

IMMEDIATE

In some cases Immediately is used as a special Completion

COMPLETION TIME Time. In this case, the Required Action is to be commenced without delay and continuously pursued in a controlled manner until complete. The use of Immediately implies the highest sense of urgency. Implementation of Immediately shall be given top priority over all other activities. 


\subsection{Completion Times (continued)}

DESCRIPTION The Completion Time is the amount of time allowed for completing a Required Action. It is referenced to the time of discovery of a situation (e.g., inoperable equipment or variable not within limits) that requires entering an ACTIONS Condition unless otherwise specified, provided the unit is in a MODE or specified condition stated in the Applicability of the LCO. Required Actions must be completed prior to the expiration of the specified Completion Time. An ACTIONS Condition remains in effect and the Required Actions must be applied until the Condition no longer exists or the unit is not within the LCO Applicability.

If situations are discovered that require entry into more than one Condition at a time within a single LCO (multiple Conditions), the Required Actions for each Condition must be performed within the associated Completion Time. When in multiple Conditions, separate Completion Times are tracked for each Condition starting from the time of discovery of the situation which required entry into the Condition.

Once a Condition has been entered, subsequent systems or variables expressed in the Condition discovered to be inoperable or not within limits, will result in separate entry into the Condition for each discovery. The Required Actions and the associated Completion Times of the Condition then apply to each additional discovery independent $7 y$. 


\subsection{Completion Times (continued)}

EXAMPLES The following examples illustrate the use of Completion Times with different types of Conditions and changing Conditions.

Example 1.3-1

ACTIONS

\begin{tabular}{l|l|l|l}
\hline \hline CONDITION & REQUIRED ACTION & COMPLETION TIME \\
\hline B. Required \\
$\begin{array}{l}\text { Action A.1 } \\
\text { and } \\
\text { associated } \\
\text { Completion } \\
\begin{array}{l}\text { Time not } \\
\text { met within } \\
\text { X hours. }\end{array}\end{array}$ & B.1 Be in STANDBY MODE. & 6 hours \\
\hline \hline
\end{tabular}

In hypothetical Example 1.3-1, Condition B has two Required Actions. Each Required Action has its own separate Completion Time. Each Completion Time is referenced to the time that Condition $B$ is entered.

The Required Actions of Condition $B$ are to be in STANDBY MODE in 6 hours AND in REPAIR MODE in 12 hours. A total of 6 hours is allowed to reach STANDBY MODE and a total of 12 hours (not 18 hours) is allowed to reach REPAIR MODE from the time that Condition B was entered. If STANDBY MODE is reached in 3 hours, the time allowed to reach REPAIR MODE is the next 9 hours because the total time allowed to reach REPAIR MODE is 12 hours.

If Condition $B$ is entered while in STANDBY MODE, the time allowed to reach REPAIR MODE is the next 12 hours. 


\subsection{Completion Times (continued)}

\section{EXAMPLES (cont inued)}

\section{Example 1.3-2}

ACTIONS

\begin{tabular}{|c|c|c|c|}
\hline CONDITION & & REQUIRED ACTION & COMPLETION TIME \\
\hline $\begin{array}{l}\text { A. One or more } \\
\text { valves } \\
\text { inoperable. }\end{array}$ & A.l & $\begin{array}{l}\text { Restore valve to } \\
\text { OPERABLE status. }\end{array}$ & 4 hours \\
\hline $\begin{array}{l}\text { B. Required } \\
\text { Action A.1 } \\
\text { and } \\
\text { associated } \\
\text { Completion } \\
\text { Time not } \\
\text { met within } \\
4 \text { hours. }\end{array}$ & $\begin{array}{l}\text { B.1 } \\
\text { AND } \\
\text { B.2 }\end{array}$ & $\begin{array}{l}\text { Be in STANDBY } \\
\text { MODE. } \\
\text { Be in REPAIR MODE. }\end{array}$ & $\begin{array}{l}6 \text { hours } \\
12 \text { hours }\end{array}$ \\
\hline
\end{tabular}

In hypothetical Example 1.3-2, Condition $A$ is entered separately for each inoperable valve and Completion Times tracked on a per valve basis. When a valve is declared inoperable, Condition A is entered and its Completion Time starts. If subsequent valves are declared inoperable, Condition $A$ is entered for each valve and separate Completion Times start and are tracked for each valve.

If the Completion Time associated with a valve in Condition A expires, Condition B is entered for that valve. If the Completion Times associated with subsequent valves in Condition A expire, Condition B is entered separately for each valve and separate Completion Times start and are tracked for each valve. If a valve that caused entry into Condition $B$ is restored to OPERABLE status, Condition $B$ is exited for that valve. 


\subsection{Completion Times (continued)}

EXAMPLES (continued)
Example 1.3-3

ACTIONS

\begin{tabular}{l|lll}
\hline CONDITION & REQUIRED ACTION & COMPLETION TIME \\
\hline $\begin{array}{l}\text { A. Annulus } \\
\text { water level } \\
\text { outside } \\
\text { limit. }\end{array}$ & A.l & Perform SR 3.X.X.X. & $\begin{array}{l}\text { Once per } \\
2 \text { hours }\end{array}$ \\
& $\begin{array}{l}\text { A.2 } \\
\text { Restore annulus } \\
\text { water level to } \\
\text { within limit. }\end{array}$ & 7 days \\
\hline $\begin{array}{l}\text { Required } \\
\text { Action } \\
\text { and } \\
\text { associated } \\
\begin{array}{l}\text { Completion } \\
\text { Time for } \\
\text { Condition A } \\
\text { not met. }\end{array}\end{array}$ & $\begin{array}{l}\text { B.1 } \\
\text { Be in STANDBY } \\
\text { MODE. }\end{array}$ & 6 hours \\
\hline \hline
\end{tabular}

In hypothetical Example 1.3-3, entry into Condition $A$ offers a choice between Required Action A.1 or A.2. If Required Action A.l is followed and the Required Action is not met within the Completion Time, Condition B is entered. If Required Action A.2 is followed and the Completion Time of 7 days is not met, Condition $B$ is entered.

If after entry into Condition B, Required Action A.1 or A.2 is met, Condition $B$ is exited and operation may then continue in Condition $A$. 
1.3 Completion Times (continued)

EXAMPLES

(cont inued)
Example 1.3-4

ACTIONS

\begin{tabular}{|c|c|c|c|c|}
\hline & CONDITION & & REQUIRED ACTION & COMPLETION TIME \\
\hline A. & $\begin{array}{l}\text { One system } \\
\text { inoperable. }\end{array}$ & $\begin{array}{l}\text { A.1 } \\
\text { AND } \\
\text { A. } 2\end{array}$ & $\begin{array}{l}\text { Perform SR 3.X.X.X. } \\
\text { Restore system to } \\
\text { OPERABLE status. }\end{array}$ & $\begin{array}{l}2 \text { hours } \\
\text { AND } \\
\text { Once per } 8 \text { hours } \\
\text { thereafter } \\
7 \text { days }\end{array}$ \\
\hline B. & $\begin{array}{l}\text { Required } \\
\text { Action A.1 } \\
\text { and } \\
\text { associated } \\
\text { Completion } \\
\text { Times not } \\
\text { met. }\end{array}$ & $\begin{array}{l}\text { B. } 1 \\
\frac{\text { AND }}{\text { B. } 2}\end{array}$ & $\begin{array}{l}\text { Be in STANDBY MODE. } \\
\text { Be in REPAIR MODE. }\end{array}$ & $\begin{array}{l}6 \text { hours } \\
12 \text { hours }\end{array}$ \\
\hline
\end{tabular}




\subsection{Completion Times (continued)}

\section{EXAMPLES}

\section{Example 1.3-4 (continued)}

In hypothetical Example 1.3-4, Required Action A.1 has two Completion Times. The 2-hour Completion Time begins at the time the Condition is entered and each "Once per 8 hours thereafter" interval begins upon performance of Required Action A.1.

If, after Condition A is entered, Required Action A.l is not met within either the initial 2-hour, or any subsequent 8-hour interval from the previous performance, Condition $B$ is entered. The Completion Time clock for Condition A does not stop after Condition $B$ is entered, but continues from the time Condition $A$ was initially entered. If Required Action A.l is met after Condition B is entered, Condition B is exited and operation may continue in accordance with Condition A, provided the Completion Time for Required Action A.2 has not expired. 
Section 1 USE AND APPLICATION

\subsection{Frequency}

PURPOSE

The purpose of this section is to define the proper use and application of Frequency requirements. Each Surveillance Requirement (SR) has a specified Frequency in which the Surveillance must be met in order to meet the associated Limiting Condition for Operation (LCO). An understanding of the correct application of the specified Frequency is necessary for compliance with the SR or ACTIONS statement, as applicable.

FREQUENCIES

Table 1.4-1 specifies the Frequencies and allowable 25\% extensions as used in Surveillance Requirements (e.g., 365 days for Surveillances specified as "Annually") and any Completion Time in an ACTIONS statement that requires the periodic performance of a Required Action on a

"once per. . ." interval (e.g., once per 12 hours thereafter).

The $25 \%$ extension does not apply to Completion Times in ACTIONS statements. For some specified Frequencies, the $25 \%$ extension may not be allowed if the time duration is short (e.g., Daily). Refer to Example 1.4-2, where a Frequency specified as "once," does not qualify for the $25 \%$ extension, in accordance with SR 3.0.2, "Frequencies."

See SR 3.0.2, "Frequencies," and the BASES for more discussion of the applications of the $25 \%$ extension.

Due dates are determined by adding the Surveillance interval to the date of the last performed Surveillance, provided that performance date did not use an extension. For example, if a yearly Surveillance is due on April 1 but is performed on March 31, the next due date is March 31 of the following year. If the Surveillance is due on April 1 but is performed on April 7 (using a part of the extension), the next Surveillance is still due on April 1 of the following year.

A strict accounting of hours is not required when determining when a Surveillance is due if the Surveillance Frequency is specified in days. For example, a daily Surveillance taken on Monday at 10:00 a.m. is not due by 10:00 a.m. on Tuesday, but may be performed any time on Tuesday. 


\subsection{Frequency (continued)}

FREQUENCIES

(cont inued)

Table 1.4-1. Frequencies and Allowable Extensions.

\begin{tabular}{|c|c|c|}
\hline NOTATION & FREQUENCY & $\begin{array}{l}\text { WITH } 25 \% \\
\text { EXTENSION* }\end{array}$ \\
\hline 1 hour & $\begin{array}{c}\text { At least once per } \\
\text { hour }\end{array}$ & 1 hour \\
\hline 8 hours & $\begin{array}{c}\text { At least once per } \\
8 \text { hours } \\
\end{array}$ & 8 hours \\
\hline 12 hours & $\begin{array}{c}\text { At least once per } \\
12 \text { hours } \\
\end{array}$ & 12 hours \\
\hline Daily & $\begin{array}{c}\text { At least once per } \\
\text { day }\end{array}$ & 1 day \\
\hline Monthly & $\begin{array}{c}\text { At least once per } \\
31 \text { days }\end{array}$ & 38 days \\
\hline Quarterly & $\begin{array}{c}\text { At least once per } \\
92 \text { days }\end{array}$ & 115 days \\
\hline Semi-annual1y & $\begin{array}{c}\text { At least once per } \\
184 \text { days }\end{array}$ & 230 days \\
\hline Annually & $\begin{array}{c}\text { At least once per } \\
365 \text { days }\end{array}$ & 456 days \\
\hline
\end{tabular}

* When the Frequency above is specified in days, no partial days are allowed. That is, the $25 \%$ extension shall be rounded conservatively (e.g., 1 day instead of 1.25 days; 456 days instead of 456.25 days). The allowable $25 \%$ extension is not intended to be used repeatedly merely as an operational convenience to extend Surveillance intervals or periodic Completion Time intervals beyond those specified.

EXAMPLES

The following examples illustrate the various ways that Frequencies are specified. 


\subsection{Frequency (continued)}

\author{
EXAMPLES \\ (continued)
}

Example 1.4-1

SURVEILLANCE REQUIREMENTS

\begin{tabular}{c|l}
\multicolumn{1}{c|}{ SURVEILLANCE } & FREQUENCY \\
\hline \hline Perform VERIFICATION. & Quarterly \\
\hline
\end{tabular}

Hypothetical Example 1.4-1 contains the type of SR most often encountered in the Technical Safety Requirements (TSRs). The Frequency specifies an interval (Quarterly) during which the associated Surveillance must be performed at least one time. Performance of the Surveillance initiates the subsequent 92-day interva1, provided the performance date did not use an extension. If the Surveillance was performed using an extension, the next Surveillance is due 92 days from the due date (without consideration of the $25 \%$ extension of SR 3.0.2, "Frequencies") of the last Surveillance. Although the Frequency is stated as Quarterly (92 days), an extension of the time interval to 1.25 times the stated Frequency is allowed by SR 3.0.2, "Frequencies, "for operational flexibility. "The measurement of this interval continues at al1 times, even when the SR is not required to be met per SR 3.0.1, "SR Met," (e.g., when the equipment is inoperable, a variable is outside specified limits, or the unit is outside the Applicability of the Limiting Condition for Operation). If the interval specified by SR 3.0.2, "Frequencies," is exceeded while the unit is in a MODE or other specified condition in the Applicability of the LCO, and the performance of the Surveillance is not otherwise modified (refer to Examples 1.4-3 and 1.4-4), then SR 3.0.3, "Delay of Required Actions," becomes applicable.

If the interval as specified by SR 3.0.2, "Frequencies," is exceeded while the unit is not in a MODE or other specified condition in the Applicability of the LCO for which performance of the SR is required, the Surveillance must be performed within the Frequency requirements of SR 3.0.2, "Frequencies," prior to entry into the MODE or other specified condition. Failure to do so would result in SR 3.0.4, "MODE Changes," not being met. 


\subsection{Frequency (continued)}

EXAMPLES (cont inued)
Sometimes special conditions dictate when a Surveillance is to be met. These conditions apply to the Surveillance or to the Frequency or both. These are "otherwise stated" conditions allowed by SR 3.0.1, "SR Met." They may be stated as clarifying Notes in the Surveillance, in the Frequency, or both. The remaining examples discuss these special conditions.

Example 1.4-2

SURVEILLANCE REQUIREMENTS

\begin{tabular}{c|l}
\hline \hline \multicolumn{1}{|c|}{ SURVEILLANCE } & \multicolumn{1}{|c}{ FREQUENCY } \\
\hline VERIFY temperature is within limits. & $\begin{array}{l}\text { Once within } \\
8 \text { hours after } \\
\text { start of } \\
\text { transfer } \\
\text { AND }\end{array}$ \\
& $\begin{array}{l}24 \text { hours } \\
\text { thereafter } \\
\text { during } \\
\text { transfer }\end{array}$ \\
\end{tabular}

Hypothetical Example 1.4-2 has two Frequencies. The first is a one-time performance Frequency, and the second is of the type shown in Example 1.4-1. The logical connector "AND" indicates that both Frequency requirements must be met. The Surveillance must initially be performed within 8 hours after the start of each transfer.

The use of "Once" indicates a single performance will satisfy the specified Frequency (assuming no other Frequencies are connected by "AND"). This type of Frequency does not qualify for the $25 \%$ extension allowed by SR 3.0.2, "Frequencies." "Thereafter" indicates future performances must be established per SR 3.0.2, "Frequencies, "but only after a specified condition is first met (i.e., the "Once" performance in this example). Once the transfer is complete, the measurement of both intervals stops. New intervals start upon the start of the next transfer.

(cont inued) 


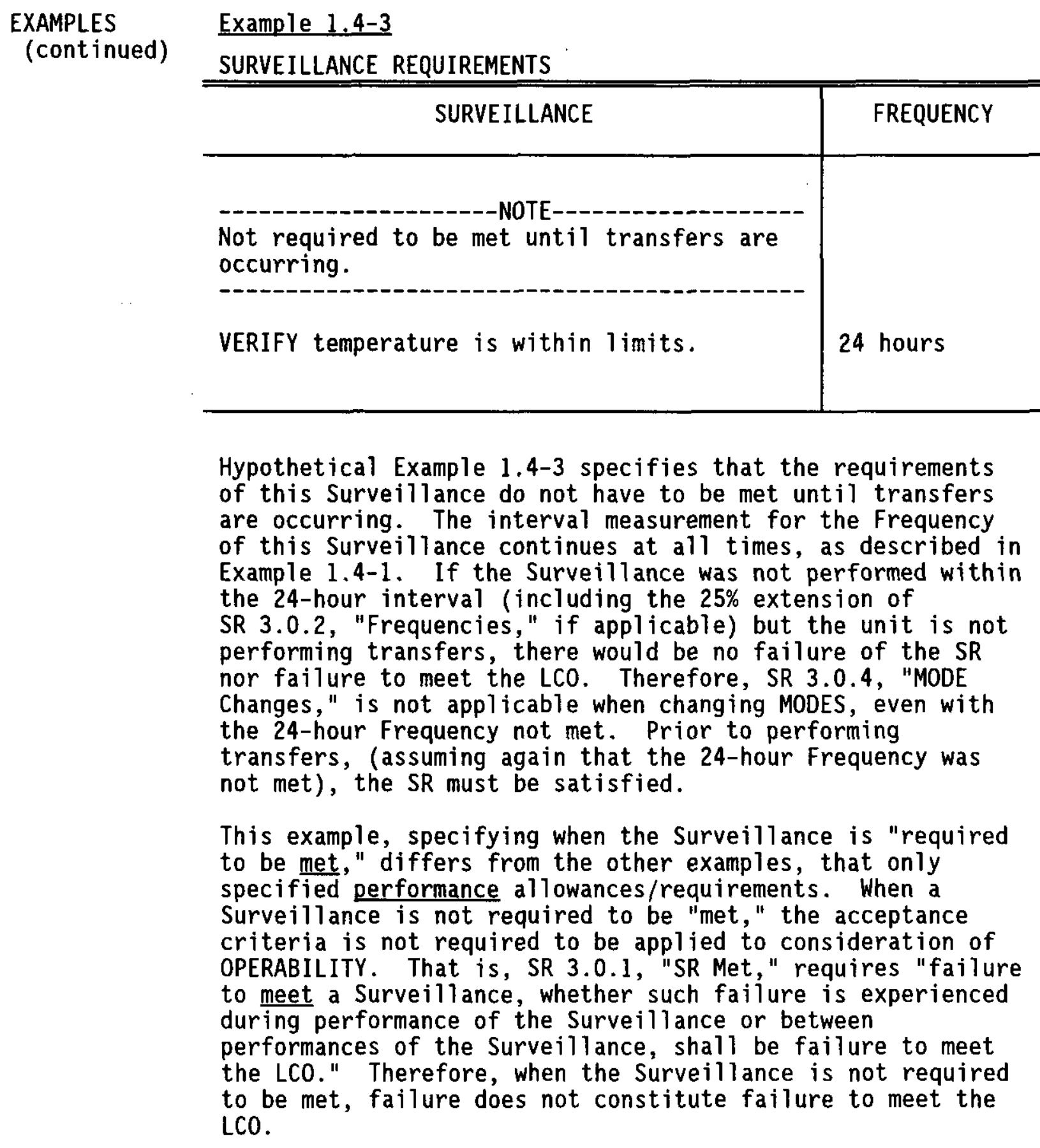


Section 1 USE AND APPLICATION

1.5 Notes

\begin{tabular}{ll}
\hline \hline PURPOSE & Notes provide additional clarification in the Limiting \\
Conditions for Operation (LCOs), Applicability, ACTIONS and \\
Surveillance Requirements (SRs). Notes in the LCOs and \\
Applicability are placed after the text they amplify. \\
Notes in the ACTIONS and SRs are placed before the text \\
they amplify. Al1 Notes are preceded by the centered \\
heading "NOTE" in uppercase type.
\end{tabular}

EXAMPLES

The following examples illustrate the various ways that Notes are specified.

Example 1.5-1

LCO 3.X.X Condúctivity probe leak detection systems installed in process pipeline encasements and clean-out boxes (COBs), diversion boxes, valve pits, pump pits, and drain pits shall be OPERABLE.

-----------------NOTE

Conductivity probe leak detection systems may be inoperable for planned work activities (e.g., maintenance):

1. For $\leq 1$ hour, or

2. When constant surveillance is provided at the locations where leak detection systems are inoperable, or

3. For process pipeline encasements that drain to pits where leak detection systems are OPERABLE.

In hypothetical Example 1.5-1 the Note is placed after the LCO requirement. 
1.5 Notes (continued)

\section{EXAMPLES Example 1.5-2 \\ (continued)}

MODE

APPLICABILITY: OPERATION, SHUTDOWN and REPAIR MODES.

NOTE-

LCO 3.0.4, "MODE Changes," is not applicable.

In hypothetical Example 1.5-2 the Note is placed after the Applicability. 
1.5 Notes (continued)

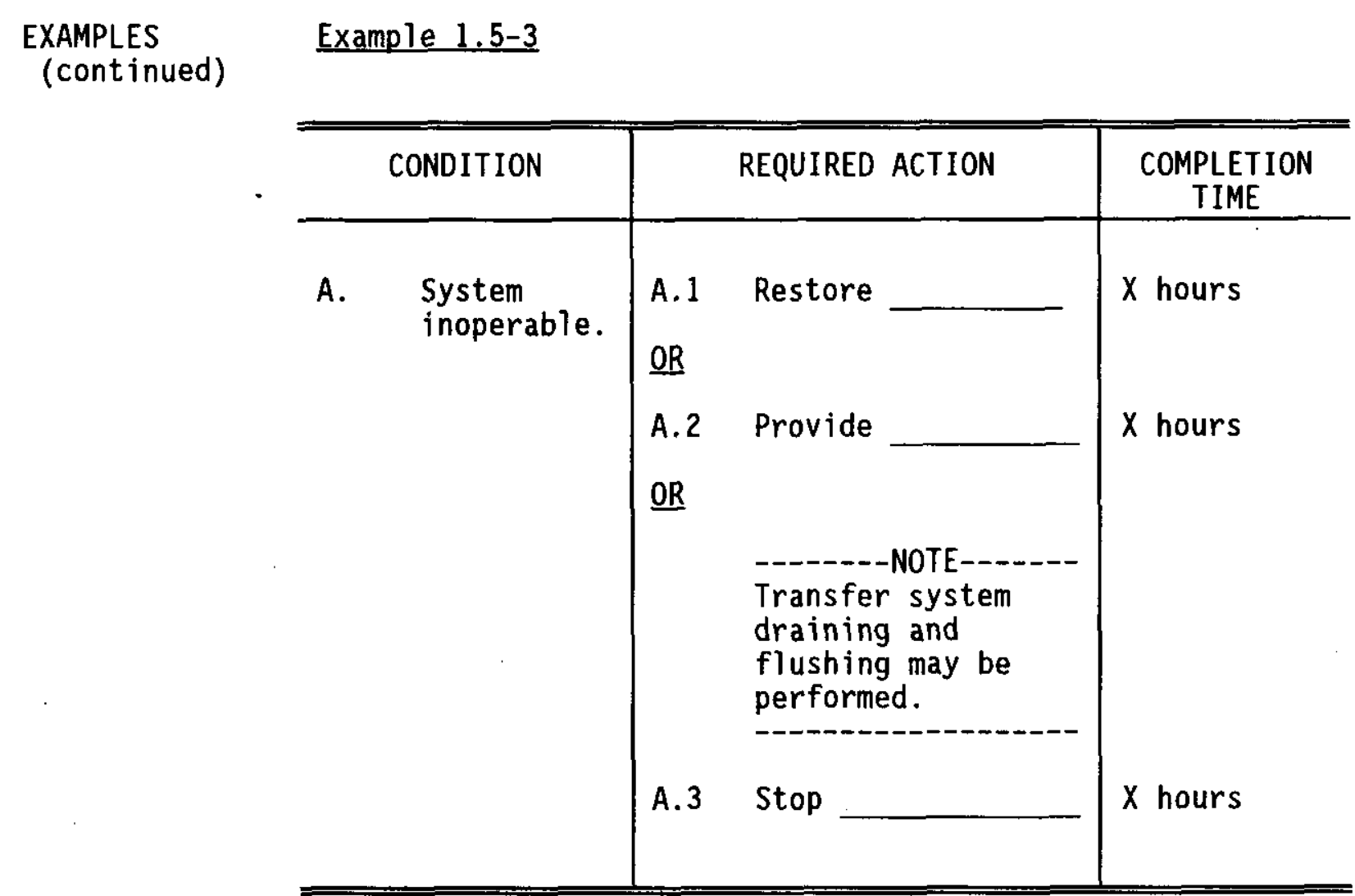

In hypothetical Example 1.5-3 the Note is placed before Required Action A.3. 
1.5 Notes (continued)

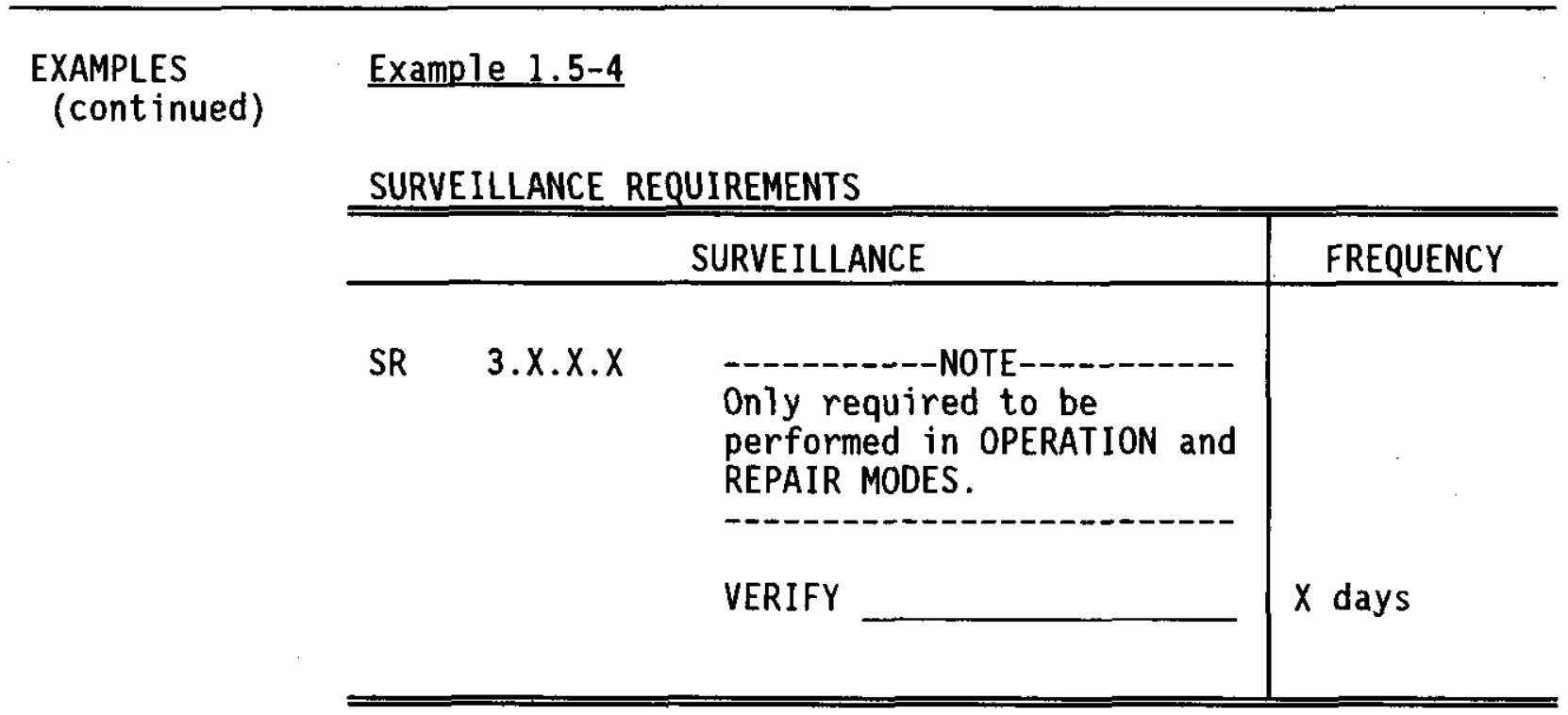

In hypothetical Example 1.5-4 the Note is placed before the Surveillance Requirement. 


\section{Section 1 USE AND APPLICATION}

\subsection{MODES}

1.6.1 The operational MODES defined for the Cold Vacuum Drying Facility are:

(Note: When the facility is in OPERATION MODE, the process bays can be in OPERATION, STANDBY, or REPAIR SUBMODES.)

OPERATION MODE

STANDBY MODE

SHUTDOWN MODE
The facility contains at least one multi-canister overpack (MCO) within the process bays, or the facility is administratively declared capable of receiving and/or processing MCOs although an MCO may not be present in any process bay. Maintenance activities are permitted in this MODE provided the associated activities will not result in entry into the LCO ACTION statements*.

The facility contains no MCOs within the process bays. Process water transfers to, from, or within the process water tank room may be occurring. Maintenance activities are permitted in this MODE provided the associated activities will not result in entry into the LCO ACTION statements".

The facility contains no MCOs within the process bays. No process water transfers to, from, or within the process water tank room are occurring. Maintenance activities are permitted in this MODE.

* For example, maintenance activities on the reference air system that take the process water tank room differential pressure indicator out of service are not allowed in OPERATION or STANDBY MODES when the circulation pump in the process water tank room is running. This is because such an action would result in entry into the ACTIONS (Condition B) for LCO 3.4.3, "Reference Air System." These same maintenance activities would be allowed in OPERATION or STANDBY MODES when the circulation pump is not running. This is because LCO 3.4.3 differential pressure requirements, indicator, and alarm are not required when the pump is not running, and entry into the ACTIONS would not result. 


\subsection{MODES (continued)}

1.6.2 The operational SUBMODES defined for the individual process bays are:

(Note: The facility is in OPERATION MODE. When the facility is in STANDBY or SHUTDOWN MODES, process bay SUBMODES do not apply.)

OPERATION SUBMODE

STANDBY SUBMODE

REPAIR SUBMODE
The process bay is receiving, containing, or processing an MCO. Maintenance activities are permitted in this SUBMODE provided the associated activities will not result in entry into the LCO ACTION statements*.

The process bay does not contain an MCO but meets the $L C O$ requirements necessary for it to receive an $\mathrm{MCO}$. Maintenance activities are permitted in this SUBMODE provided the associated activities will not result in entry into the LCO ACTION statements".

The process bay does not contain an $M C O$ and is not capable of receiving an MCO. Maintenance activities are permitted in this SUBMODE provided the associated activities will not result in entry into the $L C O A C T I O N$ statements*.

[Note: Maintenance activities involving the safety-class instrumentation and control (SCIC) system will require both of the affected process bays (i.e., those bays requiring the system's OPERABILITY to meet redundancy requirements) to be in the REPAIR SUBMODE.]

For example, maintenance activities on the safety-class helium system that take a vent path leg out of service are not allowed in the process bay OPERATION SUBMODE during MCO processing. This is because such an action would result in entry into the ACTIONS (Condition $A$ ) for LCO 3.2.1, "Safety-Class Helium System." These same maintenance activities would be allowed in the process bay OPERATION SUBMODE after the MCO was sufficiently dried per AC 5.17, "Dryness Testing," and the process port valves were closed. This is because LCO 3.2.1 does not apply at that time and entry into the ACTIONS would not result. 
Section 1 USE AND APPLICATION

\subsection{Safety Limits (SLs)}

SLs are limits on process variables (e.g., temperature, pressure) associated with those physical barriers (e.g., tanks, piping), generally passive, that are necessary for the intended facility function. Exceeding SLs could directly cause the failure of one or more of the barriers that prevent the uncontrolled release of radiological and toxicological material. The limits are stated in measurable units (e.g., $1 \mathrm{~b} / \mathrm{in}^{2}$ gauge) and are placed on primary barriers closest to the material source.

SLs are those limits required to prevent accidents with unacceptable radiological or toxicological consequences to the offsite public or onsite worker. Quantitative risk evaluation guidelines are provided for the Spent Nuclear Fuel Project facilities in HNF-3553, Spent Nuclear Fuel Project Final Safety Analysis Report, Chapter 3.0, "Hazard and Accident Analyses." 
Section 1 USE AND APPLICATION

\subsection{Limiting Control Settings (LCSS)}

LCSs are setpoints on safety systems that control process variables to prevent exceeding SLs. The specific setpoints are chosen such that, if exceeded, sufficient time is available to automatically or manually correct the condition before exceeding SLS.

The LCSs are combined with their respective LCOS with all setpoints and requirements contained within the LCOS. By combining the LCSS with the LCOs, the LCS setpoint becomes part of the OPERABILITY of the system. Furthermore, safety is enhanced by placing the Applicability, ACTIONS, and SRs for a system in a single location and reduces the complexity of the TSR document.

LCSs are those setpoints on safety systems required to prevent accidents with unacceptable radiological or toxicological consequences to the offsite public or onsite worker. Quantitative risk evaluation guidelines are provided for the Spent Nuclear Fuel Project facilities in HNF-3553, Spent Nuclear Fuel Project Final Safety Analysis Report, Chapter 3.0, "Hazard and Accident Analyses." 
Section 1 USE AND APPLICATION

\subsection{Limiting Conditions for Operation (LCOS)}

LCOs are the lowest functional capability or performance level of safety structures, systems, and components (SSCs) (and their support systems) required for normal, safe operation of the facility. LCOs are based on keeping the safety SSCS OPERABLE or on maintaining conditions within specified limits. LCOs are prepared for those safety SSCs that are identified in the accident analyses as preventing or mitigating accidents or transient events that involve the assumed failure of, or present a challenge to, the integrity of a physical barrier that prevents the uncontrolled release of radiological and toxicological material. LCOs are established only for those mitigative safety SSCs that are part of the primary success path of an accident sequence analysis; that is, the assumed sequence of events that leads to the conclusion of an accident for which the risk is judged to be acceptable.

LCOs are required to prevent or mitigate accidents with unacceptable radiological or toxicological consequences to the offsite public or onsite worker, to provide significant defense in depth, or provide significant worker safety. Quantitative risk evaluation guidelines are provided for the Spent Nuclear Fuel Project facilities in HNF-3553, Spent Nuclear Fuel Project Final Safety Analysis Report, Chapter 3.0, "Hazard and Accident Analyses." 
Section 1 USE AND APPLICATION

1.10 Surveillance Requirements (SRs)

SRs are requirements relating to testing, CALIBRATION, or inspection of SSCS or conditions. The purposes of SRs are to confirm the availability, OPERABILITY, and quality of safety SSCs and to VERIFY that specific plant conditions exist that are required to maintain the facility's operations within the SLS, LCSs, and LCOs. SRs ensure that safety SSCs will function when required or that parameters are within limits (e.g., temperature) to preserve the validity of the safety analysis and the resulting safety envelope. If a safety SSC is out of service or is inoperable, it cannot perform its required safety function.

The establishment of SR Frequencies considers (a) equipment operating history, (b) engineering judgement, (c) meantime between failures, (d) equipment degradation, (e) instrument and CALIBRATION accuracies, (f) industrial practice, (g) manufacturers' recommendations, (h) safety analys is assumptions, (i) $25 \%$ extension of SRs, (j) the risk of an inoperable safety SSC or a parameter not within limits, and (i) time to perform an SR. 
ACs are the provisions relating to organization and management, procedures, recordkeeping, reviews, audits, and specific program requirements for risk reduction necessary to ensure safe operation of the facility. The TSRs (i.e., SLs, LCSS, LCOS and ACs) establish administrative requirements that ensure TSR requirements are met in the operation of the facility and the procedures that are followed should a TSR not be met. ACs are normally written at the program level and contain program key elements, as applicable. ACs are established (1) if a safety function is best satisfied by a program instead of a hardware system, (2) if control of a condition is not measured in real-time or near to real-time, (3) if control of a condition is not under the immediate control of the operator, (4) if a condition does not require immediate action and sufficient recovery time exists to permit mitigating action, or (5) if a condition requires an evaluation based on prevalent conditions. ACS do not require ACTIONS statements or SRs. SRs necessary to demonstrate compliance with an $A C$ and the actions taken should an $A C$ requirement not be met are performed according to procedures.

ACs are established for those programs required to prevent or mitigate accidents with unacceptable radiological or toxicological consequences to the offsite public or onsite worker, to provide significant defense in depth, or provide significant worker safety. Quantitative risk evaluation guidelines are provided for the Spent Nuclear Fuel Project facilities in HNF-3553, Spent Nuclear Fuel Project Final Safety Analysis Report, Chapter 3.0, "Hazard and Accident Analyses." 


\section{Section 1 USE AND APPLICATION}

\subsection{Cross References}

Cross References direct the TSR user to other SLS, LCSS, LCOS, and ACs that are related to the SLS, LCSS, and LCOs where the Cross Reference section is located. The purpose of the cross Reference section is to make the TSR user aware that there may be other TSR controls or requirements that apply concurrently when a situation or condition is discovered. 
HNF-3673 REV 0

Section 2

Safety Limits

SECTION 2.

SAFETY LIMITS 


\subsection{SAFETY LIMITS (SLS)}

\subsection{SLS}

\subsubsection{Multi-Canister Overpack Maximum Pressure}

SL 2.1.1 The multi-canister overpack pressure shall be $\leq 340 \mathrm{lb} /$ in $^{2}$ gauge.

MODE

APPLICABILITY: Process bay OPERATION SUBMODE.

PROCESS AREA

APPLICABILITY: Prior to the successful completion of the final pressure rebound test (AC 5.17, "Dryness Testing") and the closure of both multi-canister overpack process port valves.

\subsection{SL VIOLATIONS}

If a VIOLATION of an SL occurs, proceed in accordance with AC 5.4.2, "Response to a Safety Limit VIOLATION." 
SECTION 3

OPERATING LIMITS

AND

SURVEILLANCE REQUIREMENTS 
Purpose These General Rules of Applicability provide basic rules to govern the specific LCOS (and LCSs) to ensure uniform application and implementation of the requirements. That is, these basic rules ensure activities are conducted in a consistent manner and responses to conditions and situations are taken in a uniform and predictable way.

LCO 3.0.1

LCO Met
LCOs shall be met during the MODES or other specified conditions in the Applicability, except as provided in LCO 3.0.2, "ACTION Met."
$\operatorname{LCO} 3.0 .2$ ACTION Met
Upon discovery of a failure to meet an LCO, the Required Actions of the associated Conditions shall be met.

If the LCO is met or is no longer applicable prior to expiration of the specified Completion Time(s), completion of the Required Action(s) is not required uniess otherwise stated.
$\operatorname{LCO} 3.0 .3$

ACTION Not Met or ACTION Not Provided
For ACTIONS not met (VIOLATION), proceed in accordance with $A C$ 5.4.3, "Response to a Limiting Condition for operation and Limiting Control Setting VIOLATION."

All foreseen Conditions are listed in the ACTIONS statements. Therefore, all ACTIONS are provided for all foreseen Conditions.
LCO 3.0.4 MODE Changes
When an LCO is not met, entry into a MODE or other specified condition in the Applicability shall not be made except when the associated ACTIONS to be entered permit continued operation in the MODE or other specified condition in the Applicability for an unlimited period of time. This LCO shall not prevent changes in MODES or other specified conditions in the Applicability that are required to comply with ACTIONS.

Exceptions to this LCO are stated in the individual LCOS. These exceptions allow entry into MODES or other specified conditions in the Applicability when the associated ACTIONS to be entered allow unit operation in the MODE or other specified condition in the Applicability only for a limited period of time. 
LCO 3.0.5

Return to

Service
Equipment removed from service or declared inoperable to comply with ACTIONS may be returned to service under administrative control solely to perform testing required to demonstrate its OPERABILITY or the OPERABILITY of other equipment. This is an exception to LCO 3.0.2, "ACTION Met," for the system returned to service under administrative control to perform the testing required to demonstrate OPERABILITY.
LCO 3.0.6 Support System LCO Not Met
When a supported system LCO is not met solely due to a support system LCO not being met, the Conditions and Required Actions associated with this supported system are not required to be entered. Only the support system LCO ACTIONS are required to be entered. This is an exception to LCO 3.0.2, "ACTION Met," for the supported system.

When a support system's Required Action directs a supported system to be declared inoperable or directs entry into Conditions and Required Actions for a supported system, the applicable Conditions and Required Actions shall be entered in accordance with LCO 3.0.2, "ACTION Met."
LCO 3.0.7

Emergency

Exceptions
Emergency actions that depart from the approved Technical Safety Requirements may be taken when no actions consistent with the Technical Safety Requirements are immediately apparent and when these actions are needed to protect the public health and safety. Such actions shall be approved, as a minimum, by a certified nuclear operator or Manager/Supervisor certified on that system through an approved training program.

If emergency actions are taken, verbal notifications shall be made to the Head of the Field Element (DOE-RL) within 2 hours and by written reports to the Cognizant Secretarial Officer, or designee, within 24 hours, in accordance with Section 5.5, "Occurrence Reporting." 
Purpose

These General Rules of Applicability provide basic rules to govern the specific SRs to ensure uniform application and implementation of the requirements. That is, these basic rules ensure activities are conducted in a consistent manner and responses to conditions and situations are taken in a uniform and predictable way.

SR 3.0.1

SR Met

SRs shall be met during the MODES or other specified conditions in the Applicability for individual LCOS, unless otherwise stated in the SR. Failure to meet a Surveillance, whether such failure is experienced during the performance of the Surveillance or between performances of the Surveillance, shall. be failure to meet the LCO. Failure to perform a Surveillance within the specified Frequency shall be failure to meet the LCO except as provided in SR 3.0.3, "Delay of Required Actions." If in an ACTIONS statement, performance of SRs required to demonstrate compliance with an LCO is not required.

SR 3.0.2 Frequencies
The specified Frequency for each $S R$ is met if the Surveillance is performed within 1.25 times the interval specified in the Frequency as measured from the previous performance or as measured from the time a specified condition of the Frequency is met. When the $25 \%$ extension is used, the following interval is measured from the previous Surveillance's due date (excluding the $25 \%$ extension) rather than from the performance date.

For Frequencies specified as "once," the above interval extension does not apply.

Exceptions to this SR are stated in the individual LCOs. 
SR 3.0.3 Delay of Required Actions
If it is discovered that a Surveillance was not performed within its specified Frequency, then compliance with the requirement to declare the LCO not met may be delayed from the time of discovery up to 24 hours or up to the limit of the specified Frequency, whichever is less. This delay period is permitted to allow performance of the Surveillance.

If the Surveillance is not performed within the delay period, the LCO must immediately be declared not met and the applicable Condition(s) must be entered. The Completion Times of the Required Actions begin immediately upon expiration of the delay period.

When the Surveillance is performed within the delay period and the Surveillance is not met, the LCO must immediately be declared not met and the applicable Condition(s) must be entered. The Completion Times of the Required Actions begin immediately upon failure to meet the Surveillance.
SR 3.0.4 MODE Changes
Entry into a MODE or other specified condition in the Applicability of an LCO shall not be made unless the LCO's Surveillances have been met within their specified Frequency. This provision shatl not prevent passage through or to MODES or other specified conditions in compliance with Required Actions. 


\subsection{INSTRUMENTATION}

\subsubsection{Safety-Class Instrumentation and Control System}

LCO 3.1.1 Train A and train B of the safety-class instrumentation and control (SCIC) system shall be OPERABLE with trip, interlock, and alarm functions as listed in Table 3.1.1-1.

MODE

APPLICABILITY: According to Table 3.1.1-1.

PROCESS AREA

APPLICABILITY: According to Table 3.1.1-1.

ACTIONS

\begin{tabular}{|c|c|c|c|c|}
\hline & CONDITION & & REQUIRED ACTION & COMPLETION \\
\hline A. & $\begin{array}{l}\text { Either train A or } \\
\text { train B of the SCIC } \\
\text { system inoperable. }\end{array}$ & $\begin{array}{l}\text { A.1 } \\
\frac{\text { AND }}{A .2} \\
\frac{\text { AND }}{A .3}\end{array}$ & $\begin{array}{l}\text { Actuate both train A and } \\
\text { train B of the ISO \& } \\
\text { Purge trip. } \\
\text { De-energize TW (annulus) } \\
\text { system heater. } \\
\text { Restore inoperable SCIC } \\
\text { system train to OPERABLE } \\
\text { status. }\end{array}$ & $\begin{array}{l}1 \text { hour } \\
1 \text { hour } \\
\text { Prior to } \\
\text { resuming MCO } \\
\text { process } \\
\text { operations }\end{array}$ \\
\hline
\end{tabular}




\begin{tabular}{|c|c|c|c|c|}
\hline & CONDITION & & REQUIRED ACTION & $\begin{array}{c}\text { COMPLETION } \\
\text { TIME }\end{array}$ \\
\hline B. & $\begin{array}{l}\text { Both train } A \text { and } \\
\text { train } B \text { of the SCIC } \\
\text { system inoperable. }\end{array}$ & $\begin{array}{l}\text { B.1 } \\
\frac{\text { AND }}{\text { B.2 }} \\
\frac{\text { AND }}{\text { B. } 3}\end{array}$ & $\begin{array}{l}\text { Actuate both train A and } \\
\text { train B of the ISO \& } \\
\text { Purge trip. } \\
\text { De-energize TW (annulus) } \\
\text { system heater. } \\
\text { Restore both train A and } \\
\text { train B of the SCIC } \\
\text { system to OPERABLE } \\
\text { status. }\end{array}$ & $\begin{array}{l}\text { Immediately } \\
\text { not to exceed } \\
1 \text { hour } \\
\text { Immediately } \\
\text { not to exceed } \\
1 \text { hour } \\
\text { Prior to } \\
\text { resuming MCO } \\
\text { process } \\
\text { operations }\end{array}$ \\
\hline
\end{tabular}

\begin{tabular}{lll|l}
\hline \hline & \multicolumn{1}{c|}{ SURVEILLANCE } & FREQUENCY \\
\hline SR 3.1 .1 .1 & $\begin{array}{l}\text { Perform a channel FUNCTIONAL TEST for } \\
\text { functions 1isted in Table 3.1.1-2. }\end{array}$ & Quarterly \\
\hline SR 3.1 .1 .2 & $\begin{array}{l}\text { Perform a loop CALIBRATION of the SCIC } \\
\text { programmable logic controller for functions } \\
\text { 1isted in Table 3.1.1-1. }\end{array}$ & Annual1y \\
\hline \hline
\end{tabular}




\begin{tabular}{ll|l}
\hline \hline & \multicolumn{1}{c|}{ TITLE } & NUMBER \\
\hline 1. & Vacuum Purge System Pressure Instrumentation. & LCO 3.1 .2 \\
2. & General-Service Helium System Flow instrumentation. & LCO 3.1 .3 \\
3. $\quad$ Tempered Water (Annulus) System Temperature & LCO 3.1 .4 \\
4. & Temstrumentation. & LCO 3.1 .5 \\
5. & Process Bay Temperature Instrumentation. & LCO 3.1 .6 \\
6. & Seismic Trip Instrumentation. & LCO 3.1 .7 \\
7. Isolation Valve Interlocks. & LCO 3.1 .8 \\
\hline \hline
\end{tabular}


HNF-3673 REV 0 Safety-Class Instrumentation and Control System

LCO 3.1.1

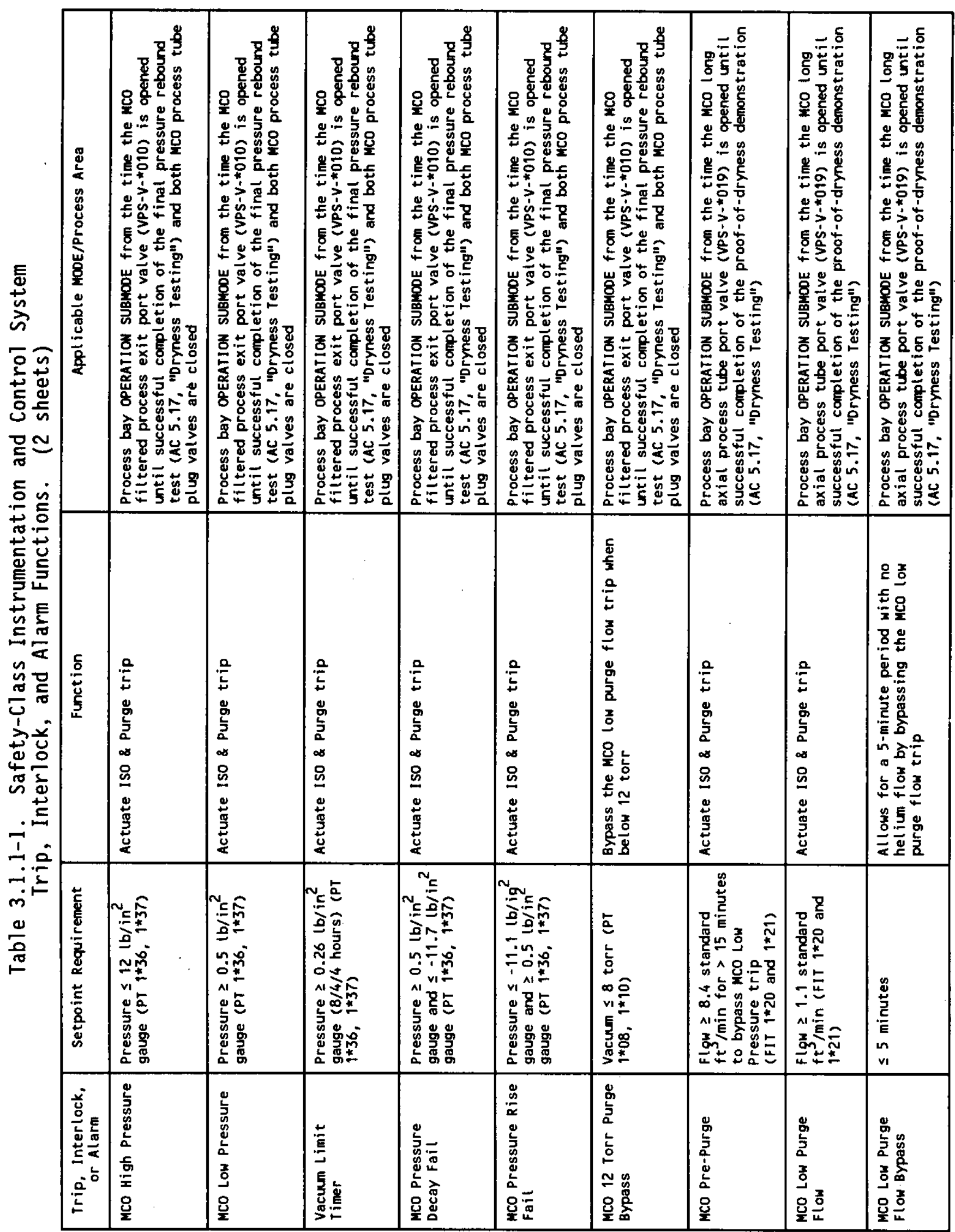


HNF-3673 REV 0 Safety-Class Instrumentation and Control System

LCO 3.1.1

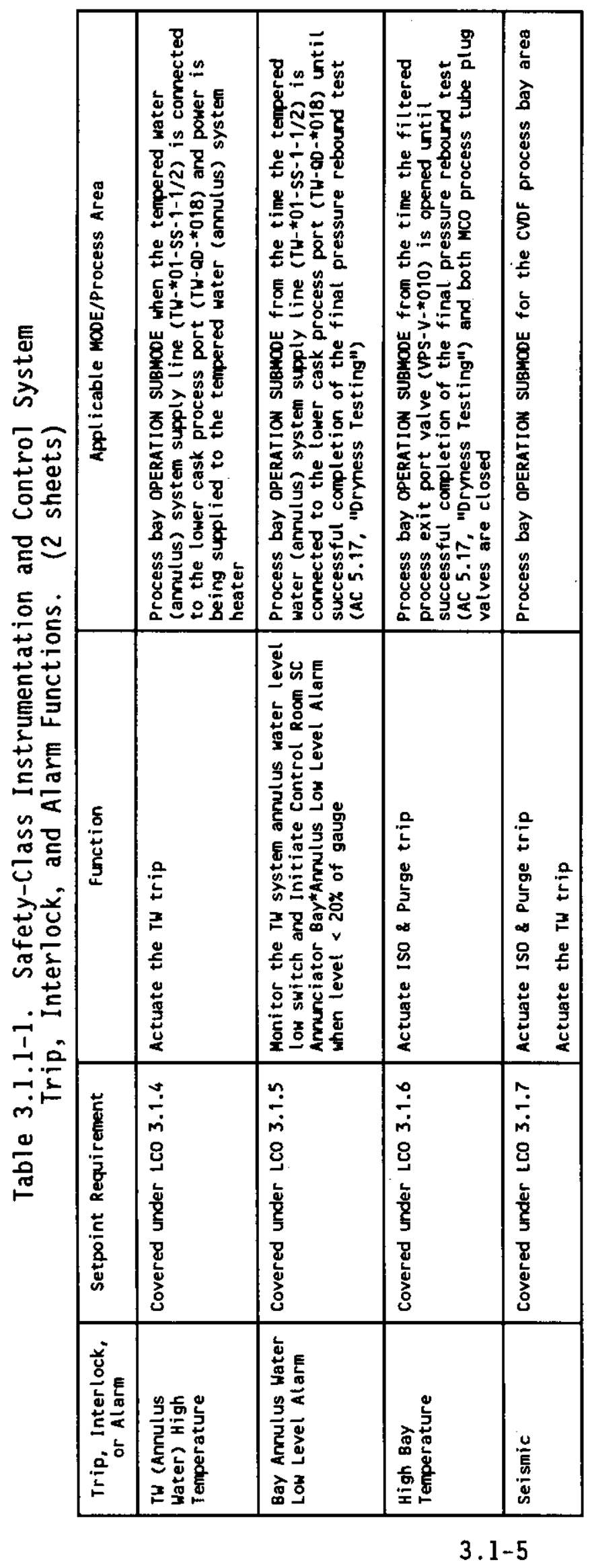




\section{HNF-3673 REV 0 Safety-Class Instrumentation and Control System}

Table 3.1.1-2. Safety-Class Instrumentation and Control System FUNCTIONAL TEST Requirements.

\begin{tabular}{|l|l|l|}
\hline \multicolumn{1}{|c|}{$\begin{array}{c}\text { FUNCTIONAL TEST } \\
\text { Initiator }\end{array}$} & \multicolumn{1}{|c|}{ Test Switches } & \multicolumn{1}{c|}{ Function } \\
\hline $\begin{array}{l}\text { TW High Temperature } \\
\text { Test Switch }\end{array}$ & $\begin{array}{l}\text { Train A and train B } \\
\text { (2 switches per bay; } \\
8 \text { per CVDF) }\end{array}$ & Actuates the TW trip \\
\hline $\begin{array}{l}\text { Bay Temperature Test } \\
\text { Switch }\end{array}$ & $\begin{array}{l}\text { Train A and train B } \\
\text { (2 switches per bay; } \\
8 \text { per CVDF) }\end{array}$ & $\begin{array}{l}\text { Actuates ISO \& Purge } \\
\text { trip }\end{array}$ \\
\hline $\begin{array}{l}\text { Annulus Low Level Test } \\
\text { Switch }\end{array}$ & $\begin{array}{l}\text { Train A and train B } \\
(2 \text { switches per bay; } \\
8 \text { per CVDF) }\end{array}$ & $\begin{array}{l}\text { Initiate Control Room SC } \\
\text { Annunciator Bay*Annulus } \\
\text { Low Level Alarm }\end{array}$ \\
\hline Seismic Test Switch & $\begin{array}{l}\text { Train A and train B } \\
\text { (3 switches per Bay 1 } \\
\text { panel; 6 per CVDF) }\end{array}$ & $\begin{array}{l}\text { Actuates ISO \& Purge } \\
\text { trip }\end{array}$ \\
\hline $\begin{array}{l}\text { Control Room Manual ISO } \\
\text { \&urge trip }\end{array}$ & $\begin{array}{l}\text { Bay * ISO \& Purge } \\
\text { Initiate } \\
(4 \text { switches per } \\
\text { Control Room panel; } \\
8 \text { per CVDF) }\end{array}$ & $\begin{array}{l}\text { Actuates ISO \& Purge } \\
\text { trip }\end{array}$ \\
\hline $\begin{array}{l}\text { Train A and train B } \\
(2 \text { switches per bay; } \\
8 \text { per CVDF) }\end{array}$ & $\begin{array}{l}\text { Actuates ISO \& Purge } \\
\text { trip }\end{array}$ \\
\hline Manual ISO \& Purge trip & & \\
\hline
\end{tabular}




\subsection{INSTRUMENTATION}

\subsubsection{Vacuum Purge System Pressure Instrumentation}

LCO 3.1.2 The vacuum purge system pressure instrumentation shall be OPERABLE, as follows:

- PT $1 * 36$ and PT $1 * 37$

- PT $1 * 08$ and PT $1 * 10$

MODE

APPLICABILITY: Process bay OPERATION SUBMODE.

PROCESS AREA

APPLICABILITY: From the time the MCO filtered process exit port valve (VPS-V-*010) is opened until successful completion of the final pressure rebound test (AC 5.17, "Dryness Testing") and both MCO process tube plug valves are closed.

Entry into the ACTIONS for PT $1 * 08$ and PT $1 * 10$ is not required unless draining and purge/flush activities have been completed.

\begin{tabular}{l|ll|l}
\hline CONDITION & REQUIRED ACTION & $\begin{array}{c}\text { COMPLETION } \\
\text { TIME }\end{array}$ \\
\hline \hline A. $\begin{array}{l}\text { Either PT } 1 * 36 \text { or } \\
\text { PT } 1 * 37 \text { inoperable. }\end{array}$ & A.1 $\begin{array}{l}\text { Actuate both train A and } \\
\text { train B of the ISO \& Purge } \\
\text { trip. }\end{array}$ & 1 hour \\
AND & A.2 & $\begin{array}{l}\text { Restore the instrumentation } \\
\text { to OPERABLE status. }\end{array}$ & $\begin{array}{l}\text { Prior to } \\
\text { resuming MC0 } \\
\text { process } \\
\text { operations }\end{array}$ \\
\hline
\end{tabular}




\begin{tabular}{|c|c|c|c|c|}
\hline & CONDITION & & REQUIRED ACTION & COMPLETION \\
\hline B. & $\begin{array}{l}\text { Both PT } 1 * 36 \text { and } \\
\text { PT } 1 * 37 \text { inoperable. }\end{array}$ & $\begin{array}{l}\text { B.1 } \\
\text { AND } \\
\text { B. } 2\end{array}$ & $\begin{array}{l}\text { Actuate both train A and } \\
\text { train B of the ISO \& Purge } \\
\text { trip. } \\
\text { Restore the instrumentation } \\
\text { to OPERABLE status. }\end{array}$ & $\begin{array}{l}1 \text { hour } \\
\text { Prior to } \\
\text { resuming MCO } \\
\text { process } \\
\text { operations }\end{array}$ \\
\hline C. & $\begin{array}{l}\text { Either PT } 1 * 08 \text { or } \\
\text { PT } 1 * 10 \text { inoperable. } \\
\text { OR } \\
\text { Both PT } 1 * 08 \text { and } \\
\text { PT } 1 * 10 \text { inoperable. }\end{array}$ & $\begin{array}{l}\text { C.1 } \\
\text { AND } \\
\text { C.2 }\end{array}$ & $\begin{array}{l}\text { Establish a positive } \\
\text { pressure in the MCO and } \\
\text { purge flow through the } M C O \text {. } \\
\text { Restore the instrumentation } \\
\text { to OPERABLE status. }\end{array}$ & $\begin{array}{l}\text { Prior to } \\
\text { placing the } \\
\text { MCO in } \\
\text { vacuum } \\
\text { operations }\end{array}$ \\
\hline
\end{tabular}

\begin{tabular}{|c|c|c|c|}
\hline & & SURVEILLANCE & FREQUENCY \\
\hline$S R$ & 3.1 .2 .1 & $\begin{array}{l}\text { Perform a CHANNEL CHECK of the following: } \\
\text { PT } 1 * 36 \text { and PT } 1 * 37 \\
\text { - PT } 1 * 08 \text { and PT } 1 * 10 \text {. }\end{array}$ & $\begin{array}{l}\text { Within } 1 \text { day } \\
\text { prior to } \\
\text { entering } \\
\text { process bay } \\
\text { OPERATION } \\
\text { SUBMODE }\end{array}$ \\
\hline SR & 3.1 .2 .2 & $\begin{array}{l}\text { Perform an instrument CALIBRATION of } \\
\text { PT } 1 * 36, \text { PT } 1 * 37, \text { PT } 1 * 08 \text { and PT } 1 * 10 \text {. }\end{array}$ & Annually \\
\hline
\end{tabular}




\begin{tabular}{l|l}
\hline \multicolumn{1}{c|}{ TITLE } & \multicolumn{1}{c}{ NUMBER } \\
\hline 1. Safety-Class Instrumentation and Control System & LCO 3.1.1 \\
2. Dryness Testing & AC 5.17 \\
\hline
\end{tabular}




\subsection{INSTRUMENTATION}

\subsubsection{General-Service Helium System Flow Instrumentation}

LCO 3.1.3 The general-service helium system flow instrumentation (FIT $1 * 20$ and FIT $1 * 21$ ) shal1 be OPERABLE.

MODE

APPLICABILITY: Process bay OPERATION SUBMODE.

PROCESS AREA

APPLICABILITY: From the time the MCO long axial process tube port valve (VPS-V-*019) is opened until successful completion of the proof-of-dryness demonstration (AC 5.17, "Dryness Testing").

ACTIONS

\begin{tabular}{|c|c|c|c|c|}
\hline & CONDITION & & REQUIRED ACTION & COMPLETION \\
\hline A. & $\begin{array}{l}\text { Either FIT } 1 * 20 \text { or } \\
\text { FIT } 1 * 21 \\
\text { inoperable. } \\
\underline{\text { OR }} \\
\text { Both FIT } 1 * 20 \text { and } \\
\text { FIT } 1 * 21 \\
\text { inoperable. }\end{array}$ & $\begin{array}{l}\text { A.1 } \\
\text { AND } \\
\text { A.2 } \\
\text { AND } \\
\text { A.3 }\end{array}$ & $\begin{array}{l}\text { Actuate both train A and } \\
\text { train B of the ISO \& Purge } \\
\text { trip. } \\
\text { De-energize TW (annulus) } \\
\text { system heater. } \\
\text { Restore the instrumentation } \\
\text { to OPERABLE status. }\end{array}$ & $\begin{array}{l}12 \text { hours } \\
\text { Prior to } \\
\text { resuming } \mathrm{MCO} \\
\text { process } \\
\text { operations }\end{array}$ \\
\hline
\end{tabular}




\begin{tabular}{|c|c|c|}
\hline & SURVEILLANCE & FREQUENCY \\
\hline SR & $\begin{array}{l}\text { 3.1.3.1. Perform a CHANNEL CHECK of FIT } 1 * 20 \text { and } \\
\text { FIT } 1 * 21 \text {. }\end{array}$ & $\begin{array}{l}\text { Within } 1 \text { day } \\
\text { prior to } \\
\text { entering } \\
\text { process bay } \\
\text { OPERATION } \\
\text { SUBMODE }\end{array}$ \\
\hline SR & $\begin{array}{l}\text { 3.1.3.2 Perform an instrument CALIBRATION of } \\
\text { FIT } 1 * 20 \text { and FIT } 1 * 21 .\end{array}$ & Annually \\
\hline \multicolumn{3}{|c|}{ CROSS REFERENCES } \\
\hline & TITLE & NUMBER \\
\hline $\begin{array}{l}1 . \\
2 .\end{array}$ & $\begin{array}{l}\text { Safety-Class Instrumentation and Control System } \\
\text { Dryness Testing }\end{array}$ & $\begin{array}{l}\text { LCO } 3.1 .1 \\
\text { AC } 5.17\end{array}$ \\
\hline
\end{tabular}




\subsection{INSTRUMENTATION}

\subsubsection{Iempered Water (Annulus) System Temperature Instrumentation}

LCO 3.1 .4

The tempered water (annulus) system temperature instrumentation (TSH $1 * 28$ and TSH $1 * 29$ ) shall be OPERABLE, with a setpoint $\leq 48.1{ }^{\circ} \mathrm{C}$.

MODE

APPLICABILITY: Process bay OPERATION SUBMODE.

PROCESS AREA

APPLICABILITY: When the tempered water (annu1us) system supply line (TW-*01-SS-1-1/2) is connected to the lower cask process port (TW-QD-*018) and power is being supplied to the tempered water (annulus) system heater.

\begin{tabular}{l|c|c}
\hline \hline CONDITION & REQUIRED ACTION & \multicolumn{1}{c}{$\begin{array}{c}\text { COMPLETION } \\
\text { TIME }\end{array}$} \\
\hline A. $\begin{array}{l}\text { Either TSH } 1 * 28 \text { or } \\
\text { TSH } 1 * 29 \\
\text { inoperable. } \\
\text { OR } \\
\begin{array}{l}\text { Both TSH } 1 * 28 \text { and } \\
\text { TSH } 1 * 29 \\
\text { inoperable. }\end{array}\end{array}$ & $\begin{array}{l}\text { De-energize TW (annulus) } \\
\text { system heater. }\end{array}$ \\
\hline \hline
\end{tabular}




\begin{tabular}{ll|l} 
SURVEILLANCE & FREQUENCY \\
\hline SR 3.1 .4 .1 & $\begin{array}{l}\text { Perform an instrument CALIBRATION of } \\
\text { TSH } 1 * 28 \text { and TSH } 1 * 29 .\end{array}$ & Quarterly \\
\hline \hline
\end{tabular}

\begin{tabular}{l|l}
\multicolumn{1}{c|}{ TITLE } & NUMBER \\
\hline \hline $\begin{array}{l}\text { 1. Safety-Class Instrumentation and Control System } \\
\text { 2. Dryness Testing }\end{array}$ & LCO 3.1.1 \\
\hline \hline
\end{tabular}




\subsection{INSTRUMENTATION}

\subsubsection{Tempered Water (Annulus) System Level Detector}

LCO 3.1 .5

The tempered water (annulus) system level detector instrumentation (LSL $1 * 24$ and $L S L 1 * 25$ ) shall be OPERABLE, with a setpoint $\geq 20 \%$ of gauge.

AND

The tempered water (annulus) system water level shall be $\geq$ the level of the fuel.

MODE

APPLICABILITY: Process bay OPERATION SUBMODE.

PROCESS AREA

APPLICABILITY: From the time the tempered water (annulus) system supply line (TW-*01-SS-1-1/2) is connected to the lower cask process port ( $T W-Q D-* 018$ ) until successful completion of the final pressure rebound test (AC 5.17, "Dryness Testing").

NOTE-

Entry into the ACTIONS may be delayed for 1 hour immediately following connection of the tempered water (annulus) system supply line to the lower cask process port unless annulus leakage can be visually confirmed.

ACTIONS

\begin{tabular}{l|l|l|l}
\hline \hline CONDITION & REQUIRED ACTION & \multicolumn{1}{c|}{$\begin{array}{c}\text { COMPLETION } \\
\text { TIME }\end{array}$} \\
\hline A. $\quad \begin{array}{l}\text { Either LSL } 1 * 24 \text { or } \\
\text { LSL } 1 * 25 \\
\text { inoperable. }\end{array}$ & A.1 & $\begin{array}{l}\text { Restore the inoperable } \\
\text { instrumentation to OPERABLE } \\
\text { status. }\end{array}$ & 5 days \\
\hline B. $\quad \begin{array}{l}\text { Both LSL 1*24 and } \\
\text { LSL } 1 * 25 \\
\text { inoperable. }\end{array}$ & B.1 $\begin{array}{l}\text { Monitor tempered water } \\
\text { (annulus) system leve1 } \\
\text { using an alternate method. }\end{array}$ & $\begin{array}{l}\text { Once per } \\
8 \text { hours }\end{array}$ \\
\hline AND & B.2 $\begin{array}{l}\text { Restore at least one } \\
\text { inoperable instrument to } \\
\text { OPERABLE status. }\end{array}$ & 24 hours \\
\hline
\end{tabular}




\begin{tabular}{|c|c|c|c|c|}
\hline & CONDITION & & REQUIRED ACTION & COMPLETION \\
\hline C. & $\begin{array}{l}\text { Tempered water } \\
\text { (annulus) system } \\
\text { water level is } \\
<\text { the level of the } \\
\text { fuel. } \\
\underline{\text { OR }} \\
\text { Required Actions } \\
\text { and associated } \\
\text { Completion Times } \\
\text { for Conditions A or } \\
B \text { not met. }\end{array}$ & $\begin{array}{l}\text { C. } 1 \\
\text { AND } \\
C .2\end{array}$ & $\begin{array}{l}\text { Manually restore/refill the } \\
\text { tempered water (annulus) } \\
\text { system level. } \\
\text { Develop a facility-approved } \\
\text { recovery plan and initiate } \\
\text { actions to restore } \\
\text { compliance with this LCO. }\end{array}$ & $\begin{array}{l}\text { Immediately, } \\
\text { not to } \\
\text { exceed } \\
8 \text { hours } \\
24 \text { hours }\end{array}$ \\
\hline
\end{tabular}

SURVEILLANCE REQUIREMENTS

\begin{tabular}{ll|l}
\hline & \multicolumn{1}{c|}{ SURVEILLANCE } & FREQUENCY \\
\hline SR 3.1 .5 .1 & VERIFY annulus refill capabilities. & $\begin{array}{l}\text { Within 1 day } \\
\text { prior to } \\
\text { entering } \\
\text { process bay } \\
\text { OPERATION } \\
\text { SUBMODE }\end{array}$ \\
\hline SR 3.1 .5 .2 & $\begin{array}{l}\text { Perform an instrument CALIBRATION of } \\
\text { LSL } 1 * 24 \text { and LSL } 1 * 25 .\end{array}$ & Annually \\
\hline \hline
\end{tabular}

CROSS REFERENCES

\begin{tabular}{|c|c|c|}
\hline & TITLE & NUMBER \\
\hline $\begin{array}{l}1 . \\
2 .\end{array}$ & $\begin{array}{l}\text { Safety-Class Instrumentation and Control System } \\
\text { Dryness Testing }\end{array}$ & $\begin{array}{l}\text { LCO } 3.1 .1 \\
\text { AC } 5.17\end{array}$ \\
\hline
\end{tabular}




\subsection{INSTRUMENTATION}

\subsubsection{Process Bay Temperature Instrumentation}

LCO 3.1.6 The process bay temperature instrumentation (TSHH $1 * 38$ and TSHH 1*39) shall be OPERABLE, with a setpoint $\leq 89^{\circ} \mathrm{F}$.

\section{AND}

The process bay temperature shall be $\leq 95^{\circ} \mathrm{F}$.

MODE

APPLICABILITY: Process bay OPERATION SUBMODE.

PROCESS AREA

APPLICABILITY: From the time the filtered process exit port valve (VPS-V-*010) is opened until successful completion of the final pressure rebound test (AC 5.17, "Dryness Testing") and both MCO process tube plug valves are closed.

\section{ACTIONS}

\begin{tabular}{|c|c|c|c|c|}
\hline & CONDITION & & REQUIRED ACTION & COMPLETION \\
\hline A. & $\begin{array}{l}\text { Either TSHH } 1 * 38 \text { or } \\
\text { TSHH } 1 * 39 \\
\text { inoperable. }\end{array}$ & A. 1 & $\begin{array}{l}\text { Restore the inoperable } \\
\text { instrumentation to OPERABLE } \\
\text { status. }\end{array}$ & 5 days \\
\hline B. & $\begin{array}{l}\text { Both TSHH } 1 * 38 \text { and } \\
\text { TSHH } 1 * 39 \\
\text { inoperable. }\end{array}$ & $\begin{array}{l}\text { B. } 1 \\
\text { AND } \\
\text { B. } 2\end{array}$ & $\begin{array}{l}\text { Monitor process bay } \\
\text { temperature using an } \\
\text { alternate method. } \\
\text { Restore at least one } \\
\text { inoperable instrument to } \\
\text { OPERABLE status. }\end{array}$ & $\begin{array}{l}\text { Once per } \\
8 \text { hours } \\
24 \text { hours }\end{array}$ \\
\hline
\end{tabular}




\begin{tabular}{|c|c|c|c|c|}
\hline & CONDITION & & REQUIRED ACTION & COMPLETION \\
\hline C. & $\begin{array}{l}\text { Required Actions } \\
\text { and associated } \\
\text { Completion Times } \\
\text { for Conditions A or } \\
\text { B not met. }\end{array}$ & $\begin{array}{l}\text { C.1 } \\
\text { AND } \\
\text { C.2 }\end{array}$ & $\begin{array}{l}\text { Actuate both train A and } \\
\text { train B of the ISO \& Purge } \\
\text { trip. } \\
\text { Restore the instrumentation } \\
\text { to OPERABLE status. }\end{array}$ & $\begin{array}{l}1 \text { hour } \\
\text { Prior to } \\
\text { resuming MCO } \\
\text { process } \\
\text { operations }\end{array}$ \\
\hline D. & $\begin{array}{l}\text { Process bay } \\
\text { temperature is } \\
\text { outside acceptable } \\
\text { limits. }\end{array}$ & $\begin{array}{l}\text { D.1 } \\
\frac{\text { AND }}{D .2}\end{array}$ & $\begin{array}{l}\text { Actuate both train A and } \\
\text { train B of the ISO \& Purge } \\
\text { trip. } \\
\text { Restore process bay } \\
\text { temperatures within limits. }\end{array}$ & $\begin{array}{l}\text { Immediately, } \\
\text { not to } \\
\text { exceed } \\
1 \text { hour } \\
\text { Immediately, } \\
\text { not to } \\
\text { exceed } \\
12 \text { hours }\end{array}$ \\
\hline
\end{tabular}

\begin{tabular}{|c|c|c|c|}
\hline & & SURVEILLANCE & FREQUENCY \\
\hline SR & 3.1 .6 .1 & $\begin{array}{l}\text { Perform an instrument CALIBRATION of } \\
\text { TSHH } 1 * 38 \text { and TSHH } 1 * 39 \text {. }\end{array}$ & Annually \\
\hline
\end{tabular}
CROSS REFERENCES

\begin{tabular}{l|l}
\hline \multicolumn{1}{c|}{ TITLE } & NUMBER \\
\hline 1. Safety-Class Instrumentation and Control System & LCO 3.1.1 \\
2. Dryness Testing & AC 5.17 \\
\hline \hline
\end{tabular}




\subsection{INSTRUMENTATION}

\subsubsection{Seismic Trip Instrumentation}

LCO 3.1.7 Two or more of the seismic trip instrumentation (ATR-5235, ATR-5336, ATR-5437, including seismic auctioneering panels $C P-120$, and $(P-121)$ shall be OPERABLE with a setpoint $\leq 0.05 \mathrm{~g}$.

MODE

APPLICABILITY: Process bay OPERATION SUBMODE.

PROCESS AREA

APPLICABILITY: Cold Vacuum Drying Facility (CVDF) process bay area.

ACTIONS

\begin{tabular}{l|ll|l}
\hline \hline CONDITION & \multicolumn{1}{|c|}{$\begin{array}{c}\text { REQUIRED ACTION } \\
\text { A. } \begin{array}{l}\text { Two or more } \\
\text { sensors/recorders } \\
\text { inoperable. }\end{array}\end{array}$} & $\begin{array}{l}\text { A.1 } \\
\text { train B of the ISO \& Purge } \\
\text { trip. }\end{array}$ & 1 hour \\
\hline AND & $\begin{array}{l}\text { A.2 } \\
\text { De-energize TW (annulus) } \\
\text { system heater. }\end{array}$ & 1 hour \\
AND & $\begin{array}{l}\text { Restore the channel(s) to } \\
\text { OPERABLE status. }\end{array}$ & $\begin{array}{l}\text { Prior to } \\
\text { resuming MCO } \\
\text { process } \\
\text { operations }\end{array}$ \\
\hline \hline
\end{tabular}




\begin{tabular}{ll|l}
\hline \hline \multicolumn{1}{c|}{ SURVEILLANCE } & FREQUENCY \\
\hline SR $3.1 .7 .1 \quad \begin{array}{l}\text { Perform a CALIBRATION of each accelerometer } \\
\text { to VERIFY the required setpoint. }\end{array}$ & Annually \\
\hline \hline \multicolumn{2}{c|}{ TITLE } & NUMBER \\
\hline \hline \multicolumn{2}{c}{ CROSS REFERENCES } & LCO 3.1.1 \\
\hline Safety-Class Instrumentation and Control System & \\
\hline \hline
\end{tabular}




\subsection{INSTRUMENTATION}

\subsubsection{Isolation Valve Interlocks}

LCO 3.1 .8

The following isolation valve interlocks shall be OPERABLE:

- Interlock to maintain VPS-GOV $1 * 11$ and VPS-GOV $1 * 17$ closed

- Interlock to maintain PWC-GOV $1 * 03$ and PWC-GOV $1 * 30$ closed.

MODE

APPLICABILITY: Process bay OPERATION SUBMODE.

PROCESS AREA

APPLICABILITY: Interlock for PWC-GOV $1 * 03$ and PWC-GOV $1 * 30$ is required when the SCIC system is in the heatup position.

AND

Both interlocks are required from the time the initial pressure rebound test begins until successful completion of the final pressure rebound test (AC 5.17, "Dryness

Testing") and both MCO process tube plug valves are closed.

ACTIONS

\begin{tabular}{|c|c|c|}
\hline CONDITION & REQUIRED ACTION & COMPLETION \\
\hline $\begin{array}{l}\text { One or more VPS } \\
\text { isolation valve } \\
\text { interlock(s) } \\
\text { inoperable. } \\
\text { OR } \\
\text { One or more PWC } \\
\text { isolation valve } \\
\text { interlock(s) } \\
\text { inoperable. }\end{array}$ & $\begin{array}{l}\text { LCO 3.0.4, "MODE Changes," is not } \\
\text { app1icable. } \\
\text { A.1 VERIFY the valves } \\
\text { associated with the } \\
\text { inoperable interlock(s) are } \\
\text { maintained closed. } \\
\text { AND } \\
\text { A.2 Restore the interlock(s) to } \\
\text { OPERABLE status. }\end{array}$ & $\begin{array}{l}\text { Immediately, } \\
\text { not to } \\
\text { exceed } \\
1 \text { hour } \\
5 \text { days }\end{array}$ \\
\hline
\end{tabular}




\begin{tabular}{ll|l}
\hline \hline & SURVEILLANCE & FREQUENCY \\
\hline SR & $3.1 .8 .1 \quad$ Perform an interlock FUNCTIONAL TEST. & Quarterly \\
\hline
\end{tabular}

CROSS REFERENCES

\begin{tabular}{l|l}
\hline \hline \multicolumn{1}{|c|}{ TITLE } & NUMBER \\
\hline 1. Safety-Class Instrumentation and Control System & LCO 3.1 .1 \\
2. Safety-Class Helium & LCO 3.2 .1 \\
3. Dryness Testing & AC 5.17 \\
\hline \hline
\end{tabular}




\subsection{HELIUM SYSTEMS}

\subsubsection{Safety-Class Helium System}

LCO 3.2.1 The safety-class helium (SCHe) system shall be OPERABLE, as follows:

- Two independent SCHe system purge supply paths (trains $A$ and $B$ ), including related pressure control valves (SCHe-PCV-5*04,5*08,5*23, 5*27, $5 * 80,5 * 82$ )

- Two independent SCHe system gas vent paths (trains $C$ and $D$ ) to the process bay local exhaust heating, ventilation, and air conditioning and process vent system, including related pressure control valves (SCHe-PCV $-5 * 43,5 * 47,5 * 54,5 * 55,5 * 63,5 * 67$, $5 * 74,5 * 75,5 * 84$, and $5 * 86$ )

- Helium cylinder pressure $\geq 17001 \mathrm{~b} / \mathrm{in}^{2}$ gauge (before actuation)

- Helium cylinder pressure instrumentation $\left(P I-5^{*} 02\right.$, $P I-5 * 21, P I-5 * 41$, and $P I-5 * 61)$.

MODE

APPLICABILITY: Process bay OPERATION SUBMODE.

PROCESS AREA

APPLICABILITY: From the time the MCO long axial process tube port valve (VPS-V-*019) is opened until successful completion of the final pressure rebound test (AC 5.17, "Dryness Testing") and both MCO process tube plug valves are closed.

ACTIONS

\begin{tabular}{l|c|c}
\hline \hline CONDITION & REQUIRED ACTION & $\begin{array}{c}\text { COMPLETION } \\
\text { TIME }\end{array}$ \\
\hline A. $\begin{array}{l}\text { One SCHe system } \\
\text { purge supply path } \\
\text { inoperable. } \\
\text { OR } \\
\begin{array}{l}\text { One SCHe system gas } \\
\text { vent path } \\
\text { inoperable. }\end{array}\end{array}$ & A.1 $\begin{array}{l}\text { Restore SCHe path to } \\
\text { OPERABLE status. }\end{array}$ & 5 days \\
\hline
\end{tabular}




\begin{tabular}{|c|c|c|c|c|}
\hline & CONDITION & & REQUIRED ACTION & COMPLETION \\
\hline B. & $\begin{array}{l}\text { Two SCHe system } \\
\text { purge supply paths } \\
\text { inoperable. } \\
\underline{\text { OR }} \\
\text { Two SCHe system gas } \\
\text { vent paths } \\
\text { inoperable. }\end{array}$ & $\begin{array}{l}\text { B. } 1 \\
\text { AND } \\
\text { B.2 }\end{array}$ & $\begin{array}{l}\text { Establish a positive } \\
\text { pressure in the MCO and } \\
\text { purge flow (if draining has } \\
\text { been completed) through the } \\
\text { MCO. } \\
\text { Restore at least one SCHe } \\
\text { path to OPERABLE status. }\end{array}$ & 1 hour \\
\hline c. & $\begin{array}{l}\text { One or more } \\
\text { isolation valves } \\
\text { inoperable. }\end{array}$ & C. 1 & $\begin{array}{l}\text { Develop a facility-approved } \\
\text { recovery plan and initiate } \\
\text { actions to restore } \\
\text { compliance with this LCO. }\end{array}$ & 24 hours \\
\hline
\end{tabular}

\begin{tabular}{|c|c|c|c|}
\hline & & SURVEILLANCE & FREQUENCY \\
\hline SR & 3.2 .1 .1 & Perform a FUNCTIONAL TEST of the SCHe system. & $\begin{array}{l}\text { Within } 1 \text { day } \\
\text { prior to } \\
\text { entering } \\
\text { process bay } \\
\text { OPERATION } \\
\text { SUBMODE }\end{array}$ \\
\hline SR & 3.2 .1 .2 & $\begin{array}{l}\text { VERIFY helium cylinder pressures are } \\
\geq 17001 \mathrm{~b} / \mathrm{in}^{2} \text { gauge. }\end{array}$ & $\begin{array}{l}\text { Within } 1 \text { day } \\
\text { prior to } \\
\text { entering } \\
\text { process bay } \\
\text { OPERATION } \\
\text { SUBMODE }\end{array}$ \\
\hline
\end{tabular}




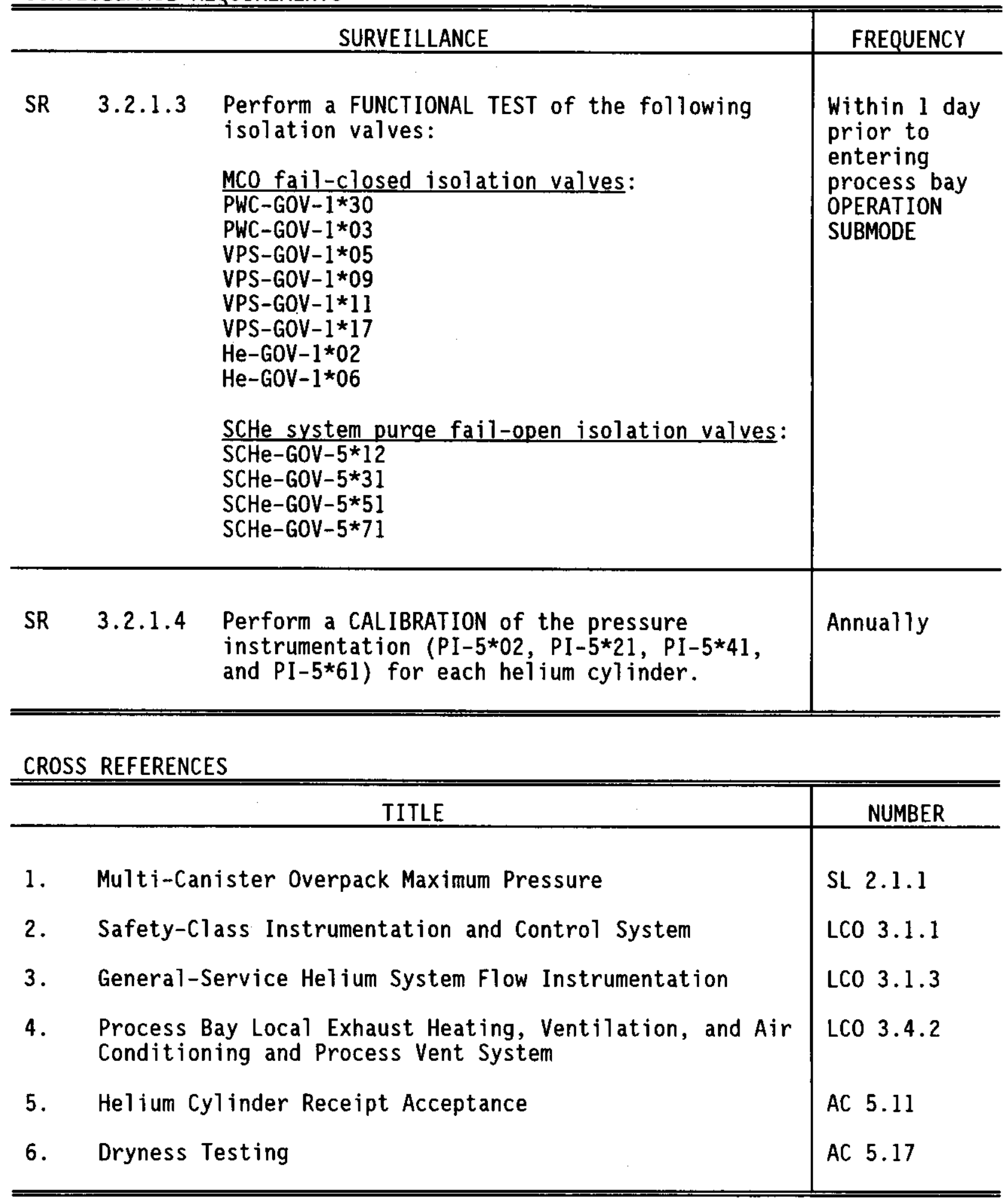




\subsection{MULTI-CANISTER OVERPACK PRESSURE PROTECTION}

\subsubsection{Multi-Canister Overpack Vacuum Purge System Connections}

\section{LCO 3.3.1}

The multi-canister overpack (MCO) vacuum purge system (VPS) connections shall be OPERABLE as follows:

- The MCO pathway to the $30 \mathrm{lb} / \mathrm{in}^{2}$ gauge vent path (VPS-PSE-1*33) shall be open.

- VPS process connections (VPS-V-*010 and VPS $-V-* 019)$ shall be leaktight prior to initiating MCO draining.

- The pressure relief valve (VPS-CKV-*112) shall crack open at a pressure $\leq 35 \mathrm{lb} / \mathrm{in}^{2}$ gauge and reseat at a pressure $\geq 201 \mathrm{~b} / \mathrm{in}^{2}$ gauge.

MODE

APPLICABILITY: Process bay OPERATION SUBMODE.

PROCESS AREA

APPLICABILITY: From the time the MCO filtered process exit port valve (VPS-V-*010) is opened until successful completion of the final pressure rebound test (AC 5.17, "Dryness Testing") and both MCO process tube plug valves are closed.

ACTIONS

\begin{tabular}{|c|c|c|c|c|}
\hline & CONDITION & & REQUIRED ACTION & COMPLETION \\
\hline A. & $\begin{array}{l}\text { VPS process } \\
\text { connections not } \\
\text { leak-tight prior to } \\
\text { initiating } \mathrm{MCO} \\
\text { draining. }\end{array}$ & A. 1 & $\begin{array}{l}\text { Restore VPS process } \\
\text { connections to be } \\
\text { leak-tight. }\end{array}$ & $\begin{array}{l}\text { Prior to } \\
\text { initiating } \\
\text { MCO draining }\end{array}$ \\
\hline B. & $\begin{array}{l}\text { Pressure relief } \\
\text { valve inoperable. }\end{array}$ & B. 1 & $\begin{array}{l}\text { Restore the valve to } \\
\text { OPERABLE status. }\end{array}$ & 7 days \\
\hline
\end{tabular}




\begin{tabular}{|c|c|c|c|}
\hline & & SURVEILLANCE & FREQUENCY \\
\hline SR & 3.3 .1 .1 & $\begin{array}{l}\text { VERIFY that the } 301 \mathrm{~b} / \mathrm{in}^{2} \text { gauge vent path } \\
\text { (VPS-PSE-1*33) to the local exhaust has been } \\
\text { connected to the filtered process exit port } \\
\text { connector and is operational. }\end{array}$ & $\begin{array}{l}\text { When MCO } \\
\text { process } \\
\text { connections } \\
\text { are made }\end{array}$ \\
\hline SR & 3.3 .1 .2 & $\begin{array}{l}\text { Perform leak testing of VPS process } \\
\text { connections to VERIFY the system is } \\
\text { leaktight. }\end{array}$ & $\begin{array}{l}\text { Prior to } \\
\text { initiating } \\
\text { MCO draining }\end{array}$ \\
\hline$S R$ & 3.3 .1 .3 & $\begin{array}{l}\text { Perform a FUNCTIONAL TEST of the pressure } \\
\text { relief valve (VPS-CKV-*112) to VERIFY that } \\
\text { the valve will crack open at a pressure } \\
\leq 351 \mathrm{~b} / \mathrm{in}^{2} \text { gauge and reseat at a pressure } \\
\geq 20 \mathrm{lb} / \mathrm{in}^{2} \text { gauge. }\end{array}$ & Annual1y \\
\hline
\end{tabular}

\begin{tabular}{l|c}
\hline \multicolumn{1}{c|}{ TITLE } & NUMBER \\
\hline 1. Multi-Canister Overpack Maximum Pressure & SL 2.1 .1 \\
2. Dryness Testing & AC 5.17 \\
\hline \hline
\end{tabular}




\subsection{MULTI-CANISTER OVERPACK PRESSURE PROTECTION}

\subsubsection{Pressure Safety Relief Valves}

LCS/LCO 3.3.2 The pressure safety relief valves (SRVs) listed below shall be OPERABLE:
a. He-SRV-5026 with a setpoint $<30 \mathrm{lb} / \mathrm{in}^{2}$ gauge AND
b. He-SRV-5031 with a setpoint $<30 \mathrm{lb} / \mathrm{in}^{2}$ gauge.

MODE

APPLICABILITY: Facility OPERATION MODE.

PROCESS AREA

APPLICABILITY: General-service helium system main supply header.

\section{ACTIONS}

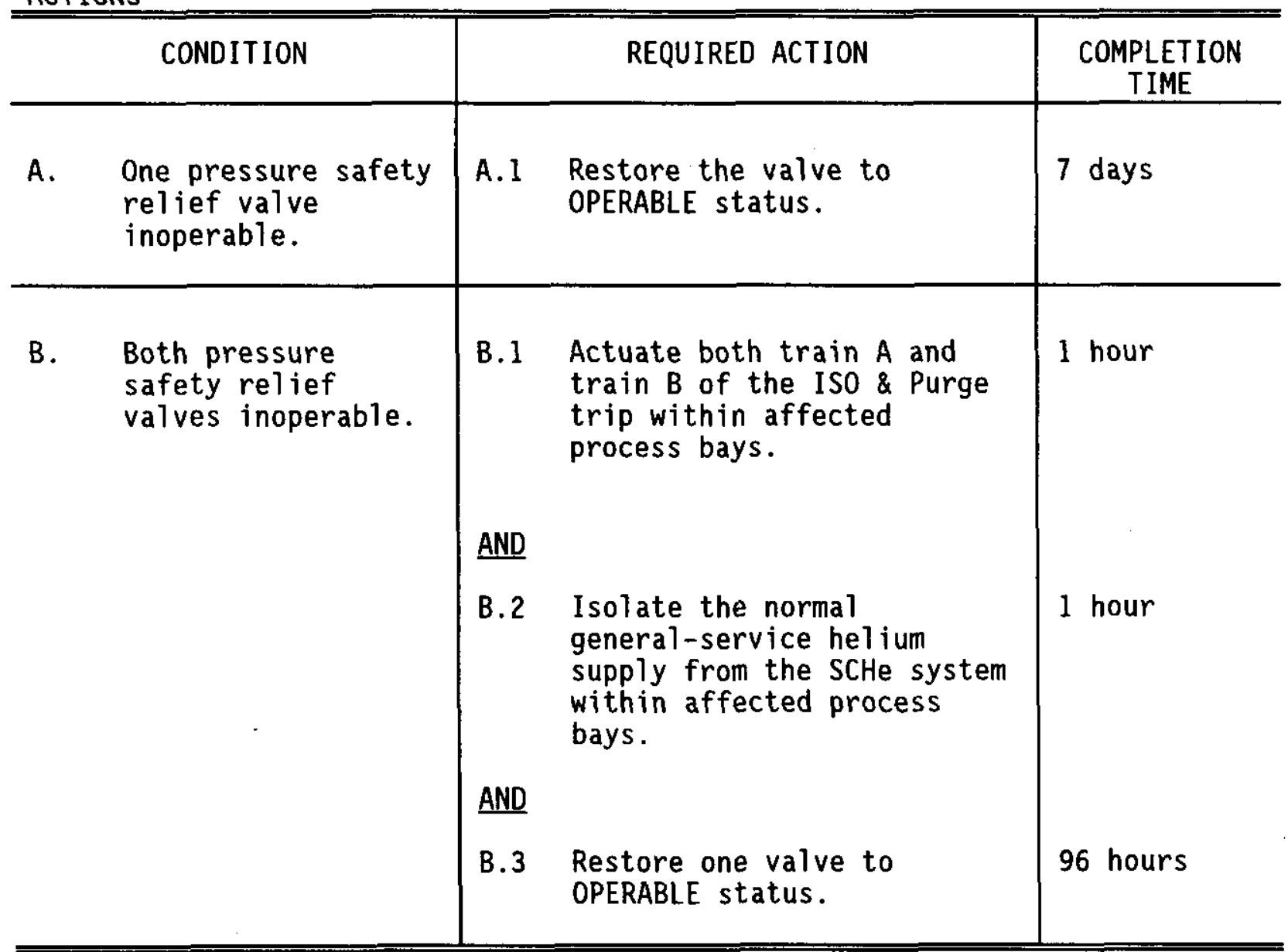




\begin{tabular}{|c|c|c|c|}
\hline & & SURVE ILLANCE & FREQUENCY \\
\hline SR & 3.3 .2 .1 & $\begin{array}{l}\text { Perform a FUNCTIONAL TEST to VERIFY that } \\
\text { pressure safety relief valves He-SRV-5026 and } \\
\text { He-SRV-503l lift at a setpoint }<301 \mathrm{~b} / \mathrm{in}^{2} \\
\text { gauge. }\end{array}$ & Annually \\
\hline
\end{tabular}

\section{CROSS REFERENCES}

\begin{tabular}{c|c}
\hline \hline TITLE & NUMBER \\
\hline 1. Multi-Canister Overpack Maximum Pressure & SL 2.1.1 \\
\hline
\end{tabular}


3.4 HEATING, VENTILATION, AND AIR CONDITIONING SYSTEMS

3.4.1 Process General Supply/Exhaust Heating, Ventilation, and Air Conditioning System

LCO 3.4 .1

The process general supply/exhaust heating, ventilation, and air conditioning (HVAC) system shall be OPERABLE as follows:

- A high-efficiency particulate air (HEPA) filter box with a filtration efficiency $\geq 99.9 \%$.

MODE

APPLICABILITY: Facility OPERATION and STANDBY MODES.

PROCESS AREA

APPLICABILITY: When the process general supply/exhaust HVAC system fans are operating.

ACTIONS

\begin{tabular}{c|c|c}
\hline \hline CONDITION & REQUIRED ACTION & $\begin{array}{c}\text { COMPLETION } \\
\text { TIME }\end{array}$ \\
\hline A. $\quad \begin{array}{l}\text { HEPA filter box } \\
\text { filtration } \\
\text { efficiency }<99.9 \% .\end{array}$ & A.1 $\begin{array}{l}\text { Stop process general } \\
\text { supply/exhaust HVAC system } \\
\text { operation. }\end{array}$ & 4 hours \\
\hline \hline
\end{tabular}

SURVEILLANCE REQUIREMENTS

\begin{tabular}{ll|l}
\hline \multicolumn{1}{c|}{ SURVEILLANCE } & FREQUENCY \\
\hline SR 3.4 .1 .1 & $\begin{array}{l}\text { VERIFY the process general supply/exhaust } \\
\text { HVAC system HEPA fijter box efficiency is } \\
\geq 99.9 \% .\end{array}$ & Annual1y \\
\hline \hline
\end{tabular}

CROSS REFERENCES

\begin{tabular}{l|c}
\multicolumn{1}{c|}{ TITLE } & NUMBER \\
\hline \hline & \\
1. Process Bay Local Exhaust HVAC and Process Vent System & LCO 3.4 .2 \\
2. Reference Air System & LCO 3.4 .3 \\
\hline \hline
\end{tabular}




\subsection{HEATING, VENTILATION, AND AIR CONDITIONING SYSTEMS}

\subsubsection{Process Bay Local Exhaust HVAC and Process Vent System}

LCO 3.4 .2

The process bay local exhaust heating, ventilation, and air conditioning (HVAC) and process vent system shall be OPERABLE as follows:

- Process bay local exhaust HVAC and process vent system flow rate instrumentation (FS-8*07) and remote alarms with a flow switch setpoint $\geq 1120$ standard $\mathrm{ft}^{3} / \mathrm{min}$

- Two exhaust fans (HVAC-EXHF-8045 and -8047) sha11 be OPERABLE, with a system flow rate in the process bay $\geq 1120$ standard $\mathrm{ft}^{3} / \mathrm{min}$

- The flow switch interlock (FS-8*52) to the cask venting flow valve shall be OPERABLE, with a flow switch setpoint $\geq 1120$ standard $\mathrm{ft}^{3} / \mathrm{min}$

- A high-efficiency particulate air (HEPA) filter box with a filtration efficiency of $\geq 99.9 \%$

- The instrument air system piping, tank, and check valve shall be leaktight with a tank pressure $\geq 90$ $1 \mathrm{~b} /$ in $^{2}$ gauge $(P I-5 * 20)$.

MODE

APPLICABILITY: Process bay OPERATION SUBMODE.

PROCESS AREA

APPLICABILITY: From the time the process bay doors are closed until successful completion of the final pressure rebound test (AC 5.17, "Dryness Testing") and both MCO process tube plug valves are closed. Flow switch interlock requirements only apply when cask venting is occurring. 
HNF-3673 REV o Process Bay Local Exhaust HVAC and Process Vent System

LCO 3.4.2

ACTIONS

\begin{tabular}{|c|c|c|c|c|}
\hline & CONDITION & & REQUIRED ACTION & COMPLETION \\
\hline A. & $\begin{array}{l}\text { FS }-8 * 07 \text { or } \\
\text { associated alarm } \\
\text { inoperable. }\end{array}$ & $\begin{array}{l}\text { A.1 } \\
\text { AND } \\
\text { A.2 }\end{array}$ & $\begin{array}{l}\text { VERIFY a process bay local } \\
\text { exhaust HVAC and process } \\
\text { vent system exhaust fan is } \\
\text { operating. } \\
\text { Restore instrumentation or } \\
\text { alarm to OPERABLE status. }\end{array}$ & $\begin{array}{l}\text { Once per } \\
12 \text { hours } \\
5 \text { days }\end{array}$ \\
\hline B. & $\begin{array}{l}\text { One process bay } \\
\text { local exhaust HVAC } \\
\text { and process vent } \\
\text { system fan } \\
\text { inoperable. }\end{array}$ & $\begin{array}{l}\text { B.1 } \\
\frac{\text { AND }}{\text { B. } 2} \\
\text { AND } \\
\text { B. } 3\end{array}$ & $\begin{array}{l}\text { VERIFY second process bay } \\
\text { local exhaust HVAC and } \\
\text { process vent fan is } \\
\text { OPERABLE and operating. } \\
\text { VERIFY process bay local } \\
\text { exhaust HVAC and process } \\
\text { vent system flow } \geq 1120 \\
\text { standard } \mathrm{ft}^{3} / \mathrm{min} \text {. } \\
\text { Restore inoperable fan to } \\
\text { OPERABLE status. }\end{array}$ & $\begin{array}{l}2 \text { hours } \\
2 \text { hours } \\
5 \text { days }\end{array}$ \\
\hline
\end{tabular}




\begin{tabular}{|c|c|c|c|c|}
\hline & CONDITION & & REQUIRED ACTION & COMPLETION \\
\hline C. & $\begin{array}{l}\text { Both process bay } \\
\text { local exhaust HVAC } \\
\text { and process vent } \\
\text { system fans } \\
\text { inoperable. } \\
\underline{\text { OR }} \\
\text { Process bay local } \\
\text { exhaust HVAC and } \\
\text { process vent system } \\
\text { flow } 1120 \\
\text { standard } \mathrm{ft}^{3} / \mathrm{min} .\end{array}$ & $\begin{array}{l}\text { C.1 } \\
\text { AND } \\
\text { C.2 } \\
\text { AND } \\
\text { C. } 3\end{array}$ & $\begin{array}{l}\text { Stop cask venting } \\
\text { operations. } \\
\text { When at least one exhaust } \\
\text { fan has been returned to } \\
\text { OPERABLE and operating } \\
\text { status, cask venting } \\
\text { operations may resume. } \\
\text { Restore at least one } \\
\text { exhaust fan to OPERABLE } \\
\text { status, VERIFYING process } \\
\text { bay local exhaust HVAC and } \\
\text { process vent system flow } \\
\geq 1120 \text { standard ft }{ }^{3} / \text { min. } \\
\end{array}$ & $\begin{array}{l}4 \text { hours } \\
5 \text { days }\end{array}$ \\
\hline D. & $\begin{array}{l}\text { HEPA filter box } \\
\text { filtration } \\
\text { efficiency }<99.9 \% \text {. }\end{array}$ & D. 1 & $\begin{array}{l}\text { Restore filtration } \\
\text { efficiency to } \geq 99.9 \% \text {. }\end{array}$ & 5 days \\
\hline E. & $\begin{array}{l}\text { Required Actions } \\
\text { and associated } \\
\text { Completion Times } \\
\text { for Condition C or } \\
\text { D not met. }\end{array}$ & E.1 & $\begin{array}{l}\text { Develop a facility- } \\
\text { approved recovery plan and } \\
\text { initiate actions to } \\
\text { restore compliance with } \\
\text { this LCO. }\end{array}$ & 24 hours \\
\hline F. & FS-8*52 inoperable. & F.1 & $\begin{array}{l}\text { VERIFY process bay local } \\
\text { exhaust HVAC and process } \\
\text { vent system flow in the } \\
\text { affected bay is } \geq 1120 \\
\text { standard } \mathrm{ft}^{3} / \mathrm{min} \text {. }\end{array}$ & $\begin{array}{l}\text { Once per hour } \\
\text { while } \\
\text { performing } \\
\text { venting } \\
\text { operations }\end{array}$ \\
\hline
\end{tabular}




\begin{tabular}{c|c|c}
\hline \hline CONDITION & REQUIRED ACTION & $\begin{array}{c}\text { COMPLETION } \\
\text { TIME }\end{array}$ \\
\hline G. $\quad \begin{array}{l}\text { Instrument air } \\
\text { system inoperable. }\end{array}$ & G.1 $\begin{array}{l}\text { Restore system to OPERABLE } \\
\text { status. }\end{array}$ & 5 days \\
\hline \hline
\end{tabular}

\begin{tabular}{|c|c|c|c|}
\hline & & SURVEILLANCE & FREQUENCY \\
\hline$S R$ & 3.4 .2 .1 & $\begin{array}{l}\text { VERIFY the flow rate in the process bay } \\
\text { local exhaust HVAC and process vent system } \\
\text { is } \geq 1120 \text { standard } \mathrm{ft}^{3} / \mathrm{min} \text {. }\end{array}$ & Daily \\
\hline SR & 3.4 .2 .2 & $\begin{array}{l}\text { VERIFY instrument air system tank pressure } \\
\text { is } \geq 901 \mathrm{~b} / \text { in }^{2} \text { gauge }(\mathrm{PI}-5 * 20) \text {. }\end{array}$ & Daily \\
\hline SR & 3.4 .2 .3 & $\begin{array}{l}\text { Perform a FUNCTIONAL TEST of the process bay } \\
\text { local exhaust HVAC and process vent system } \\
\text { (including damper availability and fan } \\
\text { restart timing). }\end{array}$ & Quarterly \\
\hline SR & 3.4 .2 .4 & $\begin{array}{l}\text { Perform CALIBRATION of the flow rate } \\
\text { instrumentation (FS-8*07 and FS-8*52). }\end{array}$ & Semi-annually \\
\hline SR & 3.4 .2 .5 & $\begin{array}{l}\text { Perform a CALIBRATION of the instrument air } \\
\text { system tank reservoir pressure gauges } \\
(P I-5 * 20) \text {. }\end{array}$ & Semi-annually \\
\hline SR & 3.4 .2 .6 & $\begin{array}{l}\text { VERIFY the process bay local exhaust HVAC } \\
\text { and process vent system HEPA filter } \\
\text { efficiency is } \geq 99.9 \% \text {. }\end{array}$ & Annually \\
\hline
\end{tabular}


HNF-3673 REV 0 Process Bay Local Exhaust HVAC and Process Vent System

LCO 3.4.2

CROSS REFERENCES

\begin{tabular}{l|c}
\hline \hline \multicolumn{1}{c|}{ TITLE } & NUMBER \\
\hline 1. Dryness Testing & AC 5.17 \\
\hline \hline
\end{tabular}




\subsection{HEATING, VENTILATION, AND AIR CONDITIONING SYSTEMS}

\subsubsection{Reference Air System}

LCO 3.4 .3

A. The reference air system shall be OPERABLE as follows:

- Process bay differential pressure indicator (PDI-8*20) and remote alarm for each bay with a setpoint $<-0.013$ in. water gauge

- Process water tank room differential pressure indicator (PDI-8080) and remote alarm with a setpoint $<-0.013$ in. water gauge.

B. Differential pressures shall be maintained as follows:

- Pressure in each process bay shall be $<0$ in. water gauge relative to the reference air system

- Pressure in the process water tank room shall be $<0$ in. water gauge relative to the reference air system.

MODE

APPLICABILITY: Facility OPERATION and STANDBY MODES.

\section{PROCESS AREA}

APPLICABILITY: Process bay minimum differential pressure requirements, indicator, and alarm apply when a multi-canister overpack is present in the bay and the process bay door is closed. Process water tank room minimum differential pressure requirements, indicator, and alarm apply if the circulation pump is running. 


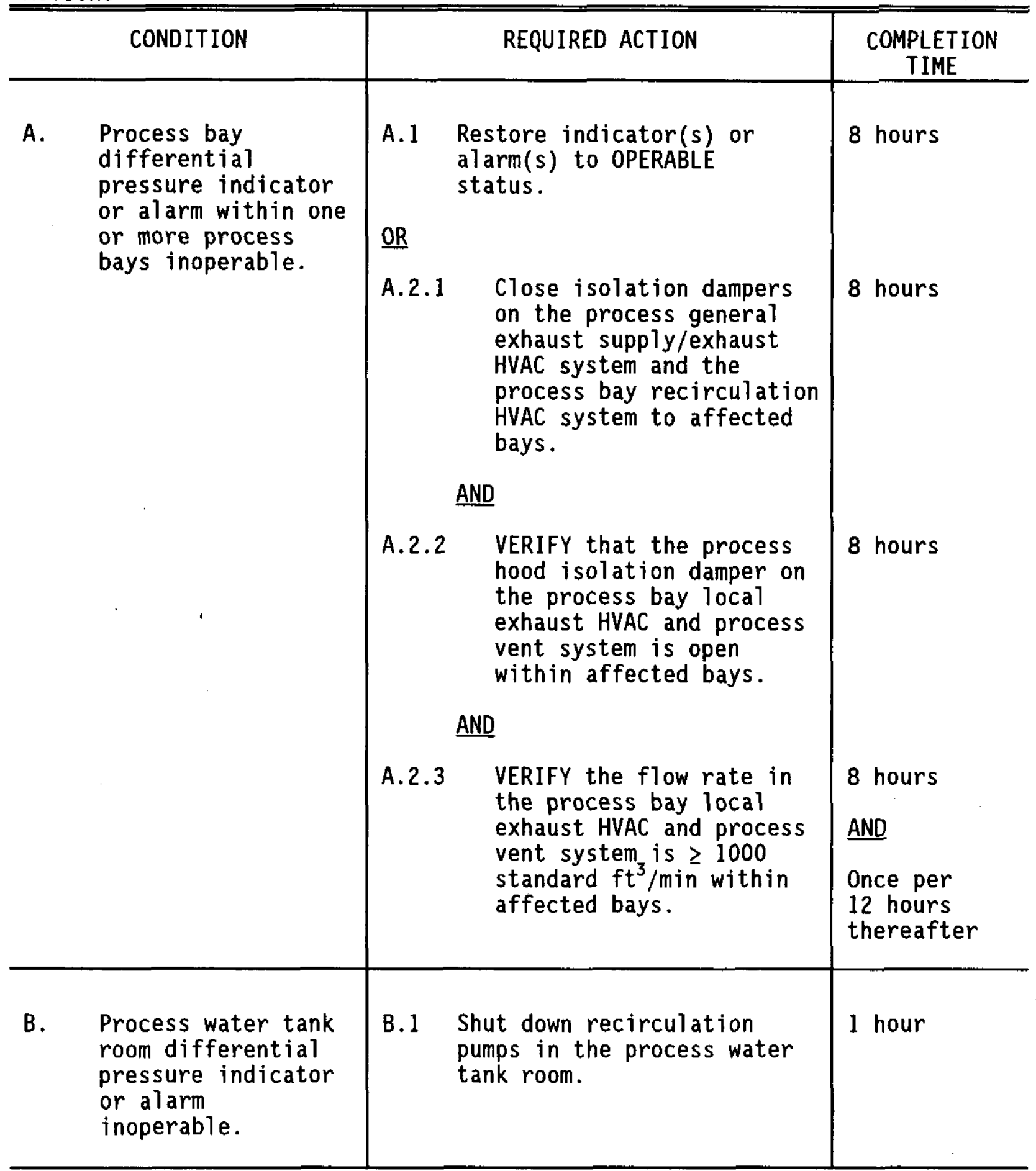




\begin{tabular}{|c|c|c|c|c|}
\hline & CONDITION & & REQUIRED ACTION & COMPLETION \\
\hline c. & $\begin{array}{l}\text { Pressure in one or } \\
\text { more process bays } \\
\geq 0 \text { in. water gauge } \\
\text { relative to the } \\
\text { reference air } \\
\text { system. }\end{array}$ & C.1 & $\begin{array}{l}\text { Restore differential } \\
\text { pressure(s) to within } \\
\text { limits in affected bays. }\end{array}$ & 8 hours \\
\hline D. & $\begin{array}{l}\text { Required Action and } \\
\text { associated } \\
\text { Completion Time for } \\
\text { Condition C not } \\
\text { met. }\end{array}$ & D. 1 & $\begin{array}{l}\text { Develop a facility-approved } \\
\text { recovery plan and initiate } \\
\text { actions to restore } \\
\text { compliance with this LCO. }\end{array}$ & 24 hours \\
\hline$E$. & $\begin{array}{l}\text { Pressure in the } \\
\text { process water tank } \\
\text { room } \geq 0 \text { in. water } \\
\text { gauge relative to } \\
\text { the reference air } \\
\text { system. }\end{array}$ & E.1 & $\begin{array}{l}\text { Shut down recirculation } \\
\text { pumps in the process water } \\
\text { tank room. }\end{array}$ & 1 hour \\
\hline
\end{tabular}




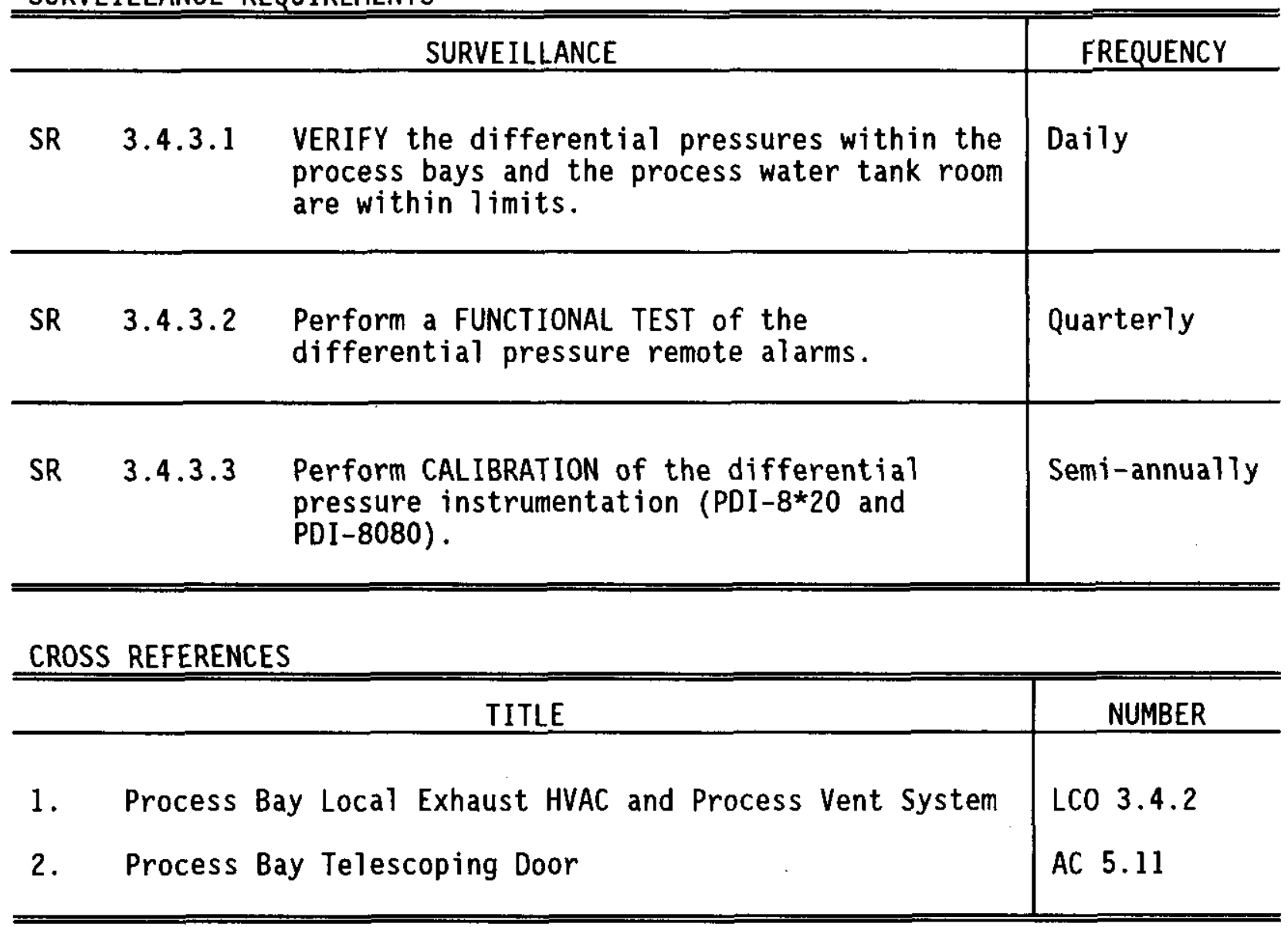




\subsection{HEATING, VENTILATION, AND AIR CONDITIONING SYSTEMS}

\subsubsection{High-Efficiency Particulate Air Filter Loading}

LCO 3.4.4 High-efficiency particulate air (HEPA) filter housing and prefilter housing contact radiation levels shall be $\leq 82$ $\mathrm{mR} / \mathrm{h}$.

MODE

APPLICABILITY: Facility OPERATION MODE.

PROCESS AREA

APPLICABILITY: HEPA filters and prefilters in the process bay local exhaust heating, ventilation, and air conditioning and process vent system.

ACTIONS

\begin{tabular}{c|c|c}
\hline \hline CONDITION & REQUIRED ACTION & $\begin{array}{c}\text { COMPLETION } \\
\text { TIME }\end{array}$ \\
\hline $\begin{array}{l}\text { A. HEPA filter housing } \\
\text { contact radiation } \\
\text { levels }>82 \mathrm{mR} / \mathrm{h} .\end{array}$ & A.1 & $\begin{array}{l}\text { Replace affected HEPA } \\
\text { filter(s). }\end{array}$ \\
\hline \hline
\end{tabular}

SURVEILLANCE REQUIREMENTS

\begin{tabular}{ll|l}
\hline \multicolumn{1}{c|}{ SURVEILLANCE } & FREQUENCY \\
\hline SR 3.4.4.1 & $\begin{array}{l}\text { VERIFY HEPA filter housing and prefilter } \\
\text { housing contact radiation levels are } \\
\leq 82 \mathrm{mR} / \mathrm{h} .\end{array}$ & Monthly \\
\hline \hline
\end{tabular}

\begin{tabular}{l|l}
\hline \hline TITLE & NUMBER \\
\hline & \\
None. & \\
\hline
\end{tabular}




\subsection{STANDBY POWER}

\subsubsection{Diesel Generator}

LCO 3.5.1 The diesel generator including the local exhaust restart circuit shall be OPERABLE.

MODE

APPLICABILITY: Facility OPERATION MODE.

PROCESS AREA

APPLICABILITY: Cold Vacuum Drying Facility (CVDF) process bay area and process support area.

ACTIONS

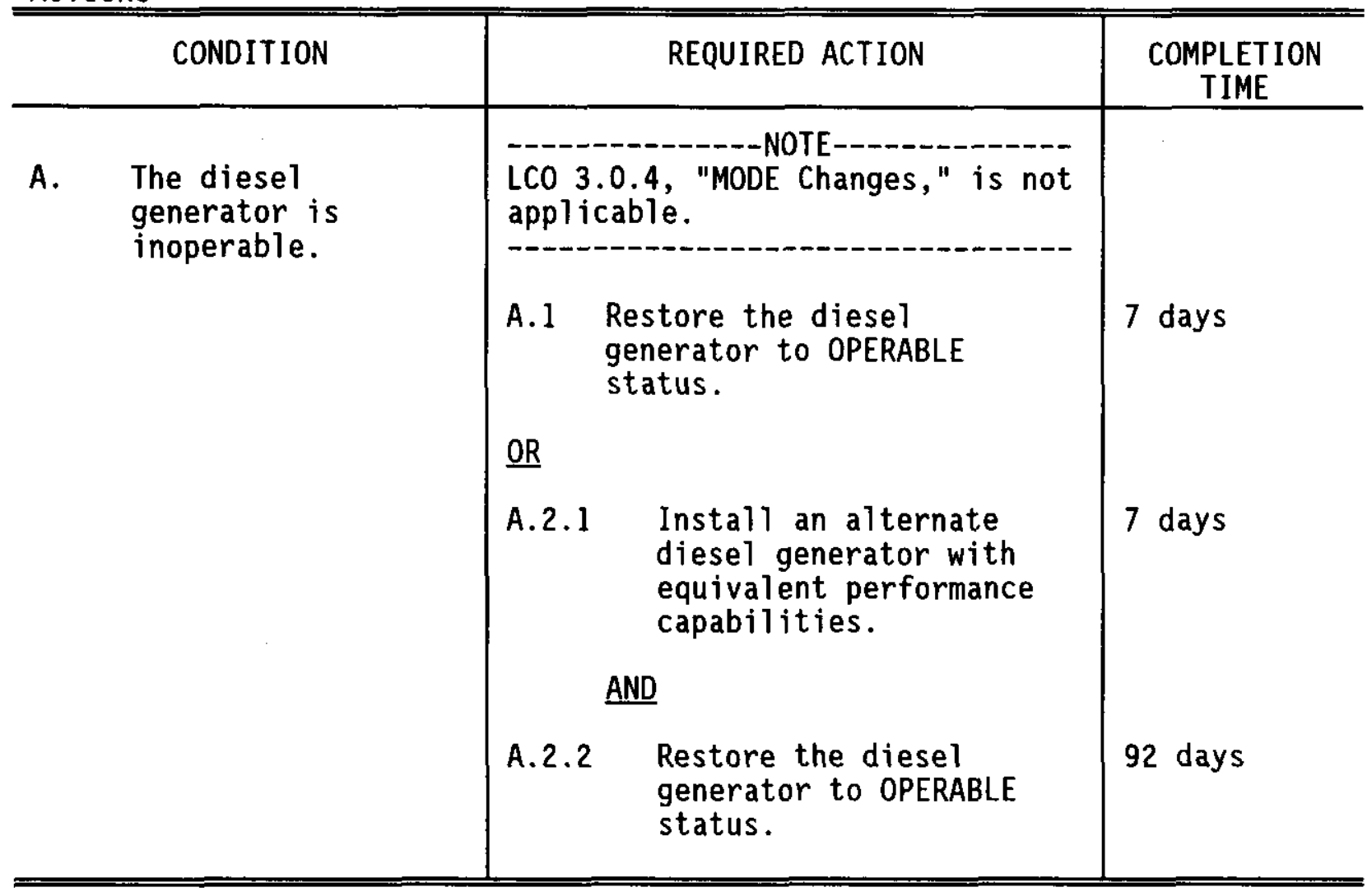




\begin{tabular}{|c|c|c|c|}
\hline & & SURVEILLANCE & FREQUENCY \\
\hline SR & 3.5 .1 .1 & $\begin{array}{l}\text { VERIFY that the fuel oil day tank on the } \\
\text { diesel generator contains } \geq 40 \text { gallons of } \\
\text { fuel (MCS-LI-0003). } \\
\text { AND } \\
\text { VERIFY that the fuel oil storage tank } \\
\text { contains } \geq 150 \text { gallons of fuel } \\
\text { (MCS-LI-0036). }\end{array}$ & $\begin{array}{l}\text { Monthly } \\
\text { AND } \\
\text { Within l day } \\
\text { after a } \\
\text { diesel } \\
\text { generator } \\
\text { shutdown }\end{array}$ \\
\hline SR & 3.5 .1 .2 & $\begin{array}{l}\text { VERIFY diesel generator starting air tank } \\
\text { pressure is greater than or equal to } 110 \\
1 \mathrm{~b} / \mathrm{in}^{2} \text { gauge (MCS-PI-0035 or DGCA-PI-0033). }\end{array}$ & $\begin{array}{l}\text { Quarterly } \\
\text { AND } \\
\text { Within } 1 \text { day } \\
\text { after a } \\
\text { diesel } \\
\text { generator } \\
\text { shutdown }\end{array}$ \\
\hline$S R$ & 3.5 .1 .3 & $\begin{array}{l}\text { VERIFY the diesel generator starts from } \\
\text { standby conditions and achieves steady-state } \\
\text { voltage and frequency within } 30 \text { seconds. }\end{array}$ & Quarterly \\
\hline SR & 3.5 .1 .4 & $\begin{array}{l}\text { Perform a load test on the diesel generator. } \\
\text { AND } \\
\text { Within } 5 \text { minutes of shutting down the diesel } \\
\text { generator following completion of the load } \\
\text { test, VERIFY the diesel generator starts and } \\
\text { achieves steady-state voltage and frequency. }\end{array}$ & Quarterly \\
\hline SR & 3.5 .1 .5 & $\begin{array}{l}\text { VERIFY fuel oil properties of new and stored } \\
\text { fuel oil are tested and maintained in } \\
\text { accordance with diesel manufacturer's } \\
\text { recommendations. }\end{array}$ & Quarterly \\
\hline
\end{tabular}




\begin{tabular}{|c|c|c|c|}
\hline \multicolumn{3}{|r|}{ SURVEILLANCE } & \multirow{2}{*}{$\begin{array}{l}\text { FREQUENCY } \\
\text { Annualiy }\end{array}$} \\
\hline SR & 3.5 .1 .6 & $\begin{array}{l}\text { VERIFY the diesel generator rejects a load } \\
\text { greater than or equal to the largest single } \\
\text { required load and does not result in an } \\
\text { overspeed trip. }\end{array}$ & \\
\hline SR & 3.5 .1 .7 & $\begin{array}{l}\text { Perform a loss of site power test on the } \\
\text { diesel generator including testing of the } \\
\text { local exhaust restart circuit. }\end{array}$ & Annually \\
\hline \multicolumn{4}{|c|}{ CROSS REFERENCES } \\
\hline & & TITLE & NUMBER \\
\hline 1 & $\begin{array}{l}\text { Process } \\
\text { Conditio }\end{array}$ & $\begin{array}{l}\text { In Local Exhaust Heating, Ventilation, and Air } \\
\text { ing and Process Vent System. }\end{array}$ & $\operatorname{LCO} 3.4 .2$ \\
\hline
\end{tabular}




\subsection{TRANSPORTATION-RELATED ACTIVITIES}

\subsubsection{Receipt Transportation Window}

LCO 3.6.1 The cask vent tool shall be connected to the transportation cask and venting completed in $\leq 24$ hours of completing the helium purge of the MCO headspace at the K Basins.

MODE

APPLICABILITY: Facility OPERATION MODE.

PROCESS AREA

APPLICABILITY: Cold Vacuum Drying Facility process bay area.

ACTIONS

\begin{tabular}{|c|c|c|c|c|}
\hline & CONDITION & & REQUIRED ACTION & COMPLETION \\
\hline A. & $\begin{array}{l}\text { Transportation cask } \\
\text { not vented in } \leq 24 \\
\text { hours of completing } \\
\text { the helium purge of } \\
\text { the MCO headspace } \\
\text { at the K Basins. }\end{array}$ & $\begin{array}{l}\text { A. } 1 \\
\text { AND } \\
\text { A.2 }\end{array}$ & $\begin{array}{l}\text { VERIFY transportation cask } \\
\text { pressure }<45 \mathrm{lb} / \mathrm{in}^{2} \text { gauge. } \\
\text { Connect cask vent tool to } \\
\text { the transportation cask and } \\
\text { complete venting. }\end{array}$ & $\begin{array}{l}1 \text { hour } \\
\text { AND } \\
\text { Once per } \\
2 \text { hours } \\
\text { thereafter } \\
24 \text { hours }\end{array}$ \\
\hline B. & $\begin{array}{l}\text { Required Actions } \\
\text { and associated } \\
\text { Completion Times } \\
\text { for Condition A not } \\
\text { met. }\end{array}$ & B.I & $\begin{array}{l}\text { Develop a facility-approved } \\
\text { recovery plan and initiate } \\
\text { actions to restore } \\
\text { compliance with this LCO. }\end{array}$ & 24 hours \\
\hline
\end{tabular}




\begin{tabular}{ll|l}
\multicolumn{1}{c|}{ SURVEILLANCE } & \multicolumn{1}{c}{ FREQUENCY } \\
\hline \hline SR 3.6.1.1 & $\begin{array}{l}\text { VERIFY the cask vent tool has been connected } \\
\text { to the cask and venting has been completed. }\end{array}$ & $\begin{array}{l}\text { Within } \\
24 \text { hours of } \\
\text { completing } \\
\text { the hel ium } \\
\text { purge of the } \\
\text { Mco } \\
\text { headspace at } \\
\text { the K Basins }\end{array}$ \\
\hline \hline
\end{tabular}

\begin{tabular}{c|c} 
TITLE & NUMBER \\
\hline 1. Process Bay Local Exhaust HVAC and Process Vent System & LCO 3.4 .2 \\
\hline
\end{tabular}


SECTION 4

SURVEILLANCE REQUIREMENTS 
Limiting Conditions for Operation (LCOS) and their associated Surveillance Requirements (SRs) are integral. Therefore, SRs are found in Section 3, "Operating Limits and Surveillance Requirements." SRs are numbered according to their respective LCOS (e.g., SR 3.1.1.1 is the first SR associated with LCO 3.1.1).

Safety Limits (SLs) do not contain SRs. SRs necessary to maintain operations within the SLs are contained within the LCOs that protect the associated SLs. 
SECTION 5

ADMINISTRATIVE CONTROLS 


\subsection{ADMINISTRATIVE CONTROLS (ACS)}

5.1 Purpose

5.1 .1

The purpose of the Administrative Controls (ACs) section is to state the provisions relating to organization and management, procedures, recordkeeping, reviews, audits, and specific program requirements for risk reduction necessary to ensure safe operation of the Cold Vacuum Drying Facility.

5.1 .2

Applicability

Unless otherwise noted, these ACS apply during all Cold Vacuum Drying Facility MODES (OPERATION, STANDBY, and SHUTDOWN) and process bay SUBMODES (OPERATION SUBMODE, STANDBY SUBMODE, and REPAIR SUBMODE). 


\subsection{ADMINISTRATIVE CONTROLS (ACs) 5.2 Contractor Responsibility}

5.2.1 Fluor Daniel Hanford, Incorporated is responsible to the U.S. Department of Energy (DOE) for the safe operation of the DOE-owned Cold Vacuum Drying Facility in accordance with the Technical Safety Requirements (TSRs) as approved by the Cognizant Secretarial officer (CSO), or designee, including any modification by the CSO. The contractor shall be responsible for maintaining the current DOE-approved TSRs as a controlled document.

5.2 .1 .1

Facility Operations Manager

The facility Operations Manager, or designee, shall be responsible for overall Cold Vacuum Drying Facility operation and shall delegate in writing the succession to this responsibility, as appropriate.

\subsubsection{Facility Manager}

The Facility Manager, or designee, shall be responsible for managing the shift operations and maintenance of the Cold Vacuum Drying Facility.

5.2 .1 .3

\section{Shift Manager}

The Shift Manager, or designee, shall be responsible for the local command function. During any absence of the Shift Manager from the facility, a designated, qualified individual shall assume the command function. 


\subsection{ADMINISTRATIVE CONTROLS (ACS)}

\subsection{Compliance}

5.3.1 The facility Operations Manager, or designee, is responsible for ensuring that the requirements of the Cold Vacuum Drying Facility TSRs are met. Compliance shall be demonstrated by:

a. Operating within the Safety Limits (SLS), Limiting Control Settings (LCSs), Limiting Conditions for Operation (LCOS), and the associated Surveillance Requirements (SRs) during their Applicability.

b. Operating within the ACTIONS of LCOs when required.

c. Performing all SRs when required.

d. Establishing, implementing, and maintaining the required $A C s$.

e. Maintaining required DESIGN FEATURES. 


\subsection{ADMINISTRATIVE CONTROLS (ACS)}

\subsection{Technical Safety Requirement VIOLATIONS}

\section{4 .1}

\section{VIOLATION Criteria}

VIOLATIONS of the TSRS occur as the result of any of four circumstances:

a. Exceeding an SL.

b. Failure to take the ACTIONS required within the required time limit following:

1. Exceeding an LCS.

2. Failure to meet an LCO.

3. Failure to successfully meet an SR.

c. Failure to perform an SR within the required time limit.

d. Failure to comply with an $A C$ requirement.

1. A VIOLATION relates only to failure to comply with an ACTIONS statement. Exceeding an LCO 1 imit by itself, or failure of an SR by itself (acceptance criteria not met), is not considered a VIOLATION.

2. Failure to perform an SR within the required time 1 imit includes the allowable $25 \%$ extension (see SR 3.0.2, "Frequencies"). The extension shall not be used routinely as an operational convenience to extend SR intervals or periodic Completion Time intervals beyond those specified.

3. $A C$ requirements are found in each $A C$ program requirement section. Minimum requirements for each $A C$ program are found in the program key elements section. Failure to comply with an $A C$ program or the intent of an AC program is considered a VIOLATION. A noncompliance within a specific procedure that implements an AC program is not necessarily a VIOLATION.

4. Planned maintenance activities, which render a system inoperable and which are performed within Completion Times specified in ACTIONS statements, do not constitute a VIOLATION. 
5.4 Technical Safety Requirement VIOLATIONS (cont inued)

5.4 .2

Response to a Safety Limit VIOLATION

If a VIOLATION of an SL occurs, proceed as follows:

a. Place the unit in the most safe and stable condition attainable Immediately.

b. Notify the DOE of the VIOLATION and prepare an occurrence report in accordance with Section 5.5, "Occurrence Reporting."

c. Perform and document a technical evaluation of the SL VIOLATION to determine if any damage may have occurred and evaluate the capacity of the unit to return to an operational MODE.

d. Prepare a recovery $\mathrm{plan}$ describing the steps leading to returning the unit to an operational MODE.

e. Obtain approval of the recovery $\mathrm{plan}$ from the PHMC President (or delegate) and the DOE-RL Manager (or delegate) prior to returning the unit to an operational MODE.

5.4.3 Response to a Limiting Condition for Operation and Limiting Control Setting VIOLATION.

If a VIOLATION of an LCO/LCS occurs, proceed as follows:

a. Place the unit in a safe and stable condition Immediately.

b. Notify the DOE of the VIOLATION and prepare an occurrence report in accordance with Section 5.5, "Occurrence Reporting."

c. Prepare a recovery $\mathrm{pl}$ an describing the steps leading to operation in a compliant condition.

d. Obtain approval of the recovery plan from the PHMC President (or delegate) and the DOE-RL Manager (or delegate) prior to returning the unit to an operational MODE. 
5.4 .4

5.4 .4 .1

5.4 .4 .2
Response to a Surveillance Requirement VIOLATION

If a VIOLATION of an SR occurs, proceed as follows:

Failure to Implement ACTIONS Upon Failure to Successfully Meet an SR

a. Notify the DOE of the VIOLATION and prepare an occurrence report in accordance with Section 5.5, "Occurrence Reporting."

Failure to Perform an SR Within the Required Time Limit

a. Enter SR 3.0.3, "Delay of Required Actions," and perform the SR within 24 hours or up to the 1 imit of the specified Frequency, whichever is less.

1. If the $S R$ is successfully met (i.e., SR acceptance criteria satisfied), exit SR 3.0.3, "Delay of Required Actions," and continue operation in a compliant condition.

2. If the $S R$ is not successfully met (i.e., SR acceptance criteria not satisfied), evaluate whether the LCO is met; that is, evaluate whether the LCO is within the MODE Applicability and Process Area Applicability. If the LCO is met, continue operation in a compliant condition. If the LCO is not met, enter the LCO ACTIONS. If the ACTIONS Completion Times are met, continue operation in a compliant condition. If the ACTIONS Completion Times are not met, proceed in accordance with Section 5.4.4.1.

b. Notify the DOE of the VIOLATION and prepare an occurrence report in accordance with Section 5.5, "Occurrence Reporting." 


\subsection{Technical Safety Requirement VIOLATIONS (continued)}

\subsubsection{Response to an AC VIOLATION}

If a VIOLATION of an AC occurs, proceed as follows:

a. Notify the DOE of the VIOLATION and prepare an occurrence report in accordance with Section 5.5, "Occurrence Reporting."

b. Prepare a recovery plan describing the steps leading to compliance with the $A C$.

c. Perform and document a technical evaluation, if appropriate, of the AC VIOLATION to determine if any damage may have occurred. 


\subsection{ADMINISTRATIVE CONTROLS (ACS) \\ 5.5 Occurrence Reporting}

5.5 .1

5.5 .2

\section{5 .3}

5.5 .4

\section{Requirement for Occurrence Reporting}

A program shall be established, implemented, and maintained for occurrence reporting of events and conditions, that may involve health and safety. Consistent reporting of occurrences ensures that both DOE and contractor line management are kept fully and currently informed of all events that could have the following results: (1) affect the health and safety of the public or (2) endanger the health and safety of workers.

\section{Program Key Elements}

The program key elements include the following:

a. Timely identification, categorization, notification, and reporting to DOE and contractor management of all reportable occurrences at DOE-owned or operated facilities.

b. Timely preparation, evaluation, and implementation of appropriate corrective actions.

c. Review of reportable occurrences to assess significance, root causes, generic implications, and the basis for actions taken to prevent recurrence.

TSR VIOLATIONS shall be reported in accordance with DOE occurrence reporting requirements.

Planned entry into an ACTIONS statement to perform Surveillance, maintenance, or investigation of operational problems is not reportable. 


\subsection{ADMINISTRATIVE CONTROLS (ACS) \\ 5.6 Organization}

5.6 .1

Lines of authority, responsibility, and communication shall be established and defined for the highest management levels through intermediate levels to and including all safety and operating organization positions. These relationships shall be documented and updated, as appropriate, in the form of organization charts, functional descriptions of departmental responsibilities and relationships, and job descriptions for key personnel positions, or in equivalent forms of documentation.

The individuals who train the operating staff and those who carry out safety and quality assurance functions may report to the facility Operations Manager. However, they shall have sufficient organizational freedom to ensure their independence from operating pressures.

5.6.1.1 Facility Operations Manager

The facility Operations Manager shall be responsible for safe operation within the facility. Safe operation shall include, as necessary, interface requirements with other onsite organizations and facilities.

5.6.1.2 Minimum Operations Shift Complement

The number of certified Shift Managers and nuclear operators available shall be adequate to operate and support the Cold Vacuum Drying Facility safely. Abnormal plant conditions shall be considered in determining operator assignments. Management shall provide additional personnel, as necessary, to support other activities.

The minimum complement of personnel can be 1 person less than the required number for a period of time not to exceed 4 hours in OPERATION, STANDBY, and SHUTDOWN facility MODES, and in OPERATION, STANDBY, and REPAIR process bay SUBMODES. The minimum complement accommodates unexpected absences, provided immediate action is taken to restore the shift complement to within the minimum requirements specified in Table 5.6-1. 


\subsection{Organization (continued)}

Table 5.6-1. Cold Vacuum Drying Facility Minimum Operations Shift Complement.

\begin{tabular}{|c|c|c|c|}
\hline & \multicolumn{3}{|c|}{ MINIMUM OPERATIONS SHIFT COMPLEMENT } \\
\hline & \multicolumn{3}{|c|}{ OPERATIONAL MODES } \\
\hline POSITION & OPERATION & STANDBY & SHUTDOWN \\
\hline $\begin{array}{l}\text { Shift Manager* } \\
\text { (or designee) }\end{array}$ & 1 & 1 & 0 \\
\hline $\begin{array}{l}\text { Nuclear } \\
\text { Operators" }\end{array}$ & 2 & 2 & 0 \\
\hline $\begin{array}{c}\text { Emergency } \\
\text { Operations Center }\end{array}$ & $\begin{array}{l}\text { Per Hanford } \\
\text { Emergency } \\
\text { Response Plan }\end{array}$ & $\begin{array}{l}\text { Per Hanford } \\
\text { Emergency } \\
\text { Response Plan }\end{array}$ & $\begin{array}{l}\text { Per Hanford } \\
\text { Emergency } \\
\text { Response Plan }\end{array}$ \\
\hline
\end{tabular}

* The Shift Manager (or designee) is required to be Building Emergency Director (BED)-qualified. Shift Managers and nuclear operators are certified in accordance with Chapter 12.0 of the project FSAR. 
5.0 ADMINISTRATIVE CONTROLS (ACS)

5.7 Nuclear Criticality Safety

5.7 .1

Requirement for Nuclear Critical ity Safety

A program shall be established, implemented, and maintained to prevent an accidental criticality at the cold Vacuum Drying Facility.

5.7 .2

Program Key Elements

a. Criticality limits and controls shall be documented in criticality safety evaluation reports (CSERs) and implemented in criticality prevention specifications (CPSs) and procedures.

b. Procedures shall be established for recovery from a CPS nonconformance.

c. Operations and technical personnel shalt receive criticality safety training.

5.7 .3

Applicability

This program applies during facility OPERATION and STANDBY MODES. 


\subsection{ADMINISTRATIVE CONTROLS (ACS) \\ 5.8 Measurement and Test Equipment}

5.8 .1

5.8 .2

\section{8 .3}

Requirement for Measurement and Test Equipment

A program shall be established, implemented, and maintained to identify and programmatically control measurement and test equipment used to VERIFY parameters to comply with the TSRs.

\section{Program Key Elements}

a. Identification and traceability of TSR-related measurement and test equipment shall be maintained.

b. Measurement and test equipment shall either have a FUNCTIONAL TEST or CALIBRATION as applicable at appropriate intervals to VERIFY required performance.

c. Records shall be maintained to provide evidence that the measurement and test equipment are within the FUNCTIONAL TEST or CALIBRATION requirements when used.

\section{Applicability}

This program applies to installed and portable measurement and test equipment when used to VERIFY parameters specified in the TSRs. 


\subsection{ADMINISTRATIVE CONTROLS (ACS) \\ 5.9 Configuration Management}

5.9 .1

Requirement for Configuration Management

A program shall be established, implemented, and maintained for configuration management of DESIGN FEATURES such that the safety function of the DESIGN FEATURES, as identified in applicable accident analyses, is maintained.

5.9 .2

\section{Program Key Elements}

a. Implement configuration management of those DESIGN FEATURES identified in applicable accident analyses in accordance with an approved configuration management plan.

b. Configuration management of the DESIGN FEATURES shall address change control, document control, configuration management implementation, and periodic asses sments.

5.9 .3

Applicability

This program applies during facility OPERATION, STANDBY, and SHUTDOWN MODES. 


\subsection{ADMINISTRATIVE CONTROLS (ACS) \\ 5.10 Transporter Placement}

5.10 .1

5.10 .2

5.10 .3

\section{Requirement for Transporter Placement}

A program shall be established, implemented, and maintained to ensure that the cask-MCO located on the transporter is properly positioned for Cold Vacuum Drying Facility process system connections.

\section{Program Key Elements}

a. Establish a method for indicating proper cask-MCO placement (e.g., painting an area on the process bay floor) in process bays 2 through 5 to ensure the cask-MCO located upon a transporter is positioned such that the cask is no greater than an established safe distance from the ideal horizontal placement in accordance with the seismic analysis.

b. VERIFY that each cask-MCO located on a transporter is properly positioned after entry into a process bay.

\section{Applicability}

This program applies during facility OPERATION MODE. 


\subsection{ADMINISTRATIVE CONTROLS (ACS)}

5.11 Helium Cylinder Receipt Acceptance

5.11 .1

5.11 .2

5.11 .3
Requirement for Helium Cylinder Receipt Acceptance

A program shall be established, implemented, and maintained for accepting helium cylinders at the Cold Vacuum Drying Facility.

\section{Program Key Elements}

VERIFY the following before accepting helium cylinders upon receipt at the Cold Vacuum Drying Facility:

- The helium cylinder contents were sampled by the supplier and supporting paperwork indicates the contents met the required helium purity specification of > 99\%. Multiple cylinders on a helium trailer may be sampled together, providing they were filled as a single unit.

Applicability

This program applies at all times to all helium cylinders (including both general service helium and safety-class helium shipments) received at the Cold Vacuum Drying Facility. 


\subsection{ADMINISTRATIVE CONTROLS (ACS)}

5.12 Process Bay Telescoping Door

5.12 .1

5.12 .2

5.12 .3

\section{Requirement for Process Bay Telescoping Door}

A program shall be established, implemented, and maintained to ensure the position of the process bay telescoping door is closed before connecting any Cold Vacuum Drying Facility process system to the multi-canister overpack (MCO).

\section{Program Key Elements}

VERIFY that the process bay telescoping door is closed prior to connecting any Cold Vacuum Drying Facility process system to the $\mathrm{MCO}$ in that process bay. The telescoping door may not be opened again until all process connections have been removed from the MCO, except when opening the telescoping door is required as part of a facility-approved recovery pian.

Applicability

This program applies during process bay OPERATION SUBMODE. 


\subsection{ADMINISTRATIVE CONTROLS (ACS)}

5.13 Combustible Loading Limits

5.13.1 Requirement for Combustible Loading Limits

A program shall be established, implemented, and maintained to limit the combustible loadings to the quantities and locations allowed in the fire hazard implementation plan (SNF-4942, Spent Nuclear Fuel Cold Vacuum Drying Facility Implementation Plan for Fire Hazard Analysis Suggested Actions), Table 3-1.

5.13 .2

Program Key Elements

a. The fire hazard implementation plan shall be reviewed periodically to ensure that the program complies with the combustible loading limits (quantity and location) within the analysis.

b. The facility's combustible loadings shall be evaluated periodically and compared against the fire hazard implementation plan limits. Any necessary adjustments shall be made to comply with the loading limitations.

5.13 .3

Applicability

This program applies during facility OPERATION and STANDBY MODES. 


\subsection{ADMINISTRATIVE CONTROLS (ACS)}

5.14 Bridge Crane Movement Restrictions

5.14 .1

Requirement for Bridge Crane Movement Restrictions

A program shall be established, implemented, and maintained to control bridge crane movement within the process bay to prevent crane movement from shearing key process lines during processing.

5.14 .2

\section{Program Key Elements}

a. Ensure bridge crane placement does not jeopardize tempered water 7 ines or process lines connected to the multi-canister overpack (MCO) within the process bay before the tempered water (annulus) system supply line (TW-*01-SS-1-1/2) is connected to the lower cask process port (TW-QD-*018).

b. Prohibit overhead bridge crane movement from the time the tempered water (annulus) system suppty line (TW-*01-SS-1-1/2) is connected to the lower cask process port (TW-QD-*018) until successful completion of the final pressure rebound test ( $A C$ 5.17, "Dryness Testing") and both MCO process tube plug valves are closed. Overhead bridge crane movement is not prohibited when such action is required as part of a facility-approved recovery plan.

5.14 .3

\section{Applicability}

This program applies during process bay OPERATION SUBMODE. 


\subsection{ADMINISTRATIVE CONTROLS (ACS)}

5.15 Multi-Canister Overpack Process Port Valve Isolation

5.15 .1

Requirement for Multi-Canister Overpack Process Port Valve Isolation

A program shall be established, implemented, and maintained to control the multi-canister overpack process port valve closure process to ensure that manual MCO isolation prior to process completion will initiate an SCIC trip.

5.15 .2

\section{Program Key Elements}

a. The $M C O$ long axial process tube port valve

(VPS-V-*019) must be closed before the MCO filtered process exit port valve (VPS-V-*010).

b. A minimum of 5 minutes must elapse between closure of the first process port valve (VPS-V-*019) and the closure of the second process port valve (VPS-V-*010).

5.15 .3

Applicability

This program applies during process bay OPERATION SUBMODE. 


\subsection{ADMINISTRATIVE CONTROLS (ACS)}

5.16 Preparation of Multi-Canister Overpack for Shipment

5.16 .1

Requirement for Preparation of Multi-Canister Overpack for Shipment

A program shall be established, implemented, and maintained to ensure the multi-canister overpack (MCO) mechanical seal and cover plate seals are leak-tested to confirm seal integrity in order to protect key safety analysis assumptions identified in HNF-3553, Spent Nuclear Fuel Project Final Safety Analysis Report, Annex A, "Canister Storage Building Final Safety Analysis Report."

5.16 .2

\section{Program Key Elements}

VERIFY the following before shipment of the MCO to the Canister Storage Building:

- The MCO leakage rate shall be $<10^{-5}$ standard $\mathrm{cm}^{3} / \mathrm{s}$. 5.16 .3 Applicability

This program applies during process bay OPERATION SUBMODE. 


\subsection{ADMINISTRATIVE CONTROLS (ACS)}

5.17 Dryness Testing

5.17 .1

5.17 .2

5.17 .3
Requirement for Dryness Testing

A program shall be established, implemented, and maintained to ensure that dryness testing is performed in accordance with the accident analysis assumptions in Chapter B3.0 of the CVDF Annex. Dryness testing provides the means of ensuring that the necessary dryness conditions have been met and protects an interface control for spent nuclear fuel transfers from the CVDF to the CSB.

\section{Program Key Elements}

VERIFY the following steps are successfully performed, in sequence, before initiating shipment preparation steps that involve MCO reconfiguration:

- Pressure rise test preparation - fuel and scrap temperatures in the MCO must be $>40{ }^{\circ} \mathrm{C}$, and the fuel/MCO must be held in stagnant or flowing helium for $\geq 4$ hours.

- An initial pressure rebound test - fuel and scrap temperatures in the $\mathrm{MCO}$ must be $\geq 40{ }^{\circ} \mathrm{C}$, and the $\mathrm{MCO}$ evacuated to $\leq 10$ torr. For a duration of $\geq 1$ hour, pressure rise within the MCO shall be $\leq 2.4$ torr per hour.

- A proof-of-dryness demonstration - fuel and scrap temperatures in the $M C O$ must be $\geq 40^{\circ} \mathrm{C}$, and the $M C O$ pressure must be maintained at $\leq 12$ torr for a total time of $\geq$ (1) 8 hours for an MCO with no scrap baskets, (2) 20 hours for an MCO with one scrap basket, (3) 28 hours for an MCO with two scrap baskets. (The total time at vacuum is not required to be a single continuous time period.)

- A final pressure rebound test - fuel and scrap temperatures in the $\mathrm{MCO}$ must be $\geq 40{ }^{\circ} \mathrm{C}$, and the $\mathrm{MCO}$ evacuated to $\leq 10$ torr. For a duration of $\geq 1$ hour, pressure rise within the MCO shall be $\leq 2.4$ torr per hour.

Applicability

This program applies during process bay OPERATION SUBMODE. 


\subsection{ADMINISTRATIVE CONTROLS (ACs)}

\subsection{Safety Programs}

5.18 .1

5.18 .2

5.18 .3

\section{Requirement for Safety Programs}

Programs shall be established, implemented, and maintained to ensure safety management.

\section{Program Key Elements}

The following programs shall exist:

- In-service surveillance and maintenance as described in Chapter 10.0 of the SNF Project FSAR

- Procedures and training as described in Chapter 12.0 of the SNF Project FSAR

- Quality assurance as described in Chapter 14.0 of the SNF Project FSAR.

Applicability

This program applies during all MODES. 
HNF-3673 REV 0

Section 6

References

\section{SECTION 6}

REFERENCES 


\section{Section 6 REFERENCES}

The following references are for the Preface, Section 1, Section 2, and Section 5 (there are no references cited in Sections 3 and 4 ). The references for Appendix $A$ and $B$ are contained within each appendix.

DOE 5480.22, 1992, Technical Safety Requirements, Change 1 (1992), and Change 2 (1996), U.S. Department of Energy, Washington, D.C.

DOE 5480.23, 1992, Nuclear Safety Analysis Reports, Change 1 (1994), U.S. Department of Energy, Washington, D.C.

DOE/RL-94-02, 1995, Hanford Emergency Response Plan, Rev. 1, U.S. Department of Energy, Washington, D.C.

HNF-3553, 1999, Spent Nuclear Fuel Project Final Safety Analysis Report, Rev. 0, Fluor Daniel Hanford, Incorporated, Richland, Washington.

HNF-3553, 1999, Spent Nuclear Fuel Project Final Safety Analysis Report, Rev. 0, Annex A, "Canister Storage Building Final Safety Analys is Report," Fluor Daniel Hanford, Incorporated, Richland, Washington.

HNF-3553, 1999, Spent Nuclear Fuel Project Final Safety Analysis Report, Rev. 0, Annex B, "Cold Vacuum Drying Facility Final Safety Analys is Report," Fluor Daniel Hanford, Incorporated, Richland, Washington.

HNF-SD-MP-TSR-001, 1997, TSR Writers' Guide, Rev. 1, Fluor Danie1 Northwest, Incorporated, Richland, Washington.

SNF-4942, 1999, Spent Nuclear Fuel Cold Vacuum Drying Facility Implementation Plan for Fire Hazard Analysis Suggested Actions, Rev. 0, Fluor Daniel Hanford, Incorporated, Richland, Washington.

NUREG 1431, 1992, Standard Technical Specifications, Westinghouse Plants, Rev. 0, U.S. Nuclear Regulatory Commission, Washington D.C.

40 CFR, "Protection of Environment," Code of Federal Regulations, as amended. 
APPENDIX A

BASES 


\section{Appendix A BASES}

This Appendix provides summary statements of the reasons for the Safety Limits, Limiting Control Settings, Limiting Conditions for Operation and the associated Surveillance Requirements. The BASES describe how the limit(s), the Applicability, the Condition(s) and the Surveillance(s) will maintain operation of the facility within the safety envelope. The primary purpose for describing the BASES for these requirements is to provide the operations and engineering staff with the necessary information to maintain operation of the facility within the safety envelope and to ensure that any future changes to these requirements will not affect their original intent or purpose. 
B 2.0 SAFETY LIMITS (SLS)

\section{B 2.1.1 Multi-Canister Overpack Maximum Pressure}

BASES

BACKGROUND

This SL on multi-canister overpack (MCO) maximum pressure prevents an uncontrolled pressurized gaseous release caused by exceeding the design pressure of the MCO. An overpressurization of the MCO can occur if the MCO is isolated and heat removal from the MCO is not sufficient. As fuel elements and scrap fuel reach excessive temperatures because of decay and chemical reaction heat, hydrogen gas formation increases causing the MCO to be overpressurized. An overpressurization of the MCO can also occur because of cascading failures of the helium supply pressure regulators for either the general-service helium system or the standby safety-class helium (SCHe) system during several phases of the cold vacuum drying operation.

The MCO, loaded with spent nuclear fuel (SNF) from the $100 \mathrm{~K}$ Reactor SNF storage basins, is shipped to the Cold Vacuum Drying Facility (CVDF). At the CVDF nearly all of the water is removed from the $\mathrm{MCO}$ and the $\mathrm{MCO}$ is backfilled with helium. The MCO is then sealed and leak tested before transport to the Canister Storage Building for interim storage. During all phases of the cold vacuum drying operation, tempered water in the cask-MCO annulus and helium flow are provided as means to remove the generated heat from the MCO. Five sources of helium are provided in the CVDF for MCO process operations, process support activities, and process safety functions. Included are the general-service helium system (tube trailer) and the standby SCHe system (four helium gas cylinders). Helium is an inert gas with good thermal conductivity and is used in process operations to provide enhanced thermal conduction, to purge the MCO of hydrogen and other gasses, to pressurize the MCO to preclude further air ingress, and to provide an inert backfill of the MCO when drying is complete. The MCO processing operations are described in HNF-3553, Spent Nuclear Fuel Project Final Safety Analysis Report, Annex B, "Cold Vacuum Drying Facility Final Safety Analysis Report," Chapter B2.0, "Facility Description."

(continued) 
BACKGROUND

(cont inued)
The primary passive barrier protected by this SL is the MCO. The MCO provides primary long-term confinement of the enclosed SNF, and maintains the SNF in a critically favorable configuration. The $\mathrm{MCO}$ is the closest primary physical barrier to the SNF (material source). The consequences of exceeding the design pressure of the MCO are a potential uncontrolled release of radiological material to the offsite public, onsite workers and the environment and potential structural failure of the MCO.

HNF-SD-SNF-SARR-005, Multi-Canister Overpack Topical Report, provides a description of the design aspects and applicable analyses and evaluations of the MCO.
APPLICABLE SAFETY ANALYSES
SL 2.1.1 is required for one accident scenario: Multi-Canister Overpack Overpressurization.

\section{Multi-Canister Overpack Overpressurization}

Overpressurization of the MCO is analyzed in SNF-2770, Cold Vacuum Drying Facility Design Basis Accident Analysis Documentation, and the results of the analysis are presented in HNF-3553, Spent Nuclear Fuel Project Final Safety Analysis Report, Annex B, "Cold Vacuum Drying Facility Final Safety Analysis Report," Chapter B3.0, "Hazard and Accident Analyses." Based on the results of the analysis, the unmitigated release of radiological material could exceed offsite release limits and onsite risk evaluation guidelines.

In this postulated accident scenario, a gaseous release results from failure of the MCO by overpressurization from the helium supply system. Operating within this SL on MCO maximum pressure prevents exceeding the MCO design pressure of $340 \mathrm{lb} / \mathrm{in}^{2}$ gauge. 
$\mathrm{SL}$

The MCO pressure is required to be $\leq 340 \mathrm{lb} / \mathrm{in}^{2}$ gauge.

The value of $340 \mathrm{lb} / \mathrm{in}^{2}$ gauge has been established as the basis for design of the MCO (HNF-SD-SNF-SARR-005). The analysis identified credible failures of the MCO (a primary passive barrier) from (1) MCO isolation that results in the slow pressurization of the MCO or (2) an overpressurization from either the general-service helium or SCHe supply system. The general-service helium system is capable of greater than $3000 \mathrm{lb} / \mathrm{in}^{2}$ gauge pressure, which could exceed the MCO design value. The SCHe system is capable of greater than $2500 \mathrm{lb} / \mathrm{in}^{2}$ gauge pressure, which could also exceed the MCO design value. Operating within this SL serves to protect the stated pressure a mechanically sealed MCO can safely survive of $3401 \mathrm{~b} / \mathrm{in}^{2}$ gauge and prevent a direct, imminent failure of the MCO.

The LCOS and LCSS/LCOS that protect this SL are:

- LCO 3.1.1, "Safety-Class Instrumentation and Control System" (LCS - MCO high pressure trip setpoint)

- LCO 3.2.1, "Safety-Class Helium System" (pressure control valves)

- LCO 3.3.1, "Multi-Canister Overpack Vacuum Purge System Connections" (MCO vent path and pressure relief valves)

- LCS/LCO 3.3.2, "Pressure Safety Relief Valves" (LCS - pressure safety relief valve setpoint)

MODE

APPLICABILITY
SL 2.1.1 applies during process bay OPERATION SUBMODE because processing of MCOs is allowed in this SUBMODE. SL 2.1.1 does not apply in process bay STANDBY or REPAIR SUBMODES because the process bay is not allowed to contain an MCO in these SUBMODES. 
PROCESS AREA APPLICABILITY
SL 2.1.1 applies prior to the successful completion of the final pressure rebound test (AC 5.17, "Dryness Testing") and the closure of both MCO process tube plug valves. Upon completion of the final pressure rebound test, the MCO is no longer capable of reaching pressures in excess of $340 \mathrm{lb} / \mathrm{in}^{2}$ gauge when isolated. Once the MCO is isolated from the CVDF processing systems, it is no longer capable of being pressurized by either the general-service helium or SCHe supply systems.

ACTIONS

Exceeding an SL is a VIOLATION of the TSRs. For this situation, proceed in accordance with AC 5.4.2, "Response to a Safety Limit VIOLATION." There are no actions that can be taken to restore the SL and avoid a VIOLATION. Exceeding an SL is indicative of significant multiple breakdowns of 1ayered protective measures such as LCSs/LCOs, action statements, surveillances, Administrative Controls, and defense in depth controls.

The actions in response to an SL VIOLATION are derived from $D O E$ requirements. The first action is to place the CVDF in the most safe and stable condition attainable Immediately (see Section 1.3, "Completion Times," for the definition of Immediately). The circumstances leading to an SL VIOLATION and the necessary recovery activities can vary widely. The first action is intended to bring the facility operation back within the $\mathrm{SL}$, if possible, to prevent potential damage to the primary barrier and release of radioactive material to the offsite public and onsite workers. The amount of time needed to complete this action cannot be set beforehand as it is dependent on the conditions and activities that are occurring at the CVDF at the time of the VIOLATION.

Subsequent actions specified in procedures include notification of DOE and contractor management; occurrence reporting, including the evaluation of root causes and corrective measures to prevent recurrence; and longer term actions to determine if any damage may have occurred before returning the CVDF to an operational MODE. 
SURVEILLANCE REQUIREMENTS
SRs are not applicable to SLs. SRs necessary to maintain operations within the SL are contained within LCO 3.1.1, "Safety-Class Instrumentation and Control System"; LCO 3.2.1, "Safety-Class Helium System"; LCO 3.3.1, "Multi-Canister Overpack Vacuum Purge System Connections"; and LCS/LCO 3.3.2, "Pressure Safety Relief Valves." These SRs are part of the layered approach for protection of the SL.
REFERENCES
HNF-3553, 1999, Spent Nuclear Fuel Project Final Safety Analysis Report, Rev. 0, Annex B, "Cold Vacuum Drying Facility Final Safety Analys is Report," Fluor Daniel Hanford, Incorporated, Richland, Washington.

SNF-2770, 1999, Cold Vacuum Drying Facility Design Basis Accident Analysis Documentation, Rev. 2, Fluor Daniel Hanford, Incorporated, Richland, Washington.

HNF-SD-SNF-SARR-005, 1999, Multi-Canister Overpack Topical Report, Rev. 1, Fluor Daniel Hanford, Incorporated, Richland, Washington. 
B 3.0 LIMITING CONDITIONS FOR OPERATION (LCOS) AND SURVEILLANCE REQUIREMENTS (SRs)

LCO 3.0.1, "LCO Met," through LCO 3.0.7, "Emergency Exceptions," establish the general requirements applicable to all LCOs and apply at all times, unless otherwise stated.

LCO 3.0.1 - LCO Met

LCO 3.0.1 establishes the Applicability within each individual $\mathrm{LCO}$ as the requirements for when the $\mathrm{LCO}$ is required to be met (i.e., when the unit is in the MODES or other specified conditions of the Applicability of each LCO).

\section{LCO 3.0.2 - ACTION Met}

LCO 3.0.2 establishes that upon discovery of a failure to meet an LCO, the associated ACTIONS shall be met. The Completion Time of each Required Action for an ACTIONS Condition is applicable from the point in time that an ACTIONS Condition is entered. The Required Actions establish those remedial measures that must be taken within specified Completion Times when the requirements of an LCO are not met. This LCO establishes that:

\section{a. Completion of the Required Actions within the} specified Completion Times constitutes compliance with an LCO; and

b. Completion of the Required Actions is not required when an LCO is met within the specified Completion Time, unless otherwise specified.

There are two basic types of Required Actions. The first type of Required Action specifies a time limit in which the LCO must be met. This time limit is the Completion Time to restore an inoperable system or component to OPERABLE status or to restore variables to within specified limits. If this type of Required Action is not completed within the specified Completion Time, a shutdown may be required to place the unit in a MODE or condition in which the LCO is not applicable. (Whether stated as a Required Action or not, correction of the entered Condition is an action that may always be considered upon entering ACTIONS). The second type of Required Action specifies the remedial measures that permit continued

(continued) 
LCO 3.0.2 (continued)

operation of the unit that is not further restricted by the Completion Time. In this case, compliance with the Required Actions provides an acceptable level of safety for continued operation.

Completing the Required Actions is not required when an LCO is met or is no longer applicable within the associated Completion Time, unless otherwise stated in the individual LCOs.

The nature of some Required Actions of some Conditions necessitates that, once the Condition is entered, the Required Actions must be completed even though the associated Conditions are resolved. The individual LCO's ACTIONS specify the Required Actions where this is the case.

The Completion Times of the Required Actions are also applicable when a system or component is removed from service intentionally. The reasons for intentionally relying on the ACTIONS include, but are not 1 imited to, performance of Surveillances, preventive maintenance, corrective maintenance, or investigation of operational problems. Entering ACTIONS for these reasons must be done in a manner that does not compromise safety. Intentional entry into ACTIONS should not be made for operational convenience. Alternatives that would not result in redundant equipment being inoperable should be used instead. Doing so limits the time both subsystems/trains of a safety function are inoperable and limits the time other conditions exist that result in $\angle C O 3.0 .3$, "ACTION Not Met or ACTION Not Provided," being entered.

Individual LCOs may specify a time limit for performing an SR when equipment is removed from service or bypassed for testing. In this case, the Completion Times of the Required Actions are applicable when this time limit expires if the SR has not been completed.

When a change in MODE or other specified condition is required to comply with Required Actions, the unit may enter a MODE or other specified condition in which a new LCO becomes applicable. In this case, the Completion Times of the associated Required Actions would apply from the point in time that the new LCO becomes applicable, and the ACTIONS Condition(s) are entered. 
LCO 3.0.3 - ACTION Not Met or ACTION Not Provided

For ACTIONS not met (VIOLATION), proceed in accordance with AC 5.4.3, "Response to a Limiting Condition for Operation and Limiting Control Setting VIOLATION."

A11 foreseen Conditions are 1 isted in the ACTIONS statements. Therefore, all ACTIONS are provided for all foreseen Conditions.

\section{LCO 3.0.4 - MODE Changes}

LCO 3.0.4 establishes limitations on changes in MODES or other specified conditions in the Applicability when an LCO is not met. It precludes placing the unit in a different MODE or other specified condition when the following exist:

a. The requirements of an LCO in the MODE or other specified condition to be entered are not met; and

b. Continued noncompliance with these requirements would result in the unit being required to be placed in a MODE or other specified condition in which the LCO does not apply to comply with the Required Actions.

Compliance with Required Actions that permit continued operation of the unit for an unlimited period of time in a MODE or other specified condition provides an acceptable level of safety for continued operation. This is without regard to the status of the unit before or after the MODE change. Therefore, in such cases, entry into a MODE or other specified condition in the Applicability may be made in accordance with the provisions of the Required Actions. The provisions of this LCO should not be interpreted as endorsing the failure to exercise the good practice of restoring systems or components to OPERABLE status before unit startup.

(cont inued) 


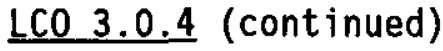

The provisions of LCO 3.0.4 shall not prevent changes in MODES or other specified conditions in the Applicability that are required to comply with ACTIONS. In addition, the provisions of LCO 3.0.4 shall not prevent changes in MODES or other specified conditions in the Applicability that result from a normal shutdown.

Exceptions to LCO 3.0.4 are stated in the individual LCOS. Exceptions may apply to all of the ACTIONS or to a specific Required Action of an LCO.

When changing MODES or other specified conditions while in an ACTIONS Condition, in compliance with LCO 3.0.4, or where an exception to LCO 3.0.4 is stated, the ACTIONS define the remedial measures that apply. Surveillances do not have to be performed on the associated inoperable equipment (or on variables outside the specified limits), as permitted by SR 3.0.1, "SR Met." Therefore, a change in MODE or other specified condition in this situation does not cause SR 3.0.1, "SR Met," or SR 3.0.4, "MODE Changes," to be not met for those Surveillances that do not have to be performed due to the associated inoperable equipment. However, SRs must be met to demonstrate OPERABILITY prior to declaring the associated equipment OPERABLE (or variable within limits) and restoring compliance with the affected LCO. 
LCO 3.0.5 - Return to Service

LCO 3.0.5 establishes the allowance of restoring equipment to service under administrative controls when it has been removed from service or declared inoperable to comply with ACTIONS. The sole purpose of this LCO is to provide an exception to LCO 3.0.2, "ACTION Met," to allow the performance of SRs to demonstrate:

a. The OPERABILITY of the equipment being returned to service; or

b. The OPERABILITY of other equipment.

The administrative controls are to ensure the time that the equipment is returned to service that is in conflict with the requirements of the ACTIONS is limited to the time absolutely necessary to perform the allowed SRs. This LCO does not provide time to perform any other preventive or corrective maintenance.

An example of demonstrating the OPERABILITY of the equipment being returned to service is reopening an isolation valve that has been closed to comply with Required Actions and must be reopened to perform the SRs.

An example of demonstrating the OPERABILITY of other equipment is taking an inoperable channel or trip system out of the tripped condition to prevent the trip function from occurring during the performance of an SR on another channel in the other trip system. A similar example of demonstrating the OPERABILITY of other equipment is taking an inoperable channel or trip system out of the tripped condition to permit the logic to function and indicate the appropriate response during the performance of an SR on another channel in the same trip system.

\section{LCO 3.0.6 - Support System LCO Not Met}

LCO 3.0.6 establishes an exception to LCO 3.0.2, "LCO Not Met," for support systems that have an LCO specified in the Technical Safety Requirements (TSRs). This exception is necessary because LCO 3.0.2, "LCO Not Met," would require that the Conditions and Required Actions of the associated inoperable supported system LCO be entered solely due to the inoperability of the support system. 
This exception is justified because the actions that ensure the unit is maintained in a safe condition are specified in the support system LCO's Required Actions. These Required Actions may include entering the supported system's Conditions and Required Actions or may specify other Required Actions.

When a support system is inoperable and there is an LCO specified for it in the TSRs, the supported system(s) are required to be declared inoperable if determined to be inoperable as a result of the support system inoperability. However, it is not necessary to enter into the supported systems' Conditions and Required Actions unless directed to do so by the support system's Required Actions. The confusion and inconsistency of interpretation of requirements related to the entry into multiple LCOs' Conditions and Required Actions are eliminated by providing all the actions that are necessary to ensure the unit is maintained in a safe condition in the support system's Required Actions.

However, there are instances where a support system's Required Action may either direct a supported system to be declared inoperable or direct entry into Conditions and Required Actions for the supported system. This may occur immediately or after some specified delay to perform some other Required Action. Regardless of whether it is immediate or after some delay, when a support system's Required Action directs a supported system to be declared inoperable or directs entry into Conditions and Required Actions for a supported system, the applicable Conditions and Required Actions shall be entered in accordance with LCO 3.0.2, "LCO Not Met."

\section{LCO 3.0.7 - Emergency Exceptions}

LCO 3.0.7 establishes that in an emergency, if a situation develops that is not addressed by the TSRs, facility operating personnel are expected to utilize their training and expertise in taking actions to correct or mitigate the situation. This LCO applies to both LCOS and ACs. 


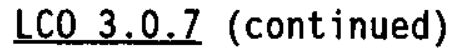

Operations personnel may take actions that depart from a requirement in the TSRs provided that: (1) an emergency situation exists, (2) these actions are immediately needed to protect the health and safety of the public, and (3) no action consistent with the TSRs can provide adequate or equivalent protection. If emergency actions are taken, verbal notifications shall be made to the Head of the Field Element (DOE-RL) within two hours and by written reports to the Program Manager (PM) with in 24 hours, in accordance with Section 5.5, "Occurrence Reporting."

SR 3.0.1, "SR Met," through SR 3.0.4, "MODE Changes," establish the general requirements applicable to all LCOs and apply at all times unless otherwise stated.

\section{SR 3.0.1 - SR Met}

SR 3.0.1 establishes the requirement that SRs must be met during the MODES or other specified conditions in the Applicability for which the requirements of the LCO apply, unless otherwise specified in the individual SRs. This SR is to ensure that Surveillances are performed to verify the OPERABILITY of systems and components, and that variables are within specified limits. Failure to meet a Surveillance within the specified Frequency, in accordance with SR 3.0.2, "Frequencies, " constitutes a failure to meet an LCO.

Systems and components are assumed to be OPERABLE when the associated SRs have been met. Nothing in this SR, however, is to be construed as implying that systems or components are OPERABLE when:

a. The systems or components are known to be inoperable although still meeting the SRs; or

b. The requirements of the Surveillance(s) are known not to be met between required Surveillance performances.

Surveillances do not have to be performed when the unit is in a MODE or other specified condition for which the requirements of the associated $L C O$ are not applicable, unless otherwise specified. The SRs associated with a test exception are only applicable when the test exception is used as an allowable exception to the requirements of an LCO.

(continued) 
Surveillances, including Surveillances invoked by Required Actions, do not have to be performed on inoperable equipment because the ACTIONS define the remedial measures that apply. SRs have to be met in accordance with SR 3.0.2, "Frequencies," prior to returning equipment to OPERABLE status.

Upon completion of maintenance, appropriate post-maintenance testing is required to declare equipment OPERABLE. This includes meeting applicable SRs in accordance with SR 3.0.2, "Frequencies." Post-maintenance testing may not be possible in the current MODE or other specified conditions in the Applicability due to the necessary unit parameters not having been established. In these situations, the equipment may be considered OPERABLE provided testing has been satisfactorily completed to the extent possible and the equipment is not otherwise believed to be incapable of performing its function. This will allow operation to proceed to a MODE or other specified condition where other necessary post-maintenance tests can be completed.

\section{$\underline{\text { SR 3.0.2 - Frequencies }}$}

SR 3.0.2 establishes the requirements for meeting the specified Frequency for Surveillances and any Required Action with a Completion Time that requires the periodic performance of the Required Action on a "once per..." interval.

SR 3.0 .2 permits a $25 \%$ extension of the interval specified in the Frequency (see Section 1.4, "Frequency"). This extension facilitates Surveillance scheduling and considers plant operating conditions that may not be suitable for conducting the Surveillance (e.g., transient conditions or other ongoing Surveillance or maintenance activities).

The $25 \%$ extension does not significantly degrade the reliability that results from performing the Surveillance at its specified Frequency. This is based on the recognition that the most probable result of any particular Surveillance being performed is the 
verification of conformance with the SRs. The exceptions to SR 3.0.2 are those Surveillances for which the $25 \%$ extension of the interval specified in the Frequency does not apply. These exceptions are stated in the individual LCOS. An example of where SR 3.0.2 does not apply is a Surveillance with a Frequency of "in accordance with federal regulations, as modified by approved exemptions." The requirements of regulations take precedence over the TSRS. The TSRs cannot in and of themselves extend a test interval specified in the regulations. Therefore, there would be a Note in the Frequency stating, "SR 3.0.2 is not app1icable."

As stated in SR 3.0.2, the $25 \%$ extension also does not apply to the initial portion of a periodic Completion Time that requires performance on a "once per. . ." basis. The $25 \%$ extension applies to each performance after the initial performance. The initial performance of the Required Action, whether it is a particular Surveillance or some other remedial action, is considered a single action with a single Completion Time. One reason for not allowing the $25 \%$ extension to this Completion Time is that such an action usually verifies that no loss of function has occurred by checking the status of redundant or diverse components or accomplishes the function of the inoperable equipment in an alternative manner.

The provisions of SR 3.0 .2 are not intended to be used repeatedly merely as an operational convenience to extend Surveillance intervals or periodic Completion Time intervals beyond those specified.

\section{SR 3.0.3 - Delay of Required Actions}

SR 3.0.3 establishes the flexibility to defer declaring affected equipment inoperable or an affected variable outside the specified limits when a Surveillance has not been completed within the specified Frequency. A delay period of up to 24 hours applies from the point in time that it is discovered that the Surveillance has not been performed in accordance with SR 3.0.2, "Frequencies," and not at the time that the specified Frequency was not met. 
$\underline{\text { SR 3.0.3 (continued) }}$

This delay period provides an adequate time limit to complete Surveillances that have been missed. This delay period permits the completion of a Surveillance before complying with Required Actions or other remedial measures would be required that may preclude completion of the Surveillance.

The basis for this delay period includes consideration of unit conditions, adequate planning, availability of personne1, the time required to perform the Surveillance, the safety significance of the delay in completing the required Surveillance, and the recognition that the most probable result of any particular Surveillance being performed is the verification of conformance with the SRs.

When a Surveillance with a Frequency based not on time intervals, but upon specified unit conditions or operational situations, is discovered not to have been performed when specified, SR 3.0.3 allows the full delay period of 24 hours to perform the Surveillance.

SR 3.0.3 also provides a time limit for completion of Surveillances that become applicable as a consequence of MODE changes imposed by Required Actions.

Failure to comply with specified Frequencies for SRs is expected to be an infrequent occurrence. Use of the delay period established by SR 3.0.3 is a flexibility which is not intended to be used as an operational convenience to extend Surveillance intervals.

If a Surveillance is not completed within the allowed delay period, then the equipment is considered inoperable or the variable is considered outside the specified limits and the Completion Times of the Required Actions for the applicable LCO Conditions begin immediately upon expiration of the delay period. If a Surveillance is failed within the delay period, then the equipment is inoperable, or the variable is outside the specified limits and the Completion Times of the Required Actions for the applicable LCO Conditions begin immediately upon the failure of the Surveillance. 
Completion of the Surveillance within the delay period allowed by this SR, or within the Completion Time of the ACTIONS, restores compliance with SR 3.0.1, "SR Met." The initial missed surveillance is still reportable as such in accordance with the DOE occurrence reporting requirements for missed surveillances.

SR 3.0.4-MODE Changes

SR 3.0.4 establishes the requirement that all applicable SRs must be met before entry into a MODE or other specified condition in the Applicability.

This SR ensures that system and component OPERABILITY requirements and variable limits are met before entry into MODES or other specified conditions in the Applicability for which these systems and components ensure safe operation of the unit. This SR applies to changes in MODES or other specified conditions in the Applicability associated with unit shutdown as well as startup.

The provisions of SR 3.0 .4 shall not prevent changes in MODES or other specified conditions in the Applicability that are required to comply with ACTIONS.

The precise requirements for performance of SRs are specified such that exceptions to SR 3.0.4 are not necessary. The specific timeframes and conditions necessary for meeting the SRs in accordance with the requirements of SR 3.0.4 are specified in the Frequency, in the Surveillance, or both. This allows performance of Surveillances when the prerequisite condition(s) specified in a Surveillance procedure require entry into the MODE or other specified condition in the Applicability of the associated LCO prior to the performance or completion of a Surveillance. A Surveillance that could not be performed until after entering the LCO Applicability would have its Frequency specified such that it is not "due" until the specific conditions needed are met. Alternately, the Surveillance may be stated in the form of a Note as not required (to be met or performed) until a particular event, condition, or time has been reached. The SRs are annotated consistent with the requirements of Section 1.4, "Frequency." 


\section{B 3.1 INSTRUMENTATION}

\section{B 3.1.1 Safety-Class Instrumentation and Control System}

BASES

BACKGROUND

This LCO ensures OPERABILITY of the safety-class instrumentation and control (SCIC) system. The SCIC system monitors certain multi-canister overpack (MCO) process operation parameters, seismic conditions, and process bay temperatures and actuates one or more safetyclass systems or alarms if upset conditions are detected. The SCIC system isolates the MCO and actuates the safety-class helium (SCHe) system and/or removes power to the tempered water (TW) (annulus) system heater. The SCIC system also provides remote alarm indication in the control room so that further recovery actions may be taken by the operators as appropriate.

The SCIC system consists of two logic trains and redundant instruments and control functions. There is a set of SCIC panels located in each process bay. One of the two panels contains a programmable logic controller (PLC) that provides one of the two logic trains for that process bay. The other PLC for that process bay is located in the adjacent process bay. Redundant instruments and control functions are provided to the two SCIC system logic trains $A$ and $B$. The PLC performs the various setpoint comparisons and provides safety-related timing functions (e.g., monitor maximum vacuum time to limit fuel heatup, monitor minimum time above atmospheric pressure for fuel cooldown). The PLC in process bay 2 provides logic train A for process bays 2 and 3 . The PLC in process bay 3 provides logic train B for process bays 2 and 3 . A similar arrangement is used for process bays 4 and 5 . Two local control panels are used to access train $A$ and train $B$ for that process bay. The SCIC system is also designed to be fail-safe.

The control room has SCIC system logic trains A and B control room panels which includes a control switch for each process bay for the different MCO process operations which include; (1) Bypass, (2) Heatup, (3) Drain, (4) Purge/Flush, (5) Drying, (6) Proof, and (7) Pressure Test. Each position of the control switch allows the SCIC system to monitor sensors with different setpoints and logic appropriate for that processing step.

(continued) 
BACKGROUND (continued)
Each MCO process operation uses unique controls to prevent accidental or unintentional events, such as introducing water into a dried MCO.

Sensors located in the process systems and elsewhere within the Cold Vacuum Drying Facility (CVDF) provide the following information to the SCIC system:

- Vacuum purge system (VPS) line pressure to detect both high and low MCO pressures when in pressure operations, and unexpected pressure rises (e.g., caused by inleakage) when under vacuum drying (these events will actuate an isolation and purge of the $\mathrm{MCO}$, and trigger an isolation and purge alarm)

The high MCO pressure setpoint serves as a Limiting Control Setting (LCS) to protect the MCO maximum pressure safety limit (SL 2.1.1).

- VPS line pressure to detect insufficient time at pressure or excessive time under vacuum during vacuum drying cycles (these events will actuate an isolation and purge of the $\mathrm{MCO}$, and trigger an isolation and purge alarm)

- General-service helium system purge flow rate and VPS pressure to detect a low helium purge flow when the MCO is above 12 torr (this event will actuate an isolation and purge of the MCO, and trigger an isolation and purge alarm)

- TW (annulus) system water level to detect 10w annulus water levels (this event will trigger an annulus low level alarm; manual actions will be required to restore annulus water levels [LCO 3.1.5])

- TW (annulus) system water temperature to detect high tempered water temperatures (this event will trigger de-energization of the TW [annulus] system heater) 
BACKGROUND (cont inued) $\bullet$

Process bay temperature to detect conditions (high temperature) that may threaten the heat sink for the $M C O$ and the safe operation of process bay instrumentation (this event will actuate an isolation and purge of the $\mathrm{MCO}$, and trigger an isolation and purge alarm; manual action will be required to restore process bay temperatures [LCO 3.1.6])

- Seismic activity to detect conditions that may threaten safe facility operations (this event will actuate isolation and purge of the MCO, and de-energization of the TW [annulus] system heater). The seismic monitors will actuate the SCIC system trip independent of the SCIC logic circuits. The seismic monitors directly trip to the SCIC system output relays.

The SCIC system also provides non-safety class signals to the facility monitoring and control system (MCS) for normal control, indication and alarms. Under normal conditions, the MCS controls eight MCO isolation valves, however, certain valves such as drain valves and process water conditioning (PWC) valves are interlocked closed by the SCIC system during certain MCO process operations. The SCHe valves are directly controlled by the SCIC system and not the MCS. The TW heater is normally controlled by the MCS unless a fault condition (high temperature) occurs at which point, the SCIC contactors open causing a loss of power to the heater. The MCS cannot override SCIC system commands and is not required to operate for the SCIC system to perform its required functions.

The SCIC system has three distinct functions under defined upset conditions, or a manual trip. These include; (1) MCO isolation and purge, (2) TW trip, and (3) control room annunciation. 
BACKGROUND (continued)
The ISO \& Purge trip isolates the MCO (de-energizes [close] the eight $M C O$ isolation valves) and actuates the SCHe system (de-energizes [open] the four $\mathrm{SCHe}$ isolation valves). The TW trip de-energizes the TW heater. The SCIC system also provides safety-class alarms in the control room. These al arms notify the operators that the water level in the cask-MCO annulus is low and that the SCIC system has initiated an MCO isolation and purge. Manual actions are required to restore the low annulus water level. The MCO isolation and purge alarm indicates a potential need for $\mathrm{SCHe}$ bottle changeout and that high bay temperature conditions may impact the available heat sink.

The SCIC system interfaces with the following safety class MCO isolation valves which are addressed in LCO 3.2.1:

- PWC-GOV- $1 * 30$ and PWC-GOV- $1 * 03$

- VPS-GOV- $1 * 05$ and VPS-GOV- $1 * 09$

- VPS-GOV-1*11 and VPS-GOV-1*17

- He-GOV-1*06 and $\mathrm{He}-\mathrm{GOV}-1 * 02$

- SCHe-GOV-5*12 and SCHe-GOV-5*31

- SCHe-GOV-5*51 and SCHe-GOV-5*71

\section{APPLICABLE SAFETY ANALYSES}

LCO 3.1.1 is required for three accident scenarios:

(1) Multi-Canister Overpack Internal Hydrogen Explosion,

(2) Multi-Canister Overpack Thermal Runaway Reaction, and

(3) Multi-Canister Overpack Overpressurization.

\section{Multi-Canister Overpack Internal Hydrogen Explosion}

A hydrogen explosion inside an MCO is analyzed in SNF-2770, Cold Vacuum Drying Facility Design Basis Accident Analysis Documentation, and the results of the analys is are presented in HNF-3553, Spent Nuclear Fuel Project Final Safety Analysis Report, Annex B, "Cold Vacuum Drying Facility Final Safety Analys is Report," Chapter B3.0, "Hazard and Accident Analyses." Based on the results of the analysis, the unmitigated release of radiological material could exceed onsite risk evaluation guidelines. 
APPLICABLE SAFETY ANALYSES (cont inued)
In this postulated accident scenario, a hydrogen explosion occurs because of a hydrogen-air mixture inside an MCO. The SCIC system is credited in the analysis to monitor process and facility parameters and detect and respond to abnormal conditions by actuating the SCHe system, isolating the $\mathrm{MCO}$, and/or removing power to the TW (annulus) system heater, as appropriate, and providing remote alarm indication in the control room so that further recovery actions may be taken by the operators as appropriate.

\section{Multi-Canister Overpack Thermal Runaway Reaction}

Thermal runaway reactions inside an $M C O$ are analyzed in SNF-2770, Cold Vacuum Drying Facility Design Basis Accident Analysis Documentation, and the results of the analysis are presented in HNF-3553, Spent Nuclear Fuel Project Final Safety Analysis Report, Annex B, "Cold Vacuum Drying Facility Final Safety Analysis Report," Chapter B3.0, "Hazard and Accident Analyses." Based on the results of the analysis, the unmitigated release of radiological material could exceed offsite release limits and onsite risk evaluation guidelines.

In this postulated accident scenario, a thermal runaway reaction occurs from insufficient heat removal from the inside of the MCO. The SCIC system is credited in the analysis to monitor process and facility parameters and detect and respond to abnormal conditions by actuating the SCHe system, isolating the MCO, and/or removing power to the TW (annulus) system heater, as appropriate, and providing remote alarm indication in the control room so that further recovery actions may be taken by the operators as appropriate.

\section{Multi-Canister Overpack Overpressurization}

Overpressurization of an MCO is analyzed in SNF-2770, Cold Vacuum Drying Facility Design Basis Accident Analysis Documentation, and the results of the analysis are presented in HNF-3553, Spent Nuclear Fuel Project Final Safety Analysis Report, Annex B, "Cold Vacuum Drying Facility Final Safety Analys is Report," Chapter B3.0, "Hazard and Accident Analyses." Based on the results of the analysis, the unmitigated release of radiological material could exceed offsite release limits and onsite risk evaluation guidelines. 
APPLICABLE SAFETY ANALYSES (continued)
In this postulated accident scenario, a high-pressure release of radioactive material results from MCO isolation and a resulting high MCO internal pressure. The SCIC system is credited in the analysis to monitor process and facility parameters and detect and respond to abnormal conditions by actuating the $\mathrm{SCHe}$ system, isolating the MCO, and/or removing power to the TW (annulus) system heater, as appropriate, and providing remote alarm indication in the control room so that further recovery actions may be taken by the operators as appropriate.

Train A and train B of the SCIC system is required to be OPERABLE to provide the capability to respond to process parameters upsets by providing isolation and purge of the MCO and/or removing power to the TW (annulus) system heater, as appropriate, and providing remote alarm indication in the control room so that further recovery actions may be taken by the operators as appropriate. Operability requirements will include the capability to receive and respond appropriately to the inputs from process system sensors and provide the function outputs as listed in Table 3.1.1-1 and described as follows.

MCO high pressure - If MCO pressure as measured from PT-1*36 (train A) or PT $1 * 37$ (train B) is $>12 \mathrm{lb} / \mathrm{in}^{2}$ gauge, the contact opens. The LCO setpoint value of $\leq 12 \mathrm{ib} /$ in $^{2}$ gauge is based on the safety analysis $1 \mathrm{imit}$ value of $\leq 25 \mathrm{lb} / \mathrm{in}^{2}$ gauge adjusted for instrument uncertainty and instrument range (refer to SNF-4451). The LCO setpoint is conservative relative to the $30 \mathrm{lb} / \mathrm{in}^{2}$ gauge rupture disk and within the range of the pressure transmitters. The SCIC system will isolate the MCO and actuate a SCHe purge. This control is required during the following MCO process operations: (2) Heatup (3) Drain, (4) Purge/Flush, (5) Drying, (6) Proof.

MCO low pressure - If MCO pressure as measured from PT-1*36 (train A) or PT $1 * 37$ (train B) is $<0.5 \mathrm{lb} / \mathrm{in}^{2}$ gauge, the contact opens. The LCO setpoint value of $\geq 0.5$ $\mathrm{lb} / \mathrm{in}^{2}$ gauge is based on the safety analys is 1 imit value of $\geq 0.24 \mathrm{lb} /$ in $^{2}$ gauge adjusted for instrument uncertainty (refer to SNF-4451). The SCIC system will isolate the MCO and actuate a SCHe purge. This control is required during the following MCO process operations: (3) Drain, (4) Purge/Flush, (5) Drying, and (6) Proof.

(continued) 
LCO (cont inued)
Vacuum limit timer - Time under vacuum (defined as $<0.24$ $1 \mathrm{~b} / \mathrm{in}^{2}$ gauge) sha11 be monitored and a trip occurs if the total time exceeds an 8 hour period for the first vacuum cycle and a 4 hour cumulative period for all subsequent cycles unless a 4 hour thermal reset (continuous pressure above $\approx 0.26 \mathrm{lb} / \mathrm{in}^{2}$ gauge) occurs prior to reaching the timed limit. The vacuum timer pre-set is set to 8 hours at the beginning of drying operations. If during the first 8 hour period, pressure is increased above 0.26 $1 \mathrm{~b} / \mathrm{in}^{2}$ gauge, the time stops. Returning to vacuum without first satisfying the 4 hour thermal reset will initiate an ISO \& Purge trip. The vacuum timer pre-set is changed from 8 hours to 4 hours once the 8 hour timer has started and a 4 hour thermal reset has been completed. When the SCIC system is reset (i.e., ISO \& Purge trip reset) the vacuum timer is set to 4 hours required at pressure and the 5 minute MCO low purge flow bypass is reset to 5 minutes. The LCO setpoint value of $\geq 0.26 \mathrm{lb} / \mathrm{in}^{2}$ gauge is based on the safety analysis limit value of $\geq 01 \mathrm{~b} / \mathrm{in}^{2}$ gauge adjusted for instrument uncertainty (refer to SNF-4451). This control is required during the following MCO process operations: (5) Drying.

MCO pressure decay fail - An MCO pressure decay fail occurs if pressure drops below $0.51 \mathrm{~b} / \mathrm{in}^{2}$ gauge (decreasing value) on PT $1 * 36$ or PT $1 * 37$ for more than 5 continuous seconds and pressure does not drop below -11.7 $1 \mathrm{~b} / \mathrm{in}^{2}$ gauge ( $\approx 155$ torr) within 5 minutes. Once $\leq-11.7$ is reached, this timer is reset and held until pressure is again above $0.5 \mathrm{lb} / \mathrm{in}^{2}$ gauge. These LCO limits of $\geq 0.5$ $1 \mathrm{~b} / \mathrm{in}^{2}$ gauge and $\leq-11.7 \mathrm{lb} / \mathrm{in}^{2}$ gauge are based on the safety analysis limit values of $\geq 0.24 \mathrm{lb} / \mathrm{in}^{2}$ gauge and $\leq$ $-11.4 \mathrm{lb} / \mathrm{in}^{2}$ gauge adjusted for instrument uncertainty (refer to SNF-4451). This is an indication of a system leak or vacuum pump degradation as the pressure decay during vacuum should be rapid. The contact opens if the timeout is reached. This control is required during the following MCO process operations: (5) Drying, and (6) Proof.

MCO pressure rise fail - An MCO pressure rise fail occurs if pressure goes above (increasing value) $-11.1 \mathrm{lb} / \mathrm{in}^{2}$ gauge $(\approx 185$ torr) on PT $1 * 36$ or PT $1 * 37$ for more than 5 continuous seconds and pressure does not increase above $0.51 \mathrm{~b} / \mathrm{in}^{2}$ gauge (using same instruments) within 5 minutes. This condition is reset when MCO pressure is $\geq$ $0.5 \mathrm{lb} / \mathrm{in}^{2}$ gauge as measured by PT $1 * 36$ and PT $1 * 37$. 
LCO (cont inued)
These LCO limits of $\leq-11.1 \mathrm{lb} / \mathrm{in}^{2}$ gauge and $\geq 0.5 \mathrm{lb} / \mathrm{in}^{2}$ gauge are based on the safety analys is 1 imit values of $\leq$ $-10.8 \mathrm{lb} / \mathrm{in}^{2}$ gauge and $\geq 0.24 \mathrm{lb} / \mathrm{in}^{2}$ gauge adjusted for instrument uncertainty (refer to SNF-4451). This is an indication of a system leak as the pressure rise should be rapid, considering helium flow is set to a very high rate. The contact opens if the timeout is reached. This control is required during the following MCO process operations: (5) Drying, (6) Proof, and (7) Pressure Test.

MCO 12 torr purge bypass - An MCO low purge flow trip logic bypass is provided when MCO pressure, as read on PT $1 * 08$ (train A) and PT $1 * 10$ (train B) is below 8.0 torr for a continuous period of 10 seconds. The LCO setpoint value of $\leq 8$ torr is based on the safety analysis limit value of $\leq 12$ torr adjusted for instrument uncertainty (refer to SNF-4451). This control is required during the following MCO process operations: (5) Drying, and (6) Proof.

MCO pre-purge - A continuous helium purge flow rate as measured from FIT $1 * 20$ (train A) or FIT $1 * 21$ (train B) of $\geq 8.4$ standard $\mathrm{ft}^{3} /$ min must be met for approximately 15 minutes to bypass the MCO low pressure trip. Once the bypass is set, the contact only opens when MCO pressure is $<0.5 \mathrm{lb} / \mathrm{in}^{2}$ gauge as read on PT $1 * 36$ (train A) and PT $1 * 37$ (train B). The LCO setpoint value of $\geq 8.4$ standard $\mathrm{ft}^{3} / \mathrm{min}$ is based on the safety analysis 1 imit value of $\geq$ 8.0 standard $\mathrm{ft}^{3} /$ min adjusted for instrument uncertainty (refer to SNF-4451). The SCIC system will isolate the MCO and actuate a SCHe purge if vacuum is entered without satisfying the pre-purge. This control is required during the following MCO process operations: (5) Drying, and (6) Proof.

MCO low purge flow - If helium flow as measured from FIJ $-1 * 20(\operatorname{train} A)$ or FIT $1 * 21$ (train $B)$ is < 1.1 standard $\mathrm{ft}^{3} /$ min the contact opens. The LCO setpoint value of $\geq$ 1.1 standard $\mathrm{ft}^{3} / \mathrm{min}$ is based on the safety analysis 1 imit value of $\geq 0.7$ standard $\mathrm{ft}^{3} / \mathrm{min}$ adjusted for instrument uncertainty (refer to SNF-4451). The SCIC system will isolate the MCO and actuate a SCHe purge. This control is required during the following MCO process operations: (5) Drying, and (6) Proof. 
LCO (cont inued)
MCO low purge flow bypass - Any time the flow is below the MCO low purge flow value as described above, a bypass timer set at $\leq \mathbf{5}$ minutes shall start. Reset occurs when flow is above the low flow reset point or a manual trip reset has occurred. For post-trip conditions, there will be zero flow indicated since FIT $1 * 20$ and FIT $1 * 21$ are isolated. To regain flow, the 5 minute bypass (MCO low purge flow bypass) is enabled at 5 minutes, allowing for reestablishment of normal flow through the MCO. This control is required during the following MCO process operations: (5) Drying, and (6) Proof.

TW (annulus water) high temperature - The SCIC system monitors the TW system annulus inlet water temperature switches $\mathrm{TSH}-1 * 28$ (train A) and TSH $-1 * 29$ (train B). If the temperature is $>48.1{ }^{\circ} \mathrm{C}$ then a contact opens on the TW system annulus inlet water temperature high switch. The LCO setpoint value of $\leq 48.1{ }^{\circ} \mathrm{C}$ is based on the safety analysis limit value of $\leq 50.0{ }^{\circ} \mathrm{C}$ adjusted for instrument accuracy and drift (refer to SNF-4451). Upon receipt of this input signal, the SCIC system (TW high temperature protection circuit) (either train A or B) provides an output signal to de-energize the TW heater contacts for that specific train. This control is required during the following MCO process operations: (2) Heatup, (3) Drain, (4) Purge/Flush, (5) Drying, (6) Proof, and (7) Pressure Test. 
LCO

(cont inued)
Annulus low water level alarm - The SCIC system monitors the TW system annulus water level low switch. Dry electrical contacts are provided from the field by the two level switch low (LSL) sensors $L S L 1 * 24$ (train $A$ ) and $L S L$ $1 * 25$ (train $B$ ) in the respective bays (Bays 2 to 5 ). These inputs open on low water level for an alarm condition. If the level is $<20 \%$ of gauge then a contact opens on the TW system annulus water level low switch providing an input signal to the SCIC system. The LCO setpoint value of $\geq 20 \%$ is based on the safety analysis requirement to have water levels at or above the fuel level in the $\mathrm{MCO}$, adjusted for instrument uncertainty and instrument range (refer to SNF-4451). Upon receipt of this input signal, the SCIC system provides an output signal to an alarm in the CVDF control room on the SCIC annunciator pane]. The operators take action based on receipt of the low level alarm to restore water level in the annulus. This control is required during the following MCO process operations: (2) Heatup, (3) Drain, (4) Purge/Flush, (5) Drying, (6) Proof, and (7) Pressure Test.

High bay temperature - A trip on bay temperature $>89^{\circ} \mathrm{F}$ is provided from the field contact for high bay temperature TSHH $1 * 38$ (train A) and TSHH $1 * 39$ (train B). The LCO setpoint value of $\leq 89^{\circ} \mathrm{F}$ is based on the parameter limit value of $\leq 95{ }^{\circ} \mathrm{F}$ adjusted for instrument error and drift (refer to SNF-4451). This control is required during the following MCO process operations: (2) Heatup, (3) Drain, (4) Purge/Flush, (5) Drying, (6) Proof, and (7) Pressure Test.

Seismic trip - The seismic monitors will actuate the SCIC system trips independent of the logic. The seismic monitors directly trip to the SCIC system output relays. Seismic trip (ATR-5235, ATR-5336, ATR-5437, CP-120, and $(P-121)$, from the SCIC system will provide the following - Isolation and purge of the MCO

- De-energization of the TW (annulus) system heater The LCO setpoint value of $\leq 0.05 \mathrm{~g}$ is based on the safety analysis limit value of $\leq 0.06 \mathrm{~g}$ adjusted for instrument uncertainty (refer to SNF-4451). This control is required during the following MCO process operations: (1) Bypass, (2) Heatup, (3) Drain, (4) Purge/Flush, (5) Drying, (6) Proof, and (7) Pressure Test. 
LCO

(continued)
It should be noted that each trip or interlock for train $A$ or train B could only affect one train. Train A's sensors or train $B^{\prime} s$ sensors could trip or interlock its respective train only (e.g., only close one set of safetyclass MCO isolation valves which is sufficient to isolate the MCO and actuate the SCHe system).

Functional requirements for determining the OPERABILITY of the safety-class instrumentation and control system are also defined in HNF-3553, Chapter B4.0, "Safety Structures, Systems, and Components." Detailed functional. requirements for determining the OPERABILITY of the system may be found in procedures.
MODE

APPLICABILITY
LCO 3.1.1 applies in process bay OPERATION SUBMODE because MCOs located within the CVDF are allowed in this MODE. LCO 3.1.1 does not apply in process bay STANDBY or REPAIR SUBMODES because MCOs are not allowed in the process bays in these MODES.
PROCESS AREA APPLICABILITY
Specific applicability for the control functions varies according to the MCO processing steps and is consistent with the applicability of the input systems as identified in LCO 3.1.2 through LCO 3.1.7. The process area applicability for each trip, interlock, and alarm function in LCO 3.1.1 is specified for each in Table 3.1.1-1. Once the $\mathrm{MCO}$ is dried sufficiently (as demonstrated by $A C 5.17$ ) and isolated, MCO overpressurizations, thermal runaways and hydrogen explosions are no longer a hazard for the MCO. 

and Limiting Control Setting VIOLATION."

See Section 1.3, "Completion Times," for the definition of Immediately.

\section{A.1, A.2, and A.3}

When either train A or train B of the SCIC system is inoperable, Condition $A$ is entered. Condition $A$ is entered separately for each process bay and the Completion Times are tracked separately for each process bay. Condition A requires Required Actions A.1, A.2, and A.3 to be performed upon discovery.

Required Action A.l requires both train A and train B of the ISO \& Purge trip to be actuated within 1 hour. Actuation of the ISO \& Purge trip isolates the MCO from the process systems by de-energizing closed the eight MCO isolation valves and actuates the SCHe system by deenergizing open the four SCHe isolation valves to provide a flow of helium to the MCO.

The Completion Time of 1 hour is based on the fact that an ISO \& Purge trip should already have occurred (depending on the failure method). This allows time for operations personnel to verify the ISO \& Purge trip actuation and if the trip has not automatically occurred, allows time for operations personnel to complete this manual action in an orderly manner.

Required Action A.2 requires that the TW (annulus) system heater be de-energized within 1 hour. Normally output from the TW (annulus) system temperature instrumentation through the SCIC system would actuate a TW trip which automatically de-energizes the TW (annulus) system heater. This stops additional heat input into the annulus water when temperature is already too high. A train A and train $B$ TW trip cannot be remotely actuated from the control room so the heater in the affected process bay must be deenergized. 
ACTIONS (continued)
The Completion Time of 1 hour is based on the fact that a TW (annulus) system temperature higher than the required setpoint should have already actuated the TW trip (depending on the failure method). This allows time for operations personnel to verify the TW trip or to complete this action in an orderly manner following the MCO draining activity. This action requires operations personnel to go to de-energize the heater in the affected process bay.

Required Action A.3 requires that the inoperable SCIC system train be restored to OPERABLE status prior to resuming MCO process operations. After the ISO \& Purge trip is actuated, the helium purge flow and blanket places the MCO in a safe and stable condition. The Completion Time of prior to resuming MCO process operations allows time after helium purge is actuated to restore the SCIC train.

\section{B.1, B.2, and B.3}

When both train A and train B of the SCIC system are inoperable, Condition B is entered. Condition B is entered separately for each process bay and the Completion Times are tracked separately for each process bay. Condition B requires Required Actions B.1, B.2, and B.3 to be performed upon discovery.

Required Action B.1 requires both train A and train B of the ISO \& Purge trip to be actuated Immediately, not to exceed 1 hour. Actuation of the ISO \& Purge trip isolates the MCO from the process systems by de-energizing closed the eight $\mathrm{MCO}$ isolation valves and actuates the SCHe system by de-energizing open the four SCHe isolation valves to provide a flow of helium to the MCO.

The Completion Time of Immediately, not to exceed 1 hour is based on the fact that an ISO \& Purge trip should already have occurred (depending on the failure method). This allows time for operations personnel to verify the ISO \& Purge trip actuation and if the trip has not automatically occurred, allows time for operations personnel to complete this manual action in an orderly manner. Immediately has been used to convey the Required Action should be commenced without delay since both trains are inoperable, potentially defeating all inputs into the system. 
ACTIONS (cont inued)
SURVEILLANCE REQUIREMENTS
Required Action B.2 requires that the TW (annulus) system heater be de-energized Immediately not to exceed 1 hour. Normally output from the TW (annulus) system temperature instrumentation through the SCIC system would actuate a TW trip which automatically de-energizes the TW (annulus) system heater to stop additional heat input into the annulus water when temperature is already too high. $A$ train $A$ and train B TW trip cannot be remotely actuated so the heater must be de-energized.

The Completion Time of Immediately, not to exceed 1 hour is a reasonable time. It is based on the fact that a TW (annulus) system temperature higher than the required setpoint should have already actuated the TW trip. This allows time for operations personnel to verify the TW trip or to complete this action in an orderly manner which requires operations personnel to de-energize the heater in the affected process bay. Immediately has been used to convey the Required Action should be commenced without delay since both trains are inoperable.

Required Action $B .3$ requires that both train $A$ and train $B$ of the SCIC system be restored to OPERABLE status prior to resuming MCO process operations. After the ISO \& Purge trip is actuated, the helium purge flow and blanket places the MCO in a safe and stable condition. The Completion Time of prior to resuming MCO process operations allows time after helium purge is actuated to restore the SCIC trains. 
SURVEILLANCE REQUIREMENTS (cont inued) $\underline{\text { SR 3.1.1.1 }}$

SR 3.1.1.1 requires that a channel FUNCTIONAL TEST for functions 1 isted in Table 3.1.1-2 be performed quarterly. The channel FUNCTIONAL TEST can be accomplished by using the key switch on each local control panel and placing it in the test position and pushing the associated test button to simulate the event trips (i.e., TW high temperature, bay high temperature, and annulus low level). Train $A$ and train $B$ of each logic test must be conducted for process bays $2,3,4$, and 5 .

A FUNCTIONAL TEST of the manual ISO \& Purge trip for each process bay shall also be conducted. This test includes manual ISO \& Purge trip initiation from the CVDF Control Room as well as from the local control panels in the process bays. The CVDF Control Room contains two manual ISO \& Purge trip actuation switches for each train in each process bay (2-5) and the local control panels have a manual ISO \& Purge actuation button. Train A and train B must be tested for each process bay.

In addition, the seismic trip FUNCTIONAL TEST can be accomplished by using the test buttons on both of the auctioneering circuit panels located in process bay 1 to simulate the seismic event trips. Each panel has three test buttons, one for each of the sensors, so individual failure as well as multiple failures to simulate the auctioneering logic can be performed. The seismic trip applies to all of CVDF (rather than individual process bays) and train A and train B for CVDF must be tested.

These FUNCTIONAL TESTS will include some of the SCIC system relay logic (but does not include testing of the PLC) and includes the output devices (i.e., closed valves, opened valves, de-energized heater, and Control Room alarms). The FUNCTIONAL TEST does not include the sensors (e.g., accelerometers). 
SURVEILLANCE REQUIREMENTS (continued)
The Frequency of quarterly was selected to provide additional testing in the interval period between the annual CALIBRATIONS. Since the FUNCTIONAL TEST is actuating all of the output devices the performance interval is reasonable without excessively disrupting normal MCO process operations. Failure mode and reliability data after a year of operation can be evaluated to determine if performance of the quarterly FUNCTIONAL TEST should be relaxed to annually.

\section{SR 3.1.1.2}

SR 3.1.1.2 requires a loop CALIBRATION of the SCIC system programmable logic controller (PLC) be performed annually. Performance of the CALIBRATION includes the FUNCTIONAL TEST so a separate FUNCTIONAL TEST does not need to be performed per SR 3.1.1.1 on the annual frequency since it can be accomplished using the Calibration and Test Computer (CTC). The CALIBRATION of the PLC will demonstrate that each of the trip, interlock, and alarm functions listed in Table 3.1.1-1 can be accomplished at the specified setpoints.

SR 3.1.1.2 applies in a variety of conditions depending on the trip, interlock or alarm function and is specified for each in Table 3.1.1-1. Also the instrument numbers, the setpoints and functional performance requirements are identified in the table. Surveillance Requirements for CALIBRATION of the individual sensors is required per LCO 3.1.2 through LCO 3.1.7.

The CTC can be used during the annual calibration and testing to assure all PLC functions as well as external control functions are operational. The CTC can display the inputs and outputs to/from the PLC. The CTC has the ability to individually trip selected analog or digital input signals to simulate actual field upset conditions. Regarding the automatic test sequences, the CTC can step through the various control operation processes (e.g., heatup, drain, purge/flush, drying, proof, and pressure) to demonstrate the logic at each operation process. 
SURVEILLANCE REQUIREMENTS (cont inued)
The specified SRs for a FUNCTIONAL TEST and CALIBRATION of the SCIC system is to confirm OPERABILITY of the system trains which will involve comparing actual signal or injecting simulated pressure, temperature, flow, and level signal inputs. Status display at the local panel and tripped alarm indicator that illuminates in the control Room can be VERIFIED.

The Frequency of annually is based on the interval assumed in the setpoint determination calculation which is based on vendor recommended intervals for performing CALIBRATIONS.

\section{REFERENCES}

HNF-3553, 1999, Spent Nuclear Fuel Project Final Safety Analysis Report, Rev. 0, Annex B, "Cold Vacuum Drying Facility Final Safety Analysis Report, "Fluor Daniel Hanford, Incorporated, Richland, Washington.

SNF-2770, 1999, Cold Vacuum Drying Facility Design Basis Accident Analysis Documentation, Rev. 2, Fluor Daniel Hanford, Incorporated, Richland, Washington.

SNF-4451, 1999, Cold Vacuum Drying (CVD) Set Point Determination, Rev. OA, Fluor Daniel Hanford, Incorporated, Richland, Washington. 


\section{B 3.1 INSTRUMENTATION}

\section{B 3.1.2 Vacuum Purge System Pressure Instrumentation}

BASES

BACKGROUND

This LCO ensures OPERABILITY of the vacuum purge system (VPS) pressure instrumentation PT $1 * 36$, PT $1 * 37$, PT $1 * 08$ and PT $1 * 10$. The VPS line pressure monitoring is designed to monitor the helium pressure in the VPS line on the process vent side of the multi-canister overpack (MCO) and provide input to the safety-class instrumentation and control (SCIC) system to isolate the MCO and actuate the safety-class helium (SCHe) system upon an improper pressure condition. The pressure in the VPS line is intended to provide an indication of the pressure inside the MCO.

When vacuum drying, excessive durations under vacuum or insufficient intermediate durations at pressure can place the MCO outside the analyzed envelop of existing thermal analysis for safe operations. In addition, an unexpected pressure rise (e.g., caused by inleakage) during vacuum drying, as well as low or high MCO pressures when the MCO is in pressure operations, indicate undesirable process conditions (e.g., process system leaks or vacuum pump degradation) that could eventually lead to process upsets. The input from these pressure instruments to the SCIC system is relied upon to respond to these conditions. Ensuring the capability to detect vacuum cycles exceeding allowable durations, pressure operation cycles of less than allowable durations, unexpected pressure rises when vacuum-purge drying, and $10 \mathrm{w}$ and high system pressures when in pressure operations provides necessary input to the SCIC system (LCO 3.1.1).

APPLICABLE SAFETY ANALYSES
LCO 3.1.2 is required for three accident scenarios:

(1) Multi-Canister Overpack Internal Hydrogen Explosion,

(2) Multi-Canister Overpack Thermal Runaway Reaction, and

(3) Multi-Canister Overpack Overpressurization. 


\section{APPL ICABLE SAFETY ANALYSES (continued)}

\section{Multi-Canister Overpack Internal Hydrogen Explosion}

A hydrogen explosion inside an MCO is analyzed in SNF-2770, Cold Vacuum Drying Facility Design Basis Accident Analysis Documentation, and the results of the analysis are presented in HNF-3553, Spent Nuclear Fuel Project Final Safety Analysis Report, Annex B, "Cold Vacuum Drying Facility Final Safety Analysis Report," Chapter B3.0, "Hazard and Accident Analyses." Based on the results of the analysis, the unmitigated release of radiological material could exceed onsite risk evaluation guidelines.

In this postulated accident scenario, a hydrogen explosion occurs because of a hydrogen-air mixture inside an MCO. The vacuum purge system pressure instrumentation is credited in the analysis to provide $\mathrm{MCO}$ pressure information to the SCIC system to initiate MCO isolation and $\mathrm{SCHe}$ system actuation during process upset conditions.. When vacuum drying, excessive durations under vacuum or insufficient intermediate durations at pressure can place the MCO outside the analyzed envelop of existing thermal analysis for safe operation. In addition, an unexpected pressure rise during vacuum drying, as well as low or high MCO pressures when the MCO is in pressure operations, indicate undesirable process conditions that could eventually lead to process upsets. The SCIC system is relied upon to initiate MCO isolation and SCHe system actuation to respond to these conditions.

\section{Multi-Canister Overpack Thermal Runaway Reaction}

Thermal runaway reactions inside an $M C O$ are analyzed in SNF-2770, Cold Vacuum Drying Facility Design Basis Accident Analysis Documentation, and the results of the analys is are presented in HNF-3553, Spent Nuclear Fuel Project Final Safety Analysis Report, Annex B, "Cold Vacuum Drying Facility Final Safety Analys is Report," Chapter B3.0, "Hazard and Accident Analyses." Based on the results of the analysis, the unmitigated release of radiological material could exceed offsite release limits and onsite risk evaluation guidelines. 
APPLICABLE SAFETY ANALYSES (cont inued)
In this postulated accident scenario, a thermal runaway reaction occurs from insufficient heat removal from the inside of the MCO. The vacuum purge system pressure instrumentation is credited in the analysis to provide $M C O$ pressure information to the SCIC system to initiate MCO isolation and SCHe system actuation during process upset conditions. When vacuum drying, excessive durations under vacuum or insufficient intermediate durations at pressure can place the MCO outside the analyzed envelop of existing thermal analysis for safe operation. In addition, an unexpected pressure rise (e.g., caused by inleakage) during vacuum drying, as well as low or high MCO pressures when the $\mathrm{MCO}$ is in pressure operations, indicate undesirable process conditions that could eventually lead to process upsets. The SCIC system is relied upon to initiate MCO isolation and SCHe system actuation to respond to these conditions.

\section{Multi-Canister Overpack Overpressurization}

Overpressurization of an MCO is analyzed in SNF-2770, Cold Vacuum Drying Facility Design Basis Accident Analysis Documentation, and the results of the analysis are presented in HNF-3553, Spent Nuclear Fuel Project Final Safety Analysis Report, Annex B, "Cold Vacuum Drying Facility Final Safety Analysis Report," Chapter B3.0, "Hazard and Accident Analyses." Based on the results of the analysis, the unmitigated release of radiological material could exceed offsite release limits and onsite risk evaluation guidelines.

In this postulated accident scenario, a high-pressure release of radioactive material results from MCO isolation and a resulting high MCO internal pressure. The vacuum purge system pressure instrumentation is credited in the analys is to provide MCO pressure information to the SCIC system to initiate MCO isolation and SCHe system actuation during process upset conditions. The SCIC system provides a high pressure trip based on the MCO internal pressure. 
The vacuum purge system pressure instrumentation is required to be OPERABLE to provide the capability to sense MCO internal pressure and transmit the information to the SCIC system. The vacuum purge system pressure instrumentation includes PT $1 * 36$, PT $1 * 37$, PT $1 * 08$, and PT $1 * 10$. PT $1 * 36$ and PT $1 * 37$ provide input for the MCO high pressure trip, MCO low pressure trip, vacuum limit timer, MCO pressure decay fail trip, and MCO pressure rise fail trip. PT $1 * 08$ and PT $1 * 10$ provide input for the MCO 12 torr purge bypass. Additional discussion of the trip, interlock, and alarm functions provided by the SCIC system based on input from these PT instruments is provided in the Bases for LCO 3.1.1, "Safety-Class Instrumentation and Control System". Failure of any instrument renders the vacuum purge system pressure input to the associated SCIC train (A or B) inoperable.

Functional requirements for determining the OPERABILITY of the vacuum purge system pressure instrumentation are al so defined in HNF-3553, Chapter B4.0, "Safety Structures, Systems, and Components." Detailed functional requirements for determining the OPERABILITY of the instrumentation may be found in procedures.

MODE APPLICABILITY

LCO 3.1.2 app 7 ies in process bay OPERATION SUBMODE because MCOs located within the Cold Vacuum Drying Facility (CVDF) are allowed in this MODE. LCO 3.1.2 does not apply in process bay STANDBY or REPAIR SUBMODES because MCOs are not allowed in the process bays in these MODES. 
PROCESS AREA APPLICABILITY
LCO 3.1.2 applies to process bays in OPERATION SUBMODE from the time the MCO filtered process exit port valve is opened until successful completion of the final pressure rebound test (AC 5.17, "Dryness Testing") and both MCO process tube plug valves are closed. Once the MCO is dried sufficiently (as demonstrated by $A C$ 5.17) and isolated, MCO overpressurization, thermal runaways and hydrogen explosions are no longer a hazard for the CVDF.

A note has been included that indicates entry into the ACTIONS for PT $1 * 08$ and PT $1 * 10$ is not required unless draining and purge/flush activities have been completed. PT $1 * 08$ and PT $1 * 10$ provide input for the MCO 12 torr purge bypass which is only required during drying and proof activities. This note allows draining and purge/flush activities to be initiated, performed, and completed since PT $1 * 08$ and PT $1 * 10$ pressure input to the SCIC system is not required for these activities.

\section{ACTIONS}

Failure to take the ACTIONS required within the required time limit following failure to meet the LCO is a VIOLATION. For this situation, proceed in accordance with AC 5.4.3, "Response to a Limiting Condition for Operation and Limiting Control Setting VIOLATION."

\section{A. 1 and $A .2$}

When either PT $1 * 36$ or PT $1 * 37$ is inoperable, Condition A is entered. Condition $A$ is entered and tracked separately for each process bay. Condition A requires Required Actions $A .1$ and A.2 to be performed upon discovery.

Required Action A.1 requires both train $A$ and train $B$ of the ISO \& Purge trip to be actuated within 1 hour. Actuation of the ISO \& Purge trip isolates the MCO from the process systems by de-energizing closed the eight MCO isolation valves and actuates the SCHe system by deenergizing open the four SCHe isolation valves to provide a flow of helium to the MCO. I solation of the MCO from CVDF processing systems ( 1 ines $\mathrm{Di} / \mathrm{He}-{ }^{*} 01-S S$, VPS-*02-SS, and PWC-*01-SS) prevents 1 ine breaks (which could go undetected due to the loss of pressure instrumentation) from affecting the MCO. Actuation of the SCHe system establishes an initial purge of the MCO followed by a helium blanket, and opens a pressure vent path from the MCO headspace to the local exhaust system. 
ACTIONS (cont inued)
The Completion Time of 1 hour is based on the fact that an ISO \& Purge trip should al ready have occurred (depending on the failure method). This allows time for operations personnel to verify the ISO \& Purge trip actuation and if the trip has not automatically occurred, allows time for operations personnel to complete this manual action in an orderly manner.

Required Action A. 2 requires that the instrumentation be restored to OPERABLE status prior to resuming MCO process operations. Once the MCO is isolated from non-safety systems and a reliable vent path established to relieve any pressure caused through hydrogen generation, the MCO is in a safe and stable condition. (The presence of hel ium may also be dictated for those MCOs which have begun draining. The trip of the safety-class instrumentation and control system isolation and purge function will accomplish this at the same time it establishes a vent path.) The Completion Time of prior to resuming MCO process operation allows time after the safe and stable state is reached to restore the required instrumentation.

\section{B. 1 and B.2}

When both PT $1 * 36$ and PT $1 * 37$ are inoperable, Condition B is entered. Condition $B$ is entered and tracked separately for each process bay. Condition $B$ requires Required Actions B.1 and B.2 to be performed upon discovery.

Required Action B.1 requires both train $A$ and train $B$ of the ISO \& Purge trip to be actuated within 1 hour. Actuation of the ISO \& Purge trip isolates the MCO from the process systems by de-energizing closed the eight MCO isolation valves and actuates the SCHe system by deenergizing open the four $\mathrm{SCHe}$ isolation valves to provide a flow of helium to the MCO. Isolation of the MCO from CVDF processing systems ( 1 ines $\mathrm{Di} / \mathrm{He}-* 01-\mathrm{SS}$, VPS $-* 02-S S$, and PWC-*01-SS) prevents line breaks (which could go undetected due to the loss of pressure instrumentation) from affecting the MCO. Actuation of the SCHe system establishes an initial purge of the MCO followed by a helium blanket, and opens a pressure vent path from the MCO headspace to the local exhaust system. 
ACTIONS

(continued)
The Completion Time of 1 hour is based on the fact that an ISO \& Purge trip should already have occurred (depending on the failure method). This allows time for operations personnel to verify the ISO \& Purge trip actuation and if the trip has not automatically occurred, allows time for operations personnel to complete this manual action in an orderly manner.

Required Action B. 2 requires that the instrumentation be restored to OPERABLE status prior to resuming MCO process operations. Once the $M C O$ is isolated from non-safety systems and a reliable vent path established to relieve any pressure caused through hydrogen generation, the MCO is in a safe and stable condition. (The presence of helium may also be dictated for those MCOs which have begun draining. The trip of the safety-class instrumentation and control system isolation and purge function will accomplish this at the same time it establishes a vent path.) The Completion Time of prior to resuming MCO process operations allows time after the safe and stable state is reached to restore the required instrumentation.

\section{1 and $C .2$}

When either PT $1 * 08$ or PT $1 * 10$ or both PT $1 * 08$ and PT $1 * 10$ are inoperable, Condition $C$ is entered. Condition $C$ is entered separately for each process bay and the Completion Times are tracked separately for each process bay. Condition $C$ requires Required Actions $C .1$ and $C .2$ to be performed upon discovery. 
ACTIONS (cont inued)
Required Action C.l establishes a positive pressure in the MCO and purge flow through the MCO from the primary helium supply through the normal processing path. This must be performed within 1 hour. Required Action C.l establishes a vent path from the MCO headspace to the local exhaust system. Because of the note included in the Process Area Applicability section, Required Actions C.l and C.2 would not be entered unless draining and purge/flush activities have been completed. Therefore, there are no restrictions during draining and purge/flush so MCO process operations can continue. However, upon entry into drying, the inoperable instrument must be restored before entering MCO vacuum operations. If the instruments become inoperable during vacuum operations then establishing a purge flow exits the vacuum condition where the instruments are required and the inoperable instruments must be restored before vacuum operations can be resumed.

Once vacuum operations are started, a vacuum purge system pressure not meeting the required setpoint should have already actuated the ISO \& Purge trip (depending on the failure method). The Completion Time of 1 hour allows time for operations personnel to verify the ISO \& Purge trip actuation and if the trip has not automatically occurred allows time for operations personnel to complete this manual action in an orderly manner.

Required Action $C .2$ requires that the instrumentation be restored to OPERABLE status prior to placing the MCO in vacuum operations. Once a reliable vent path is established to relieve any pressure caused through hydrogen generation, the $M C O$ is in a safe and stable condition. The Completion Time of prior to placing the MCO in vacuum operations allows time after the safe and stable state is reached to restore the required instrumentation. 
SURVEILLANCE REQUIREMENTS
Failure to successfully meet the SR (i.e., SR acceptance criteria not satisfied) during the Surveillance or between performances of the Surveillance is a failure to meet the LCO. For this situation, entry into the LCO ACTIONS is required. Failure to perform the Surveillance within the specified Frequency (including the allowable 25\% extension) is a VIOLATION. For this situation, proceed in accordance with AC 5.4.4.2, "Failure to Perform an SR Within the Required Time Limit."

\section{SR 3.1.2.1}

SR 3.1.2.1 requires that a CHANNEL CHECK be performed for PT $1 * 36$ and PT $1 * 37$ and a CHANNEL CHECK also be performed for PT $1 * 08$ and PT $1 * 10$ within 1 day prior to entering process bay OPERATION SUBMODE. A jumper shall be used between process connections on the hood to simulate MCO process operations. This allows a qualitative assessment (through observation) of channel behavior to be made between two separate instruments in a process bay which are monitoring the same parameter. The comparison can be made using information from the monitoring and control system (MCS) to compare data between train $A$ and train $B$ instruments.

The Frequency of within 1 day prior to entering process bay OPERATION SUBMODE was selected because it provides additional assurance that the instrumentation required for MCO process operation is OPERABLE shortly before an MCO enters each process bay. The setpoint determination only included an annual CALIBRATION so this test provides additional indication of instrumentation OPERABILITY in the interval between the CALIBRATIONS.

This SR is performed before the LCO becomes applicable so if the instrumentation is determined to be inoperable, it can be restored to OPERABLE status before it is required for MCO process operations. 
SURVEILLANCE REQUIREMENTS (cont inued)

\section{$\underline{S R ~ 3.1 .2 .2 ~}$}

SR 3.1.2.2 requires an instrument CALIBRATION be performed on PT $1 * 36$, PT $1 * 37$, PT $1 * 08$, and PT $1 * 10$ annual ly. The specified SR to perform a CALIBRATION on each of the vacuum purge system pressure instrumentation will confirm OPERABILITY prior to processing operations. VERIFICATION of the sensor setpoints ensures that the instruments will function consistent with the assumptions from the safety analysis. Performance of the CALIBRATION will measure and record the as-found sensor actuation value. If the as-found value is outside the allowable value, the sensor will be reset.

The Frequency of CALIBRATIONS of safety-related vacuum purge system pressure instrumentation is consistent with manufacturer's recommendations, the assumptions made in the setpoint determination for an annual calibration and the Frequencies for such Surveillance of protection and safeguards instrumentation in commercial nuclear power plants.

REFERENCES

HNF-3553, 1999, Spent Nuclear Fuel Project Final Safety Analysis Report, Rev. O, Annex B, "Cold Vacuum Drying Facility Final Safety Analysis Report, "Fluor Daniel Hanford, Incorporated, Richland, Washington.

SNF-2770, 1999, Cold Vacuum Drying Facility Design Basis Accident Analysis Documentation, Rev. 2, Fluor Daniel Hanford, Incorporated, Richland, Washington. 


\section{B 3.1 INSTRUMENTATION}

\section{B 3.1.3 General-Service Helium System Flow Instrumentation}

BACKGROUND

This LCO ensures OPERABILITY of the general-service helium system flow instrumentation. Maintaining general-service helium system flow prevents the multi-canister overpack (MCO) internal hydrogen explosion caused by buildup of flammable concentrations of hydrogen. The redundant flow elements and flow indicating transmitters, FIT $1 * 20$ (train A) and FIT $1 * 21$ (train B) are located in the hard piping line outside the MCO isolation valves.

Low helium purge flows after MCO draining is complete indicate undesirable process conditions (e.g., insufficient hydrogen dilution or an isolated $\mathrm{MCO}$ configuration) that could eventually lead to an MCO internal hydrogen explosion. The safety-class instrumentation and control (SCIC) system is relied upon to respond to these conditions. Ensuring the capability to provide flow indication to the SCIC system to detect low helium purge flows provides necessary input to the SCIC system.

The SCIC system compares the helium flow input information to the trip setpoint for the MCO process operation and if the helium flowrate is less than the required setpoint (depending on the MCO process operation) the SCIC system initiates $\mathrm{MCO}$ isolation and actuates the SCHe system.

The MCO Low Purge Flow trip in the SCIC system (LCO 3.1.1), will be initiated if flow is below the setpoint when required. This flow rate or greater assures low hydrogen levels during drying and proof. The setpoint is based on achieving equilibrium hydrogen levels below the lower flammability limit (LFL).

The MCO Pre-purge trip in the SCIC system (LCO 3.1.1), will detect a low purge flow rate or inadequate time of purge prior to achieving a vacuum in the MCO. The MCO Low Pressure trip is active; however, the MCO Pre-purge bypasses this trip if the MCO pre-purge is complete. This trip assures that the gas in the MCO is below the LFL for hydrogen prior to obtaining a vacuum which could introduce oxygen should an undetected leak be present. 
APPLICABLE SAFETY ANALYSES
LCO 3.1.3 is required for one accident scenario:

Multi-Canister Overpack Internal Hydrogen Explosion.

\section{Multi-Canister Overpack Internal Hydrogen Explosion}

A hydrogen explosion inside an MCO is analyzed in SNF-2770, Cold Vacuum Drying Facility Design Basis Accident Analysis Documentation, and the results of the analysis are presented in HNF-3553, Spent Nuclear Fuel Project Final Safety Analysis Report, Annex B, "Cold Vacuum Drying Facility Final Safety Analys is Report," Chapter B3.0, "Hazard and Accident Analyses." Based on the results of the analysis, the unmitigated release of radiological material could exceed onsite risk evaluation guidelines.

In this postulated accident scenario, a hydrogen explosion occurs because of a hydrogen-air mixture inside an MCO. The general-service helium system flow instrumentation is credited in the analys is to provide helium flow information to the SCIC system. Low helium purge flows after MCO draining is complete, indicate undesirable process conditions (e.g., insufficient hydrogen dilution) that could lead to process upsets. The SCIC system is relied upon to isolate the $\mathrm{MCO}$ and actuate the $\mathrm{SCHe}$ system. (FIT $1 * 20$ and FIT $1 * 21$ ) is required to be OPERABLE to provide the capability to sense the helium flow rate and transmit the information to the SCIC system. FIT $1 * 20$ and FIT $1 * 21$ provide input for the MCO pre-purge, MCO low purge flow, and MCO low purge flow bypass. Additional discussion of the trip, interlock, and alarm functions provided by the SCIC system based on input from these FIT instruments is provided in the Bases for LCO 3.1.1, "Safety-Class Instrumentation and Control System". Failure of any instrument renders the helium flow rate input to the associated SCIC train (A or B) inoperable.

Functional requirements for determining the OPERABILITY of the general-service helium system flow instrumentation are al so defined in HNF-3553, Chapter B4.0, "Safety Structures, Systems, and Components." Detailed functional requirements for determining the OPERABILITY of the system may be found in procedures. 
MODE

APPLICABILITY
LCO 3.1.3 applies in process bay OPERATION SUBMODE because MCOs located within the Cold Vacuum Drying Facility (CVDF) are allowed in this MODE. LCO 3.1 .3 does not apply in process bay STANDBY or REPAIR SUBMODES because MCOS are not allowed in the process bays in these MODES.
PROCESS AREA APPLICABILITY
LCO 3.1 .3 applies to process bays in OPERATION SUBMODE from the time the MCO long axial process tube port valve is opened until successfui completion of the proof-ofdryness demonstration (AC 5.17, "Dryness Testing"). At the start of the final pressure rebound test, the flow path through the $\mathrm{MCO}$ is isolated to preclude any water addition to the MCO. Once the MCO is sufficiently dried (as demonstrated by $A C$ 5.17), helium flow is no longer required because of the low amount of bulk water available to generate pressure and the low hydrogen generation rate within the MCO.

Although general-service helium flow is not a process variable of concern until drying operations are begun, the LCO applies when MCO process connections are made. The process of drying an MCO is very sequence and duration oriented. It is important to ensure that all equipment needed throughout the process is available prior to beginning processing. The applicability of this LCO reflects this fact. This minimizes the possibility for unintentional entry into LCO Conditions. (For example, if draining was begun with inoperable flow instrumentation because the flow instrumentation was not required at this stage, then upon completion of the drain, the facility could find itself unintentionally in a Condition with inoperable equipment as the process necessarily progressed to the next processing sequence.)

ACTIONS

Failure to take the ACTIONS required within the required time limit following failure to meet the $\mathrm{LCO}$ is a VIOLATION. For this situation, proceed in accordance with AC 5.4.3, "Response to a Limiting Condition for Operation and Limiting Control Setting VIOLATION." 
ACTIONS (cont inued)
A.1, A.2, and A.3

When either FIT $1 * 20$ or FIT $1 * 21$ is inoperable or both FIT $1 * 20$ and FIT $1 * 21$ are inoperable, Condition $A$ is entered. Condition $A$ is entered separately for each process bay and the Completion Times are tracked separately for each process bay. Condition $A$ requires Required Actions A.1, A.2, and A.3 to be performed upon discovery.

Required Action $A .1$ requires both train $A$ and train $B$ of the ISO \& Purge trip to be actuated within 1 hour. Actuation of the ISO \& Purge trip isolates the MCO from the process systems by de-energizing closed the eight MCO isolation valves and actuates the SCHe system by deenergizing open the four SCHe isolation valves to provide a flow of helium to the MCO. Isolation of the MCO from CVDF processing systems (1 ines $\mathrm{Di} / \mathrm{He}-{ }^{*} 01-S S$, VPS-*02-SS, and PWC-*01-SS) prevents line breaks (which could allow air ingress without appropriate general service helium flow) from affecting the MCO. Actuation of the SCHe system establishes an initial purge of the MCO followed by a helium blanket, and opens a pressure vent path from the MCO headspace to the local exhaust system.

The Completion Time of 1 hour is based on the fact that an ISO \& Purge trip should already have occurred (depending on the failure method). This allows time for operations personnel to verify the ISO \& Purge trip actuation and if the trip has not automatically occurred, allows time for operations personnel to complete this manual action in an orderly manner.

Required Action A.2 requires that the Tempered Water (TW) (annulus) system heater be de-energized in 12 hours. Turning off the TW (annulus) system heater allows the water in the annulus to cool down which reduces the hydrogen ( $f 7$ ammable gas) generation rate thereby reducing hydrogen venting from the MCO to the local exhaust system. De-energizing the TW (annulus) system heater is not a credited function when the flow instrumentation is inoperable but was included as an added measure of safety. Reducing temperatures minimizes the hydrogen generation rate. The Completion Time of 12 hours allows time to restore the instrumentation to OPERABLE status before the heater is de-energized which may result in certain process operations (e.g., heatup) having to be performed again.

(continued) 
ACTIONS (cont inued)
Required Action A.3 requires that the instrumentation be restored to OPERABLE status prior to resuming MCO process operations. After the TW (annulus) system heater is de-energized, the hydrogen (flammable gas) generation rate is reduced. Also the helium purge flow places the MCO in a safe and stable condition. The Completion Time of prior to resuming MCO process operations allows time after helium purge is actuated and the heater is turned off to restore the required instrumentation.
SURVEILLANCE REQUIREMENTS
Failure to successfully meet the SR (i.e., SR acceptance criteria not satisfied) during the Surveillance or between performances of the Surveillance is a failure to meet the LCO. For this situation, entry into the LCO ACTIONS is required. Failure to perform the Surveillance within the specified Frequency (including the allowable 25\% extension) is a VIOLATION. For this situation, proceed in accordance with AC 5.4.4.2, "Failure to Perform an SR Within the Required Time Limit."

\section{$\underline{S R ~ 3.1 .3 .1 ~}$}

SR 3.1.3.1 requires that a CHANNEL CHECK be performed for FIT $1 * 20$ and FIT $1 * 21$ within 1 day prior to entering process bay OPERATION SUBMODE. A jumper shall be used between process connections on the hood to simulate MCO process operations. This allows a qualitative assessment (through observation) of channel behavior to be made between two separate instruments in a process bay which are monitoring the same parameter. The comparison can be made using information from the monitoring and control system (MCS) to compare data between train $A$ and train $B$ instruments.

The Frequency of within 1 day prior to entering process bay OPERATION SUBMODE was selected because it provides additional assurance that the instrumentation required for MCO process operation is OPERABLE shortly before an MCO enters each process bay. The setpoint determination only included an annual CALIBRATION so this test provides additional indication of instrumentation OPERABILITY in the interval between the CALIBRATIONS. 
SURVEILLANCE REQUIREMENTS (cont inued)
This SR is performed before the LCO becomes applicable so if the instrumentation is determined to be inoperable, it can be restored to OPERABLE status before it is required for MCO process operations.

\section{SR 3.1.3.2}

SR 3.1.3.2 requires an instrument CALIBRATION be performed on FIT $1 * 20$ and FIT $1 * 21$ annually. The specified SR to perform a CALIBRATION on each of the general-service helium flow instruments will confirm OPERABILITY prior to processing operations. VERIFICATION of the sensor setpoints ensures that the instruments will function consistent with the assumptions from the safety analysis. Performance of the CALIBRATION will measure and record the as-found sensor actuation value. If the as-found value is outside the allowable value, the sensor will be reset.

The Frequency of CALIBRATIONS of safety-related generalservice helium flow instrumentation is consistent with manufacturer's recommendations, the assumptions made in the setpoint determination for an annual calibration, and the Frequencies for such Surveillance of protection and safeguards instrumentation in commercial nuclear power plants.

REFERENCES

HNF-3553, 1999, Spent Nuclear Fuel Project Final Safety Analysis Report, Rev. 0, Annex B, "Cold Vacuum Drying Facility Final Safety Analysis Report," Fluor Daniel Hanford, Incorporated, Richland, Washington.

SNF-2770, 1999, Cold Vacuum Drying Facility Design Basis Accident Analysis Documentation, Rev. 2, Fluor Daniel Hanford, Incorporated, Richland, Washington. 


\section{B 3.1 INSTRUMENTATION}

\section{B 3.1.4 Tempered Water (Annulus) System Temperature Instrumentation}

\section{BASES}

BACKGROUND. This LCO ensures OPERABILITY of the tempered water (TW) (annulus) system temperature instrumentation and that the instrumentation setpoint is $\leq 48.1^{\circ} \mathrm{C}$. This LCO prevents an multi-canister overpack (MCO) internal hydrogen explosion, an MCO thermal runaway, and an MCO overpressurization by limiting excessive TW (annulus) system heater output which limits the heat input into the cask which transfers it's heat into the MCO gas or water to the fuel.

The tempered water temperature switch is designed to detect elevated water temperature on the cask inlet line of the tempered water recirculation system. Upon detection of elevated temperatures, the system is designed to send a signal to the safety-class instrumentation and control (SCIC) system to de-energize the TW (annulus) system heater. Since all thermal analysis presented in HNF-3553, Spent Nuclear Fuel Project Final Safety Analysis Report, Annex B, "Cold Vacuum Drying Facility Final Safety Analys is Report," Chapter B3.0, "Hazard and Accident Analysis," was based on the $50{ }^{\circ} \mathrm{C}$ value, the SCIC system must actuate below this 1 imit allowing for instrument uncertainty. The temperature setpoint based on incorporation of instrument uncertainty is $48.1{ }^{\circ} \mathrm{C}$.

APPLICABLE SAFETY ANALYSES
LCO 3.1.4 is required for three accident scenarios:

(1) Multi-Canister Overpack Internal Hydrogen Explosion, (2) Multi-Canister Overpack Thermal Runaway Reaction, and (3) Multi-Canister Overpack Overpressurization. 


\section{APPLICABLE SAFETY ANALYSES (continued)}

\section{Multi-Canister Overpack Internal Hydrogen Explosion}

A hydrogen explosion inside an MCO is analyzed in SNF-2770, Cold Vacuum Drying Facility Design Basis Accident Analysis Documentation, and the results of the analysis are presented in HNF-3553, Spent Nuclear Fuel Project Final Safety Analysis Report, Annex B, "Cold Vacuum Drying Facility Final Safety Analys is Report," Chapter B3.0, "Hazard and Accident Analyses." Based on the results of the analysis, the unmitigated release of radiological material could exceed onsite risk evaluation guidelines.

In this postulated accident scenario, a hydrogen explosion occurs because of a hydrogen-air mixture inside an MCO. The TW (annulus) system temperature instrumentation is credited in the analysis to detect high water supply temperature and provide a signal to the SCIC system to initiate the TW trip that de-energizes the TW heater.

\section{Multi-Canister Overpack Thermal Runaway Reaction}

Thermal runaway reactions inside an MCO are analyzed in SNF-2770, Cold Vacuum Drying Facility Design Basis Accident Analysis Documentation, and the results of the analysis are presented in HNF-3553, Spent Nuclear Fuel Project Final Safety Analysis Report, Annex B, "Cold Vacuum Drying Facility Final Safety Analys is Report," Chapter B3.0, "Hazard and Accident Analyses." Based on the results of the analysis, the unmitigated release of radiological material could exceed offsite release limits and onsite risk evaluation guidelines.

In this postulated accident scenario, a thermal runaway reaction occurs from insufficient heat removal from the inside of the MCO. The TW (annulus) system temperature instrumentation is credited in the analys is to detect high water supply temperature and provide a signal to the SCIC system to initiate the TW trip that de-energizes the TW heater. 
APPLICABLE SAFETY ANALYSES (cont inued)

\section{Multi-Canister Overpack Overpressurization}

Overpressurization of the MCO is analyzed in SNF-2770, Cold Vacuum Drying Facility Design Basis Accident Analysis Documentation, and the results of the analysis are presented in HNF-3553, Spent Nuclear Fuel Project Final Safety Analysis Report, Annex B, "Cold Vacuum Drying Facility Final Safety Analysis Report," Chapter B3.0, "Hazard and Accident Analyses." Based on the results of the analysis, the unmitigated release of radiological material could exceed offsite release limits and onsite risk evaluation guidelines.

In this postulated accident scenario, a high-pressure release of radioactive material results from MCO isolation and a resulting high MCO internal pressure. The TW (annulus) system temperature instrumentation is credited in the analysis to detect high water supply temperature and provide a signal to the SCIC system to initiate the TW trip that de-energizes the TW heater.

The TW (annulus) system temperature instrumentation (TSH $1 * 28$ and TSH $1 * 29$ ) is required to be OPERABLE to provide the capability to monitor TW (annulus) system temperature and transmit information to the SCIC system when temperatures rise too high. The TW (annulus) system temperature instrumentation shall have a setpoint $\leq 48.1{ }^{\circ} \mathrm{C}$. This setpoint incorporates an expected instrument drift of $1.4{ }^{\circ} \mathrm{C}$ (representing an allowable value of $\leq 49.5{ }^{\circ} \mathrm{C}$ ), and an instrument error allowance of $0.5{ }^{\circ} \mathrm{C}$ to protect the parameter 1 imit of $50{ }^{\circ} \mathrm{C}$ assumed within the accident analysis. Failure of any instrument renders the TW (annulus) system temperature input to the associated SCIC train (A or B) inoperable.

Functional requirements for determining the OPERABILITY of the TW (annulus) system temperature instrumentation are al so defined in HNF-3553, Chapter B4.0, "Safety Structures, Systems, and Components." Detailed functional requirements for determining the OPERABILITY of the system may be found in procedures. 
MODE

APPLICABILITY
LCO 3.1.4 applies to process bays in OPERATION SUBMODE because MCOs located within the Cold Vacuum Drying Facility (CVDF) are allowed in this MODE. LCO 3.1.4 does not apply in process bay STANDBY or REPAIR SUBMODES because MCOs within the process bays are not allowed in these MODES.
PROCESS AREA APPLICABILITY
LCO 3.1.4 applies to process bays in OPERATION SUBMODE when power is being supplied to the TW (annulus) system heater. When power is supplied to the heater, excessive heater output is possible, a situation that requires detection.

ACTIONS

Failure to take the ACTIONS required within the required time limit following failure to meet the LCO is a VIOLATION. For this situation, proceed in accordance with AC 5.4.3, "Response to a Limiting Condition for Operation and Limiting Control Setting VIOLATION."

See Section 1.3, "Completion Times," for the definition of Immediately.

\section{A.1}

When either TSH $1 * 28$ or TSH $1 * 29$ is inoperable or both TSH $1 * 28$ and TSH $1 * 29$ are inoperable, Condition $A$ is entered. Condition $A$ is entered separately for each process bay and the Completion Times are tracked separately for each process bay. Condition A requires Required Action A.1 to be performed upon discovery.

Required Action A.l requires that the TW (annulus) system heater be de-energized within 1 hour. Normally output from the TW (annulus) system temperature instrumentation through the SCIC system would actuate a TW trip which automatically de-energizes the TW (annulus) system heater to stop additional heat input into the annulus water when temperature is already too high. A train A and train B TW trip cannot be remotely actuated so the heater must be de-energized. 
ACTIONS (cont inued)
The Completion Time of 1 hour is based on the fact that a TW (annulus) system temperature higher than the required setpoint should have already actuated the TW trip. This allows time for operations personnel to verify the TW trip or to complete this action in an orderly manner which requires operations personnel to de-energize the heater in the affected process bay.

Completion of Required Action A.1 removes power from the TW (annulus) system heater so the LCO would no longer be applicable. After the TW (annulus) system heater is deenergized, the source of heat input that can raise the temperature $>50{ }^{\circ} \mathrm{C}$ has been stopped and ambient losses can mitigate the heat generated from the fuel in the MCO. The tempered water temperature instrumentation would need to be restored before power could be restored to the TW (annulus) system heater.
SURVE ILLANCE REQUIREMENTS
Failure to successfully meet the SR (i.e., SR acceptance criteria not satisfied) during the Surveillance or between performances of the Surveillance is a failure to meet the LCO. For this situation, entry into the LCO ACTIONS is required. Failure to perform the Surveillance within the specified Frequency (including the allowable 25\% extension) is a VIOLATION. For this situation, proceed in accordance with AC 5.4.4.2, "Failure to Perform an SR Within the Required Time Limit."

\section{SR 3.1.4.1}

SR 3.1.4.1 requires an instrument CALIBRATION be performed on TSH $1 * 28$ and TSH $1 * 29$ quarterly. The specified SR to perform a CALIBRATION on each of the TW (annulus) system temperature instrumentation will confirm OPERABILITY prior to processing operations. VERIFICATION of the sensor setpoints ensures that the instruments will function consistent with the assumptions from the safety analysis. Performance of the CALIBRATION will measure and record the as-found sensor actuation value. If the as-found value is outside the allowable value, the sensor will be reset. 
SURVEILLANCE REQUIREMENTS

(continued)
The Frequency of CALIBRATIONS of safety-related TW (annulus) system temperature instrumentation is consistent with manufacturer's recommendations, the assumptions made in the setpoint determination for a quarterly calibration, and the Frequencies for such Surveillance of protection and safeguards instrumentation in commercial nuclear power plants.

REFERENCES

HNF-3553, 1999, Spent Nuclear Fuel Project Final Safety Analysis Report, Rev. 0, Annex B, "Cold Vacuum Drying Facility Final Safety Analysis Report," Fluor Daniel Hanford, Incorporated, Richland, Washington.

SNF-2770, 1999, Cold Vacuum Drying Facility Design Basis Accident Analysis Documentation, Rev. 2, Fluor Daniel Hanford, Incorporated, Richland, Washington. 


\section{B 3.1 INSTRUMENTATION}

\section{B 3.1.5 Tempered Water (Annulus) System Level Detector}

BACKGROUND

This LCO ensures OPERABILITY of the tempered water (TW) (annulus) system level detector to protect against the loss of sufficient heat transfer capability for the multicanister overpack (MCO) internal hydrogen explosion, MCO thermal runaway reaction, and $M C O$ overpressurization. The annulus water level switch is designed to detect low water level and alarm to the control room so manual corrective actions can be taken to realign the system and refill the annulus with water.

A low level in the Cask annulus is required to alarm if water level in the annulus drops below the level of the fuel. The physical position of the level gauges and attached switch is approximately a foot above the MCO, which is substantially above the fuel level. The level switch low alarm is set at approximately $20 \%$ of the reading of the level gauges (LG $1 * 24$ and $L G 1 * 25$ ), which assures a level alarm well above the level of the fuel. The level 1imit of $20 \%$ of gauge incorporates instrument uncertainty and protects the safety analys is assumption that the water level is above the level of the fuel. Basically any gauge indication above $10 \%$ would meet this requirement.

If the level of the Cask annulus water drops below the designated level, the low level switches (LSL $1 * 24$ and LSL $1 * 25)$ send a signal to the safety-class instrumentation and control (SCIC) system that initiates a low level alarm in the Cold Vacuum Drying Facility (CVDF) Control Room to signal the operators that the water level has dropped below the setpoint for the annulus. When the alarm is activated, corrective measures are to be taken by the operator. Additional details on these corrective measures are included in the bases for the Actions. 
APPLICABLE SAFETY ANALYSES
LCO 3.1.5 is required for three accident scenarios:

(1) Multi-Canister Overpack Internal Hydrogen Explosion,

(2) Multi-Canister Overpack Thermal Runaway Reaction, and

(3) Multi-Canister Overpack Overpressurization.

Multi-Canister Overpack Internal Hydrogen Explosion

A hydrogen explosion inside an $\mathrm{MCO}$ is analyzed in SNF-2770, Cold Vacuum Drying Facility Design Basis Accident Analysis Documentation, and the results of the analysis are presented in HNF-3553, Spent Nuclear Fuel Project Final Safety Analysis Report, Annex B, "Cold Vacuum Drying Facility Final Safety Analysis Report," Chapter B3.0, "Hazard and Accident Analyses." Based on the results of the analysis, the unmitigated release of radiological material could exceed onsite risk evaluation guidelines.

In this postulated accident scenario, a hydrogen explosion occurs because of a hydrogen-air mixture inside an MCO. The TW (annulus) system level detector is credited in the analysis to detect low water level in the cask-MCO annulus and provide a signal to the SCIC system to actuate the low-level alarm. The low-level alarm is relied upon to alert the operators to this condition so that manual corrective actions can be taken to restore TW (annulus) system water levels.

\section{Multi-Canister Overpack Thermal Runaway Reaction}

Thermal runaway reactions inside an $M C O$ are analyzed in SNF-2770, Cold Vacuum Drying Facility Design Basis Accident Analysis Documentation, and the results of the analys is are presented in HNF-3553, Spent Nuclear Fuel Project Final Safety Analysis Report, Annex B, "Cold Vacuum Drying Facility Final Safety Analysis Report," Chapter B3.0, "Hazard and Accident Analyses." Based on the results of the analysis, the unmitigated release of radiological material could exceed offsite release limits and onsite risk evaluation guidelines. 
APPLICABLE SAFETY ANALYSES (cont inued)
In this postulated accident scenario, a thermal runaway reaction occurs from insufficient heat removal from the inside of the MCO. The TW (annulus) system level detector is credited in the analysis to detect low water level in the cask-MCO annulus and provide a signal to the SCIC system to actuate the low-level alarm. The low-level alarm is relied upon to alert the operators to this condition so that manual corrective actions can be taken to restore TW (annulus) system water levels.

\section{Multi-Canister Overpack Overpressurization}

Overpressurization of the MCO is analyzed in SNF-2770, Cold Vacuum Drying Facility Design Basis Accident Analysis Documentation, and the results of the analysis are presented in HNF-3553, Spent Nuclear Fuel Project Final Safety Analysis Report, Annex B, "Cold Vacuum Drying Facility Final Safety Analys is Report," Chapter B3.0, "Hazard and Accident Analyses." Based on the results of the analysis, the unmitigated release of radiological material could exceed offsite release limits and onsite risk evaluation guidelines.

In this postulated accident scenario, a high-pressure release of radioactive material results from MCO isolation and a resulting high MCO internal pressure. The TW (annulus) system level detector is credited in the analysis to detect low water level in the cask-MCO annulus and provide a signal to the SCIC system to actuate the low-level alarm. The low-level alarm is relied upon to alert the operators to this condition so that manual corrective actions can be taken to restore TW (annulus) system water levels.

The TW (annulus) system level detector is required to be OPERABLE to provide the capability to detect low annulus water levels, transmit the information to the SCIC system, and provide local indication of TW (annulus) system water levels so that in situations in which the control room is unavailable (e.g., because of a seismic event), information on annulus water levels will still be available. Manual actions will be required to restore levels to within limits. 
LCO (cont inued)
For the TW (annulus) system level detector to be OPERABLE, the low level switches (LSL $1 * 24$ and LSL $1 * 25$ ) and the level gauges (LG $1 * 24$ and $L G 1 * 25$ ) shall be OPERABLE with an instrument setpoint $\geq 20 \%$ of gauge. The tempered water (annulus) level shall be $\geq$ the level of the fuel. Failure of any instrument renders the TW (annulus) system level input to the associated SCIC train (A or B) inoperable.

Functional requirements for determining the OPERABILITY of the TW (annulus) system level detector are also defined in HNF-3553, Chapter B4.0, "Safety Structures, Systems, and Components." Detailed functional requirements for determining the OPERABILITY of the system may be found in procedures.
MODE

APPLICABILITY
LCO 3.1 .5 applies in process bay OPERATION SUBMODE because MCOs located within the CVDF are allowed in this MODE. LCO 3.1.5 does not apply in process bay STANDBY or REPAIR SUBMODES because the MCOs with in the process bays are not allowed in these MODES.
PROCESS AREA APPLICABILITY
LCO 3.1.5 applies to process bays in OPERATION SUBMODE from the time the TW (annulus) system supply line is connected to the lower cask process port until successful completion of the final pressure rebound test (AC 5.17, "Dryness Testing"). Once the MCO is dried sufficiently (as demonstrated by AC 5.17), the MCO heat generation potential is sufficiently low that annulus water loss is no longer a safety concern.

A Note has been included such that entry into the ACTIONS may be delayed for the first 1 hour immediately following connection of the tempered water (annulus) system supply line to the lower cask process port unless annulus leakage can be visually confirmed. This Note allows a short period of time to complete the process connection operations without requiring entry into the ACTIONS. This addresses situations such as the anticipated receipt of a transient low level alarm due to air in the upper TW (annulus) system supply line. The anticipated alarm may not clear until the TW pump is started and sweeps the air out of the line. However, if leakage is detected during process connection operations then entry into the ACTIONS is required. 
ACTIONS

Failure to take the ACTIONS required within the required time limit following failure to meet the LCO is a VIOLATION. For this situation, proceed in accordance with AC 5.4.3, "Response to a Limiting Condition for Operation and Limiting Control Setting VIOLATION."

See Section 1.3, "Completion Times," for the definition of Immediately.

\section{$\underline{A .1}$}

When either LSL $1 * 24$ or LSL $1 * 25$ is inoperable, Condition $A$ is entered. Condition $A$ is entered separately for each process bay and the Completion Times are tracked separately for each process bay. Condition $A$ requires Required Action A.1 be performed upon discovery.

Required Action A.l requires that the inoperable instrumentation be restored to OPERABLE status within 5 days. With either LSL $1 * 24$ or LSL $1 * 25$ inoperable, one TW (annulus) level detector still remains OPERABLE and can provide the necessary indication of a low level condition.

Normally output from the TW (annulus) system level instrumentation through the SCIC system would actuate an Annulus Low Level Alarm. The alarm is relied upon to alert the operators to this condition so that manual corrective actions can be taken to restore TW (annulus). system water levels. With one of the level detectors remaining OPERABLE, the required safety function can still be provided. The Completion Time of 5 days is a reasonable time in which to restore the inoperable TW (annulus) system level detector to OPERABLE status while minimizing the period of time operation can continue without both detectors OPERABLE. The completion Time also recognizes that one level detector remains OPERABLE that can provide the required safety function. 
ACTIONS

(continued)

\section{B. 1 and B.2}

When both LSL $1 * 24$ and LSL $1 * 25$ are inoperable, Condition $B$ is entered. Condition B is entered separately for each process bay and the Completion Times are tracked separately for each process bay. Condition $B$ requires Required Actions B.1 and B.2 to be performed upon discovery.

Required Action B.l requires that the TW (annulus) system level be monitored once every 8 hours using an alternate method. This can be accomplished by a variety of methods. One method for monitoring the cask-MCO annulus water level during MCO processing is provided by the safety-class level gauges (LG $1 * 24$ and $L G 1 * 25$ ). These gauges (combined with the low-level switches) will detect a water leakage condition. The gauges are located on the process hood support stand for easy viewing access by the operators to alert the operator to abnormal conditions. These level gauges are also utilized during responses to low-level alarms. A TW level check petcock also allows visual verification that the cask-MCO annulus water level is above the level of the fuel in the MCO. Also the TW (annulus) system surge/holding tank level can be monitored. Tank level would be monitored to identify any changes that would indicate a potential loss of level in the TW (annulus) system level. The TW (annulus) system surge/holding tank (TW-TK-3*12) level can be monitored using $L I-3 * 04$ and there is also a high level alarm $(\mathrm{LAH}-3 * 06)$.

Normally output from the TW (annulus) system level instrumentation through the SCIC system would actuate an Annulus Low Level Alarm. The alarm is relied upon to alert the operators to this condition so that manual corrective actions can be taken to restore TW (annulus) system water levels. The Completion Time of once every 8 hours is a reasonable time to periodically monitor for level trends and indications to identify if there is a reduction in the TW (annulus) system level. 
ACTIONS (cont inued)
Required Action B.2 requires that at least one inoperable instrument be restored to OPERABLE status within 24 hours. The Completion Time of 24 hours is acceptable because Required Action B.1 provides an alternate method for monitoring level every 8 hours to identify if the TW (annulus) system level may be decreasing. When at least one of the inoperable instruments is restored to OPERABLE status, Condition $B$ may be exited and operation can continue in accordance with Condition $A$ to restore the other inoperable instrument.

\section{C.1 and $C .2$}

When the TW (annulus) system water level is < the level of the fuel, or Required Actions and associated Completion Times of Condition $A$ or $B$ are not met, Condition $C$ is entered. Condition $C$ requires Required Actions $C .1$ and C.2 to be performed upon discovery.

Required Action C.1 requires that the TW (annulus) system level be manually restored Immediately not to exceed 8 hours. When the alarm is activated, corrective measures are to be taken by the operator. If refill deionized water cannot be added through the TW (annulus) system general-service re-circulation 10op, deionized water can be manually added to the annulus through a refill connection (stub-out) on the seal ring outlet line. A vent port is provided on the seal ring to assist the manual refill process. The operator adds deionized water from a 55-gallon drum with hand truck using a hand pump and gallon bucket by pouring through a funnel at the stubout until there is a visible level out the vent port. This response requires that there is no leakage of water past the seal ring assembly seals. If there is leakage from the TW inlet line lower connection to the cask, the line can be disconnected and the cover plate can be installed to bring the MCO into a safe-standby condition. A petcock is provided on the supply piping to facilitate manual refill operation by providing a visual indication that the annulus water level is above the level of the fuel inside the MCO. This system allows backup verification of adequate cask-MCO annulus water level if the safety-class level gauges with remote alarms cannot be reset because of leakage from the general-service seals on the process hood seal ring assembly. The seal ring is above the fuel level inside the MCO but below the safetyclass level gauges.

(cont inued) 
ACTIONS (continued)
SURVEILLANCE REQUIREMENTS
Two parallel safety-class antisiphon valves are connected between the safety-class portion of the inlet and outlet piping to prevent water from being inadvertently siphoned from the annulus in the event there is a line break in the general-service piping.

The Completion Time of Immediately, not to exceed 8 hour is a reasonable time. This allows time for operations personnel to complete this action in an orderly manner which requires operations personnel to go to manually refill the TW (annulus) system to restore the required level.

Required Action C.2 requires that a facility-approved recovery $\mathrm{plan}$ be developed and the actions initiated in accordance with the facility-approved recovery plan to restore compliance with this LCO within 24 hours. Manually restoring/refilling the TW (annulus) system level may not have fully restored the TW (annulus) system flow path or the level detectors to OPERABLE status so the recovery plan will address the planned corrective actions for the existing conditions. The recovery plan may be modified as conditions change.

Failure to successfully meet the SR (i.e., SR acceptance criteria not satisfied) during the Surveillance or between performances of the Surveillance is a failure to meet the LCO. For this situation, entry into the LCO ACTIONS is required. Failure to perform the Surveillance within the specified Frequency (including the allowable 25\% extension) is a VIOLATION. For this situation, proceed in accordance with AC 5.4.4.2, "Failure to Perform an SR Within the Required Time Limit."

\section{SR 3.1.5.1}

SR 3.1.5.1 requires that TW (annuTus) system refil1 capabilities be VERIFIED within 1 day prior to entering process bay OPERATION SUBMODE. The specified SR VERIFIES that the necessary tools and water supply are available if it becomes necessary to manually restore the TW (annulus) system water level. 
SURVEILLANCE REQUIREMENTS (cont inued)
The Frequency of within 1 day prior to entering process bay OPERATION SUBMODE ensures the necessary TW (annulus) system level refill capabilities are available if needed prior to when an MCO is in a process bay.

\section{SR 3.1.5.2}

SR 3.1.5.2 requires an instrument CALIBRATION be performed on LSL $1 * 24$ and LSL $1 * 25$ annually. The specified SR to perform a CALIBRATION on each of the TW (annulus) system level detector instrumentation will confirm OPERABILITY prior to processing operations. VERIFICATION of the sensor setpoints ensures that the instruments will function consistent with the assumptions from the safety analysis. Performance of the CALIBRATION will measure and record the as-found sensor actuation value. If the as-found value is outside the allowable value, the sensor will be reset.

The Frequency of CALIBRATIONS of safety-related TW (annulus) system level instrumentation is consistent with manufacturer's recommendations, the assumptions made in the setpoint determination for an annual calibration, and the Frequencies for such Surveillance of protection and safeguards instrumentation in commercial nuclear power plants.

REFERENCES

HNF-3553, 1999, Spent Nuclear Fuel Project Final Safety Analysis Report, Rev. 0, Annex B, "Cold Vacuum Drying Facility Final Safety Analysis Report," Fluor Daniel Hanford, Incorporated, Richland, Washington.

SNF-2770, 1999, Cold Vacuum Drying Facility Design Basis Accident Analysis Documentation, Rev. 2, Fluor Daniel Hanford, Incorporated, Richland, Washington. 
B 3.1 .6

\section{B 3.1 INSTRUMENTATION}

\section{B 3.1.6 Process Bay Temperature Instrumentation}

BACKGROUND

This LCO ensures OPERABILITY of the process bay temperature instrumentation for the multi-canister (MCO) internal hydrogen explosion, MCO thermal runaway reaction, and MCO overpressurization.

The process bay temperature instrumentation is designed to detect elevated temperatures in the process bay and isolate the MCO, actuate the safety-class helium ( $\mathrm{SCHe}$ ) system, and provide an isolation and purge alarm. The accident analysis identified the possibility that elevated temperatures in the process bay could result in instrumentation and control malfunctions that would affect the function of the safety-class systems (whether due to facility fire, bay heater control failure, or loss of bay cooling in conjunction with extended, extreme temperatures).

The combustible loading limitations resulting from the fire hazards analysis are based on initial bay temperatures of no greater than $95^{\circ} \mathrm{F}$ to protect the SCIC system from being challenged by localized fires. Chapter B4.0 therefore identifies a parameter limit of $95{ }^{\circ} \mathrm{F}$ for the process bays to protect initial condition assumptions related to combustible loading limitations to protect the SCIC system. The LCO process bay temperature setpoint limit of $\leq 89^{\circ} \mathrm{F}$ incorporates instrument uncertainty to be conservative to the safety analysis parameter limit of $\leq 95^{\circ} \mathrm{F}$. 
BACKGROUND (continued)
High temperatures in the process bay have the potential to exceed the rated performance limits of the SCIC system. While most of the SCIC components are not affected at temperatures lower than $115^{\circ} \mathrm{F}$, two vacuum pressure transmitters, PT $1 * 08$ and PT $1 * 10$, have a calibration 1 imit of $105^{\circ} \mathrm{F}$. The two pressure transmitters provide input for the MCO 12 torr purge bypass. The 12 torr bypass limit is required in drying, proof, and pressure operations. The $M C O$ is placed into a safe configuration (i.e., the SCHe system is actuated and the MCO isolation valves are closed) before temperatures exceeding performance limits are reached. Ensuring the capability to detect high process bay temperatures is therefore necessary to support the operability of the SCIC system (LCO 3.1.1).

For stagnant tempered water conditions, the process bay becomes the heat sink for the MCO and must stay below $115^{\circ} \mathrm{F}$. The safety-class instrumentation and control (SCIC) system is relied upon to respond to high process bay temperatures and take precautionary actions (via interlocks that actuate the safety-class helium system and provide an isolation and purge alarm) before maximum heat sink temperatures are exceeded.
APPLICABLE SAFETY ANALYSES
LCO 3.1 .6 is required for four accident scenarios:

(1) Multi-Canister Overpack External Hydrogen Explosion,

(2) Multi-Canister Overpack Internal Hydrogen Explosion,

(3) Multi-Canister Overpack Thermal Runaway Reaction, and

(4) Multi-Canister Overpack Overpressurization.

In addition to the credited functions related directly to the accidents below, the process bay temperature instrumentation is also credited to protect initial condition assumptions related to the fire hazard analysis. By actuating the SCIC system prior to bay temperatures exceeding initial conditions assumed in the fire hazards analysis, the SCIC safety function is protected (since it has already been performed) from impact from any fire capable of compromising the rated performance limits of the SCIC system. 


\section{APPLICABLE SAFETY ANALYSES (cont inued)}

\section{Multi-Canister Overpack External Hydrogen Explosion}

A hydrogen explosion outside an MCO is analyzed in SNF-2770, Cold Vacuum Drying Facility Design Basis Accident Analysis Documentation, and the results of the analysis are presented in HNF-3553, Spent Nuclear Fuel Project Final Safety Analysis Report, Annex B, "Cold Vacuum Drying Facility Final Safety Analysis Report," Chapter B3.0, "Hazard and Accident Analyses." Based on the results of the analysis, the unmitigated release of radiological material could exceed onsite risk evaluation guidelines.

In this postulated accident scenario, a hydrogen explosion occurs because of accumulation of hydrogen inside an MCO, followed by ignition and explosion of the hydrogen gas when it is vented from the MCO into the local exhaust process ventilation system and mixed with air. The process bay temperature instrumentation is credited in the analys is to detect high temperatures in the process bay that could cause instrument inaccuracy or malfunction and provide a signal to the SCIC system to initiate MCO isolation and SCHe pressurization and purge.

\section{Multi-Canister Overpack Internal Hydrogen Explosion}

A hydrogen explosion inside an MCO is analyzed in SNF-2770, Cold Vacuum Drying Facility Design Basis Accident Analysis Documentation, and the results of the analys is are presented in HNF-3553, Spent Nuclear Fuel Project Final Safety Analysis Report, Annex B, "Cold Vacuum Drying Facility Final Safety Analys is Report," Chapter B3.0, "Hazard and Accident Analyses." Based on the results of the analysis, the unmitigated release of radiological material could exceed onsite risk evaluation guidelines.

In this postulated accident scenario, a hydrogen explosion occurs because of a hydrogen-air mixture inside an MCO. The process bay temperature instrumentation is credited in the analysis to detect high temperatures in the process bay that could cause instrument inaccuracy or malfunction and provide a signal to the SCIC system to initiate MCO isolation and SCHe pressurization and purge. 


\author{
APPLICABLE \\ SAFETY ANALYSES \\ (continued)
}

\section{Multi-Canister Overpack Thermal Runaway Reaction}

Thermal runaway reactions inside an $M C O$ are analyzed in SNF-2770, Cold Vacuum Drying Facility Design Basis Accident Analysis Documentation, and the results of the analysis are presented in HNF-3553, Spent Nuclear Fuel Project Final Safety Analysis Report, Annex B, "Cold Vacuum Drying Facility Final Safety Analys is Report," Chapter B3.0, "Hazard and Accident Analyses." Based on the results of the analysis, the unmitigated release of radiological material could exceed offsite release limits and onsite risk evaluation guidelines.

In this postulated accident scenario, a thermal runaway reaction occurs from insufficient heat removal from the inside of the MCO. The process bay temperature instrumentation is credited in the analys is to detect high temperatures in the process bay that could cause instrument inaccuracy or malfunction and provide a signal to the SCIC system to initiate MCO isolation and SCHe pressurization and purge. In addition, the process bay temperature instrumentation initiates an isolation and purge alarm which alerts operations to the process bay condition such that response actions can be initiated.

\section{Multi-Canister Overpack Overpressurization}

Overpressurization of the MCO is analyzed in SNF-2770, Cold Vacuum Drying Facility Design Basis Accident Analysis Documentation, and the results of the analysis are presented in HNF-3553, Spent Nuclear Fuel Project Final Safety Analysis Report, Annex B, "Cold Vacuum Drying Facility Final Safety Analysis Report," Chapter B3.0, "Hazard and Accident Analyses." Based on the results of the analysis, the unmitigated release of radiological material could exceed offsite release limits and onsite risk evaluation guidelines.

In this postulated accident scenario, a high-pressure release of radioactive material results from MCO isolation and a resulting high MCO internal pressure. The process bay temperature instrumentation is credited in the analysis to detect high temperatures in the process bay that could cause instrument inaccuracy or malfunction and provide a signal to the SCIC system to initiate MCO isolation and SCHe pressurization and purge. 
The process bay temperature instrumentation (TSHH $1 * 38$ and TSHH $1 * 39$ ) is required to be OPERABLE with a setpoint of $\leq 89^{\circ} \mathrm{F}$ to provide the capability to detect high process bay temperatures and transmit the information to the SCIC system. This setpoint incorporates a $3{ }^{\circ} \mathrm{C}$ allowance for instrument drift (representing an allowable value of $92{ }^{\circ} \mathrm{C}$ ), and an additional $3{ }^{\circ} \mathrm{C}$ allowance for instrument error to protect the parameter limit of $95{ }^{\circ} \mathrm{C}$ identified in HNF-3553. The process bay temperature shall be $\leq 95$ ${ }^{\circ} \mathrm{F}$. Failure of any instrument renders the process bay temperature input to the associated SCIC train (A or B) inoperable.

Functional requirements for determining the OPERABILITY of the process bay temperature instrumentation are also defined in HNF-3553, Chapter B4.0, "Safety Structures, Systems, and Components." Detailed functional

requirements for determining the OPERABILITY of the system may be found in procedures.

MODE APPLICABILITY
LCO 3.1.6 applies in process bay OPERATION SUBMODE because MCOs located within the Cold Vacuum Drying Facility (CVDF) are allowed in this MODE. LCO 3.1.6 does not apply in process bay STANDBY or REPAIR SUBMODES because MCOs within the process bays are not allowed in these MODES.
PROCESS AREA APPLICABILITY
LCO 3.1.6 applies to process bays in OPERATION SUBMODE from the time the filtered process exit port valve is opened until successful completion of the final pressure rebound test (AC 5.17, "Dryness Testing") and both MCO process tube plug valves are closed. Once the $M C O$ is dried sufficiently (as demonstrated by $A C$ 5.17) and isolated, the pressure instrumentation being protected by this LCO is no longer required to be OPERABLE, and the MCO is no longer at risk from high process bay temperatures due to its low water content. 
Failure to take the ACTIONS required within the required time limit following failure to meet the $L C O$ is a VIOLATION. For this situation, proceed in accordance with $A C$ 5.4.3, "Response to a Limiting Condition for Operation and Limiting Control Setting VIOLATION."

See Section 1.3, "Completion Times," for the definition of Immediately.

\section{A.1}

When either TSHH $1 * 38$ or TSHH $1 * 39$ is inoperable, Condition $A$ is entered. Condition $A$ is entered separately for each process bay and the Completion Times are tracked separately for each process bay. Condition A requires Required Action A.l to be performed upon discovery.

Required Action A.1 requires that the inoperable process bay temperature instrument be restored to OPERABLE status within 5 days. With only one of the two process bay temperature instruments inoperable, process bay temperature can still be monitored for high temperature conditions with the remaining OPERABLE instrumentation. Process bay temperature is being monitored to identify any changes that would indicate unacceptable temperatures. The output from the process bay temperature instrumentation through the SCIC system can still actuate an ISO \& Purge trip because one train of the instrumentation remains OPERABLE. The Completion Time of 5 days is a reasonable time to restore the inoperable process bay temperature instrumentation.

\section{B. 1 and B.2}

When both TSHH $1 * 38$ and TSHH $1 * 39$ are inoperable, Condition $B$ is entered. Condition $B$ is entered separately for each process bay and the Completion Times are tracked separately for each process bay. Condition B requires Required Actions B.l, and B.2 to be performed upon discovery. 
ACTIONS (continued)
Required Action B.l requires that the process bay temperature be monitored using an alternate method once per 8 hours. Process bay temperature is being monitored to identify any changes that would indicate temperature is $>95^{\circ} \mathrm{F}$ (as adjusted by the instrument uncertainty of the alternate monitoring method). Normally output from the process bay temperature instrumentation through the SCIC system would actuate an ISO \& Purge trip. The Completion Time of once every 8 hours is a reasonable time to periodically monitor for process bay temperature trends and indications that there is an increase in temperature above the allowable value.

Required Action B. 2 requires that at least one inoperable instrument be restored to OPERABLE status within 24 hours. The Completion Time of 24 hours is acceptable because Required Action B.1 is monitoring process bay temperature using an alternate method every 8 hours to identify if the process bay temperature may be increasing. When at least one of the inoperable instruments is restored to OPERABLE status, Condition B can be exited and operation can continue in accordance with Condition $A$ to restore the other inoperable instrument.

\section{$\underline{C .1}$ and $\dot{C} .2$}

When the Required Actions and associated Completion Times of Conditions $A$ or $B$ are not met, Condition $C$ is entered. Condition $C$ is entered separately for each process bay and the Completion Times are tracked separately for each process bay. Condition C requires Required Actions C.1 and $C .2$ to be performed upon discovery. 
BASES

ACTIONS (cont inued)
Required Action C.l requires both train $A$ and train $B$ of the ISO \& Purge trip to be actuated within 1 hour. Actuation of the ISO \& Purge trip isolates the MCO from the process systems by de-energizing closed the eight MCO isolation valves and actuates the SCHe system by deenergizing open the four SCHe isolation valves to provide a flow of helium to the MCO. Isolation of the MCO from CVDF processing systems ( 1 ines $\mathrm{Di} / \mathrm{He}-{ }^{*} 01-\mathrm{SS}$, VPS-*02-SS, and PWC-*01-SS) prevents line breaks (which could go undetected due to undetected temperature effects on the pressure instrumentation) from affecting the MCO. Actuation of the SCHe system establishes an initial purge of the MCO followed by a helium blanket, and opens a pressure vent path from the MCO headspace to the local exhaust system.

The Completion Time of 1 hour is based on the fact that an ISO \& Purge trip should already have occurred (depending on the failure method). This allows time for operations personnel to verify the ISO \& Purge trip actuation and if the trip has not automatically occurred, allows time for operations personnel to complete this manual action in an orderly manner.

Required Action $C .2$ requires that the instrumentation be restored to OPERABLE status prior to resuming MCO process operations. Once the $\mathrm{MCO}$ is isolated from non-safety systems and a reliable vent path established to relieve any pressure caused through hydrogen generation, the MCO is in a safe and stable condition. (The presence of helium may also be dictated for those MCOs which have begun draining. The trip of the safety-class instrumentation and control system isolation and purge function will accomplish this at the same time it establishes a vent path.) The Completion Time of prior to resuming MCO process operations allows time after the safe and stable state is reached to restore the required instrumentation to OPERABLE status. 
ACTIONS (continued)

\section{D.1 and D.2}

When process bay temperatures go outside acceptable limits ( $>95^{\circ} \mathrm{F}$ as adjusted by the accuracy of the instrument of record), Condition $D$ is entered. Condition $D$ is entered separately for each process bay and the Completion Times are tracked separately for each process bay. Condition D requires Required Actions $D .1$ and $D .2$ to be performed upon discovery.

Required Action D.I requires both train $A$ and train $B$ of the ISO \& Purge trip to be actuated Immediately, not to exceed 1 hour. Actuation of the ISO \& Purge trip isolates the MCO from the process systems by de-energizing closed the eight $\mathrm{MCO}$ isolation valves and actuates the SCHe system by de-energizing open the four SCHe isolation valves to provide a flow of helium to the MCO. Isolation of the MCO from CVDF processing systems ( 1 ines $\mathrm{Di} / \mathrm{He}-{ }^{*} 01$ SS, VPS-*02-SS, and PWC-*01-SS) prevents 1 ine breaks from affecting the MCO. Actuation of the SCHe system establishes an initial purge of the MCO followed by a helium blanket, and opens a pressure vent path from the MCO headspace to the local exhaust system.

The Completion Time of Immediately, not to exceed 1 hour is based on the fact that an ISO \& Purge trip should already have occurred (depending on the failure method). This allows time for operations personnel to verify the ISO \& Purge trip actuation and if the trip has not automatically occurred, allows time for operations personnel to complete this manual action in an orderly manner.

Required Action $D .2$ requires that the process bay temperatures be restored within limits Immediately, not to exceed 12 hours. Because the process bay is the ultimate heat sink for the cask-MCO when the TW (annulus) system is not actively controlling temperatures, high process bay temperatures must be brought under control in a timely fashion. The Completion Time of Immediately, not to exceed 12 hours reflects this high priority. This Completion Time also allows sufficient time for restoration activities to be conducted and for temperatures to return within limits. 
ACTIONS

(continued)
It is noted that since the heater on the recirculation HVAC system can be a significant source of heat for the process bay, it would be prudent to shut down this system as one of the first actions taken upon entering this Condition to restore temperatures within limits.
SURVEILLANCE REQUIREMENTS
Failure to successfully meet the SR (i.e., SR acceptance criteria not satisfied) during the Surveillance or between performances of the Surveillance is a failure to meet the LCO. For this situation, entry into the LCO ACTIONS is required. Failure to perform the Surveillance within the specified Frequency (including the allowable 25\% extension) is a VIOLATION. For this situation, proceed in accordance with AC 5.4.4.2, "Failure to Perform an SR Within the Required Time Limit."

SR 3.1.6.1

SR 3.1.6.1 requires an instrument CALIBRATION be performed on TSHH $1 * 38$ and TSHH $1 * 39$ annually. The specified SR to perform a CALIBRATION on each of the process bay temperature instrumentation will confirm OPERABILITY prior to processing operations. VERIFICATION of the sensor setpoints ensures that the instruments will function consistent with the assumptions from the safety analysis. Performance of the CALIBRATION will measure and record the as-found sensor actuation value. If the as-found value is outside the allowable value, the sensor will be reset.

The Frequency of CALIBRATIONS of safety-related process bay temperature instrumentation is consistent with manufacturer's recommendations, the assumptions made in the setpoint determination for an annual calibration, and the Frequencies for such Surveillance of protection and safeguards instrumentation in commercial nuclear power plants. 
REFERENCES HNF-3553, 1999, Spent Nuclear Fuel Project Final Safety Analysis Report, Rev. 0, Annex B, "Cold Vacuum Drying Facility Final Safety Analysis Report, "Fluor Daniel Hanford, Incorporated, Richland, Washington.

SNF-2770, 1999, Cold Vacuum Drying Facility Design Basis Accident Analysis Documentation, Rev. 2, Fluor Daniel Hanford, Incorporated, Richland, Washington. 


\section{B 3.1 INSTRUMENTATION}

\section{B 3.1.7 Seismic Trip Instrumentation}

BACKGROUND

This LCO ensures OPERABILITY of the seismic trip instrumentation. The seismic trip instrumentation is designed to detect a seismic event (ground motion acceleration above $0.05 \mathrm{~g}$ triaxial) and actuate the safety-class instrumentation and control (SCIC) system output relays, which open (tripped position) on loss of electrical power. The LCO seismic trip limit of $\leq 0.05 \mathrm{~g}$ incorporates instrument uncertainty to be conservative to the safety analysis limit of $\leq 0.06 \mathrm{~g}$. The accident analysis identified the possibility that a design basis earthquake (DBE) could damage SCIC systems that are not seismically qualified (e.g., tempered water [TW] heater protection circuits or the multi-canister overpack [MCO] pressure sensor). Thus, the MCO is placed into a safe configuration before such seismic acceleration levels are reached.

To ensure sufficient reliability of the system and to reduce spurious trips, three independent sensors (actually, recorders with three triaxial detectors each) (ATR-5235, ATR-5336, and ATR-5437) are located in separate process bays. In addition, two-out-of-three trip logic is used to initiate a seismic trip. Sensors are located in process bays 2, 3, and 4. A trip or a loss of a single sensor will result in an alarm to the monitoring and control system (MCS) and will account for one of the three signals to the two-out-of-three trip circuit. A trip of two sensors will result in a trip of the TW system (heater), isolation of the MCO, and actuation of a safetyclass helium (SCHe) purge. The design relies on failsafe, auctioneered signals to two independent auctioneering panels in process bay 1 (CP-120 and CP-121), which make up train $A$ and $B$ trip circuits. 
BACKGROUND (continued)
The seismic monitors will actuate the SCIC system trip independent of the logic circuits. The seismic monitors directly trip the SCIC system output relays, which actuates the SCHe system and MCO isolation valves. A seismic event will also trip the TW high temperature protection circuit that shuts down the TW heater (although the PWC pump is also tripped, this function is defense-indepth only). The seismic trip directly controls the SCIC final output relays, which either are closed to allow power to the safety-class valves and TW heater or are opened on a trip or loss of power. Once a seismic trip is actuated, all other logic is circumvented and no longer has a safety-class function.
APPLICABLE SAFETY ANALYSES
LCO 3.1.7 is required for three accident scenarios:

Multi-Canister Overpack Internal Hydrogen Explosion,

(2) Multi-Canister Overpack Thermal Runaway Reaction, and

(3) Multi-Canister Overpack Overpressurization.

\section{Multi-Canister Overpack Internal Hydrogen Explosion}

A hydrogen explosion inside an MCO is analyzed in SNF-2770, Cold Vacuum Drying Facility Design Basis Accident Analysis Documentation, and the results of the analysis are presented in HNF-3553, Spent Nuclear Fuel Project Final Safety Analysis Report, Annex B, "Cold Vacuum Drying Facility Final Safety Analys is Report," Chapter B3.0, "Hazard and Accident Analyses." Based on the results of the analysis, the unmitigated release of radiological material could exceed onsite risk evaluation guidelines.

In this postulated accident scenario, a hydrogen explosion occurs because of a hydrogen-air mixture inside an MCO. The seismic trip instrumentation is credited in the analysis to detect a seismic event that could impair SCIC function and initiates MCO isolation and SCHe pressurization and purge and de-energizes the TW (annulus) system heater. The seismic trip instrumentation will actuate the SCIC system trip independent of the logic circuits as a precaution during seismic events to preclude unacceptable process upsets. 


\section{APPLICABLE SAFETY ANALYSES (cont inued)}

\section{Multi-Canister Overpack Thermal Runaway Reaction}

Thermal runaway reactions inside an MCO are analyzed in SNF-2770, Cold Vacuum Drying Facility Design Basis Accident Analysis Documentation, and the results of the analys is are presented in HNF-3553, Spent Nuclear Fuel Project Final Safety Analysis Report, Annex B, "Cold Vacuum Drying Facility Final Safety Analys is Report," Chapter B3.0, "Hazard and Accident Analyses." Based on the results of the analysis, the unmitigated release of radiological material could exceed offsite release limits and onsite risk evaluation guidelines.

In this postulated accident scenario, a thermal runaway reaction occurs from insufficient heat removal from the inside of the MCO. The seismic trip instrumentation is credited in the analysis to detect a seismic event that could impair SCIC function and initiates MCO isolation and SCHe pressurization and purge and de-energizes the TW (annulus) system heater. The seismic trip instrumentation will actuate the SCIC system trip independent of the logic circuits as a precaution during seismic events to preclude unacceptable process upsets.

\section{Multi-Canister Overpack Overpressurization}

Overpressurization of the MCO is analyzed in SNF-2770, Cold Vacuum Drying Facility Design Basis Accident Analysis Documentation, and the results of the analysis are presented in HNF-3553, Spent Nuclear Fuel Project Final Safety Analysis Report, Annex B, "Cold Vacuum Drying Facility Final Safety Analys is Report, "Chapter B3.0, "Hazard and Accident Analyses." Based on the results of the analysis, the unmitigated release of radiological material could exceed offsite release limits and onsite risk evaluation guidelines. 
APPLICABLE

SAFETY ANALYSES

(cont inued)
In this postulated accident scenario, a high-pressure release of radioactive material results from $M C O$ isolation and a resulting high MCO internal pressure. The seismic trip instrumentation is credited in the analys is to detect a seismic event that could impair SCIC function and initiates $\mathrm{MCO}$ isolation and SCHe pressurization and purge and de-energizes the TW (annulus) system heater. The seismic trip instrumentation will actuate the SCIC system trip independent of the logic circuits as a precaution during seismic events to preclude unacceptable process upsets.

The seismic trip instrumentation is required to be OPERABLE to detect seismic activity and trip the SCIC system at a setpoint $\leq 0.05 \mathrm{~g}$ in all process bays processing MCOS. For the seismic trip instrumentation to be OPERABLE, two or more of the sensor/recorders (ATR-5235, ATR-5336, or ATR-5437) are required to be OPERABLE. Each sensor/recorder has triaxial detectors/accelerometers. If one accelerometer (x-axis, $y$-axis, or z-axis) is inoperable then the associated sensor is inoperable. Both seismic auctioneering panels $C P-120$ and $C P-121$ are required.

Maintaining the system OPERABLE ensures removal of power to provide the ISO \& Purge trip and TW trip upon receipt of a seismic input signal in excess of the accelerometer setpoint.

Functional requirements for determining the OPERABILITY of the seismic trip instrumentation are also defined in HNF-3553, Chapter B4.0, "Safety Structures, Systems, and Components." Detailed functional requirements for determining the OPERABILITY of the system may be found in procedures.

MODE

APPLICABILITY

LCO 3.1.7 applies to process bays OPERATION SUBMODE because MCOS located within the Cold Vacuum Drying Facility (CVDF) are allowed in the OPERATION SUBMODE. 

time limit following failure to meet the LCO is a VIOLATION. For this situation, proceed in accordance with AC 5.4.3, "Response to a Limiting Condition for Operation and Limiting Control Setting VIOLATION."

\section{A.1, A.2, and A.3}

When two or more sensor/recorders are inoperable, Condition $A$ is entered. Condition $A$ requires Required Actions A.1, A.2 and A.3 be performed upon discovery.

Each sensor/recorder has three accelerometers. When any one accelerometer (X-Axis, Y-Axis, or Z-Axis channels) is inoperable, the associated sensor/recorder is inoperable. An accelerometers being inoperable may include as applicable the accelerometer, signal conditioners, main contactors, relay modules, or setpoint modules.

Normally output from one sensor/recorder would actuate an alarm. The alarm also normally indicates that one third of the coincidence logic for the seismic trip is provided. With two sensors/recorders OPERABLE a seismic event can be detected and the 2 of 3 coincidence logic to initiate a seismic trip is available. If the inoperable accelerometer failed-safe this condition is even more conservative because it would have already provided part of the coincidence logic for the seismic trip. Although the redundancy has been lost there are still sufficient accelerometers to provide the seismic trip function credited in the accident analysis.

Required Action $A .1$ requires that both train $A$ and train $B$ of the ISO \& Purge trip be actuated within 1 hour. Actuation of the ISO \& Purge trip isolates the MCO by deenergizing closed the eight $M C O$ isolation valves and actuates the SCHe system by de-energizing open the four SCHe isolation valves to provide a flow of helium to the MCO. The Completion Time of 1 hour is based on the fact that the seismic instrumentation should have already actuated the ISO \& Purge trip. This allows time for operations personnel to verify the Iso \& Purge trip actuation and if the trip has not automatically occurred allows time for operations personnel to complete this manual action in an orderly manner. 
ACTIONS (cont inued)
Required Action A.2 requires that the TW (annulus) system heater be de-energized within 1 hour. Normally the seismic instrumentation through the SCIC system would actuate a TW trip which automatically de-energizes the TW (annulus) system heater to stop additional heat input into the annulus water. A train A and train B TW trip cannot be remotely actuated so the heater must be de-energized. The Completion Time of 1 hour is based on the fact that a TW (annulus) system trip should have already occurred.

This allows time for operations personnel to verify the TW trip or to complete this manual action in an orderly manner which requires operations personnel to de-energize the heater in the affected process bay.

Required Action A.3 requires that the channel(s) be restored to OPERABLE status prior to resuming operation. Upon restoration of the channel(s) to OPERABLE status, Condition $A$ is exited and MCO processing operations can be resumed.
SURVEILLANCE REQUIREMENTS
Failure to successfully meet the SR (i.e., SR acceptance criteria not satisfied) during the Surveillance or between performances of the Surveillance is a failure to meet the LCO. For this situation, entry into the LCO ACTIONS is required. Failure to perform the Surveillance within the specified Frequency (including the allowable 25\% extension) is a VIOLATION. For this situation, proceed in accordance with AC 5.4.4.2, "Failure to Perform an SR Within the Required Time Limit."

\section{$\underline{S R ~ 3.1 .7 .1}$}

SR 3.1.7.1 requires a CALIBRATION be performed on each accelerometer (ATR-5235, ATR-5336, ATR-5437 including the seismic auctioneering panels $(P-120$ and $(P-121)$ annually. The specified SR for a CALIBRATION check of each factory-set accelerometer will be performed to VERIFY the accelerometer setpoint required by the safety analysis. 
SURVEILLANCE REQUIREMENTS

(continued)
The Frequency of CALIBRATIONS of the seismic accelerometers is consistent with manufacturer's recommendations, the assumptions made in the setpoint determination for an annual calibration, and the Frequencies for such Surveillance of protection and safeguards instrumentation in commercial nuclear power plants. The Frequency of annually is reasonable since the accelerometers are factory-set and are not subject to large magnitude of setpoint drift.

REFERENCES

HNF-3553, 1999, Spent Nuclear Fuel Project Final Safety Analysis Report, Rev. 0, Annex B, "Cold Vacuum Drying Facility Final Safety Analysis Report," Fluor Daniel Hanford, Incorporated, Richland, Washington.

SNF-2770, 1999, Cold Vacuum Drying Facility Design Basis Accident Analysis Documentation, Rev. 2, Fluor Daniel Hanford, Incorporated, Richland, Washington. 


\section{B 3.1 INSTRUMENTATION}

\section{B 3.1.8 Isolation Valve Interlocks}

BASES

BACKGROUND

The vacuum purge system (VPS) isolation valves on the deionized water side (VPS-GOV-1*11 and VPS-GOV-1*17) prevent water from the deionized water supply from entering the multi-canister overpack (MCO) following MCO drying operations. The process water conditioning (PWC) isolation valves (PWC-GOV-1*03 and PWC-GOV-1*30) prevent water from being drained from the MCO to the process water conditioning system during heatup and prevents the potential of water leakage back into the MCO following MCO drying operations. Inadvertent water addition to the MCO once pressure rebound testing and the dryness

demonstration has begun has the potential to leave the MCO susceptible to thermal runaway reaction or overpressurization events. In addition, the PWC isolation valves ensure a premature drain of the MCO does not occur prior to placing the SCIC system in the drain position and prior to the MCO low pressure trip being active.

This LCO control addresses a safety analysis assumption to protect the interface between the Canister Storage Building (CSB) and the Cold Vacuum Drying Facility (CVDF). Preventing inadvertent water addition preserves the dryness testing requirements which are critical for ensuring that the CVDF mission has been successful (i.e., the applicable CSB receipt acceptance criteria are met) and that the MCO may be safely shipped to the CSB.

The isolation valve interlocks that maintain the VPS isolation valves on the deionized water side (VPS-GOV-1*11 and VPS-GOV-1*17) and the PWC isolation valves (PWC-GOV$1 * 03$ and PWC-GOV-1*30) closed are required to be OPERABLE per this LCO. OPERABILITY of the individual valves is addressed separately in LCO 3.2.1, "Safety-Class Helium". 
APPLICABLE SAFETY ANALYSES
LCO 3.1.8 is required for two accident scenarios:

(1) Multi-Canister Overpack Thermal Runaway Reaction and

(2) Multi-Canister Overpack Overpressurization.

\section{Multi-Canister Overpack Thermal Runaway Reaction}

Thermal runaway reactions inside an $M C O$ are analyzed in SNF-2770, Cold Vacuum Drying Facility Design Basis Accident Analysis Documentation, and the results of the analys is are presented in HNF-3553, Spent Nuclear Fuel Project Final Safety Analysis Report, Annex B, "Cold Vacuum Drying Facility Final Safety Analysis Report," Chapter B3.0, "Hazard and Accident Analyses." Based on the results of the analysis, the unmitigated release of radiological material could exceed offsite release limits and onsite risk evaluation guidelines.

In this postulated accident scenario, a thermal runaway reaction occurs from insufficient heat removal from the inside of the MCO. The VPS and PWC isolation valve interlocks are credited in the analys is to keep the isolation valves closed once drying is complete, to prevent the introduction of water that can lead to a thermal runaway reaction. The interlock with the PWC isolation valves also prevents a premature drain of the MCO when SCIC interlocks credited while draining, are not active.

\section{Multi-Canister Overpack Overpressurization}

Overpressurization of an MCO is analyzed in SNF-2770, Cold Vacuum Drying Facility Design Basis Accident Analysis Documentation, and the results of the analysis are presented in HNF-3553, Spent Nuclear Fuel Project Final Safety Analysis Report, Annex B, "Cold Vacuum Drying Facility Final Safety Analysis Report," Chapter B3.0, "Hazard and Accident Analyses." Based on the results of the analysis, the unmitigated release of radiological material could exceed offsite release limits and onsite risk evaluation guidelines.

In this postulated accident scenario, a high-pressure release of radioactive material results from MCO isolation and a resulting high MCO internal pressure. A significant contributor to the overpressurization is excessive water content inside of the MCO. The VPS and PWC isolation valve interlocks are credited in the analysis to keep the isolation valves closed once drying is complete, to 
APPLICABLE SAFETY ANALYSES (cont inued) prevent the introduction of water that can lead to overpressurization. As stated previously, the interlock with the PWC isolation valves also prevents a premature drain of the MCO when SCIC interlocks credited while draining, are not active.

LCO

The LCO requires the VPS isolation valve interlocks (on the deionized water side) and the PWC isolation valve interlocks to be OPERABLE to keep the isolation valves closed at all times during drying, initial pressure rebound testing, the proof-of-dryness demonstration, and final pressure rebound testing. In addition, the PWC isolation valve interlocks are required to be OPERABLE when the safety-class instrumentation and control (SCIC) system is in the heatup position to prevent a premature drain when the MCO low pressure trip is not active. Although the interlocks are available in other conditions than discussed above, they are only credited in the accident analysis for the specific applicability mentioned.

The VPS isolation valves necessary to isolate the water supply must be OPERABLE to support the safety function of the interlocks. These valves are VPS-GOV-1*11 and VPSGOV-1*17. Also the PWC isolation valves PWC - GOV $-1 * 03$ and PWC-GOV-1*30 must be OPERABLE. The OPERABILITY of these valves is addressed in LCO 3.2.1, "Safety-Class Helium," since these isolation valves are critical to the OPERABILITY of this system as well.

Functional requirements for determining the OPERABILITY of the vacuum purge system isolation valve interlocks are also defined in HNF-3553, Chapter B4.0, "Safety Structures, Systems, and Components." Detailed functional requirements for determining the OPERABILITY of the instrumentation may be found in procedures.

MODE

APPLICABILITY
LCO 3.1 .8 applies in process bay OPERATION SUBMODE because MCOs located within the CVDF are allowed in this MODE. LCO 3.1 .8 does not apply in process bay STANDBY or REPAIR SUBMODES because MCOs within the process bays are not allowed in these MODES. 
PROCESS AREA APPLICABILITY
LCO 3.1 .8 applies to process bays in OPERATION SUBMODE when the SCIC system is in the heatup position, as well as from the time the initial pressure rebound test begins until successful completion of the final pressure rebound test (AC 5.17, "Dryness Testing") and both MCO process tube plug valves are closed. When the SCIC system is in the heatup position, the interlock on the PWC isolation valves prevents a premature drain of the MCO when SCIC interlocks, credited while draining, are not active. During dryness testing, interlocks on both the PWC isolation valves and the VPS isolation valves (on the deionized water side) are needed to prevent water additions to the MCO once drying is complete. Once the MCO is isolated by the process port valves, water intrusion is no longer possible, and the LCO to protect against it is therefore no longer required. The LCO will require the OPERABILITY of the VPS isolation valve interlocks (on the deionized water side) and the PWC isolation valve interlocks to keep the isolation valves closed at all times when the SCIC is in the heatup position, as well as during initial pressure rebound testing, the proof-of-dryness demonstration, and final pressure rebound testing.

Failure to take the ACTIONS required within the required time limit following failure to meet the LCO is a VIOLATION. For this situation, proceed in accordance with AC 5.4.3, "Response to a Limiting Condition for Operation and Limiting control Setting VIOLATION."

See Section 1.3, "Completion Times," for the definition of Immediately.

\section{A. 1 and $A .2$}

When one or more vacuum purge system isolation valve interlock is inoperable or one or more PWC isolation valve interlock is inoperable, Condition $A$ is entered.

Condition $A$ is entered separately for each process bay and the Completion Times are tracked separately for each process bay. Condition A requires Required Actions A.1, and A.2 to be performed upon discovery.

A note has been included that indicates LCO 3.0.4, "MODE Changes," is not applicable. This was included because the function the interlock would provide is being met by maintaining the valves associated with the inoperable 
ACTIONS (cont inued) interlock(s) closed. Since the LCO applies during heatup and then becomes applicable again for the pressure rebound test this note allows completion of MCO process operations once they have been started. ATso, the note does not prohibit the initiation of MCO process operations when the interlock is inoperable.

Required Action A.1 VERIFIES that the valves associated with the inoperable interlock(s) are maintained closed Immediately, not to exceed 1 hour. This accomplishes the action that the interlock is performing which is to maintain the valves associated with the interlock closed. To ensure the associated valves remain closed the motive force (e.g., power, air) should be removed or the valves should be locked closed. The completion Time of Immediately, not to exceed 1 hour allows time to remove power or air from the associated valves so that the valves associated with the inoperable interlock are VERIFIED to be maintained closed. Immediately has been used to convey the Required Action should be commenced without delay since isolation valve interlock inoperability impacts the ability of the SCIC to place the process in a safe state.

Required Action A.2 requires that the interlock(s) be restored to OPERABLE status within 5 days. Restoring the inoperable isolation valve interlocks would allow exit from the Required Actions, since the LCO will no longer apply. The Completion Time of 5 days is based upon the fact that with the interlock(s) inoperable, the method to prohibit inadvertent draining when associated controls are not available or water addition during drying has been compromised. This condition, while mitigated by the associated valves being maintained closed, is not a desirable state to remain in for any significant length of time. The Completion Time of 5 days, ensures that proper attention is given to this degraded state and that actions to restore the primary method of isolation are restored in a reasonable length of time. The Completion Time of 5 days is sufficient to perform normal maintenance or surveillance activities that repair the interlock(s) or to finish MCO process operations.

It is based on the fact that introduction of water with the isolation valve interlocks inoperable can result in a thermal runaway reaction or overpressurization once drying is completed. Also during heatup if the PWC isolation valve interlocks are inoperable, a premature drain could occur when the SCIC protection controls for draining are not available. 
SURVEILLANCE REQUIREMENTS
Failure to successfully meet the SR (i.e., SR acceptance criteria not satisfied) during the Surveillance or between performances of the Surveillance is a failure to meet the LCO. For this situation, entry into the LCO ACTIONS is required. Failure to perform the Surveillance within the specified Frequency (including the allowable 25\% extension) is a VIOLATION. For this situation, proceed in accordance with AC 5.4.4.2, "Failure to Perform an SR Within the Required Time Limit."

\section{$\underline{\text { SR 3.1.8.1 }}$}

An interlock FUNCTIONAL TEST shall be performed quarterly. The interlock FUNCTIONAL TEST shall demonstrate the capability of the VPS isolation vajlves (VPS-GOV-1*11 and VPS-GOV-1*17) to be closed and remain closed since they are necessary to isolate the water supply. The interlock FUNCTIONAL TEST shall also demonstrate the capability of the PWC isolation vaives (PWC-GOV-1*03 and PWC-GOV-1*30) to be closed and remain closed since they are necessary to isolate a potential source of water backflowing through a process upset of the PWC system.

The FUNCTIONAL TEST demonstrates that the various isolation valves move to the proper (fail-closed) state when the interlock is actuated. Credit may be taken for the performance of other SRs (e.g., SR 3.2.1.3) that also demonstrate the required functions.

The Frequency of quarterly is based on engineering judgement. It should be noted that SR 3.2.1.3 may result in more frequent testing of these valves.
REFERENCES
HNF-3553, 1999, Spent Nuclear Fuel Project Final Safety Analysis Report, Rev. 0, Annex B, "Cold Vacuum Drying Facility Final Safety Analysis Report," Fluor Daniel Hanford, Incorporated, Richland, Washington.

SNF-2770, 1999, Cold Vacuum Drying Facility Design Basis Accident Analysis Documentation, Rev. 2, Fluor Daniel Hanford, Incorporated, Richland, Washington. 


\section{B 3.2 HELIUM SYSTEMS}

\section{B 3.2.1 Safety-Class Helium System}

BACKGROUND

This LCO ensures OPERABILITY of the safety-class helium (SCHe) system to prevent a thermal runaway reaction caused by insufficient heat removal from the inside of the multi-canister overpack (MCO), an overpressurization of the MCO from the helium supply, and MCO internal and external hydrogen explosions caused by buildup of flammable concentrations of hydrogen and oxygen. This LCO also protects SL 2.1.1, "Multi-Canister Overpack Maximum Pressure."

The MCO, loaded with spent nuclear fuel (SNF) from the $100 \mathrm{~K}$ Reactor SNF storage basins, is shipped to the Cold Vacuum Drying Facility (CVDF). At the CVDF nearly all of the water is removed from the MCO and the MCO is backfilled with helium. Then, the MCO is sealed and leak tested before transport to the Canister Storage Building for interim storage. Five sources of helium are provided in each process bay. Included are the general-service helium system (tube trailer) and the standby SCHe system (four helium gas cylinders). Helium is an inert gas with good thermal conductivity and is used in process operations to provide enhanced thermal conduction, to purge the MCO of hydrogen and other gasses, to pressurize the MCO to preclude further air ingress, and to provide an inert backfill of the MCO when drying is complete.

The SCHe system is a standby safety system to the general-service helium system. There is an independent and identical SCHe system for each process bay. Each process bay SCHe system (four bays with one SCHe system each) consists of helium supply tanks, pressure control valves, and fail-open gas operated isolation valves with associated piping and instrumentation. Each SCHe system contains four separate purge paths. There are two parallel SCHe lines for the MCO inlet (long axial process tube) purge and two parallel SCHe lines for the MCO outlet (filtered process exit port) purge. The four SCHe lines provide a redundancy to the $\mathrm{SCHe}$ system that ensures the safety functions can be met. The essential safety function of the SCHe system is to inert the MCO and associated process piping upon actuation by the safety-class instrumentation and control (SCIC) system during process upsets. 
BACKGROUND During process upsets, the SCHe system performs the (continued) following safety functions: (1) remove either hydrogen and/or oxygen to maintain the MCO at less than the lower flammability limit, (2) maintain positive pressure in the MCO to preclude or 1 imit air ingress, and (3) repressurize the MCO to provide enhanced thermal conductivity within the MCO. The SCHe system also has the normal process function of blowdown of the SCHe lines to remove water trapped in the lines after MCO draining.

The SCHe system interfaces with the general-service helium system, process vent lines, MCO inlet (long axial process tube port), MCO outlet (filtered process exit port), and SCHe tanks. The boundaries to the SCHe system are the check valves on the general-service helium supply lines, pressure control valves on the process vent lines, and the tie-ins on the MCO inlet and outlet ports.

The SCHe system is described in SNF-3068, Cold Vacuum Drying Facility Safety Class Helium System Design Description.

APPLICABLE SAFETY ANALYSES
LCO 3.2.1 is required for four accident scenarios:

(1) Multi-Canister Overpack Internal Hydrogen Explosion, (2) Multi-Canister Overpack External Hydrogen Explosion, (3) Multi-Canister Overpack Thermal Runaway Reaction, and (4) Multi-Canister Overpack Overpressurization.

\section{Multi-Canister Overpack Internal Hydrogen Explosion}

A hydrogen explosion inside an MCO is analyzed in SNF-2770, Cold Vacuum Drying Facility Design Basis Accident Analysis Documentation, and the results of the analysis are presented in HNF-3553, Spent Nuclear Fuel Project Final Safety Analysis Report, Annex B, "Cold Vacuum Drying Facility Final Safety Analysis Report," Chapter B3.0, "Hazard and Accident Analyses." Based on the results of the analysis, the unmitigated release of radiological material could exceed onsite risk evaluation guidelines.

In this postulated accident scenario, a hydrogen explosion occurs because of a hydrogen-air mixture inside an MCO. The SCHe system is credited in the analysis to prevent a hydrogen explosion by preventing flammable concentrations of hydrogen and oxygen from forming within the MCO by pressurizing and purge. functions.

(continued) 


\author{
APPLICABLE \\ SAFETY ANALYSES \\ (continued)
}

\section{Multi-Canister Overpack External Hydrogen Explosion}

A hydrogen explosion outside an MCO is analyzed in SNF-2770, Cold Vacuum Drying Facility Design Basis Accident Analysis Documentation, and the results of the analysis are presented in HNF-3553, Spent Nuclear Fuel Project Final Safety Analysis Report, Annex B, "Cold Vacuum Drying Facility Final Safety Analys is Report," Chapter B3.0, "Hazard and Accident Analyses." Based on the results of the analysis, the unmitigated release of radiological material could exceed onsite risk evaluation guidelines.

In this postulated accident scenario, a hydrogen explosion occurs because of accumulation of hydrogen inside an MCO, followed by ignition and explosion of the hydrogen gas when it is vented from the MCO into the local exhaust process ventilation system and mixed with air. The SCHe system is credited in the analysis to delay, through the use of pressure control valves, the initial purge of hydrogen to the process bay local exhaust heating, ventilation, and air conditioning (HVAC) and process vent system. A delay period of at least one minute will ensure that on a loss of power, the diesel unit has enough time to supply power to the exhaust fans and for minimum flow rates to be established to prevent accumulation of flammable concentrations of hydrogen and oxygen in the process bay local exhaust HVAC and process vent system.

\section{Multi-Canister Overpack Thermal Runaway Reaction}

Thermal runaway reactions inside the $M C O$ are analyzed in SNF-2770, Cold Vacuum Drying Facility Design Basis Accident Analysis Documentation, and the results of the analysis are presented in HNF-3553, Spent Nuclear Fuel Project Final Safety Analysis Report, Annex B, "Cold Vacuum Drying Facility Final Safety Analys is Report," Chapter B3.0, "Hazard and Accident Analyses." Based on the results of the analysis, the unmitigated release of radiological material could exceed offsite release limits and onsite risk evaluation guidelines.

In this postulated accident scenario, a high-pressure thermal runaway reaction occurs from insufficient heat removal from the inside of the MCO. The SCHe system is credited in the analysis to provide a pressure-regulated discharge flow path from the MCO to the local exhaust system. 
APPLICABLE SAFETY ANALYSES (cont inued)

\section{Multi-Canister Overpack Overpressurization}

Overpressurization of the MCO is analyzed in SNF-2770, Cold Vacuum Drying Facility Design Basis Accident Analysis Documentation, and the results of the analysis are presented in HNF-3553, Spent Nuclear Fuel Project Final Safety Analysis Report, Annex B, "Cold Vacuum Drying Facility Final Safety Analysis Report," Chapter B3.0, "Hazard and Accident Analyses." Based on the results of the analysis, the unmitigated release of radiological material could exceed offsite release limits and onsite risk evaluation guidelines.

In this postulated accident scenario, a gaseous release results from failure of the $M C O$ by overpressurization from the SCHe supply system. The SCHe system is credited in the analysis to provide a pressure-regulated discharge flow path from the MCO to the local exhaust system. The pressure control valves (in conjunction with the rupture disks which are DESIGN FEATURES) are credited in the analys is to protect the MCO from hel ium overpressure from the SCHe cylinders.

The SCHe system is required to be OPERABLE during CVDF operations.

OPERABILITY requirements for the SCHe system include the need for two independent purge supply paths. The purge supply path provides the initial purge function through the MCO, and a sufficient supply of helium (helium cylinder pressures $\geq 1700 \mathrm{lb} / \mathrm{in}^{2}$ gauge before actuation) is required in each cylinder to provide a minimum of 27 minutes of purge flow, to ensure that any hydrogen in the MCO at the time of system activation is removed and replaced with helium.

OPERABILITY requirements for the SCHe system similarly include the need for two independent gas vent paths. The gas vent path provides pressure venting of the MCO to ensure an MCO does not become fully isolated and provides a static blanket of helium to the MCO once the initial purge is over. An MCO without the proper vent path is capable of generating high internal pressures. 
BASES

LCO (continued)
MODE APPLICABILITY
OPERABILITY requirements for all paths include related pressure control valves to protect the MCO $340 \mathrm{lb} / \mathrm{in}^{2}$ safety limit and provide necessary purge delays to the process bay local exhaust HVAC and process vent system. OPERABILITY requirements also include helium cylinder pressures $\geq 1700 \mathrm{lb} / \mathrm{in}^{2}$ gauge before actuation. The SAR requires a 27 minute purge flow capability of at least 1.4 standard $\mathrm{ft}^{3} / \mathrm{min}$ through the MCO for each of the bottles to ensure non-flammable mixtures within the MCO following postulated air ingress accidents. HNF-3553, Chapter B4.0, "Safety Structures, Systems, and Components" references calculations that identify a bottle pressure of $\geq 1540 \mathrm{lb} / \mathrm{in}^{2}$ gauge to achieve this function. When adjusted for instrument uncertainty $\left(60 \mathrm{lb} / \mathrm{in}^{2}\right.$ gauge allowance based on SNF-4451) and readability $\left(100 \mathrm{lb} / \mathrm{in}^{2}\right.$ based on gauge marks every $2001 \mathrm{~b} / \mathrm{in}^{2}$ ), the cylinder pressure must be $\geq 1700 \mathrm{lb} / \mathrm{in}^{2}$ gauge as read by instrumentation to ensure the capability to provide the required purge flow is present. This pressure also provides sufficient capacity to provide a 96-hour helium blanket based on normal system leakage. Associated pressure instrumentation for the helium cylinders must also be OPERABLE to VERIFY that adequate supplies for both purging and blanketing (relatively static helium following the initial purge) operations are available.

OPERABILITY requirements for the overall SCHe system also include the need for the isolation valves that isolate the MCO from the vacuum purge system and process water conditioning system function as required. Without the proper functioning of these isolation valves, the SCHe system cannot provide its safety function.

Functional requirements for determining the OPERABILITY of the SCHe system are also defined in HNF-3553, Chapter B4.0. Detailed functional requirements for determining the OPERABILITY of the SCHe system may be found in procedures. 
PROCESS AREA APPLICABILITY
LCO 3.2.1 applies from the time the MCO long axial process tube port valve (VPS-V-*019) is opened until successful completion of the final pressure rebound test (AC 5.17, "Dryness Testing") and both MCO process tube plug valves are closed. The SCHe system may be called upon at any point in the process to provide the necessary helium purge flow to the MCO and a pressure vent path to the local exhaust system. Once the MCO is dried sufficiently (as demonstrated by $A C$ 5.17) and isolated, hydrogen explosions, thermal runaways, and MCO overpressurization are no longer a hazard for the CVDF.

ACTIONS

Failure to take the ACTIONS required with in the required time limit following failure to meet the LCO is a VIOLATION. For this situation, proceed in accordance with AC 5.4.3, "Response to a Limiting Condition for Operation and Limiting Control Setting VIOLATION."

\section{A.1}

When one purge supply path or one gas vent path is inoperable, Condition $A$ is entered. Because the SCHe system contains redundancy, the loss of one path does not prevent the system from performing its safety function. Condition A can be entered separately for one purge supply path and one vent path. In this event, the Completion Times for each SCHe path are tracked separately.

Required Action A.I requires restoration of the affected SCHe path to OPERABLE status within 5 days. As discussed above, although a degraded condition does exist due to decreased reliability, the safety function is preserved and allows continued processing while restoration activities are performed. The Completion Time of 5 days is adequate based on the low likelihood of the alternate path failing for the short duration that this condition exists and the low likelihood for need of the SCHe system.

\section{B. 1 and B.2}

When two purge supply paths or two gas vent paths are inoperable, Condition $B$ is entered. In this state, the safety functions of the SCHe system are compromised, and timely action to restore them is required. 
ACTIONS (cont inued)
Required Action B.1 establishes a positive pressure in the MCO and purge flow (if draining has been completed) through the MCO from the primary helium supply through the normal processing path within l hour. A positive pressure in the MCO from the normal processing helium supply will ensure that in the event of future MCO isolation due to SCIC trip, the MCO headspace will be pressurized with helium (i.e., no vacuum exists to allow air ingress in the event of line leakage). This is the safest configuration for the MCO in this situation. The Completion Time of 1 hour reflects the need for timely action in this event, and allows personnel sufficient time to complete the actions to place the MCO in the necessary configuration.

Required Action B. 2 requires restoration of at least one SCHe path to OPERABLE status within 12 hours. Without the capability to place the MCO in a long-term safe and stable state, a significantly degraded condition exists.

Restoring at least one SCHe path to OPERABLE status will restore the safety function of the system, and allow the capability to place the MCO in a long-term, safe, and stable state. The Completion Time of 12 hours is based on the low likelihood of an accident requiring the $\mathrm{SCHe}$ system during this duration, and the need for personnel to take orderly actions to restore system OPERABILITY. The exact nature of activities needed to restore path OPERABILITY are greatly dependent on the nature of the failure and the CVDF conditions at the time, making a shorter Completion Time impractical.

\section{C.1}

When one or more isolation valves are inoperable, Condition $C$ is entered. Required Action C.l requires that a facility-approved recovery plan be developed and actions initiated to restore compliance with this LCO within 24 hours. Isolation valve inoperability is considered an extremely low likelihood event by the accident analysis, and the nature of the failure and the facility conditions at the time make specific TSR Required Actions impossible to define. Because the isolation valves form part of the confinement boundary, restoration during processing may require special actions depending on the state of the MCO and the specific isolation valve declared inoperable. A recovery plan is appropriate in this case to resolve these situations. 
SURVEILLANCE REQUIREMENTS
Failure to successfully meet the SR (i.e., SR acceptance criteria not satisfied) during the Surveillance or between performances of the Surveillance is a failure to meet the LCO. For this situation, entry into the LCO ACTIONS is required. Failure to perform the Surveillance within the specified Frequency (including the allowable 25\% extension) is a VIOLATION. For this situation, proceed in accordance with AC 5.4.4.2, "Failure to Perform an SR Within the Required Time Limit."

\section{SR 3.2.1.1}

This Surveillance, to perform a FUNCTIONAL TEST of the SCHe system within 1 day prior to entering process bay OPERATION SUBMODE, demonstrates OPERABILITY of the system to perform its safety function. FUNCTIONAL TESTING needs to demonstrate that, when activated, the $\mathrm{SCHe}$ system pressure control valve settings are within expected ranges to provide at least 1.4 standard $\mathrm{ft}^{3} / \mathrm{min}$ of helium but no more than 4.0 standard $\mathrm{ft}^{3} / \mathrm{min}$ (as adjusted for instrument uncertainty) to the MCO as specified in HNF-3553, and are adequate to ensure that venting to the process bay local exhaust HVAC and process vent system on a loss of power will be delayed at least 60 seconds. This will allow standby power to be supplied to the necessary exhaust fans and minimum flow to be established to prevent a hydrogen concern.

\section{SR 3.2.1.2}

This Surveillance, to VERIFY helium cylinder pressures are $\geq 1700 \mathrm{lb} / \mathrm{in}^{2}$ gauge (as read by instrumentation) within 1 day prior to entering process bay OPERATION SUBMODE, is necessary to ensure that an adequate supply of helium is available to accomplish the SCHe safety function.

Sufficient helium must be available within each helium cylinder to provide a 27-minute purge of the MCO to ensure that the capability is present to remove hydrogen from the MCO upon SCHe activation and replace it with helium.

This pressure also ensures that sufficient helium is available within each SCHe system gas vent path to provide a 96-hour blanket of helium to the MCO headspace based on normal leakage so that air is excluded for long-term stability. 
SURVEILLANCE REQUIREMENTS

(cont inued)

\section{SR 3.2.1.3}

This Surveillance, to perform a FUNCTIONAL TEST of the isolation valves identified within 1 day prior to entering process bay OPERATION SUBMODE, demonstrates the necessary capability to place the MCO in an isolation and purge configuration. This capability is necessary to ensure SCHe OPERABILITY, and is critical to ensure the pressure boundary of the MCO is preserved throughout processing.

The FUNCTIONAL TEST must include a demonstration of the isolation valve's ability to hold pressure or vacuum. This can be demonstrated with a vacuum decay or pressure rise test. In addition, the FUNCTIONAL TEST should VERIFY proper local position indication, and that the various isolation valves move to the proper (fail-open, failclosed) state upon loss of power.

\section{$\underline{\mathrm{SR} 3.2 .1 .4}$}

HNF-3553, Chapter B4.0, "Safety Structures, Systems, and Components" identifies a bottle pressure of $\geq 1700 \mathrm{ib} / \mathrm{in}^{2}$ gauge to achieve this function, which accounts for instrument uncertainty and readability. Any observed variance in accuracy will be corrected at the time of the calibration. This Surveillance, to perform a CALIBRATION of the pressure instrumentation for each helium cylinder, wi11 confirm OPERABILITY of the instrumentation for use in SR 3.2.1.2.

The Frequency of annually is consistent with the anticipated requirements of the Spent Nuclear Fuel Project Preventive Maintenance/Testing Program. 
REFERENCES

HNF-3553, 1999, Spent Nuclear Fuel Project Final Safety Analysis Report, Rev. 0, Annex B, "Cold Vacuum Drying Facility Final Safety Analysis Report," Fluor Daniel Hanford, Incorporated, Richland, Washington.

SNF-2770, 1999, Cold Vacuum Drying Facility Design Basis Accident Analysis Documentation, Rev. 2, Fluor Daniel Hanford, Incorporated, Richland, Washington.

SNF-3068, 1999, Cold Vacuum Drying Facility Safety Class Helium System Design Description, Rev. 1, Fluor Daniel Hanford, Incorporated, Richland, Washington.

SNF-4451, 1999, Cold Vacuum Drying (CVD) Set Point Determination, Rev. OA, Fluor Daniel Hanford, Incorporated, Richland, Washington. 


\section{B 3.3 MULTI-CANISTER OVERPACK PRESSURE PROTECTION}

\section{B 3.3.1 Multi-Canister Overpack Vacuum Purge System Connections}

BASES

BACKGROUND

This LCO ensures OPERABILITY of the multi-canister overpack (MCO) vacuum purge system (VPS) connections to provide a primary confinement boundary for the MCO and ensures a controlled release from the MCO during overpressurization events and leakage from the MCO. Overpressurizations can occur from a hydrogen explosion, thermal runaway reaction, or from an isolated MCO. Leakage from the MCO can occur because of faulty VPS process connections. This $L C O$ also protects SL 2.1.1, "Multi-Canister Overpack Maximum Pressure."

The VPS connections provide a primary confinement boundary for the MCO by an MCO vent path and MCO process connections capability. The MCO vent path consists of a $30 \mathrm{lb} / \mathrm{in}^{2}$ gauge rupture disk (DESIGN FEATURE) and a pressure relief valve that are credited within the safety analysis to relieve pressure at less than or equal to $35 \mathrm{lb} /$ in $^{2}$ gauge. The system is connected to the MCO filtered process exit port and vents to the local exhaust duct. The $30 \mathrm{lb} /$ in $^{2}$ gauge vent system provides protection of the MCO $150 \mathrm{lb} / \mathrm{in}^{2}$ gauge rupture disk. The VPS process connections provide leaktight process connectors for joining flexible hoses to MCO processing ports. These connections are part of the extended pressure boundary for the $\mathrm{MCO}$ and are rated for $150 \mathrm{lb} / \mathrm{in}^{2}$ gauge. 
APPLICABLE SAFETY ANALYSES
LCO 3.3.1 is required for four accident scenarios:

(1) Gaseous Release, (2) Multi-Canister Overpack Internal Hydrogen Explosion, (3) Multi-Canister Overpack Thermal Runaway Reactions, and (3) Multi-Canister Overpack Overpressurization.

\section{Gaseous Release}

Gaseous release events are analyzed in SNF-2770, Cold Vacuum Drying Facility Design Basis Accident Analysis Documentation, and the results of the analysis are presented in HNF-3553, Spent Nuclear Fue7 Project Final Safety Analysis Report, Annex B, "Cold Vacuum Drying Facility Final Safety Analys is Report," Chapter B3.0, "Hazard and Accident Analyses." Based on the results of the analysis, the unmitigated release of radiological material could exceed onsite risk evaluation guidelines.

In this postulated accident scenario, a gaseous release results from a pressurized release of helium gas and entrained contaminated particulate through a process 1 ine leak. The MCO vacuum purge system connections are credited in the analysis to protect the pressure boundary for the MCO.

\section{Multi-Canister Overpack Internal Hydrogen Explosion}

A hydrogen explosion inside an $\mathrm{MCO}$ is analyzed in SNF-2770, Cold Vacuum Drying Facility Design Basis Accident Analysis Documentation, and the results of the analysis are presented in HNF-3553, Spent Nuclear Fuel Project Final Safety Analysis Report, Annex B, "Cold Vacuum Drying Facility Final Safety Analys is Report," Chapter B3.0, "Hazard and Accident Analyses." Based on the results of the analysis, the unmitigated release of radiological material could exceed onsite risk evaluation guidelines.

In this postulated accident scenario, a hydrogen explosion occurs because of a hydrogen-air mixture inside an MCO. The MCO VPS connections are credited in the analysis in protecting the pressure boundary for the MCO. 
APPL ICABLE SAFETY ANALYSES (continued)

\section{Multi-Canister Overpack Thermal Runaway Reaction}

Thermal runaway reactions inside the $M C O$ are analyzed in SNF-2770, Cold Vacuum Drying Facility Design Basis Accident Analysis Documentation, and the results of the analysis are presented in HNF-3553, Spent Nuclear Fuel Project Final Safety Analysis Report, Annex B, "Cold Vacuum Drying Facility Final Safety Analysis Report," Chapter B3.0, "Hazard and Accident Analyses." Based on the results of the analysis, the unmitigated release of radiological material could exceed offsite release 1 imits and onsite risk evaluation guidelines.

In this postulated accident scenario, a high-pressure thermal runaway reaction occurs from insufficient heat removal from the inside of the $M C O$. The $M C O$ vacuum and purge system connections are credited in the analysis to protect the pressure boundary for the MCO.

\section{Multi-Canister Overpack Overpressurization}

Overpressurization of the MCO is analyzed in SNF-2770, Cold Vacuum Drying Facility Design Basis Accident Analysis Documentation, and the results of the analysis are presented in HNF-3553, Spent Nuclear Fuel Project Final Safety Analysis Report, Annex B, "Cold Vacuum Drying Facility Final Safety Analys is Report," Chapter B3.0, "Hazard and Accident Analyses." Based on the resuits of the analysis, the unmitigated release of radiological material could exceed offsite release limits and onsite risk evaluation guidelines.

In this postulated accident scenario, a high-pressure release of radioactive material results from MCO isolation and a resulting high MCO internal pressure. The MCO VPS connections are credited in the analysis in providing a vent path from the MCO to the high-efficiency particulate air (HEPA)-filtered process bay local exhaust heating, ventilation, and air conditioning and process vent system to control high-pressure releases from an MCO isolated from the process system. 


\section{BASES}

LCO

The MCO VPS connections are required to be OPERABLE with a $30 \mathrm{lb} / \mathrm{in}^{2}$ gauge vent path and leaktight VPS process connections prior to initiating MCO draining. For the MCO vent path to be OPERABLE, it must be aligned properly to the $30 \mathrm{lb} / \mathrm{in}^{2}$ gauge rupture disk (DESIGN FEATURE) and pressure relief valve. The pressure relief valve, which is an active component of the vent path, must be capable of reljeving pressures less than or equal to $35 \mathrm{lb} / \mathrm{in}^{2}$ gauge and reseat at pressures greater than or equal to 20 $\mathrm{lb} / \mathrm{in}^{2}$ gauge. The $30 \mathrm{lb} / \mathrm{in}^{2}$ gauge vent path provides a margin of safety to protect the $150 \mathrm{lb} / \mathrm{in}^{2}$ gauge MCO rupture disk. For the process connections to be OPERABLE, they must be leaktight.

Functional requirements for determining the OPERABILITY of the MCO VPS connections are also defined in HNF-3553, Chapter B4.0, "Safety Structures, Systems, and Components." Detailed functional requirements for determining the OPERABILITY of the system may be found in procedures.

MODE

APPLICABILITY
LCO 3.3.1 applies during process bay OPERATION SUBMODE because processing of MCOs is allowed in this SUBMODE. LCO 3.3.1 does not apply in process bay STANDBY or REPAIR SUBMODES because the process bay is not allowed to contain an MCO in these SUBMODES.
PROCESS AREA APPLICABILITY
LCO 3.3.1 applies from the time the MCO filtered process exit port valve is opened until successful completion of the final pressure rebound test (AC 5.17, "Dryness Testing") and both MCO process tube plug valves are closed. Once the MCO is dried sufficiently (as demonstrated by $A C$ 5.17) and isolated, pressure control from the $30 \mathrm{lb} / \mathrm{in}^{2}$ gauge VPS vent path is no longer needed and system leakage is no longer a hazard for the MCO. 

time limit following failure to meet the LCO is a VIOLATION. For this situation, proceed in accordance with AC 5.4.3, "Response to a Limiting Condition for Operation and Limiting Control Setting VIOLATION."

\section{$\underline{A .1}$}

When the VPS process connections are not leaktight prior to initiating MCO draining, Condition $A$ is entered. Condition A requires Required Action A.1 to be performed prior to initiating MCO draining.

Required Action A.1 requires the VPS process connections to be leaktight prior to initiating MCO draining. When the process connections are not leaktight, the primary confinement boundary for the MCO is compromised and the potential exists for system leaks. Restoring the VPS process connections to be leaktight would allow exit from the Required Actions because the LCO will be met. The Completion Time of prior to initiating MCO draining allows sufficient time to complete the necessary activities to prepare for draining while limiting the length of time between the leak test and actual draining operations.

\section{$\underline{B .1}$}

When the pressure relief valve is inoperable, Condition $B$ is entered. Condition B requires Required Action B.1 to be performed within 7 days of the discovery.

Required Action B.l requires the valve to be restored to OPERABLE status within 7 days. With an inoperable pressure relief valve, the capability of the $30 \mathrm{lb} / \mathrm{in}^{2}$ gauge vent path to relieve excessive MCO pressures is compromised. Restoring the valve to OPERABLE status would allow exit from the Required Actions because the LCO will be met. The Completion Time of 7 days allows sufficient time for performance of activities to restore the valve in a safe and orderly manner and minimizes the time in which the primary confinement boundary for the MCO is compromised. 
SURVEILLANCE REQUIREMENTS
Failure to successfully meet the SR (i.e., SR acceptance criteria not satisfied) during the Surveillance or between performances of the Surveillance is a failure to meet the LCO. For this situation, entry into the LCO ACTIONS is required. Failure to perform the Surveillance within the specified Frequency (including the allowable 25\% extension) is a VIOLATION. For this situation, proceed in accordance with $A C 5.4 .4 .2$, "Failure to Perform an SR Within the Required Time Limit."

\section{SR 3.3.1.1}

This Surveillance requires a VERIFICATION that the $30 \mathrm{lb} / \mathrm{in}^{2}$ gauge vent path to the local exhaust has been connected to the filtered process exit port connector and is operational (i.e., the related MCO process tube plug valve is open). This VERIFICATION ensures that the vent path is aligned properly to the $30 \mathrm{lb} / \mathrm{in}^{2}$ gauge rupture disk (DESIGN FEATURE) and pressure relief valve. The Frequency of when MCO process connections are made has been established based on the fact that this VERIFICATION must be performed at the same time the connections are made. When properly aligned, the $301 \mathrm{~b} / \mathrm{in}^{2}$ gauge vent path becomes part of the extended pressure boundary of the MCO.

\section{SR 3.3.1.2}

This Surveillance requires a leak test of the VPS process connections to VERIFY that the system is leaktight. This VERIFICATION ensures that no unacceptable leakage exists from the connections prior to initiating MCO draining. When the process connections are demonstrated to be leak-tight, they become part of the extended pressure boundary of the MCO. VERIFICATION of the system leakage rate can be performed by a pressure decay test or by pressurizing the MCO long axial process tube port and filtered process exit port with helium and using mass spectrometer leak detection capability or other available means to detect helium leakage. 
SURVEILLANCE REQUIREMENTS (cont inued)
The Frequency of prior to initiating MCO draining has been established based upon the need to confirm adequate leak-tightness prior to draining, and engineering judgement that such a confirmation too far in advance of draining operations increases the likelihood of events that have the potential to cause leaks. The Frequency of prior to initiating MCO draining allows sufficient time to complete the necessary activities to prepare for draining, while limiting the length of time between the leak test and actual draining operations.

\section{$\underline{\operatorname{SR~} 3.3 .1 .3}$}

This Surveillance requires a FUNCTIONAL TEST of the spring-loaded pressure relief valve to VERIFY that the valve will crack open at a pressure $\leq 351 \mathrm{~b} / \mathrm{in}^{2}$ gauge and reseat at a pressure $\geq 20 \mathrm{lb} / \mathrm{in}^{2}$ gauge. The pressure safety relief valve is part of the $30 \mathrm{lb} / \mathrm{in}^{2}$ gauge vent path and protects the MCO $150 \mathrm{lb} / \mathrm{in}^{2}$ gauge rupture disk.

The Frequency of annualiy is consistent with the anticipated requirements of the Spent Nuclear Fuel Project Preventive Maintenance/Testing Program.

REFERENCES

HNF-3553, 1999, Spent Nuclear Fuel Project Final Safety Analysis Report, Rev. 0, Annex B, "Cold Vacuum Drying Facility Final Safety Analys is Report," Fluor Daniel Hanford, Incorporated, Richland, Washington.

SNF-2770, 1999, Cold Vacuum Drying Facility Design Basis Accident Analysis Documentation, Rev. 2, Fluor Daniel Hanford, Incorporated, Richland, Washington. 


\section{B 3.3 MULTI-CANISTER OVERPACK PRESSURE PROTECTION}

\section{B 3.3.2 Pressure Safety Relief Valves}

BASES

BACKGROUND

This LCS/LCO ensures OPERABILITY of pressure safety relief valves to prevent an uncontrolled pressurized gaseous release caused by exceeding the design pressure of the multi-canister overpack (MCO). An overpressurization of the MCO can occur because of cascading failures of the helium supply pressure regulators for either the general-service helium system or the standby safety-class helium (SCHe) system during several phases of the cold vacuum drying operation. This LCS/LCO protects SL 2.1.1, "Multi-Canister Overpack Maximum Pressure," against general-service helium supply overpressurization. In the event of SCHe supply overpressurization, the MCO is protected by rupture disks (DESIGN FEATURES) and pressure control valves (LCO 3.2.1, "Safety-Class Helium System").

The MCO, loaded with spent nuclear fuel (SNF) from the $100 \mathrm{~K}$ Reactor SNF storage basins, is shipped to the Cold Vacuum Drying Facility (CVDF). At the CVDF nearly all of the water is removed from the MCO and the MCO is backfilled with helium. Then, the MCO is sealed and leak tested before transport to the Canister Storage Building for interim storage. Five sources of helium are provided in each process bay. Included are the general-service helium system (tube trailer) and the standby SCHe system (four helium gas cylinders). Helium is an inert gas with good thermal conductivity and is used in process operations to provide enhanced thermal conduction, to purge the MCO of hydrogen and other gasses, to pressurize the MCO to preclude further air ingress, and to provide an inert backfill of the MCO when drying is complete.

The general-service helium system provides pressurized helium for process operations, process support activities, and process safety functions. The general-service helium system is located both inside and outside the CVDF. Outside the facility, the general-service helium system is composed of helium tube (storage) transporters (truck/trailers) and the piping and valving associated with delivering the helium to the CVDF. 
BACKGROUND (continued)
Within the CVDF, the general-service helium system consists of a piping system, with associated valves and controls, for delivering helium to each of the four processing bays and the process water conditioning tank room. The general-service hel ium system provides helium for purging the headspace of the cask prior to opening to the process bay, for purging the MCO headspace, for purging the vacuum purge system equipment, and for purging the process water conditioning line and tanks.

Redundant pressure relief is provided on the generalservice helium system by safety relief valves He-SRV-5026 and He-SRV-5031 to reduce helium supply pressures to acceptable levels prior to entering the process system within the process equipment skid. The redundant valves are located on the main helium supply header for all of the process bays in the CVDF. The general-service helium system and safety relief valves are described in SNF-3067, Cold Vacuum Drying Facility General Service Helium System Design Description. The SCHe system and pressure relief devices are described in SNF-3068, Cold Vacuum Drying Facility Safety Class Helium System Design Description.

The consequences of exceeding the design pressure of the MCO is a potential uncontrolled release of radiological material to onsite workers and the environment and potential structural failure of the MCO. 
APPLICABLE SAFETY ANALYSES
LCS/LCO 3.3.2 is required for one accident scenario: Multi-Canister Overpack Overpressurization.

\section{Multi-Canister Overpack Overpressurization}

Overpressurization of the MCO is analyzed in SNF-2770, Cold Vacuum Drying Facility Design Basis Accident Analysis Documentation, and the results of the analysis are presented in HNF-3553, Spent Nuclear Fuel Project Final Safety Analysis Report, Annex B, "Cold Vacuum Drying Facility Final Safety Analysis Report, "Chapter B3.0, "Hazard and Accident Analyses." Based on the results of the analysis, the unmitigated release of radiological material could exceed offsite release limits and onsite risk evaluation guidelines.

In this postulated accident scenario, a gaseous release results from failure of the MCO by overpressurization from the general-service helium supply system. The pressure safety relief valves are credited in the analysis to protect the MCO from helium overpressure from the generalservice helium tube trailers.

Redundant pressure safety relief valves He-SRV-5026 and He-SRV-5031 are required to be OPERABLE to ensure that helium supply pressures are reduced to acceptable levels prior to the helium entering the process system.

The setpoint of $<301 \mathrm{~b} / \mathrm{in}^{2}$ gauge for each valve was conservatively selected as the LCS value to protect SL 2.1.1, "Mu1ti-Canister Overpack Maximum Pressure." The setpoint provides a significant margin of safety to the safety limit of $340 \mathrm{lb} / \mathrm{in}^{2}$ gauge for the MCO and protects the $30 \mathrm{lb} / \mathrm{in}^{2}$ gauge vent path on the $\mathrm{MCO}$. The setpoint also allows for a normal valve setting of $25 \mathrm{lb} / \mathrm{in}^{2}$ gauge.

Functional requirements for determining the OPERABILITY of the pressure safety relief valves are also defined in HNF-3553, Chapter B4.0, "Safety Structures, Systems, and Components." Detailed functional requirements for determining the OPERABILITY of the valves may be found in procedures. 
MODE

APPLICABILITY
LCS/LCO 3.3.2 applies during facility OPERATION MODE because processing of MCOs in the process bays is allowed in this MOOE. LCS/LCO 3.3.2 does not apply in facility STANDBY or SHUTDOWN MODES because the facility is not allowed to contain MCOs within the process bays in these MODES.
PROCESS AREA APPLICABILITY
LCS/LCO 3.3.2 applies to the general-service helium system main supply header. The general-service helium system main supply header supplies helium to all of the process bays in the CVDF and is the location in which the pressure safety relief valves are installed.

ACTIONS

Failure to take the ACTIONS required within the required time limit following failure to meet the LCO is a VIOLATION. For this situation, proceed in accordance with AC 5.4.3, "Response to a Limiting Condition for Operation and Limiting Control Setting VIOLATION."

\section{A. 1}

When one pressure safety relief valve is inoperable, Condition $A$ is entered. Condition $A$ requires Required Action A.1 to be performed within 7 days of the discovery.

Required Action A.l requires the valve to be restored to OPERABLE status within 7 days. With one valve inoperable, a redundant safety-class valve still remains available to prevent excessive helium pressure inside the MCO from the general-service helium supply system. The Completion Time of 7 days allows sufficient time for performance of activities to restore the valve in a safe and orderly manner and minimizes the time in which the required safety-class redundancy is lost. Upon restoration of the valve to OPERABLE status, Condition $A$ is exited. 
ACTIONS (cont inued)

\section{B.1, B.2, and B.3}

When both pressure safety relief valves are inoperable, Condition $B$ is entered. Condition $B$ requires Required Actions B.1, B.2, and B.3 to be performed upon discovery.

Required Action B.1 requires both train $A$ and train $B$ of the ISO \& Purge trip within the affected process bays to be actuated within I hour. Actuation of the ISO \& Purge trip isolates the MCO from the process systems by de-energizing closed the eight $M C O$ isolation valves and actuates the SCHe system by de-energizing open the four SCHe isolation valves to provide a flow of helium to the MCO. The Completion Time of 1 hour allows sufficient time for operations personnel to complete this manual action in an orderly manner. Required Action B. 2 requires isolation of the normal general-service helium supply from the $\mathrm{SCHe}$ system within the affected process bays to be performed within 1 hour. The Completion Time of 1 hour allows sufficient time for performance of activities to physically isolate the general-service helium system from the SCHe system. Completion of Required Actions B.1 and B.2 establish a safe condition for the facility by precluding a blowdown through the MCO.

Required Action B. 3 requires one valve to be restored to OPERABLE status within 96 hours. The Completion Time of 96 hours is based on the maximum credible leak in the SCHe system and the capacity of the SCHe supply. 
SURVEILLANCE REQUIREMENTS
Failure to successfully meet the SR (i.e., SR acceptance criteria not satisfied) during the Surveillance or between performances of the Surveillance is a failure to meet the LCO. For this situation, entry into the LCO ACTIONS is required. Failure to perform the Surveillance within the specified Frequency (including the allowable 25\% extension) is a VIOLATION. For this situation, proceed in accordance with AC 5.4.4.2, "Failure to Perform an SR Within the Required Time Limit."

\section{SR 3.3.2.1}

This Surveillance requires a FUNCTIONAL TEST to VERIFY that pressure safety relief valves He-SRV-5026 and He-SRV-503l lift at a setpoint $<301 \mathrm{~b} / \mathrm{in}^{2}$ gauge. The valves are tested by raising the system pressure to the valve's set pressure. The Frequency of annually is consistent with the anticipated requirements of the Spent Nuclear Fuel Project Preventive Maintenance/Testing Program.
REFERENCES
HNF-3553, 1999, Spent Nuclear Fuel Project Final Safety Analysis Report, Rev. 0, Annex B, "Cold Vacuum Drying Facility Final Safety Analysis Report, "Fluor Daniel Hanford, Incorporated, Richland, Washington.

SNF-2770, 1999, Cold Vacuum Drying Facility Design Basis Accident Analysis Documentation, Rev. 2, Fluor Daniel Hanford, Incorporated, Richland, Washington.

SNF-3067, 1999, Cold Vacuum Drying Facility General Service Helium System Design Description, Rev. 1, Fluor Daniel Hanford, Incorporated, Richland, Washington.

SNF-3068, 1999, Cold Vacuum Drying Facility Safety Class Helium System Design Description, Rev. 1, Fluor Daniel Hanford, Incorporated, Richland, Washington. 
B 3.4 HEATING, VENTILATION, AND AIR CONDITIONING SYSTEMS

B 3.4.1 Process General Supply/Exhaust Heating, Ventilation, and Air Conditioning System

BASES

BACKGROUND

Two heating, ventilation, and air conditioning (HVAC) systems, the process bay local exhaust HVAC and process vent system and the general supply/exhaust HVAC system, provide airborne radioactive material confinement within the radiologically controlled areas of the Cold Vacuum Drying Facility (CVDF) and provide high-efficiency particulate air (HEPA)-filtered discharge via the CVDF stack. Each process bay also has an independent process bay recirculation system that provides outside HEPA-filtered air supply and recirculation for heating and air conditioning. During normal operations all exhaust systems are functioning. Confinement is maintained with differential pressure control. Differential pressures are monitored via the reference air system.

The transfer corridor, associated support rooms (excluding the electrical support room), the tank room, and the mechanical room are supplied with conditioned air from the process general supply/exhaust HVAC system. Two 100\%-capacity exhaust fans are provided for the general supply/exhaust HVAC system. The air in this system is not recirculated. Pneumatic isolation dampers are provided on the outside air intake and tank room supply duct to prevent backflow of air in the event of system shutdown. Only the exhaust portion of the system is credited with mitigation (HEPA filtration) to accomplish confinement.

The CVDF confinement systems are described in HNF-3553, Spent Nuclear Fuel Project Final Safety Analysis Report, Annex B, "Cold Vacuum Drying Facility Final Safety Analysis Report," Chapter B2.0, "Facility Description." 
APPLICABLE SAFETY ANALYSES
LCO 3.4.1 is required for five accident scenarios:

(1) Gaseous Release, (2) Liquid Release,

(3) Multi-Canister Overpack Internal Hydrogen Explosion,

(4) Multi-Canister Overpack External Hydrogen Explosion, and (5) Multi-Canister Overpack Overpressurization.

\section{Gaseous Release}

Gaseous release events are analyzed in SNF-2770, Cold Vacuum Drying Facility Design Basis Accident Analysis Documentation, and the results of the analys is are presented in HNF-3553, Spent Nuclear Fuel Project Final Safety Analysis Report, Annex B, "Cold Vacuum Drying Facility Final Safety Analysis Report," Chapter B3.0, "Hazard and Accident Analyses." Based on the results of the analysis, the unmitigated release of radiological material could exceed onsite risk evaluation guidelines.

In this postulated accident scenario, a gaseous release results from a pressurized release of helium gas and entrained contaminated particulate through a process line leak. The process general supply/exhaust HVAC system is credited in the analysis to mitigate releases to the process bay through HEPA filtration.

\section{Liquid Release}

Liquid release events are analyzed in SNF-2770, Cold Vacuum Drying Facility Design Basis Accident Analysis Documentation, and the results of the analysis are presented in HNF-3553, Spent Nuclear Fuel Project Final Safety Analysis Report, Annex B, "Cold Vacuum Drying Facility Final Safety Analys is Report," Chapter B3.0, "Hazard and Accident Analyses." Based on the results of the analysis, the unmitigated release of radiological material could exceed onsite risk evaluation guidelines.

In this postulated accident scenario, a liquid release results from a pressurized leak of water and entrained contaminated particulate from the process water conditioning piping. The process general supply/exhaust HVAC system is credited in the analys is to mitigate releases to the process water tank room through HEPA filtration. 
APPLICABLE SAFETY ANALYSES (continued)
Multi-Canister Overpack Internal Hydrogen Explosion

A hydrogen explosion inside an MCO is analyzed in SNF-2770, Cold Vacuum Drying Facility Design Basis Accident Analysis Documentation, and the results of the analys is are presented in HNF-3553, Spent Nuclear Fuel Project Final Safety Analysis Report, Annex B, "Cold Vacuum Drying Facility Final Safety Analysis Report," Chapter B3.0, "Hazard and Accident Analyses." Based on the results of the analysis, the unmitigated release of radiological material could exceed onsite risk evaluation guidelines.

In this postulated accident scenario, a hydrogen explosion occurs because of a hydrogen-air mixture inside an MCO. The process general supply/exhaust HVAC system is credited in the analysis to mitigate releases to the process bay through HEPA filtration in the event of a release.

Multi-Canister Overpack External Hydrogen Explosion

A hydrogen explosion outside an $M C O$ is analyzed in SNF-2770, Cold Vacuum Drying Facility Design Basis Accident Analysis Documentation, and the results of the analysis are presented in HNF-3553, Spent Nuclear Fuel Project Final Safety Analysis Report, Annex B, "Cold Vacuum Drying Facility Final Safety Analysis Report," Chapter B3.0, "Hazard and Accident Analyses." Based on the results of the analysis, the unmitigated release of radiological material could exceed onsite risk evaluation guidelines.

In this postulated accident scenario, a hydrogen explosion occurs because of accumulation of hydrogen inside an MCO, which is subsequently vented into the process bay and mixed with air. The resulting flammable mixture is postulated to explode, causing a particulate release. 


\section{APPLICABLE SAFETY ANALYSES (cont inued)}

\section{Multi-Canister Overpack Overpressurization}

Overpressurization of the MCO is analyzed in SNF-2770, Cold Vacuum Drying Facility Design Basis Accident Analysis Documentation, and the results of the analysis are presented in HNF-3553, Spent Nuclear Fuel Project Final Safety Analysis Report, Annex B, "Cold Vacuum Drying Facility Final Safety Analysis Report," Chapter B3.0, "Hazard and Accident Analyses." Based on the results of the analysis, the unmitigated release of radiological material could exceed offsite release limits and onsite risk evaluation guidelines.

In this postulated accident scenario, a high-pressure release of radioactive material results from MCO isolation and a resulting high MCO internal pressure. The process general supply/exhaust HVAC system is credited in the analysis to mitigate releases to the process bay through HEPA filtration.

The process general supply/exhaust HVAC system is required to be OPERABLE, with a HEPA filter box filtration efficiency $\geq 99.9 \%$.

The HEPA filter efficiency is necessary to provide mitigation of particulate releases to within the onsite risk evaluation guidelines. The filtration efficiency specified for the HEPA filter protects the assumptions within the safety analysis that assumed a $99.9 \%$ filter efficiency. This efficiency brought the mitigated dose down more than an order of magnitude less than the onsite evaluation guideline value.

Functional requirements for determining the OPERABILITY of the process general supply/exhaust HVAC system are also defined in HNF-3553, Chapter B4.0, "Safety Structures, Systems, and Components." Detailed functional

requirements for determining the OPERABILITY of the system may be found in procedures. 
MODE

APPLICABILITY
LCO 3.4.1 applies in facility OPERATION and STANDBY MODES because MCO processing occurs in OPERATION MODE. Even in STANDBY MODE, process water tank room transfers or recirculation may be occurring. While these activities are occurring, gaseous or spray leaks that require filtration are possible. LCO 3.4.1 does not apply in SHUTDOWN MODE because MCOs are not present and process water tank room pumping operations are not allowed in this MODE.
PROCESS AREA APPLICABILITY
LCO 3.4.1 applies when the process general supply/exhaust HVAC system fans are operating. When the process general supply/exhaust HVAC system fans are not operating, the system is not providing any differential pressure to the bays or the process water tank room. This effectively eliminates the process general HVAC system as a credited exit path for any releases, making the confinement (i.e., HEPA filtration) function of the process general HVAC system no longer applicable.

ACTIONS

Failure to take the ACTIONS required within the required time limit following failure to meet the $\mathrm{LCO}$ is a VIOLATION. For this situation, proceed in accordance with AC 5.4.3, "Response to a limiting Condition for Operation and Limiting Control Setting VIOLATION."

\section{A.1}

When the HEPA filter box filtration efficiency is $<99.9 \%$, Condition $A$ is entered. This constitutes a degraded condition that prevents the system from performing its safety function to provide confinement within the process bays and the process water tank room. 
ACTIONS (cont inued)
Required Action A.1 requires that the process general supply/exhaust HVAC system operation be stopped within 4 hours. The completion Time of 4 hours allows time to correct small process upsets without requiring the process general supply/exhaust HVAC system to be taken out of service. The Completion Time provides an adequate margin of safety, based on conservative analysis assumptions that show that onsite risk evaluation guidelines are not exceeded for release durations of less than approximately 12 hours.

Stopping the process general supply/exhaust HVAC system operation entails isolating the process bays from the HVAC system and shutting down the exhaust fans. Because the process bay local exhaust HVAC and process vent system is capable of maintaining differential pressures within the bays, this effectively eliminates the process general HVAC system as an exit path for any releases, making the confinement function of the process general HVAC system no longer required for the bays. For the process water tank room, the loss of the process general supply/exhaust HVAC system will result in a loss of differential pressure. This will necessitate the shutdown of any circulating pumps that may be operating to protect the LCO requirements of LCO 3.4.3, "Reference Air System." Shutting down the pumps before the process general supply/exhaust HVAC system is stopped may be prudent as this will prevent entry into the ACTIONS of LCO 3.4.3. 
SURVEILLANCE REQUIREMENTS
Failure to successfully meet the SR (i.e., SR acceptance criteria not satisfied) during the Surveillance or between performances of the Surveillance is a failure to meet the LCO. For this situation, entry into the LCO ACTIONS is required. Failure to perform the Surveillance within the specified Frequency (including the allowable 25\% extension) is a VIOLATION. For this situation, proceed in accordance with AC 5.4.4.2, "Failure to Perform an SR Within the Required Time Limit."

\section{$\underline{\operatorname{SR} 3.4 .1 .1}$}

This Surveillance to VERIFY the HEPA filter box efficiency to be $\geq 99.9 \%$ is a direct measure of the system's OPERABILITY. Although there are two separate banks of HEPA filters within the filter box, only the combined efficiency of the unit as a whole was credited in the safety analysis. Therefore, the efficiency of individual filters are not required as part of this Surveillance but, rather, the overall unit efficiency.

The VERIFICATION Frequency of annually is consistent with manufacturer recommendations and the Frequencies for such Surveillance of nuclear power plants.

REFERENCES

HNF-3553, 1999, Spent Nuclear Fuel Project Final Safety Analysis Report, Rev. 0, Annex B, "Cold Vacuum Drying Facility Final Safety Analys is Report," Fluor Daniel Hanford, Incorporated, Richland, Washington.

SNF-2770, 1999, Cold Vacuum Drying Facility Design Basis Accident Analysis Documentation, Rev. 2, Fluor Daniel Hanford, Incorporated, Richland, Washington. 
HNF-3673 REV 0 Process Bay Local Exhaust HVAC and Process Vent System

B 3.4.2

B 3.4 HEATING, VENTILATION, AND AIR CONDITIONING SYSTEMS

B 3.4.2 Process Bay Local Exhaust Heating, Ventilation, and Air Conditioning and Process Vent System

BASES

BACKGROUND

Two heating, ventilation, and air conditioning (HVAC) systems, the process bay local exhaust HVAC and process vent system and the general supply/exhaust HVAC system, provide airborne radioactive material confinement within the radiologically controlled areas of the Cold Vacuum Drying Facility (CVDF) and provide high-efficiency particulate air (HEPA)-filtered discharge via the CVDF stack. Each process bay also has an independent process bay recirculation system that provides outside HEPA-filtered air supply and recirculation for heating and air conditioning. During normal operations all exhaust systems are functioning. Confinement is maintained with differential pressure control. Differential pressures are monitored via the reference air system.

The process bay local exhaust HVAC and process vent system serves the multi-canister overpack (MCO) process hoods and the process vent system streams that may normally be contaminated. Two $100 \%$ capacity exhaust fans (10cated in the mechanical room) are provided for the process bay local exhaust system. The air in the process bay local exhaust system passes through an air handling unit (located in the mechanical equipment room) containing a prefilter and two HEPA filter stages before exhausting through the CVDF stack. If the lead local exhaust fan fails to start or fails during operation, an alarm is given at the control station and the stand-by local exhaust fan automatically starts. Standby power is provided to the fans to protect against a loss of facility power.

The CVDF confinement systems are described in HNF-3553, Spent Nuclear Fuel Project Final Safety Analysis Report, Annex B, "Cold Vacuum Drying Facility Final Safety Analysis Report," Chapter B2.0, "Facility Description." 
APPLICABLE SAFETY ANALYSES
LCO 3.4.2 is required for five accident scenarios:

(1) Gaseous Release, (2) Multi-Canister Overpack Internal Hydrogen Explosion, (3) Multi-Canister Overpack External Hydrogen Explosion, (4) Multi-Canister Overpack Thermal Runaway Reaction, and (5) Multi-Canister Overpack Overpressurization.

\section{Gaseous Release}

Gaseous release events are analyzed in SNF-2770, Cold Vacuum Drying Facility Design Basis Accident Analysis Documentation, and the results of the analysis are presented in HNF-3553, Spent Nuclear Fuel Project Final Safety Analysis Report, Annex B, "Cold Vacuum Drying Facility Final Safety Analysis Report," Chapter B3.0, "Hazard and Accident Analyses." Based on the results of the analysis, the unmitigated release of radiological material could exceed onsite risk evaluation guidelines.

In this postulated accident scenario, a gaseous release results from a pressurized release of helium gas and entrained contaminated particulate through a process line leak. The process bay local exhaust HVAC and process vent system is credited in the analysis to mitigate releases to the process bay through HEPA filtration.

\section{Multi-Canister Overpack Internal Hydrogen Explosion}

A hydrogen explosion inside an MCO is analyzed in SNF-2770, Cold Vacuum Drying Facility Design Basis Accident Analysis Documentation, and the results of the analysis are presented in HNF-3553, Spent Nuclear Fuel Project Final Safety Analysis Report, Annex B, "Cold Vacuum Drying Facility Final Safety Analysis Report," Chapter B3.0, "Hazard and Accident Analyses." Based on the results of the analysis, the unmitigated release of radiological material could exceed onsite risk evaluation guidelines.

In this postulated accident scenario, a hydrogen explosion occurs because of a hydrogen-air mixture inside an MCO. The process bay local exhaust HVAC and process vent system is credited in the analysis to mitigate releases to the process bay through HEPA filtration. 
APPLICABLE SAFETY ANALYSES (cont inued)
Multi-Canister Overpack External Hydrogen Explosion

A hydrogen explosion outside an $\mathrm{MCO}$ is analyzed in SNF-2770, Cold Vacuum Drying Facility Design Basis Accident Analysis Documentation, and the results of the analysis are presented in HNF-3553, Spent Nuclear Fuel Project Final Safety Analysis Report, Annex B, "Cold Vacuum Drying Facility Final Safety Analys is Report," Chapter B3.0, "Hazard and Accident Analyses." Based on the results of the analysis, the unmitigated release of radiological material could exceed onsite risk evaluation guidelines.

In this postulated accident scenario, a hydrogen explosion occurs because of accumulation of hydrogen inside an MCO, followed by ignition and explosion of the hydrogen gas when it is vented from the MCO into the local exhaust process ventilation system and mixed with air. The process bay local exhaust HVAC and process vent system is credited in the analysis to provide sufficient flow to dilute hydrogen concentrations to prevent flammable mixtures from forming.

\section{Multi-Canister Overpack Thermal Runaway Reaction}

Thermal runaway reactions inside the $M C O$ are analyzed in SNF-2770, Cold Vacuum Drying Facility Design Basis Accident Analysis Documentation, and the results of the analysis are presented in HNF-3553, Spent Nuclear Fuel Project Final Safety Analysis Report, Annex B, "Cold Vacuum Drying Facility Final Safety Analys is Report," Chapter B3.0, "Hazard and Accident Analyses." Based on the results of the analysis, the unmitigated release of radiological material could exceed offsite release limits and onsite risk evaluation guidelines.

In this postulated accident scenario, a thermal runaway reaction occurs from insufficient heat removal from the inside of the MCO. The process bay local exhaust HVAC and process vent system is credited in the analysis to mitigate releases due to safety-class helium actuation by providing HEPA filtration. 
APPLICABLE SAFETY ANALYSES (continued)

\section{Multi-Canister Overpack Overpressurization}

Overpressurization of the MCO is analyzed in SNF-2770, Cold Vacuum Drying Facility Design Basis Accident Analysis Documentation, and the results of the analys is are presented in HNF-3553, Spent Nuclear Fuel Project Final Safety Analysis Report, Annex B, "Cold Vacuum Drying Facility Final Safety Analys is Report," Chapter B3.0, "Hazard and Accident Analyses." Based on the results of the analysis, the unmitigated release of radiological material could exceed offsite release limits and onsite risk evaluation guidelines.

In this postulated accident scenario, a high-pressure release of radioactive material results from MCO isolation and a resulting high MCO internal pressure. The process bay local exhaust HVAC and process vent system is credited in the analysis to mitigate releases to the process bay through HEPA filtration.

The process bay local exhaust HVAC and process vent system is required to be OPERABLE with:

- Flow rate instrumentation and remote alarms with a flow switch setpoint $\geq 1120$ standard $\mathrm{ft}^{3} / \mathrm{min}$.

The instrumentation that measures the flow through the process bay local exhaust HVAC and process vent system and the remote alarms associated with the instrumentation are required to alert operators to a loss of proper system flow so appropriate operator actions can be taken. The setpoint must be set at or above 1120 standard $\mathrm{ft}^{3} / \mathrm{min}$ to account for instrument uncertainties of $10 \%$ of the read value. This setpoint will ensure that flows less than 1000 standard $\mathrm{ft}^{3} / \mathrm{min}$, as assumed in the accident analysis, do not go undetected by CVDF personnel. 
LCO (continued)
Two exhaust fans with a system flow rate in the process bay $\geq 1120$ standard $\mathrm{ft}^{3} / \mathrm{min}$.

The process bay local exhaust HVAC and process vent system is credited in the safety analys is as providing a highly reliable source of both differential pressure to the bays and hydrogen dilution. Both functions are accomplished by establishing a minimum flow through the process bay local exhaust HVAC and process vent system. The motive power for this flow is provided by the exhaust fans. Both fans must be OPERABLE (only one fan is operating at any one time) for the system to be considered OPERABLE, A value of 1000 standard $\mathrm{ft}^{3} / \mathrm{min}$ was assumed in the accident analysis. To account for an instrument error of $10 \%$, the flow rate through the system must be maintained $\geq 1120$ standard $\mathrm{ft}^{3} / \mathrm{min}$ (as read by instrumentation) in order to achieve its purpose of providing

differential pressures and hydrogen dilution.

- A flow switch interlock to the cask venting flow valve with a flow switch setpoint $\geq 1120$ standard $\mathrm{ft}^{3} / \mathrm{min}$.

The flow switch interlock is credited during cask venting for stopping the cask vent should 1 ocal exhaust flows fall below 1000 standard $\mathrm{ft}^{3} / \mathrm{min}$ as assumed in the accident analysis. This stops the flow of hydrogen to the process bay local exhaust HVAC and process vent system when insufficient dilution capabilities are present. The setpoint must be set at or above 1120 standard $\mathrm{ft}^{3} / \mathrm{min}$ to account for instrument uncertainties of $10 \%$ of the read value. This setpoint will ensure that hydrogen is not delivered to the process bay local exhaust HVAC and process vent system when inadequate dilution flows are present. 
LCO (continued)

MODE

APPL ICABILITY
A HEPA filter box with a filtration efficiency $\geq 99.9 \%$.

The HEPA filter efficiency is necessary to provide mitigation of particulate releases to within the onsite risk evaluation guidelines. The filtration efficiency specified for the HEPA filter protects the assumptions within the safety analysis that assumed a $99.9 \%$ filter efficiency. This efficiency brought the mitigated dose down more than an order of magnitude less than the onsite evaluation guideline value.

- Instrument air system piping, tank, and check valve with a tank pressure $\geq 90 \mathrm{lb} / \mathrm{in}^{2}$ gauge.

The process bay local exhaust HVAC and process vent system isolation dampers fail closed if there is a loss of electrical power. To ensure the process hood dampers on the process bay local exhaust HVAC and process vent system are reopened when standby power is activated and the local exhaust fans restart, an instrument air system is installed in each air line to each process bay hood isolation damper. The value of $90 \mathrm{lb} / \mathrm{in}^{2}$ ensures that sufficient pressure exists to operate the hood isolation damper.

Functional requirements for determining the OPERABILITY of the process bay local exhaust HVAC and process vent system are also defined in HNF-3553, Chapter B4.0, "Safety Structures, Systems, and Components." Detailed functional requirements for determining the OPERABILITY of the system may be found in procedures.

LCO 3.4.2 applies in process bay OPERATION SUBMODE because MCO processing occurs in process bay OPERATION SUBMODE. While processing is occurring, radioactive material and hydrogen releases that require filtration and dilution are possible. LCO 3.4.2 does not apply to a process bay when the facility is in the facility STANDBY or SHUTDOWN MODES, nor in the process bay STANDBY or REPAIR SUBMODES because MCO processing in the process bay is not allowed in these MODES. 
PROCESS AREA APPLICABILITY
LCO 3.4.2 applies from the time the process bay doors are closed until successful completion of the final pressure rebound test (AC 5.17, "Dryness Testing") and both MCO process tube plug valves are closed. Flow switch interlock requirements only apply when cask venting is occurring. When an MCO is not present in a bay, confinement and dilution functions are not credited as a safety function because there is insufficient material at risk and no hydrogen generation hazard to exceed risk evaluation guidelines. In addition, once the $M C O$ is dried sufficiently (as demonstrated by $A C 5.17$ ) and isolated, hydrogen explosions, thermal runaways, and $M C O$ overpressurizations are no longer a hazard for the CVDF.

\section{ACTIONS}

Failure to take the ACTIONS required within the required time limit following failure to meet the LCO is a VIOLATION. For this situation, proceed in accordance with AC 5.4.3, "Response to a Limiting Condition for Operation and Limiting Control Setting VIOLATION."

See Section 1.3, "Completion Times," for the definition of Immediately.

\section{A.1 and A.2}

When the process bay local exhaust HVAC and process vent system flow rate instrumentation (FS-8*07) or alarm is inoperable, Condition $A$ is entered. Although the loss of flow rate instrumentation and/or the alarm associated with the instrumentation does not mean that the required system flow is inadequate, it does represent a degraded condition where immediate notification of the loss of system flow is no Tonger possible. Required Action A.l implements compensatory measures to minimize the risk for the duration that this condition exists, and Action A.2 requires the system to be restored to OPERABLE status within 5 days. 
ACTIONS (continued)
Required Action A.l requires the periodic VERIFICATION that a process bay local exhaust HVAC and process vent system exhaust fan is operating once per 12 hours. Although specific flow rate information may not be available, a VERIFICATION that the exhaust fan is operating provides objective evidence that the system function is still being maintained and will alert CVDF personnel to a loss of local exhaust flow within 12 hours of its failure. The Frequency of 12 hours is based on the reliability of the process bay local exhaust HVAC and process vent system (i.e., redundant fans and standby power in the event of a loss of power) and the low likelihood of a radioactive material or hydrogen release during the short interval between VERIFICATIONS.

Required Action A.2 requires the restoration of the instrumentation and/or alarm to OPERABLE status within 5 days. The Completion Time of 5 days is established based upon the presence of compensatory measures and the low likelihood of an accident within this relatively short duration. Note that although processing may be completed within the 5-day interval, once the MCO exits the process bay the process bay enters STANDBY SUBMODE, and reentry into OPERATION SUBMODE (i.e., receipt of a new MCO within the affected bay) is not allowed until such time that this LCO is met as identified in LCO 3.0.4, "MODE Changes."

\section{B. $1, B .2$, and B.3}

When one process bay local exhaust HVAC and process vent system exhaust fan is inoperable, Condition $B$ is entered. Although the loss of one exhaust fan does not mean that the required system flow has been lost, it does represent a degraded condition with lowered system reliability. 
ACTIONS (cont inued)
Required Action B.1 requires a VERIFICATION that the alternate exhaust fan is OPERABLE and operating within 2 hours. Required Action B.2 requires a VERIFICATION that the process bay local exhaust HVAC and process vent system flow is $\geq 1120$ standard $\mathrm{ft}^{3} / \mathrm{min}$ (as read by instrumentation). If the second exhaust fan is inoperable or not capable of meeting the minimum required exhaust flow, Condition $E$ must be entered. VERIFICATION that the alternate fan is OPERABLE and operating, and that exhaust flows are adequate, provides assurance that the safety function provided by the process bay local exhaust HVAC and process vent system is maintained. The Completion Time of 2 hours allows the time necessary to perform the VERIFICATION in an orderly manner.

Required Action B. 3 requires restoration of the inoperable fan to OPERABLE status within 5 days. The Completion Time is based on the fact that the process bay local exhaust HVAC and process vent system safety function is still being maintained during this time period and on the low likelihood of an accident within this relatively short duration. Note that although processing may be completed within the 5-day interval, once the MCO exits the process bay the process bay enters STANDBY SUBMODE, and reentry into OPERATION SUBMODE (i.e., receipt of a new MCO within the affected bay) is not allowed until such time that this LCO is met as identified in LCO 3.0.4, "MODE Changes."

\section{$C .1, C .2$, and $C .3$}

When both process bay local exhaust HVAC and process vent system fans are inoperable, or the minimum system flow rate is not maintained, Condition $C$ is entered.

Required Action C.1 requires stopping any cask venting operations that may be occurring Immediately. Without the required minimum flow in the process bay local exhaust HVAC and process vent system to dilute hydrogen releases, continued venting could pose a hydrogen explosion hazard. 
ACTIONS

(continued)
Required Action C.2 requires the restoration of at least one exhaust fan to OPERABLE status within 4 hours, VERIFYING process bay local exhaust HVAC and process vent system flow $\geq 1120$ standard $\mathrm{ft}^{3} / \mathrm{min}$. The Completion Time is based on the need to restore system flows in a timely manner, and allows adequate time to perform the necessary actions for restoration in an orderly fashion. The Completion Time provides an adequate margin of safety, based on conservative analysis assumptions that show that onsite risk evaluation guidelines are not exceeded for release durations of less than approximately 12 hours.

The Note (that when at least one exhaust fan has been returned to OPERABLE and operating status, cask venting operations may resume) acknowledges that once proper dilution flows are restored, cask venting is once again allowed. Cask venting is an important activity in the pressure management of an MCO, and should be allowed as soon as conditions are acceptable.

Required Action C. 3 requires restoration of the system (i.e., full OPERABILITY) within 5 days. The Completion Time is based on the fact that restoration of the safety function has been successful with the completion of Required Action C.2 and that there is a relatively low likelihood of an accident requiring the minimum system flow within this relatively short duration.

\section{$\underline{D .1}$}

When process bay local exhaust HVAC and process vent system HEPA filter box filtration efficiency $<99.9 \%$, Condition $D$ is entered. If the HEPA filter box efficiency drops below the value assumed within the accident analysis, the ability of the process bay local exhaust HVAC and process vent system to filter radioactive material releases is in a degraded condition. Although flows still provide adequate dilution to protect against hydrogen releases, the filtration efficiency must be restored to $\geq 99.9 \%$ to protect against any future releases of radioactive material. 
ACTIONS (continued)
The Completion Time of 5 days is established to allow time for any MCOs in the facility to finish processing so the process bay local exhaust HVAC and process vent system can be shutdown. This course of action is based on the importance of flow maintenance while MCOs are being processed and the low likelihood of an accident occurring during the relatively short duration of this condition. In addition, the Completion Time recognizes that most entries into this condition are expected to be due to minor system degradation or an improperly performed surveillance, and therefore some level of filtration is expected to be present.

\section{$\underline{E .1}$}

When the Required Actions and associated Completion Times of Condition $C$ or $D$ are not met, Condition $E$ is entered. Required Action E.l requires that a facility-approved recovery plan be developed and actions initiated to restore compliance with this LCO within 24 hours. Long-term loss of the process bay local exhaust HVAC and process vent system's safety function is considered an extremely low likelihood event by the accident analysis. The nature of the outage and the facility conditions at the time make specific TSR Required Actions impossible to define. A recovery plan is appropriate in this case to resolve these situations.

\section{$\underline{F .1}$}

When the flow switch interlock to the cask venting flow valve is inoperable, Condition $F$ is entered. Required Action $F .1$ requires a VERIFICATION that the process bay local exhaust HVAC and process vent system flow in the affected bay is $\geq 1120$ standard $\mathrm{ft}^{3} / \mathrm{min}$ (as read by instrumentation) once per hour while performing venting operations. Performing this VERIFICATION provides a compensatory measure to ensure flow conditions are acceptable while venting activities are being conducted. Cask (and/or MCO) venting actions are important activities in the pressure management of an MCO, and should be allowed with compensatory measures for this short duration activity. Indefinitely postponing these activities poses a higher risk than taking compensatory measure and continuing with pressure management activities. 
ACTIONS

(cont inued)

\section{$\underline{G .1}$}

When the instrument air system is inoperable, Condition $G$ is entered. Without the capability to re-open the hood isolation damper following a loss of power, restoration of flow in the affected process bay cannot be assured.

Required Action G.l requires the restoration of the system to OPERABLE status within 5 days. The Completion Time of 5 days is based on the low likelihood of a facility power loss within this relatively short duration with a concurrent accident in the affected process bay requiring the presence of the process bay local exhaust HVAC and process vent system flow.
SURVEILLANCE REQUIREMENTS
Failure to successfully meet the SR (i.e., SR acceptance criteria not satisfied) during the Surveillance or between performances of the Surveillance is a failure to meet the LCO. For this situation, entry into the LCO ACTIONS is required. Failure to perform the Surveillance within the specified Frequency (including the allowable 25\% extension) is a VIOLATION. For this situation, proceed in accordance with AC 5.4.4.2, "Failure to Perform an SR Within the Required Time Limit."

\section{$\underline{\operatorname{SR} 3.4 .2 .1}$}

This Surveillance to VERIFY the flow rate in the process bay local exhaust HVAC and process vent system to be $\geq 1120$ standard $\mathrm{ft}^{3} / \mathrm{min}$ (as read by instrumentation) confirms OPERABILITY of the system to dilute hydrogen releases under accident conditions. This Surveillance is established so that undue reliance is not placed on the instrumentation provided to automatically alarm upon a loss of adequate flow. 
SURVEILLANCE REQUIREMENTS (cont inued)
The VERIFICATION Frequency of daily is based on the low potential for a hydrogen release to occur between Surveillances in conjunction with the low likelihood of the loss of adequate exhaust flow.

\section{SR 3.4.2.2}

This Surveillance to VERIFY that instrument air system tank pressure is $\geq 90 \mathrm{lb} / \mathrm{in}^{2}$ gauge will confirm OPERABILITY. The Frequency of daily is based on the low potential for a facility power loss to occur between Surveillances in conjunction with the low likelihood of an accident in the affected process bay requiring the presence of the process bay exhaust HVAC and process vent system flow.

\section{$\underline{S R ~ 3.4 .2 .3 ~}$}

This Surveillance to perform a FUNCTIONAL TEST of the process bay local exhaust HVAC and process vent system will confirm OPERABILITY. This FUNCTIONAL TEST should include VERIFICATION that alarms work as required, hood isolation dampers are capable of opening on demand, that both fans are capable of maintaining minimum flow requirements, and that each of the exhaust fans are capable of bringing flows up to minimum values within 30 seconds of being started. This function is required to ensure adequate flows are available upon a loss of power, which will trigger a safety-class instrumentation and control trip of the isolation and purge of the MCO to the process bay local exhaust HVAC and process vent system. Damper availability should include a pressure drop test of the instrument air system tank reservoir to ensure the system is leaktight. Chapter 4.0 of the SAR identifies a $0.5 \mathrm{lb} / \mathrm{in}^{2}$ pressure drop per hour as representing an acceptable leakage rate to ensure the safety function.

The Frequency of quarterly is consistent with manufacturer recommendations and the Frequencies for such Surveillance of nuclear power plants. 
SURVEILLANCE REQUIREMENTS

(continued)
SR 3.4.2.4

This Surveillance to perform a CALIBRATION of the flow rate instrumentation will confirm OPERABILITY prior to system operation.

The Frequency of semi-annually is consistent with manufacturer recommendations and the Frequencies for such Surveillance of nuclear power plants.

\section{SR 3.4 .2 .5}

This Surveillance to perform a CALIBRATION of the instrument air system tank reservoir pressure gauges will confirm OPERABILITY prior to system operation.

The Frequency of semi-annually is consistent with manufacturer recommendations and the Frequencies for such Surveillance of nuclear power plants.

\section{$\underline{\operatorname{SR} 3.4 .2 .6}$}

This Surveillance to VERIFY the HEPA filter box efficiency to be $\geq 99.9 \%$ is a direct measure of the system's OPERABILITY. Although there are two separate banks of HEPA filters within the filter box, only the combined efficiency of the unit as a whole was credited in the safety analysis. Therefore, the efficiency of individual filters are not required as part of this Surveillance but, rather, the overall unit efficiency.

The VERIFICATION Frequency of annually is consistent with manufacturer recommendations and the Frequencies for such Surveillance of nuclear power plants.

REFERENCES

HNF-3553, 1999, Spent Nuclear Fuel Project Final Safety Analysis Report, Rev. 0, Annex B, "Cold Vacuum Drying Facility Final Safety Analysis Report," Fluor Daniel Hanford, Incorporated, Richland, Washington.

SNF-2770, 1999, Cold Vacuum Drying Facility Design Basis Accident Analysis Documentation, Rev. 2, Fluor Daniel Hanford, Incorporated, Richland, Washington. 
B 3.4 HEATING, VENTILATION, AND AIR CONDITIONING SYSTEMS

\section{B 3.4.3 Reference Air System}

BASES

BACKGROUND

Two heating, ventilation, and air conditioning (HVAC) systems, the process bay local exhaust HVAC and process vent system and the general supply/exhaust HVAC system, provide airborne radioactive material confinement within the radiologically controlled areas of the Cold Vacuum Drying Facility (CVDF) and provide high-efficiency particulate air (HEPA)-filtered discharge via the CVDF stack. Each process bay also has an independent process bay recirculation system that provides outside HEPA-filtered air supply and recirculation for heating and air conditioning. During normal operations all exhaust systems are functioning. Confinement is maintained with differential pressure control. Differential pressures are monitored via the reference air system.

The reference air system provides continuous monitoring of the static pressure, relative to atmospheric pressure, of various spaces throughout the facility. The process bays and the process water tank room are maintained at a slight negative pressure with respect to atmosphere and to the remainder of the CVDF by the process bay local exhaust HVAC and process vent system and the process general supply/exhaust HVAC system. The reference air system consists of a series of static differential pressure sensors, located throughout the CVDF, that are interconnected by copper tubing. The reference pressure is measured by a static pressure sensor located above the administration building roof.

The CVDF confinement systems are described in HNF-3553, Spent Nuclear Fuel Project Final Safety Analysis Report, Annex B, "Cold Vacuum Drying Facility Final Safety Analysis Report," Chapter B2.0, "Facility Description." 
APPLICABLE SAFETY ANALYSES
LCO 3.4 .3 is required for five accident scenarios:

(1) Gaseous Release, (2) Liquid Release,

(3) Multi-Canister Overpack Internal Hydrogen Explosion,

(4) Multi-Canister Overpack External'Hydrogen Explosion, and (5) Multi-Canister Overpack Overpressurization.

\section{Gaseous Release}

Gaseous release events are analyzed in SNF-2770, Cold Vacuum Drying Facility Design Basis Accident Analysis Documentation, and the results of the analysis are presented in HNF-3553, Spent Nuclear Fuel Project Final Safety Analysis Report, Annex B, "Cold Vacuum Drying Facility Final Safety Analysis Report," Chapter B3.0, "Hazard and Accident Analyses." Based on the results of the analysis, the unmitigated release of radiological material could exceed onsite risk evaluation guidelines.

In this postulated accident scenario, a gaseous release results from a pressurized release of helium gas and entrained contaminated particulate through a process line leak. The reference air system is credited in the analysis to mitigate releases to the process bay by providing indication of adequate differential pressures to ensure the necessary HEPA filtration.

\section{Liquid Release}

Liquid release events are analyzed in SNF-2770, Cold Vacuum Drying Facility Design Basis Accident Analysis Documentation, and the results of the analysis are presented in HNF-3553, Spent Nuclear Fuel Project Final Safety Analysis Report, Annex B, "Cold Vacuum Drying Facility Final Safety Analysis Report, "Chapter B3.0, "Hazard and Accident Analyses." Based on the results of the analysis, the unmitigated release of radiological material could exceed onsite risk evaluation guidelines.

In this postulated accident scenario, a liquid release results from a pressurized leak of water and entrained contaminated particulate from the process water conditioning piping. The reference air system is credited in the analysis to mitigate releases to the process water tank room by providing assurance that adequate differential pressures exist to ensure the necessary HEPA filtration. 
APPLICABLE SAFETY ANALYSES (continued).

\section{Multi-Canister Overpack Internal Hydrogen Explosion}

A hydrogen explosion inside an $\mathrm{MCO}$ is analyzed in SNF-2770, Cold Vacuum Drying Facility Design Basis Accident Analysis Documentation, and the results of the analys is are presented in HNF-3553, Spent Nuclear Fuel Project Final Safety Analysis Report, Annex B, "Cold Vacuum Drying Facility Final Safety Analysis Report," Chapter B3.0, "Hazard and Accident Analyses." Based on the results of the analysis, the unmitigated release of radiological material could exceed onsite risk evaluation guidelines.

In this postulated accident scenario, a hydrogen explosion occurs because of a hydrogen-air mixture inside an MCO. The reference air system is credited in the analysis to mitigate a hydrogen explosion by providing assurance that adequate differential pressures exist to ensure the necessary HEPA filtration in the event of release.

\section{Multi-Canister Overpack External Hydrogen Explosion}

A hydrogen explosion outside an $M C O$ is analyzed in SNF-2770, Cold Vacuum Drying Facility Design Basis Accident Analysis Documentation, and the results of the analysis are presented in HNF-3553, Spent Nuclear Fuel Project Final Safety Analysis Report, Annex B, "Cold Vacuum Drying Facility Final Safety Analys is Report," Chapter B3.0, "Hazard and Accident Analyses." Based on the results of the analysis, the unmitigated release of radiological material could exceed onsite risk evaluation guidelines.

In this postulated accident scenario, a hydrogen explosion occurs because of accumulation of hydrogen inside an MCO during draining, followed by ignition and explosion of the hydrogen gas when it is vented into the process water tank room receiver tank and mixed with air. The reference air system is credited in the analysis to mitigate releases to the process water tank room by providing assurance that adequate differential pressures exist to ensure the necessary HEPA filtration. 


\begin{tabular}{|c|c|}
\hline \multirow{3}{*}{$\begin{array}{l}\text { APPLICABLE } \\
\text { SAFETY ANALYSES } \\
\text { (continued) }\end{array}$} & ti-Canister Overpack Overpressurization \\
\hline & $\begin{array}{l}\text { Overpressurization of the MCO is analyzed in SNF-2770, } \\
\text { Cold Vacuum Drying Facility Design Basis Accident Analysis } \\
\text { Documentation, and the results of the analysis are } \\
\text { presented in HNF-3553, Spent Nuclear Fuel Project Final } \\
\text { Safety Analysis Report, Annex B, "Cold Vacuum Drying } \\
\text { Facility Final Safety Analysis Report, "Chapter B3.0, } \\
\text { "Hazard and Accident Analyses." Based on the results of } \\
\text { the analysis, the unmitigated release of radiological } \\
\text { material could exceed offsite release limits and onsite } \\
\text { risk evaluation guidelines. }\end{array}$ \\
\hline & $\begin{array}{l}\text { In this postulated accident scenario, a high-pressure } \\
\text { release of radioactive material results from MCO isolation } \\
\text { and a resulting high MCO internal pressure. The reference } \\
\text { air system is credited in the analysis to mitigate } \\
\text { releases to the process bay by providing assurance that } \\
\text { adequate differential pressures exist to ensure the } \\
\text { necessary HEPA filtration in the event of release. }\end{array}$ \\
\hline
\end{tabular}


The reference air system shall be OPERABLE, with a process bay differential pressure indicator and remote alarm for each bay with a setpoint $<-0.013$ in. water gauge (i.e., $-0.013 \mathrm{in}$. Water gauge or more negative), and a process water tank room differential pressure indicator and remote al arm with a setpoint $<-0.013$ in. water gauge. This setpoint accounts for instrument error of 0.013 in. water gauge (refer to SNF-4451) to protect requirements of $<0$ in. water gauge specified in HNF-3553, Chapter B4.0, "Safety Structures, Systems, and Components." In addition, differential pressures in the process bays shall be maintained $<0$ in. water gauge (adjusted by the uncertainty of the monitoring instrumentation) relative to the reference air system, and differential pressures in the process water tank room shall be maintained $<0$ in. water gauge (as adjusted by the uncertainty of the monitoring instrumentation) relative to the reference air system.

The differential pressure instrumentation and remote al arms are necessary to alert CVDF personnel to a loss of adequate differential pressure within the process bays and the process water tank room. Differential pressures in these areas are relied upon to maintain confinement in the event of a radioactive material release. Any releases are directed to the appropriate HVAC system providing the differential pressure (confinement) and are filtered by a set of HEPA filters within the HVAC systems.

Functional requirements for determining the OPERABILITY of the reference air system are also defined in HNF-3553, Chapter B4.0, "Safety Structures, Systems, and Components." Detailed functional requirements for determining the OPERABILITY of the system may be found in procedures.

MODE

APPLICABILITY
LCO 3.4.3 applies during facility OPERATION and STANDBY MODES because MCO processing and process water tank room transfers occur in OPERATION MODE. Even in STANDBY MODE process water tank room transfer and recirculation activities are allowed. While these activities are occurring, gaseous or spray leaks that require confinement and filtration are possible. LCO 3.4.3 does not apply in SHUTDOWN MODE because MCOs are not present and process water tank room pumping operations are not allowed in this MODE. 
PROCESS AREA APPLICABILITY
Process bay minimum differential pressure requirements, indicator, and alarm are not required when an MCO is not present in the bay or when the process bay door is open. Process water tank room minimum differential pressure requirements, indicator, and alarm are not required if the circulation pump is not running.

When an MCO is not present within a bay, confinement of the bay is not necessary as a credited safety function because there is insufficient material at risk to exceed risk evaluation guidelines. In addition, when in the process of receiving or shipping an $\mathrm{MCO}$, the process bay door must be open, breaking confinement. During processing operations, the door remains closed at all times (per AC 5.12, "Process Bay Telescoping Door").

When the circulation pumps in the process water tank room are not running, no MCO draining is possible to the process water tank room. In addition, without the circulation pumps there is insufficient motive force to cause a release from line leakage in excess of the risk evaluation guidelines. Confinement of the room is therefore not necessary at these times.

ACTIONS

Failure to take the ACTIONS required within the required time limit following failure to meet the LCO is a VIOLATION. For this situation, proceed in accordance with AC 5.4.3, "Response to a Limiting Condition for Operation and Limiting Control Setting VIOLATION."

\section{$\underline{A .1}$}

When a differential pressure indicator or alarm for a process bay becomes inoperable, Condition $A$ is entered. Required Action A.1 requires the restoration of the inoperable equipment to OPERABLE status. The Completion Time of 8 hours allows time to perform the actions required to restore OPERABILITY in an orderly manner. The Completion Time reflects the low likelihood of losing differential pressure in conjunction with a release during the short duration of this condition. 
ACTIONS (continued)
A.2.1, A.2.2, and A.2.3

If conditions within the facility are such that restoration of equipment to OPERABLE status is not possible or prudent, an alternate set of Required Actions that impose an acceptable set of compensatory measures to allow drying activities to continue are identified. These actions allow the process bay to exit the LCO Applicability by completing MCO drying with these compensatory measures.

Without the capability to detect a loss of differential pressure, an acceptable compensatory measure is to establish a process bay configuration known to provide adequate differential pressures. This configuration relies solely upon safety-related engineered features with a high reliability to provide configuration.

Required Action A.2.1 requires the closure of the isolation dampers on the process general exhaust supply/exhaust HVAC system and the process bay recirculation HVAC system to affected bays. By isolating these general-service systems, the process bay local exhaust HVAC and process vent system becomes the relied upon source of differential pressure. (If the process general exhaust supply/exhaust HVAC system were left in service to this bay, a failure of this general-service system could jeopardize the confinement function due to the presence of additional in-flow locations to the process bay.) The Completion Time of 8 hours reflects the low likelihood of losing differential pressure in conjunction with a release during this short duration.

Required Action A.2.2 requires the VERIFICATION that the process hood isolation damper on the process bay local exhaust HVAC and process vent system is open within affected bays. This ensures that an open path to the process bay local exhaust HVAC and process vent system exists to provide confinement. The Completion Time of 8 hours reflects the low likelihood of losing differential pressure in conjunction with a release during this short duration. 
ACTIONS (continued)
Required Action A.2.3 requires periodic VERIFICATIONS that the flow rate in the process bay local exhaust HVAC and process vent system is $\geq 1000$ standard $\mathrm{ft}^{3} / \mathrm{min}$ within affected bays. This VERIFICATION provides assurance that the flow necessary to maintain differential pressures in the established configuration is maintained. Although alarm instrumentation exists on the system flow, this periodic VERIFICATION is required within 8 hours and once per 12 hours thereafter, to heighten awareness of this degraded condition and to provide additional reliability that any flow losses are detected so that corrective measures can be taken. Corrective actions are even more critical in this configuration because the process bay local exhaust HVAC and process vent system is the sole source of confinement.

\section{B.1}

When the process water tank room differential pressure indicator or alarm becomes inoperable, Condition $B$ is entered. Required Action B.I requires that the recirculation pumps in the process water tank room be shut down within 1 hour. When the circulation pumps in the process water tank room are not running, MCO draining to the process water tank room is not possible and there is insufficient motive force to cause a release in excess of the risk evaluation guidelines. Stopping the pumps exits the LCO Applicability. The Completion Time of 1 hour is based on the simplicity of the actions required, and allows sufficient time to complete shutdown in an orderly manner.

\section{$\underline{\text { C. } 1}$}

When the differential pressure in one or more process bays is $\geq 0$ in. water gauge relative to the reference air system (as adjusted for instrumentation uncertainty), Condition $C$ is entered. Required Action C.l requires that differential pressures in affected bays be restored to within limits within 8 hours. The Completion Time of 8 hours is based on the need to restore adequate confinement in a timely manner and allows adequate time to perform the necessary actions for restoration in an orderly fashion. 
ACTIONS

(continued)

\section{$\underline{D .1}$}

When the Required Action and associated Completion Time of Condition $C$ is not met, Condition $D$ is entered. Required Action 0.1 requires that a facility-approved recovery $\mathrm{plan}$ be developed and actions initiated to restore compliance with this LCO within 24 hours. Long-term loss of process bay confinement is considered an extremely low likelihood event by the accident analysis, and the nature of the outage and the facility conditions at the time make specific TSR Required Actions impossible to define. A recovery $\mathrm{plan}$ is appropriate in this case to resolve these situations.

\section{E.1}

When the differential pressure in the process water tank room is $\geq 0$ in. water gauge relative to the reference air system (as adjusted for instrumentation uncertainty), Condition $E$ is entered. Required Action E.l requires that the recirculation pumps in the process water tank room be shut down within 1 hour. When the circulation pumps in the process water tank room are not running, MCO draining to the process water tank room is not possible and there is insufficient motive force to cause a release in excess of the risk evaluation guidelines. Stopping the pumps exits the LCO Applicability. The Completion Time of 1 hour is based on the simplicity of the actions required, and allows sufficient time to complete shutdown in an orderly manner. 
SURVEILLANCE REQUIREMENTS
Failure to successfully meet the SR (i.e., SR acceptance criteria not satisfied) during the Surveillance or between performances of the Surveillance is a failure to meet the LCO. For this situation, entry into the LCO ACTIONS is required. Failure to perform the Surveillance within the specified Frequency (including the allowable $25 \%$ extension) is a VIOLATION. For this situation, proceed in accordance with AC 5.4.4.2, "Failure to Perform an SR Within the Required Time Limit."

\section{SR 3.4.3.1}

This Surveillance to perform a VERIFICATION of the differential pressures within the process bays and the process water tank room to VERIFY the values are within limits is an objective measure of the system's OPERABILITY. This Surveillance is established so that undue reliance is not placed on the instrumentation provided to automatically alarm upon a loss of adequate differential pressure.

The VERIFICATION Frequency of daily is based on the low potential for an accident to occur between Surveillances in conjunction with the low likelihood of undetected loss of confinement.

\section{SR 3.4.3.2}

This Surveillance to perform a FUNCTIONAL TEST of the differential pressure remote alarm will confirm OPERABILITY of the alarm to provide their safety function on demand.

The Frequency of quarterly is consistent with manufacturer recommendations and the Frequencies for such Surveillance of nuclear power plants.

\section{SR 3.4.3.3}

This Surveillance to perform a CHANNEL CALIBRATION of the differential pressure instrumentation maintains the OPERABILITY of the system to provide the proper information on differential pressures in the areas of concern.

The Frequency of semi-annually is consistent with manufacturer recommendations and the Frequencies for such Surveillance of nuclear power plants. 
REFERENCES HNF-3553, 1999, Spent Nuclear Fuel Project Final Safety Analysis Report, Rev. 0, Annex B, "Cold Vacuum Drying Facility Final Safety Analys is Report, "Fluor Danie1 Hanford, Incorporated, Richland, Washington.

SNF-2770, 1999, Cold Vacuum Drying Facility Design Basis Accident Analysis Documentation, Rev. 2, Fluor Daniel Hanford, Incorporated, Richland, Washington.

SNF-4451, 1999, Cold Vacuum Drying (CVD) Set Point Determination, Rev. OA, Fluor Daniel Hanford, Incorporated, Richland, Washington. 
B 3.4 HEATING, VENTILATION, AND AIR CONDITIONING SYSTEMS

B 3.4.4 High-Efficiency Particulate Air Filter Loading

BACKGROUND. This LCO ensures that the contact radiation levels of the high-efficiency particulate air (HEPA) filters are $\leq 82 \mathrm{mR} / \mathrm{h}$ in the Cold Vacuum Drying Facility (CVDF) process bay local exhaust heating, ventilation, and air conditioning (HVAC) system and process vent system. A hydrogen explosion in the vicinity of these HEPA filters can cause a release of particulates accumulated on the filters. The consequences of such an event are proportional to the particulate loading of the filters. Without controls, a hydrogen explosion in the vicinity of a particulate-loaded HEPA filter can result in unacceptable onsite consequences.

Each process bay contains a process bay local exhaust HVAC and process vent system that provides secondary airborne radiological material confinement for the multi-canister overpack (MCO) process hoods and the process vent system streams. The exhaust stream passes through two HEPA filter stages before discharge to the environment via the CVDF stack. The CVDF confinement systems are described in HNF-3553, Spent Nuclear Fuel Project Final Safety Analysis Report, Annex B, "Cold Vacuum Drying Facility Final Safety Analysis Report," Chapter B2.0, "Faci1ity Description." 
APPLICABLE SAFETY ANALYSES
LCO 3.4.4 is required for one accident scenario:

Multi-Canister Overpack External Hydrogen Explosion.

Multi-Canister Overpack External Hydrogen Explosion

A hydrogen explosion outside an $M C O$ is analyzed in SNF-2770, Cold Vacuum Drying Facility Design Basis Accident Analysis Documentation, and the results of the analysis are presented in HNF-3553, Spent Nuclear Fuel Project Final Safety Analysis Report, Annex B, "Cold Vacuum Drying Facility Final Safety Analysis Report," Chapter B3.0, "Hazard and Accident Analyses." Based on the results of the analysis, the unmitigated release of radiological material could exceed onsite risk evaluation guidelines.

In this postulated accident scenario, a release of radiological particulate in the HEPA filter occurs from a hydrogen explosion. Limiting the inventory of radiological material available for release from the process bay local exhaust HVAC and process vent system HEPA filters mitigates the quantity of release to below onsite risk evaluation guidelines.
The HEPA filter housing and prefilter housing contact radiation levels shall be $\leq 82 \mathrm{mR} / \mathrm{h}$.

Based on the results of the analysis, the release of radiological material caused by a hydrogen explosion near the filters could exceed onsite risk evaluation guidelines. This LCO protects the source term assumption in the accident analysis ( $94 \mathrm{~g}$ of particulate) by limiting the inventory on the filters available for release. The LCO value for the filter housing serves to ensure that the controls identified for risk reduction in the accident analysis remain valid. 
MODE

APPLICABILITY
LCO 3.4.4 applies during facility OPERATION MODE because the process bay local exhaust HVAC and process vent system is functioning during normal operations to maintain confinement. When the HVAC system is operating, flammable mixtures of hydrogen and air could be formed in the HVAC and process vent system when the cask-MCO is vented. LCO 3.4.4 does not apply during facility STANDBY or SHUTDOWN MODES because there are no sources of hydrogen present within the facility to cause a hazard associated with explosions in the process bay local exhaust HVAC and process vent system.
PROCESS AREA APPLICABILITY
LCO 3.4.4 applies to the HEPA filters and prefilters in the process bay local exhaust HVAC and process vent system. These filters were identified in the analysis as being capable of releasing radiological material to the environment in the event of a hydrogen explosion.

ACTIONS

Failure to take the ACTIONS required within the required time limit following failure to meet the LCO is a VIOLATION. For this situation, proceed in accordance with $A C$ 5.4.3, "Response to a Limiting Condition for Operation and Limiting Control Setting VIOLATION."

A.1

When the HEPA filter housing contact radiation levels exceed $82 \mathrm{mR} / \mathrm{h}$, Required Action $A .1$ requires the affected HEPA filter(s) to be replaced within 7 days. Filter replacement is accomplished using facility procedures in accordance with the institutional Hanford Site as low as reasonably achievable (ALARA) program.

The Completion Time of 7 days allows MCO processing in progress to be completed and the MCO to be shipped within a reasonable time frame. Note that although MCO processing and shipment may be completed within the 7-day interval, once the MCO exits the process bay the process bay enters STANDBY SUBMODE, and reentry into OPERATION SUBMODE (i.e., receipt of a new MCO within the affected bay) is not allowed until such time that this LCO is met as identified in LCO 3.0.4, "MODE Changes." The Completion Time is judged to be acceptable because the likelihood of a hydrogen explosion occurring during this time period is low. 
SURVEILLANCE REQUIREMENTS
Failure to successfully meet the SR (i.e., SR acceptance criteria not satisfied) during the Surveillance or between performances of the Surveillance is a failure to meet the LCO. For this situation, entry into the LCO ACTIONS is required. Failure to perform the Surveillance within the specified Frequency (including the allowable 25\% extension) is a VIOLATION. For this situation, proceed in accordance with AC 5.4.4.2, "Failure to Perform an SR Within the Required Time Limit."

\section{$\underline{\operatorname{SR} 3.4 .4 .1}$}

This Surveillance requires a VERIFICATION that the HEPA filter housing and prefilter housing contact radiation levels are $\leq 82 \mathrm{mR} / \mathrm{h}$ monthly.

Chapter B4.0 of HNF-3553 requires that a total of six dose readings shall be taken using an ion chamber instrument at designated points on the surface of the local exhaust filter box. These points are defined as the centerline of each of the three vertical filter rows for both the prefilter bank and the first HEPA filter bank. The readings shall be taken on the west side of the filter box at the center of each cover plate for that row of filters. A reading at or below $82 \mathrm{mR} / \mathrm{h}$ must be observed at each survey point for the Surveillance to be met.

The Frequency of monthly has been established based on the fact that the buildup of radiological particulates on the HEPA filters and prefilters is minimal when the process bay local exhaust HVAC and process vent system is operating.

REFERENCES

HNF-3553, 1999, Spent Nuclear Fuel Project Final Safety Analysis Report, Rev. 0, Annex B, "Cold Vacuum Drying Facility Final Safety Analysis Report, "Fluor Daniel Hanford, Incorporated, Richland, Washington.

SNF-2770, 1999, Cold Vacuum Drying Facility Design Basis Accident Analysis Documentation, Rev. 2, Fluor Daniel Hanford, Incorporated, Richland, Washington. 


\section{B 3.5 STANDBY POWER}

\section{B 3.5.1 Diesel Generator}

BASES

BACKGROUND

This LCO ensures OPERABILITY of the diesel generator to provide power to the local exhaust fans such that a satisfactory local exhaust flow is maintained for a gaseous release, hydrogen explosion, thermal runaway reaction, and multi-canister overpack (MCO) overpressurization. The local exhaust flow is necessary both to dilute hydrogen releases to the local exhaust from the $M C 0$, as well as to maintain adequate differential pressure within the process bays. Without differential pressure detection (because of the normal power loss), a configuration is required that ensures an adequate differential pressure. A local exhaust restart circuit will place the process bay local exhaust heating, ventilation, and air conditioning (HVAC) and process vent system in the required configuration (including fan motor logic) to ensure adequate system flow within 60 seconds after a loss of facility power. (Diesel power must be supplied to the process bay local exhaust HVAC and process vent system within 30 seconds, and the process bay local exhaust HVAC and process vent system fans must come up to the necessary speed within an additional 30 seconds.)

The diesel generator supplies standby power to specific independent loads through an automatic transfer switch. Normal power is monitored by the automatic transfer switch and if voltage and frequency fall below an established value, the diesel generator receives a start signal. Diesel generator startup is accomplished using a starting air system. The starting air tank which is maintained at a pressure greater than or equal to $1101 \mathrm{~b} / \mathrm{in}^{2}$ gauge provides the diesel generator with multiple start attempt capability. Once the diesel generator has reached rated voltage and frequency, standby power can be supplied through the automatic transfer switch to the loads credited in the safety analys is which include the process bay local exhaust HVAC and process vent system exhaust fan (only one fan runs at a time) and the process hood isolation damper actuator solenoid valves in each process bay. The diesel generators also supply loads that were not credited in the safety analysis and these may include facility uninterruptable power supply, instrument air compressors and heat trace for process bay fire protection and deionized water lines. 
BACKGROUND (continued)
The diesel generator building houses the generator, air start system, and control panel. The generator, fueled from a 50-gallon day tank containing at least 40 gallons and a 500-gallon fuel oil storage tank containing at least 150 gallons, allows approximately 24 hours of operation without refueling. A load bank is also provided to test the diesel generator.

The diesel generator has adequate capacity and rating for simultaneously operating designated loads and minimizes the impacts of a loss of normal power on process continuity and safety.
APPLICABLE SAFETY ANALYSES
LCO 3.5.1 is required for five accident scenarios: (1) Gaseous Release, (2) Multi-Canister Overpack Internal Hydrogen Explosion, (3) Multi-Canister Overpack External Hydrogen Explosion, (4) Multi-Canister Overpack Thermal Runaway Reaction, and (5) Multi-Canister Overpack Overpressurization.

\section{Gaseous Release}

Gaseous release events are analyzed in SNF-2770, Cold Vacuum Drying Facility Design Basis Accident Analysis Documentation, and the results of the analysis are presented in HNF-3553, Spent Nuclear Fuel Project Final Safety Analysis Report, Annex B, "Cold Vacuum Drying Facility Final Safety Analysis Report," Chapter B3.0, "Hazard and Accident Analyses." Based on the results of the analysis, the unmitigated release of radiological material could exceed onsite risk evaluation guidelines.

In this postulated accident scenario, a gaseous release results from a pressurized release of helium gas and entrained contaminated particulate through a process 1 ine leak. The diesel generator is credited in the analys is to mitigate particulate release by providing standby power to the local exhaust fans such that satisfactory local exhaust flow is maintained (reestablished) upon loss of facility power (normal AC power). This flow is necessary both to dilute hydrogen releases to the local exhaust from the MCO, as well as to maintain adequate differential pressure within the process bays. The local exhaust restart circuitry is used to reestablish local exhaust flow so that adequate differential pressure is maintained after process bay local exhaust HVAC and process vent system flow is interrupted.

(continued) 
APPLICABLE SAFETY ANALYSES (continued)
Multi-Canister Overpack Internal Hydrogen Explosion

A hydrogen explosion inside an $\mathrm{MCO}$ is analyzed in SNF-2770, Cold Vacuum Drying Facility Design Basis Accident Analysis Documentation, and the results of the analysis are presented in HNF-3553, Spent Nuclear Fuel Project Final Safety Analysis Report, Annex B, "Cold Vacuum Drying Facility Final Safety Analysis Report," Chapter B3.0, "Hazard and Accident Analyses." Based on the results of the analysis, the unmitigated release of radiological material could exceed onsite risk evaluation guidelines.

In this postulated accident scenario, a hydrogen explosion occurs because of a hydrogen-air mixture inside an MCO. The diesel generator is credited in the analys is to mitigate particulate release by providing standby power to the local exhaust fans such that satisfactory local exhaust flow is maintained (reestablished) upon loss of facility power (normal AC power). This flow is necessary both to dilute hydrogen releases to the local exhaust from the MCO, as well as to maintain adequate differential pressure within the process bays. The local exhaust restart circuitry is used to reestablish local exhaust flow so that adequate differential pressure is maintained after process bay local exhaust HVAC and process vent system flow is interrupted.

\section{Multi-Canister Overpack External Hydrogen Explosion}

A hydrogen explosion outside an MCO is analyzed in SNF-2770, Cold Vacuum Drying Facility Design Basis Accident Analysis Documentation, and the results of the analys is are presented in HNF-3553, Spent Nuclear Fuel Project Final Safety Analysis Report, Annex B, "Cold Vacuum Drying Facility Final Safety Analysis Report," Chapter B3.0, "Hazard and Accident Analyses." Based on the results of the analysis, the unmitigated release of radiological material could exceed onsite risk evaluation guidelines. 
APPLICABLE SAFETY ANALYSES (continued)
In this postulated accident scenario, a hydrogen explosion occurs because of accumulation of hydrogen inside an MCO, followed by ignition and explosion of the hydrogen gas when it is vented from the MCO into the local exhaust process ventilation system and mixed with air. The diesel generator is credited in the analys is to mitigate particulate release by providing standby power to the local exhaust fans such that satisfactory local exhaust flow is maintained (reestablished) upon loss of facility power (normal AC power). This flow is necessary both to dilute hydrogen releases to the local exhaust from the $\mathrm{MCO}$, as well as to maintain adequate differential pressure within the process bays. The local exhaust restart circuitry is used to re-establish local exhaust flow so that adequate differential pressure is maintained after the process bay local exhaust HVAC and process vent system flow is interrupted.

\section{Multi-Canister Overpack Thermal Runaway Reaction}

Thermal runaway reactions inside an MCO are analyzed in SNF-2770, Cold Vacuum Drying Facility Design Basis Accident Analysis Documentation, and the results of the analys is are presented in HNF-3553, Spent Nuclear Fuel Project Final Safety Analysis Report, Annex B, "Cold Vacuum Drying Facility Final Safety Analys is Report," Chapter B3.0, "Hazard and Accident Analyses." Based on the results of the analysis, the unmitigated release of radiological material could exceed onsite risk evaluation guidelines.

In this postulated accident scenario, a thermal runaway reaction occurs from insufficient heat removal from the inside of the $\mathrm{MCO}$. The diesel generator is credited in the analysis to mitigate particulate release by providing standby power to the local exhaust fans such that satisfactory local exhaust flow is maintained (reestablished) upon loss of facility power (normal AC power). This flow is necessary both to dilute hydrogen releases to the local exhaust from the $M C O$, as well as to maintain adequate differential pressure within the process bays. The local exhaust restart circuitry is used to reestablish local exhaust flow so that adequate differential pressure is maintained after process bay local exhaust HVAC and process vent system flow is interrupted. 
APPLICABLE SAFETY ANALYSES (continued)
Multi-Canister Overpack Overpressurization

Overpressurization of the MCO is analyzed in SNF-2770, Cold Vacuum Drying Facility Design Basis Accident Analysis Documentation, and the results of the analys is are presented in HNF-3553, Spent Nuclear Fuel Project Final Safety Analysis Report, Annex B, "Cold Vacuum Drying Facility Final Safety Analys is Report," Chapter B3.0, "Hazard and Accident Analyses." Based on the results of the analysis, the unmitigated release of radiological material could exceed onsite risk evaluation guidelines.

In this postulated accident scenario, a high-pressure release of radioactive material results from $M C O$ isolation and a resulting high MCO internal pressure. The diesel generator is credited in the analysis to provide standby power to Cold Vacuum Drying Facility (CVDF) to reestablish local exhaust flow to ensure sufficient differential pressure is maintained in the process bays during an electrical outage. The local exhaust restart circuitry is used to reestablish local exhaust flow so that adequate differential pressure is maintained after process bay local exhaust HVAC and process vent system flow is interrupted. 
OPERABILITY requirements include the following:

- The diesel must have a fuel oil day tank with $\geq 40$ gallons and a fuel oil storage tank with $\geq 150$ gallons of fuel to ensure that the diesel can operate 24 hours at full load. This provides adequate time to refuel as necessary.

- The diesel fuel oil properties must meet established requirements including the temperature being maintained above $40^{\circ} \mathrm{F}$.

- The starting air system shall be available and capable of providing starting air at the required pressure.

- The automatic transfer switch shall be OPERABLE to sense loss of the normal power supply and provide a transfer to standby power.

- The local exhaust restart circuit shall be able to start the local exhaust fan (only one fan runs at a time) and process hood isolation damper actuator solenoid valves.

- The diesel generator shall be capable of starting to supply power to the loads within 30 seconds of the start signal and all necessary loads shall be operational within an additional 30 seconds (total of 60 seconds).

These requirements are necessary to prevent hydrogen accumulation and a particulate release to prevent exceeding offsite and onsite risk evaluation guidelines. Functional requirements for determining the OPERABILITY of the diesel generator are al so defined in HNF-3553, Chapter B4.0, "Safety Structures, Systems, and Components." Detailed functional requirements for determining the OPERABILITY of the system may be found in procedures.

MODE APPLICABILITY
LCO 3.5.1 applies in the facility OPERATION MODE because MCOs are allowed in this MODE and the process bay local exhaust HVAC and process vent system is required to be in operation. LCO 3.5.1 does not apply in STANDBY MODE or SHUTDOWN MODE because MCOs are not allowed in the process bays in these MODES. 
PROCESS AREA APPLICABILITY
LCO 3.5.1 applies to the CVDF process bay area and process support area.

ACTIONS

Failure to take the ACTIONS required within the required time limit following failure to meet the $L C O$ is a VIOLATION. For this situation, proceed in accordance with AC 5.4.3, "Response to a Limiting Condition for 0peration and Limiting Control Setting VIOLATION."

\section{A. 1}

When the diesel generator is inoperable, Required Action A.1 requires the diesel generator to be restored to OPERABLE status within 7 days. It is acceptable to replace the diesel generator rather than repair the previously installed diesel generator to complete the restoration requirement provided the replacement diesel generator meets the same LCO requirements (e.g., fuel consumption rates are similar such that fuel level requirement remains the same, air start capability remains the same, etc.)

A note has been included that indicates LCO 3.0.4 is not applicable. This was included primarily because of Required Action A.2.2 which allows the installation and use of an alternate diesel generator for a period of 92 days. Since an alternate standby power source is provided that is equivalent to the normal diesel generator then it is acceptable to allow MCO process operations to be initiated and continued while restoration of the normal diesel generator is being completed. 
ACTIONS (continued)
Restoring the diesel generator would allow the Required Actions to be exited, since the LCO will no longer apply. The Completion Time of 7 days is based upon the fact that with the system inoperable, the standby power supply has been compromised. This condition, while mitigated by the availability of normal $A C$ power, is not a desirable state to remain in for any significant length of time. The Completion Time of 7 days, ensures that proper attention is given to this degraded state and that actions to restore the primary confinement are restored in a reasonable length of time. The Completion Time of 7 days is sufficient to perform normal maintenance or surveillance activities that require removing the diesel generator from service.

\section{A.2.1 and A.2.2}

If Required Action A.1 is not performed then Required Actions A.2.1 and A.2.2 shall be performed. Required Action A.2.1 requires the installation of an alternate diesel generator with equivalent performance capabilities. This alternate diesel generator shall be capable of providing an equivalent power source for design loads including the same auto-start capabilities. The alternate diesel generator shall also have an adequate fuel supply to provide 24 hours of continuous operation at full load, adequate starting system, loading and loss of power response capability shall be demonstrated. Since this is an alternate diesel generator, the parameter 1 imits for operation (e.g., fuel quantity based in diesel engine consumption rate, battery start versus air start, etc.) may differ. The required alternate diesel generator operation limits would be established and maintained when following Required Actions A.2.1 and A.2.2.

The Completion Time for installation and demonstration of OPERABILITY of the alternate diesel generator is also 7 days from when Condition $A$ was entered.

If the alternate diesel generator is installed in accordance with Required Action A.2.1, Required Action A.2. 2 requires that the normal diesel generator be restored to OPERABLE status within 92 days. A Completion Time of 92 days is considered an acceptable amount of time to operate an alternate diesel generator and to perform major maintenance or restoration activities on the normal diesel generator. 
SURVEILLANCE REQUIREMENTS
Failure to successfully meet the SR (i.e., SR acceptance criteria not satisfied) during the Surveillance or between performances of the Surveillance is a failure to meet the LCO. For this situation, entry into the LCO ACTIONS is required. Failure to perform the Surveillance within the specified Frequency (including the allowable 25\% extension) is a VIOLATION. For this situation, proceed in accordance with AC 5.4.4.2, "Failure to Perform an SR Within the Required Time Limit."

\section{SR 3.5.1.1}

This Surveillance requires a VERIFICATION that the fuel level in the diesel fuel oil day tank is $\geq 40$ gallons and the fuel level in the fuel oil storage tank is $\geq 150$ gallons monthly and within 1 day after each diesel generator shutdown. The VERIFICATION ensures the minimum amount of fue 1 necessary to provide 24 hours of continuous operation at full load, thus ensuring sufficient diesel operation time for refueling. The Frequency of monthly and within 1 day after each diesel generator shutdown is consistent with the anticipated requirements of the SNF Project Preventive Maintenance/Testing Program.

\section{SR 3.5.1.2}

This Surveillance requires the diesel generator starting air tank pressure be checked quarterly and within 1 day after a diesel generator shutdown to ensure that it is capable of starting the diesel generator. This check will include VERIFICATION of an adequate air supply by ensuring the air tank pressure is greater than or equal to 110 $1 \mathrm{~b} / \mathrm{in}^{2}$ gauge. The Frequency of quarterly has been established based on manufacturer's recommendations and guidance from D0E-STD-3003-94, "Backup Power Sources for DOE Facilities". The Frequency of within 1 day after a diesel generator shutdown ensures that activities such as start tests and load tests do not result in air tank pressures below $110 \mathrm{lb} / \mathrm{in}^{2}$ gauge. 
SURVEILLANCE REQUIREMENTS (cont inued)
$\underline{S R ~ 3.5 .1 .3 ~ a n d ~ S R ~ 3.5 .1 .4 ~}$

These Surveillances demonstrate that the diesel generator automatically starts from standby conditions and attains the required voltage and frequency within the specified time of 30 seconds. An engine prelube and warm-up period in accordance with manufacturer recommendations may precede all planned demonstration starts. The diesel generator building is to be maintained above the minimum diesel generator starting temperature of $40^{\circ} \mathrm{F}$. After reaching rated speed and voltage, VERIFY that the diesel generator can accept loads of up to $90 \%$ of its continuous rating and operate up to 1 hour. Loads may be applied sequentially or the load bank may be used. If the diesel is supplying all required loads (or the $\mathrm{kW}$ load equivalent) and the $90 \%$ rating has not been reached it will not be required to add additional loads simply to reach the $90 \%$ rating. Restarting the diesel generator within 5 minutes of shutting it down following the load test demonstrates that the diesel can restart from a hot condition, such as shutdown following performance of a normal surveillance. Credit can be taken for successful unplanned starts of the emergency diesel generators in satisfying this quarterly Surveillance if the requirements of the Surveillance are met.

The Frequency of quarterly is adequate to ensure that the diesel will auto-start when required and the required loads can receive power. This Frequency is based on manufacturer's recommendations and guidance from DOE-STD3003-94. 
SURVEILLANCE REQUIREMENTS

(cont inued)
$\underline{\operatorname{SR} 3.5 .1 .5}$

This Surveillance requires diesel fuel in the main supply tank be sampled and analyzed quarterly in accordance with diesel manufacturer's recommendations to VERIFY that the fuel oil will not have an immediate detrimental impact on diesel engine combustion. In addition, the diesel fuel temperature must be maintained above $40{ }^{\circ} \mathrm{F}$. The limits established may identify that fuel oil is degraded but this may not necessarily represent a failure of this surveillance provided the fuel is determined to allow diesel engine operation and actions are taken to address the situation (e.g., removal of excessive water, run the diesel to burn the fuel so it can be replaced with a higher quality). For example, the presence of particulates does not mean the fuel oil will not burn properly in a diesel engine. However particulates can cause fouling of filters and fuel oil injection equipment and this condition needs to be addressed.

The Frequency of quarterly is adequate to protect the diesel fuel supply. The Frequency is based on manufacturer's recommendations and guidance from DOE-STD3003-94.

\section{$\underline{\operatorname{SR} 3.5 .1 .6}$}

This Surveillance demonstrates that the diesel generator is capable of rejecting the largest single load without tripping due to overspeed. This testing ensures that the diesel generator is tested under load conditions that are as close to the design basis as possible.

The Frequency of annually is adequate to ensure that the diesel will not trip from overspeed conditions due to the largest single load rejection and is performed when other annual testing is conducted. This Frequency is based on manufacturer's recommendations and guidance from DOE-STD3003-94. 
SURVEILLANCE REQUIREMENTS (cont inued)
SR 3.5.1.7

This Surveillance demonstrates that the diesel generator automatically starts from standby conditions to simulate a loss of offsite power, attain the required voltage and frequency within the specified time of 30 seconds, and is capable of having the required loads operational within an additional 30 seconds (total of 60 seconds). This Surveillance demonstrates OPERABILITY of the automatic transfer switch to detect a loss of the normal $A C$ power supply, provide a diesel generator start signal, and transfer supply to the diesel generator. This Surveillance also demonstrates the local exhaust restart circuit will pickup and supply power to the local exhaust fan and the process hood isolation damper actuator solenoid valves. The diesel generator shall be run at facility required load for at least 1 hour. Credit can be taken for successful unplanned starts of the emergency diesel generators in satisfying this annual Surveillance if the requirements of the Surveillance are met.

The Frequency of annually is adequate to ensure that the diesel will automatically start when required and is capable of assuming the required loads. This Frequency is based on manufacturer's recommendations and guidance from DOE-STD-3003-94.
REFERENCES
DOE-STD-3003-94, 1994, Backup Power Sources for DOE Facilities, Washington D.C.

HNF-3553, 1999, Spent Nuclear Fuel Project Final Safety Analysis Report, Rev. O, Annex B, "Cold Vacuum Drying Facility Final Safety Analysis Report," Fluor Daniel Hanford, Incorporated, Richland, Washington.

SNF-2770, 1999, Cold Vacuum Drying Facility Design Basis Accident Analysis Documentation, Rev. 2, Fluor Daniel Hanford, Incorporated, Richland, Washington. 


\section{B 3.6 TRANSPORTATION-RELATED ACTIVITIES}

\section{B 3.6.1 Receipt Transportation Window}

BACKGROUND

The transportation cask functions to provide a flooded shipping container for multi-canister overpack (MCO) transport from the $K$ Basins to the Cold Vacuum Drying Facility (CVDF). During transport to the CVDF, the MCO is vented to the cask headspace. Internal cask pressure is expected to increase as a result of hydrogen gas generation, and temperature is expected to increase as a result of radioactive decay heat, solar heating, and water-uranium corrosion reactions.

When the cask-MCO first arrives at the CVDF, it will contain helium and hydrogen in the void space over the water-covered fuel. One of the first actions at the CVDF is to vent the excess pressure to the process bay local exhaust heating, ventilation, and air conditioning (HVAC) and process vent system. The cask lid can then be safely removed and replaced with the process hood.

A transportation window has been established to protect initial condition assumptions at the CVDF and is defined from the time that the helium purge of the MCO headspace at the $K$ Basins is completed unt $i l$ cask venting to the process bay local exhaust HVAC and process vent system at the CVDF. The shipping window duration is 24 hours, and the safety analyses in HNF-3553, Spent Nuclear Fuel Project Final Safety Analysis Report, Annex B, "Cold Vacuum Drying Facility Final Safety Analysis Report," Chapter B3.0, "Hazard and Accident Analyses" used this duration as a bounding value in the calculations. 
APPLICABLE SAFETY ANALYSES
LCO 3.6.1 is required for one accident scenario: Multi-Canister Overpack External Hydrogen Explosion.

\section{Multi-Canister Overpack External Hydrogen Explosion}

A hydrogen explosion outside an MCO is analyzed in SNF-2770, Cold Vacuum Drying Facility Design Basis Accident Analysis Documentation, and the results of the analysis are presented in HNF-3553, Spent Nuclear Fuel Project Final Safety Analysis Report, Annex B, "Cold Vacuum Drying Facility Final Safety Analysis Report," Chapter B3.0, "Hazard and Accident Analyses." Based on the results of the analysis, the unmitigated release of radiological material could exceed onsite risk evaluation guidelines.

In this postulated accident scenario, a hydrogen explosion occurs because of accumulation of hydrogen inside the cask (which the MCO is vented to), followed by ignition and explosion of the hydrogen gas when it is vented from the cask into the process bay local exhaust HVAC and process vent system and mixed with air. The receipt transportation window is credited in the analysis to prevent accumulations of hydrogen within the cask in excess of analyzed values.
The cask vent tool shall be connected to the transportation cask and venting completed in $\leq 24$ hours of completing the heljum purge of the MCO headspace at the $K$ Basins. The cask vent tool directs the flow of any accumulated hydrogen into the process bay local exhaust HVAC and process vent system, where flows are sufficient to dilute the hydrogen gas so that flammable mixtures are not a concern. Completion of cask venting is achieved when there is an open path from the MCO-cask headspace and headspace pressures no longer are decreasing.

For a bounding MCO case, exceeding the specified transportation window has the potential of invalidating the assumptions within the safety analyses in HNF-3553, Annex B, Chapter B3.0, and placing the facility in an unanalyzed state. 
MODE

APPLICABILITY
LCO 3.6.1 applies during facility OPERATION MODE. Facility OPERATION MODE is the MODE in which MCOs are received at the CVDF and cask venting operations are performed. This LCO does not apply in the facility STANDBY or SHUTDOWN MODES because no MCOs are present or being received in these MODES.
PROCESS AREA APPLICABILITY
LCO 3.6.1 applies to the CVDF process bay area. The process bay area encompasses the process bays of the CVDF where MCOs are received from the $K$ Basins.

ACTIONS

Failure to take the ACTIONS required within the required time limit following failure to meet the LCO is a VIOLATION. For this situation, proceed in accordance with AC 5.4.3, "Response to a Limiting Condition for Operation and Limiting Control Setting VIOLATION."

\section{A.1 and A.2}

In the event that a transportation cask is not vented within 24 hours of completing the helium purge of the MCO headspace at the $K$ Basins, Condition $A$ is entered.

The primary concerns related to the safety analyses for this condition are cask pressure and the hydrogen concentration within the cask prior to venting. These variables have a relation to each other in that until the maximum pressure assumed within the analysis is reached within the cask ( $79.61 \mathrm{~b} / \mathrm{in}^{2}$ gauge), the hydrogen concentration is still within analyzed concentrations. For the majority of the MCOs received, which have parameters that are well below the bounding values assumed, failure to meet the transportation window does not immediately correlate to a condition outside the bounds of the analysis. 
ACTIONS (continued)
Required Action A.1 requires a VERIFICATION that the transportation cask pressure is less than $451 \mathrm{~b} /$ in $^{2}$ gauge. If the pressure is below $451 \mathrm{~b} / \mathrm{in}^{2}$ gauge, then the maximum analyzed pressure (and therefore hydrogen concentration), even at the maximum assumed generation rate, will not be reached for a number of hours. As long as venting occurs within 2 hours of the most recent pressure check that demonstrates acceptable cask pressure, the MCO and cask will remain within the analyzed bounds of the safety analysis.

The Completion Time of 1 hour and once per 2 hours thereafter, is established to protect the analyzed bounds of the analysis. A timely initial reading to determine current status is necessary so that if pressures are too high, appropriate recovery actions can be taken as soon as possible. The following VERIFICATIONS (once per 2 hours thereafter) ensure that this extended window remains valid for the MCO in question so that venting preparations and activities can continue. If any VERIFICATION cannot be completed (i.e., the pressures are at $451 \mathrm{~b} / \mathrm{in}^{2}$ gauge or higher or the VERIFICATION is not conducted within the time frame specified), then Condition B is entered.

Required Action $A .2$ requires that venting of the cask be completed within 24 hours of entry into Condition $A$. This establishes an upper limit allowed for restoration activities to return to baseline conditions. Beyond this time, Condition B must be entered so that an appropriate recovery plan can be initiated.

\section{B.1}

When the Required Actions and associated Completion Times for Condition $A$ are not met, Condition $B$ is entered. Required Action $B .1$ requires that a facility-approved recovery $\mathrm{plan}$ be developed and actions initiated to restore compliance with this LCO within 24 hours. Long-term delays in venting the cask or a pressure value and hydrogen concentration beyond analyzed values are indicative of a profound process upset that cannot be anticipated and requires knowledge of the specific nature of the problem to develop appropriate recovery actions. For these reasons, specific TSR Required Actions for this case are impossible to define. A recovery plan is appropriate in this case to resolve this situation. 
SURVEILLANCE REQUIREMENTS
Failure to successfully meet the SR (i.e., SR acceptance criteria not satisfied) during the Surveillance or between performances of the Surveillance is a failure to meet the LCO. For this situation, entry into the LCO ACTIONS is required. Failure to perform the Surveillance within the specified Frequency (including the allowable 25\% extension) is a VIOLATION. For this situation, proceed in accordance with AC 5.4.4.2, "Failure to Perform an SR Within the Required Time Limit."

\section{SR 3.6.1.1}

This Surveillance to VERIFY that the cask vent tool has been connected to the cask and venting has been completed establishes the mechanism for entry into the Conditions, as appropriate. The Frequency of within 24 hours of completing the helium purge of the MCO headspace at the $K$ Basins is based upon safety analysis assumptions of bounding MCO pressures and hydrogen concentrations as discussed above. Note that this frequency, which is stated using "24 hours" instead of "1 day" as stated in other frequencies, requires a strict accounting of hours.

REFERENCES
HNF-3553, 1999, Spent Nuclear Fuel Project Final Safety Analysis Report, Rev. 0, Annex B, "Cold Vacuum Drying Facility Final Safety Analysis Report," Fluor Daniel Hanford, Incorporated, Richland, Washington.

SNF-2770, 1999, Cold Vacuum Drying Facility Design Basis Accident Analysis Documentation, Rev. 2, Fluor Daniel Hanford, Incorporated, Richland, Washington. 
APPENDIX B

DESIGN FEATURES 
DESIGN FEATURES are those features not covered elsewhere in the TSRs and that, if altered or modified, would have a significant effect on safety. DESIGN FEATURES are normally permanently built-in features that do not require, or infrequently require, maintenance or surveillance and are normally not subject to change by operations personnel. Until a facility has a DOE-approved FSAR, a DESIGN FEATURES Appendix should be included with the TSRs. After DOE approves the FSAR, the Appendix may be eliminated, provided that assurance is made that the provisions of the Appendix are present in the approved FSAR or elsewhere in the TSRs. The categories of DESIGN FEATURES to be addressed in accordance with DOE 5480.22, Technical Safety Requirements, include the following:

a. Vital passive components such as piping, vessels, supports, confinement structures, and containers.

b. Configuration and physical arrangement of the facility where safety is a concern including site characteristics such as the locations of public access roads, collocated facilities, facility area boundaries, site boundaries, and distances to the nearest residences.

c. Building materials, if the safe operation of the facility depends on any component being constructed of a particular material.

Changes to DESIGN FEATURES are considered significant modifications. The change control process in conjunction with the unreviewed safety question (USQ) process required by DOE 5480.21 , Unreviewed Safety Questions, ensures that changes to DESIGN FEATURES are appropriately analyzed and controlled so that they do not adversely affect safe operation of the Cold Vacuum Drying Facility.

The DESIGN FEATURES for the Cold Vacuum Drying Facility that, if altered or modified, would have a significant effect on safe operation are 1 isted in HNF-3553, Spent Nuclear Fuel Project Final Safety Analysis Report, Annex B, "Cold Vacuum Drying Facility Final Safety Analysis Report," Chapter B5.0, "Derivation of Technical Safety Requirements." 


\section{Appendix B DESIGN FEATURES REFERENCES}

References for Appendix B:

DOE 5480.21, 1991, Unreviewed Safety Questions, U.S. Department of Energy, Washington, D.C.

DOE 5480.22, 1992, Technical Safety Requirements, Change 1 (1992), and Change 2 (1996), U.S. Department of Energy, Washington, D.C.

HNF-3553, 1999, Spent Nuclear Fuel Project Final Safety Analysis Report, Rev. 0, Annex B, "Cold Vacuum Drying Facility Final Safety Analysis Report," Fluor Daniel Hanford, Incorporated, Richland, Washington. 